\author{
Economics Working Paper Series
}

2018/016

\title{
Relative productivity and search unemployment in an open economy
}

Luisito Bertinelli, Olivier Cardi, and Romain Restout

The Department of Economics

Lancaster University Management School

Lancaster LA1 4YX

UK

(C) Authors

All rights reserved. Short sections of text, not to exceed two paragraphs, may be quoted without explicit permission, provided that full acknowledgement is given. 


\title{
RELATIVE PRODUCTIVITY AND SEARCH UNEMPLOYMENT IN AN OPEN ECONOMY*
}

\author{
Luisito BERTINELLI ${ }^{\dagger}$ \\ Olivier CARDI ${ }^{\ddagger}$ \\ University of Luxembourg CREA Lancaster University Management School \\ Romain RESTOUT ${ }^{\S}$ \\ Université de Lorraine BETA (CNRS UMR 7522)
}

\begin{abstract}
This paper develops a tractable version of a two-sector open economy model with search frictions to disentangle the implications of workers' mobility costs and labor market institutions following higher relative productivity of tradables. Using a panel of eighteen OECD countries, our estimates show that higher productivity in tradables relative to non tradables causes a decline in non traded relative to traded wages. The fall in the relative wage reveals the presence of labor mobility costs which mitigate the appreciation in the relative price of non tradables and lower the relative unemployment rate of tradables following higher relative productivity of tradables. Whilst our evidence suggests that such responses have increased over time as the result of decreasing labor mobility costs, our estimates also reveal that the magnitude of the effects vary considerably across countries. Using a set of indicators capturing the heterogeneity of labor market frictions across economies, we find that both the relative wage and the relative unemployment rate of tradables decline significantly more and the relative price appreciates less in countries where labor market regulation is more pronounced. We show that these empirical findings can be rationalized in a two-sector open economy model with search in the labor market as long as we allow for an endogenous sectoral labor force participation decision. When we calibrate the model to country-specific data, numerical results reveal that the responses of the relative wage, the relative price, and to a lesser extent the relative unemployment rate display a wide dispersion across countries. Importantly, all variables display a significant negative relationship with labor market regulation.
\end{abstract}

Keywords: Relative productivity of tradables; Search theory; Labor market institutions; Labor mobility; Sectoral price and wage differences; Sectoral unemployment; Current account.

JEL Classification: E24; F16; F32; F41; J64.

\footnotetext{
${ }^{*}$ We are grateful to Fondazione Rodolfo De Benedetti to grant us access to the Labour Institutions Database. We thank participants at conferences and seminars for valuable comments. Obviously, all remaining shortcomings are ours.

${ }^{\dagger}$ Correspondence address: University of Luxembourg, CREA, Faculty of Law, Economics and Finance. 162 A, avenue de la Faïencerie, L-1511 Luxembourg. Phone: +352466644 6620. Fax: +352 4666446633. E-mail: luisito.bertinelli@uni.lu.

${ }^{\ddagger}$ Corresponding author: Olivier Cardi. Correspondence address: Lancaster University Management School, Bailrigg, Lancaster LA1 4YX. E-mail: o.cardi@lancaster.ac.uk.

${ }^{\S}$ Correspondence address: Université de Lorraine, Université de Strasbourg, CNRS, BETA, 54000, Nancy, France. Phone: +3303545043 72. Fax: +3303545043 51. E-mail: romain.restout@univ-lorraine.fr.
} 


\section{Introduction}

According to the conventional wisdom, trade liberalization and productivity shocks biased toward the traded sector should be followed by intersectoral labor shifts. Labor reallocation would in turn gradually arbitrage away spatial and sectoral differences in wages. However, empirical findings cast doubt over the assumption of perfect labor mobility. Wacziarg and Wallack [2004] find that trade liberalization leads to little or no inter-industry worker reallocation, thus suggesting large switching costs across sectors. Only recently have researchers begun measuring mobility costs across sectors or regions. Adopting a structural empirical approach, Artuç et al. [2010], Dix-Carneiro [2014], Dix-Carneiro and Kovak [2017], Lee and Wolpin [2006] find substantial barriers of mobility and furthermore that wages are not equalized across sectors or regions neither in the short run nor in the long run. Despite the significance of limited labor mobility across sectors, only very few attempts have been made to investigate the consequences of technology shocks when workers experience costs of switching sectors. This analysis is all the more relevant that traded industries experience much larger productivity gains than non traded industries, thus leading to labor reallocation between sectors. While workers' mobility costs may hamper labor movements across sectors, labor market institutions which vary across countries also influence the shifts of employment and thus the sectoral output adjustment to technology shocks.

This paper proposes to disentangle quantitatively the implications of workers' mobility costs and labor market institutions for the relative price and the relative wage of non tradables responses to technology shocks biased toward the traded sector. While labor mobility costs are key to producing a sectoral wage differential in the long-run and mitigating the appreciation in the relative price, international differences in labor market regulation can account for the dispersion in sectoral wage and sectoral price differences across countries. The advantage to work on relative wage and relative price effects is that their movements estimated empirically can reveal the presence of labor market frictions. ${ }^{1}$ Because such frictions in the labor market imply that hiring in the traded and non traded sector occurs at uneven paces, a key contribution of our paper is to show that higher relative productivity of tradables lowers the unemployment rate differential between tradables and non tradables in the long-run.

To set the stage of the quantitative analysis, we first assess empirically the effects of higher productivity in tradables relative to non tradables on both the relative wage and the relative price of non tradables. Our estimates reveal that a productivity differential between tradables and non tradables by $1 \%$ lowers the relative wage by $0.22 \%$ and appreciates the

\footnotetext{
${ }^{1}$ The open economy version of the neoclassical model abstracting from labor market frictions predicts that the relative wage is unaffected while the relative price of non tradables appreciates by the same amount as the productivity differential, see e.g., Canzoneri et al. [1999], Kakkar [2003]. Contrasting empirically estimated effects on the relative wage and relative price with the baseline model's predictions allows us to gauge the presence of labor mobility costs whereas working on relative quantities could not give us such an information.
} 
relative price by $0.64 \%$ for the whole sample. The long-run decline in the relative wage suggests the presence of labor market frictions preventing wage equalization across sectors. Such frictions can also rationalize the relative price appreciation which is less than that predicted by the standard neoclassical model abstracting from labor market frictions. A way to gauge the role of labor mobility costs is to investigate how vary the elasticities of the relative wage and the relative price over time and if their movements are positively related to the magnitude of labor reallocation caused by higher relative productivity. When estimating elasticities of the relative wage and relative price with respect to relative productivity on overlapping windows of fixed length, our estimates reveal that the former has been reduced over time by a factor of two, passing from -0.3 to -0.15 , whilst the relative price appreciated significantly more. Strikingly, our estimates also show that the magnitude of labor reallocation across sectors following a productivity differential has almost doubled over the same period. These findings thus suggest that labor mobility costs have been reduced markedly which resulted in increases in relative wage and relative price elasticities with respect to relative productivity.

Whilst our evidence suggests that labor mobility costs can rationalize estimated effects of higher relative productivity of tradables, our empirical findings also reveal that international differences in labor market institutions can account for the cross-country dispersion in estimated effects. Using a set of indicators to capture the extent of labor market regulation, the decline in the relative wage is found empirically to be more pronounced and the appreciation in the relative price to be less in countries where the unemployment benefit scheme is more generous or the worker bargaining power measured by the bargaining coverage is larger. While the relative wage also falls more in countries where legal protection against dismissals is stricter, we find empirically that the relative price appreciates by a larger amount.

Labor market frictions are also empirically found to have major implications for the long-run adjustment in sectoral unemployment rates. Whilst higher relative productivity of tradables lowers the unemployment rate of tradables relative to that of non tradables for the whole sample as a result of labor mobility costs, our estimates also reveal that the decline in the relative unemployment rate of tradables is more pronounced in countries where labor markets are more regulated.

In order to account for our evidence, we put forward a variant of the two-sector open economy model with tradables and non tradables and search in the labor market along with an endogenous labor force participation decision in the lines of Shi and Wen [1999]. ${ }^{2}$ Like Alvarez and Shimer [2011], imperfect mobility across sectors arises because searching for a job in one sector is a time-consuming and thus a costly activity. In our model, the

\footnotetext{
${ }^{2}$ In contrast to Merz [1995], Andolfatto [1996], Shi and Wen [1999], Heer and Schubert [2012] who construct dynamic general equilibrium models with labor markets characterized by search frictions, we abstract from physical capital accumulation and consider a two-sector open economy setup.
} 
elasticity of labor supply at the extensive margin plays a pivotal role because it measures the extent of workers' moving costs: the smaller the elasticity of labor supply, the larger the switching cost, and thus the lower the degree of labor mobility across sectors. ${ }^{3}$ Conversely, when we let the elasticity of labor supply tend toward infinity, the case of perfect labor mobility is obtained in the long-run so that the relative wage remains (almost) unaffected by productivity shocks biased toward the traded sector, in contradiction with our empirical findings. Standard search frictions are thus insufficient on their own to produce significant long-run movements in the relative wage. Conversely, as long as the elasticity of labor supply at the extensive margin takes intermediate values, the relative wage may fall. Because hiring is also a costly activity which depends on labor market institutions, the magnitude of the decline in the relative wage is determined by labor market regulation.

One key feature of our open economy model with search frictions is its dynamic nature. Because a productivity shock biased toward the traded sector leads to more hiring and the recruitment process is costly, it is optimal for the open economy to run a current account deficit along the transitional path. As the country must fulfill the intertemporal solvency condition, the trade balance must improve in the long-run. Higher net exports has an expansionary effect on the demand for tradables and thus on traded firms' hirings. If workers incur mobility costs, such demand shift lowers non traded wages relative to traded wages. It also mitigates the appreciation in the relative price of non tradables and thus the ability of non traded firms to compensate for lower productivity gains. ${ }^{4}$ As a result, the unemployment rate of tradables falls more than that of non tradables, in line with the evidence. The dynamic nature of our setup plays a pivotal role since keeping net exports fixed prevents the model from matching the evidence when traded and non traded goods are complements in consumption. With an elasticity of substitution between traded and non traded goods smaller than one, higher relative productivity of tradables increases the share of non tradables and thus has an expansionary effect on hirings in the non traded sector. As a result, the relative wage of non tradables increases instead of declining. Because the relative price appreciates more than the productivity differential, the unemployment rate differential between tradables and non tradables also increases instead of declining.

Importantly, when we calibrate our model to a representative OECD economy, our quantitative analysis reveals that our model can account for our aforementioned evidence. Even when traded and non traded goods are complements, the long-run increase in net

\footnotetext{
${ }^{3}$ We consider an endogenous sectoral labor force participation decision by assuming that representative household members experience disutility from working and searching efforts in each sector. Relocating hours worked from one sector to another is costly as the representative household must incur a searching cost for a job in this sector; such utility loss may capture sector-specific human capital and/or geographical mobility costs. Thus, in contrast to Matsuyama [1992] who assumes the irreversibility of the career decision, workers can move between sectors, at some cost though.

${ }^{4}$ This result echoes estimates by Lane and Milesi-Ferretti [2004] who find that countries with a larger decline in the net foreign position have more depreciated relative price of non tradables. In a world where labor market frictions are absent, the net foreign position would have no effect neither on the relative price, the relative wage nor the unemployment differential.
} 
exports driven by the accelerated hiring process more than offsets the decline in the share of tradables so that the relative wage falls. Because the appreciation in the relative price is not large enough to offset lower productivity gains in the non traded sector, higher relative productivity of tradables drives down the unemployment rate differential between tradables and non tradables.

When exploring the impact of labor institutions, our sensitivity analysis reveals that more generous unemployment benefits or a higher worker bargaining power amplify the decline in both the relative wage and the relative unemployment rate of tradables and mitigate the appreciation in the relative price following a productivity differential, in line with our evidence. Intuitively, such labor market policies make firms' hiring in the traded sector more elastic to productivity gains and thus amplify the long-run rise in net exports which in turn exerts a larger negative impact on the relative wage of non tradables. Since the relative price appreciates less, unemployment of tradables falls more relative to that of non tradables. In addition, as firms' hiring in the non traded sector is less sensitive to productivity gains in countries where the firing cost is larger, stringent employment protection legislation causes the relative price to appreciate more, and both the relative wage and the relative unemployment rate of tradables to fall by a larger amount, in accordance with our empirical findings.

To assess the performance of the model and investigate the implications of labor market institutions for the cross-country dispersion in estimated effects, we calibrate the model to country-specific data. We thus allow for two pivotal sets of parameters which we estimate for each economy to vary across countries: search parameters and labor market policies which account for cross-country labor market differentials and the elasticity of substitution between tradables and non tradables. When we compare numerically computed responses of the relative wage and relative price to our empirical estimates for each OECD economy in our sample, we find that the model predicts the relative wage decline pretty well and to a lesser extent the rise in the relative price. Importantly, while the model generates a wide dispersion in the relative wage and the relative price responses across countries, we find quantitatively that it can account for the larger decline in the relative wage and the smaller appreciation in the relative price in countries where labor market regulation is more pronounced. ${ }^{5}$ Our cross-country analysis also reveals that a productivity differential of one percent results in a decline in the relative unemployment rate of tradables which appears to be insignificant in countries having more flexible labor markets, while the decrease ranges between twofold and fourfold of that obtained in the baseline case in economies with more regulated labor markets.

The remainder of the paper is organized as follows. In section 2, we provide empirical

\footnotetext{
${ }^{5}$ When using a measure of labor market regulation which encompasses the three dimensions of labor market institutions, we find that the relative price significantly appreciates less in countries where labor markets are more regulated.
} 
facts on the effects of higher relative productivity of tradables suggesting the presence of labor mobility costs and document evidence on the implications of labor market regulation. In section 3, we develop an open economy version of the two-sector model with both imperfect mobility of labor arising from searching efforts and unemployment arising from matching frictions in both sectors. Section 4 sheds some light on the role of labor mobility costs and disentangles the implications of the three dimensions of labor market regulation. In section 5, we discuss numerical results. Section 6 summarizes our main results and concludes. $^{6}$

Related literature. Our paper is at the cross-roads of three strands of the literature investigating the adjustment of open economies to structural shocks. First, it is closely related to the theory developed by Balassa [1964] and Samuelson [1964] which has been renewed recently, notably by Bergin et al. [2006], Ghironi and Melitz [2005], and Christopoulos et al. [2012]. The former two papers relax the assumption of perfectly competitive goods market and show that heterogenous productivity among firms and/or entry and exit of firms amplifies the effect of higher productivity in tradables relative to non tradables on domestic prices. ${ }^{7}$ In contrast, in our paper, we consider imperfectly competitive labor markets and show that labor market frictions moderate the appreciation in the relative price of non tradables following a productivity differential between tradables and non tradables by reducing the relative wage of non tradables. In this regard, Cardi and Restout [2015] show that imperfect mobility of labor across sectors is key to producing an elasticity of the relative price with respect to the productivity differential smaller than one. However, the paper abstracts from search frictions and thus neither addresses the role of labor market institutions nor the adjustment in sectoral unemployment rates. One of the main contributions of the present paper is to show both empirically and numerically that search frictions on workers' side are key to producing a decline in the relative wage along with the less than proportional increase in the relative price while international differences in labor market regulation account for the cross-country dispersion in both the relative wage and relative price responses. In this respect, our work complements that by Christopoulos et al. [2012] who put forward financial frictions as an explanation of the cross-country dispersion in the relative price movements. Unlike the aforementioned papers which abstract from search frictions, we show that the relative price adjustment to higher relative productivity plays a pivotal role in determining the magnitude of the decline in sectoral unemployment rates.

Second, our study can be viewed as complementary to the growing literature which

\footnotetext{
${ }^{6}$ An online technical appendix, available at http://cred.u-paris2.fr/cardi, provides a very detailed description of the dataset along with additional empirical results, and contains all the proofs and derivations of analytical results.

${ }^{7}$ Ghironi and Melitz [2005] show that higher traded productivity triggers firm entry which stimulates labor demand, raises wages and thus increases traded prices, amplifying the rise in domestic prices commonly induced by the appreciation in the price of non traded goods. According to Bergin et al. [2006], higher productivity in tradables relative to non tradables induces the least productive firms in the traded sector to cease exporting; as a result, the share of non tradables in the economy increases, thus amplifying the effect of the appreciation in the relative price of non tradables on domestic prices.
} 
investigates the quantitative implications of barriers of mobility following trade shocks, e.g., Kambourov [2009] and Cosar [2013]. Developing and calibrating general equilibrium sectoral models of a small open economy with sector specific human capital, both Kambourov [2009] and Cosar [2013] find that human capital is a substantial barrier mobility along with firing costs for the former and search frictions for the latter. Like the authors, we uncover the factors that affects sectoral reallocation. In our setup, job search costs hamper labor reallocation, whilst labor market institutions may mitigate or amplify labor shifts across sectors. More precisely, by raising the marginal benefit of search, a more generous unemployment benefit scheme or a higher worker bargaining power encourages workers to shift from one sector to another. In contrast, in countries where firing costs are more pronounced, the shifts of labor are lower because firms are less prone to post more job vacancies. However, both our objective and modelling strategy are very different from those by Kambourov [2009] and Cosar [2013]. We abstract from workers' heterogeneity and rather emphasize the importance of various dimensions of labor market regulation in explaining cross-country differences in estimated effects of higher relative productivity. While we base most of our analysis on the long-run effects of a productivity differential, by keeping our setup simple enough, we are able to fully characterize analytically the transitional adjustment of the open economy toward the steady-state, focusing mainly on the dynamics of sectoral unemployment rates. ${ }^{8}$ Moreover, instead of considering sector-specific human capital, we generate imperfect mobility of labor by assuming that workers must search for a job before shifting from one sector to another, in the lines of Alvarez and Shimer [2011]. This modelling strategy enables us to derive analytical expressions for the response of the unemployment differential between tradables and non tradables to higher relative productivity of tradables. In this regard, our analysis is related to that by Curuk and Vannoorenberghe [2017] who derive analytical expressions of industry's employment to aggregate shocks. In contrast to them, we consider a model with search frictions and thus are interested in sectoral unemployment rates' adjustment and emphasize the implications of international differences in labor market regulation. Unlike the aforementioned papers, we show that the shift in the demand of goods and services along with the change in the net foreign asset position play a key role in determining the size and the direction of the effects of a technology shock.

The dynamic nature of our model along with time-varying net foreign asset position along the transitional path makes our setup very different from that constructed by Dutt, Mitra and Ranjan [2009] who analyze the effects of trade openness on unemployment by assuming that trade is balanced. In our model, the share of tradables varies as the result of imperfect substitutability between tradables and non tradables and net exports'

\footnotetext{
${ }^{8}$ While we employ 'long-run' to refer to steady-state values, it refers to a medium-run analysis as we abstract from physical capital and we find numerically that the adjustment is rapid since it takes the open economy between 3 and 5 years to reach the steady-state.
} 
adjustment. Most importantly, our model allows for an endogenous sectoral labor force participation decision which produces intersectoral mobility costs; such a feature enables us to rationalize the responses we document empirically. Moreover, in addition to providing analytical results, we solve the model numerically.

Third, like the literature employing multi-sector model with search frictions in the labor market, we emphasize that sectoral shocks that hit the economy unevenly produce shortrun effects which are quite distinct from those prevailing in the long-run. More specifically, Phelan and Trejos [2000] show that an adverse sectoral demand shock originating from a cut in military purchases can be greatly magnified as a result of the combined effect of labor shifts across sectors and a slow reallocation. The gradual adjustment in sectoral labor plays also a key role in our model as the long-run effects are reversed in the short-run. While in the long-run, an increase in relative productivity of tradables lowers the unemployment rate of tradables relative to that of non tradables, we get the opposite result on impact. When the shock hits the economy, the unemployment rate of non tradables falls dramatically as a result of the combined effect of the positive wealth effect along with the sector-biased technology shock. Unlike Phelan and Trejos [2000], changes in sectoral demand occur endogenously in our model. Moreover, the present paper endogenously generates workers' costs of switching sectors caused by job search costs and differentiate their implications from those driven by hiring costs supported by firms which are influenced by labor market institutions. One close paper to ours is Chang [2012] who develops a two-sector model with search frictions and emphasizes the key role of the combined effect of standard search frictions and imperfect mobility of labor following sectoral TFP shocks biased toward one sector. However, our work differs in many respects. First, Chang [2012] formalizes the mobility decision such that the switching cost vanishes in the long-run whereas we consider that workers experience a mobility cost at the steady-state in line with our evidence which reveals that the sectoral wage differential is persistent in the long-run. Second, we consider an open economy where both consumers' preferences and the dynamics of the net foreign asset position play a pivotal role in determining the long-run effects. These features are absent from Chang's setup. Third, we perform a cross-country quantitative analysis. Fourth, a rise in relative productivity produces quantitatively much greater unemployment effects in our setup since the aggregate labor force is not constant as we allow for the transition between leisure and the labor force, in accordance with the Real Business Cycle literature.

\section{Empirical Facts}

In this section, we document a set of empirical facts related to the effects of higher productivity in tradables relative to non tradables and investigate how labor market frictions shape estimated effects. We denote the level of the variable in upper case, the logarithm in lower case (except for the unemployment rate which is expressed in percentage point), and 
the percentage deviation from its initial steady-state by a hat.

\subsection{A Simple Model with Labor Market Frictions}

To set the stage for the empirical analysis, we revisit the theory that Balassa [1964] and Samuelson [1964] (BS hereafter) developed by relaxing the assumption of perfectly competitive labor markets in order to build up intuition regarding the implications of labor market frictions. As it is commonly assumed, the country is small in terms of both world goods and capital markets, and thus faces an exogenous international price for the traded good normalized to unity. Each sector produces $Y^{j}$ by using labor, $L^{j}$, according to a linear technology, $Y^{j}=A^{j} L^{j}$, where $A^{j}$ represents the labor productivity index.

Because firms face a cost by maintaining job vacancies, they receive a surplus equal to the marginal revenue of labor $\Xi^{j}$ less the product wage $W^{j}$. Symmetrically, so as to compensate for the cost of searching for a job, unemployed workers receive a surplus equal to $W^{j}$ less the reservation wage $W_{R}^{j}$. We denote by $\Psi^{j}$ the overall surplus created when a job-seeking worker and a firm with a job vacancy conclude a contract:

$$
\Psi^{j}=\Xi^{j}-W_{R}^{j}\left(\theta^{j}\right)
$$

where $\Xi^{T}=A^{T}, \Xi^{N}=P A^{N}$ with $P$ corresponding to the relative price of non tradables, and we denote by $\theta^{j}$ the labor market tightness in sector $j$, defined as the ratio of job vacancies to unemployed workers; when firms post more job vacancies, $\theta^{j}$ rises which raises the reservation wage, i.e., $\hat{w}_{R}^{j}=\chi^{j} \hat{\theta}^{j}$ where $0<\chi^{j}<1$ represents the share of the surplus associated with a labor contract in the marginal benefit of search.

The product wage $W^{j}$ paid to the worker in sector $j$ is equal to the reservation wage plus a share $\alpha_{W}$ of the overall surplus:

$$
W^{j}=W_{R}^{j}\left(\theta^{j}\right)+\alpha_{W} \Psi^{j}
$$

where the worker bargaining power $\alpha_{W}$ is assumed to be symmetric across sectors. Denoting the relative wage by $\Omega \equiv W^{N} / W^{T}$ and differentiating (2) leads to the sectoral wage differential:

$$
\hat{\omega} \equiv \hat{w}^{N}-\hat{w}^{T}=-\frac{\chi W_{R}}{W}\left(\hat{\theta}^{T}-\hat{\theta}^{N}\right)-\frac{\alpha_{W} \Psi}{W}\left(\hat{\Psi}^{T}-\hat{\Psi}^{N}\right),
$$

where we assume that initially $W^{j} \simeq W$ and $\chi^{j} W_{R}^{j} \simeq \chi W_{R}$ and $\Psi^{j} \simeq \Psi$ to ease the interpretation. In a model abstracting from labor market frictions, as the standard BS model, searching for a job is a costless activity so that $\Psi$ and $\chi$ are nil; hence sectoral wages rise at the same speed. Conversely, in a model with labor market frictions, a productivity differential between tradables and non tradables may lower $\omega$. The reason is as follows. First, as captured by the first term on the RHS of (3), higher $A^{T} / A^{N}$ induces traded firms to recruit more than non traded firms; because agents experience a utility loss when increasing the search intensity for a job in the traded sector, traded firms must increase 
wages to attract workers as reflected by the rise in the ratio $\theta^{T} / \theta^{N}$. Moreover, as shown by the second term on the RHS of (3), by raising $\Psi^{T} / \Psi^{N}$, a productivity differential between tradables and non tradables lowers $\omega$; intuitively, higher $A^{T} / A^{N}$ increases the surplus from an additional job in the traded sector relative to the non traded sector, $\Psi^{T} / \Psi^{N}$, the worker obtaining a share equal to $\alpha_{W}$.

Denoting the job destruction rate by $s^{j}$ and the job finding rate by $m^{j}$, and using the fact that at the steady-state, the flow of unemployed workers who find a job is equalized with the flow of employed workers who lose their job, the unemployment rate $u^{j}$ in sector $j$ reads as $u^{j}=\frac{s^{j}}{s^{j}+m^{j}\left(\theta^{j}\right)}$. Totally differentiating $u^{j}$ and denoting the elasticity of vacancies in job matches by $\alpha^{V}$, allows us to express the unemployment rate differential between tradables and non tradables in terms of the differential in sectoral labor market tightness:

$$
d u^{T}-d u^{N}=-\alpha_{V} u(1-u)\left(\hat{\theta}^{T}-\hat{\theta}^{N}\right)
$$

where we assume that at the initial steady-state, search parameters are such that $u^{j} \simeq u$. According to (4), higher $A^{T} / A^{N}$ results in a decline in $u^{T}$ relative to $u^{N}$ by raising the ratio $\theta^{T} / \theta^{N}$ as traded firms recruit more than non traded firms.

When a labor contract is concluded with a worker, the representative firm in sector $j$ receives the marginal revenue of labor $\Xi^{j}$ which must cover the recruiting cost plus the dividend per worker equivalent to $\left(1-\alpha_{W}\right) \Psi^{j}$ and the wage rate paid to the worker:

$$
\Xi^{j}=\left(1-\alpha_{W}\right) \Psi^{j}+W^{j}
$$

Differentiating (5) and subtracting $\hat{\Xi}^{T}$ from $\hat{\Xi}^{N}$ leads to:

$$
\hat{p}=\left(\hat{a}^{T}-\hat{a}^{N}\right)+\frac{W}{\Xi}\left(\hat{w}^{N}-\hat{w}^{T}\right)-\frac{\left(1-\alpha_{W}\right) \Psi}{\Xi}\left(\hat{\Psi}^{T}-\hat{\Psi}^{N}\right),
$$

where we assume that initially $\Xi^{j} \simeq \Xi, \Psi^{j} \simeq \Psi$, and $W^{j} \simeq W$. According to (6), when abstracting from labor market frictions, as the BS model, the surplus $\Psi$ is nil while sectoral wages increase at the same speed so that $p$ must appreciate by the same amount as $\hat{a}^{T}-\hat{a}^{N}$. Conversely, in a model with labor market frictions, as captured by the second term on the RHS of (6), $\omega$ falls because traded firms have to pay higher wages to compensate for the workers' mobility costs. Moreover, as shown by the third term on the RHS of (6), since traded firms recruit more than non traded firms, the hiring cost must be covered by an increase in $\Psi^{T} / \Psi^{N}$, the firm obtaining a share equal to $1-\alpha_{W}$. Thus, by lowering $\omega$ and increasing the hiring cost in the traded sector relative to that in the non traded sector, a productivity differential of $1 \%$ appreciates $p$ by less than $1 \%$.

The relative wage and relative price equations described by (3) and (6), respectively, allow us to explain why labor market frictions imply that sectoral wages may no longer rise at the same speed and the elasticity of the relative price w.r.t. the productivity differential may be smaller than one. However, such conclusions are established by abstracting from 
the goods market equilibrium which matters as long as labor is not perfectly mobile across sectors. In section 4 , we show that the full steady-state can be solved for the relative price and the relative wage, i.e., $P \equiv P^{N} / P^{T}=P\left(A^{T}, A^{N}\right)$ and $\Omega \equiv W^{N} / W^{T}=\Omega\left(A^{T}, A^{N}\right)$. Because all variables display trends, our empirical strategy consists in estimating the cointegrating relationships with relative productivity.

In the following, we also explore empirically whether higher $A^{T} / A^{N}$ leads to $d u^{T}-d u^{N}<$ 0. Whilst the standard BS model abstracting from labor market frictions cannot address unemployment issues, standard search frictions are not sufficient on their own to lower the unemployment rate differential following a rise in $A^{T} / A^{N}$. More specifically, for higher relative productivity to result in a decline in $u^{T}$ relative to $u^{N}$, as shown in eq. (4), traded firms must recruit more than non traded firms. For this to happen, the appreciation in the $p$ must be less than the productivity differential otherwise non traded firms are able to exactly offset lower productivity gains by setting higher prices. As discussed above, the relative price appreciates less than proportionately if workers experience mobility costs.

\subsection{Data Construction}

Before empirically exploring the effects of higher relative productivity, we briefly describe the dataset we use and provide details about data construction below and in Appendix A. Our sample consists of a panel of eighteen OECD countries for eleven 1-digit ISIC-rev.3 industries. To split these eleven industries into traded and non traded sectors, we follow the classification suggested by De Gregorio et al. [1994] that we updated by following Jensen and Kletzer [2006].

For the relative price and the relative wage, our sample covers the period 1970-2007. We use the EU KLEMS [2011] database which provides domestic currency series of value added in current and constant prices, labor compensation and employment (number of hours worked) for each sector $j$ (with $j=T, N$ ), permitting the construction of price indices $p^{j}$ (in $\log$ ) which correspond to sectoral value added deflators, sectoral wage rates $w^{j}$ (in $\log$ ), and sectoral measures of productivities $a^{j}$ (in log). The relative price of non tradables at time $t$ in country $i, p_{i, t}$, is the log of the ratio of the non traded value added deflator to the traded value added deflator (i.e., $p_{i, t}=p_{i, t}^{N}-p_{i, t}^{T}$ ). The relative wage $\omega_{i, t}$ is the log of the ratio of the non traded wage to the traded wage (i.e., $\omega_{i, t}=w_{i, t}^{N}-w_{i, t}^{T}$ ). We use sectoral labor productivities $A_{i, t}^{j}=Y_{i, t}^{j} / L_{i, t}^{j}$ to approximate technical change which are constructed from constant-price series of value added $Y_{i, t}^{j}$ and hours worked $L_{i, t}^{j}$.

We construct time series for sectoral unemployment rate, $u^{j}$, as the ratio of the number of unemployed workers $U^{j}$ in sector $j$ to the labor force $F^{j} \equiv L^{j}+U^{j}$ in this sector. Data are taken from LABORSTA database from ILO which provides series for unemployed workers by economic activity for fourteen OECD countries out of eighteen listed in Appendix A. The longest available period ranges from 1987 to 2007. On average, our data covers thirteen 
years per country (see Appendix B.3). ${ }^{9}$

\subsection{Estimating the Effects of Higher Relative Productivity}

We regress the $(\log )$ relative wage $\omega$ and the $(\log )$ relative price $p$ on the $(\log )$ relative productivity, respectively: ${ }^{10}$

$$
\begin{aligned}
\omega_{i, t} & =\delta_{i}+\beta \cdot\left(a_{i, t}^{T}-a_{i, t}^{N}\right)+v_{i, t}, \\
p_{i, t} & =\alpha_{i}+\gamma \cdot\left(a_{i, t}^{T}-a_{i, t}^{N}\right)+u_{i, t},
\end{aligned}
$$

where $i$ and $t$ index country and time and $v_{i, t}$ and $u_{i, t}$ are i.i.d. error terms. Country fixed effects are captured by country dummies $\delta_{i}$ and $\alpha_{i}$.

Since $p, \omega$ and $a^{T}-a^{N}$ display trends, we ran unit root and then cointegration tests. Having verified that these two assumptions are empirically supported, we estimate the cointegrating relationships by using fully modified OLS (FMOLS) and dynamic OLS (DOLS) procedures for the cointegrated panel proposed by Pedroni [2000], [2001]. Both estimators give similar results and coefficients $\beta$ and $\gamma$ of the cointegrating relationships are significant at 1\%. Two major results emerge. First, estimates reported in the Table 1 reveal that a productivity differential between tradables and non tradables by $1 \%$ lowers the relative wage by about $0.22 \%$ and appreciates the relative price by $0.64 \%$. Second, as shown in the second line and the third line of Table 1, the predictions of the model abstracting from labor market frictions are strongly rejected: the slope of the cointegrating vector $\beta(\gamma)$ is statistically significantly different from zero (one).

We now assess if our conclusion for the whole sample also holds for each country. To do so we run again the regression of relative wage and relative price on relative productivity by letting $\beta$ and $\gamma$ vary across countries. Table 2 shows DOLS and FMOLS estimates for the eighteen countries of our sample. The first result that emerges is that the responses display a wide dispersion across countries. The second result is that despite these large crosscountry variations, higher productivity in tradables relative to non tradables significantly lowers $\omega$ in all countries while $p$ rises less than the productivity differential.

Because long-run movements in both the relative wage and relative price reveal the presence of labor market frictions, we also run the regression of the change in the unemployment rate differential between tradables and non tradables on the relative productivity

\footnotetext{
${ }^{9}$ Whereas we are able to construct time series of sectoral unemployment rates for Korea, data for the unemployment benefit replacement rate, used as a control variable, are not available before 2002 and thus this country is removed from the sample.

${ }^{10}$ In contrast to Kakkar [2003], Cardi and Restout [2015] who do not identify empirically the role of labor market institutions following a productivity differential, our dataset includes eighteen OECD countries instead of fourteen and we measure technological change with sectoral labor productivity instead of sectoral TFP in order to be consistent with the model developed in section 3 where we abstract from physical capital accumulation. It is worth mentioning that the two-sector open economy model with search frictions we develop is tractable enough to enable us to derive analytical expressions of elasticities $\beta, \gamma$ (see section 5.3) and $\sigma$ (see section 5.4) estimated empirically.
} 
of tradables in growth rate: ${ }^{11}$

$$
d u_{i, t}^{T}-d u_{i, t}^{N}=\eta_{i}+\sigma \cdot\left(\hat{a}_{i, t}^{T}-\hat{a}_{i, t}^{N}\right)+z_{i, t}
$$

where $\eta_{i}$ are the country fixed effects and $z_{i, t}$ are i.i.d. error terms. As can be seen in the first line of Table 3, a rise in the productivity differential by $1 \%$ lowers the unemployment rate in the traded relative to the non traded sector by 0.034 percentage point. Columns 2 to 4 reveal that our result is robust to the inclusion of control variables for labor market regulation and thus sectoral unemployment rates adjust unevenly in all specifications. ${ }^{12}$

$<$ Please insert Tables 1,2 and 3 about here $>$

\subsection{How to Explain Estimated Effects?}

As stressed in section 2.1, the decline in the relative wage following higher relative productivity points the presence of labor market frictions which are responsible for the less than proportional appreciation in the relative price along with the significant fall in $u^{T}$ relative to $u^{N}$.

While the causes of labor market frictions hampering labor reallocation are diverse, they can be classified into two categories: those related to the workers' characteristics, thus affecting labor supply, and those related to rigid labor markets influencing firms' labor demand. The present paper endogenously generates workers' costs of switching sectors caused by job search costs and differentiate their implications from those driven by hiring costs supported by firms which are influenced by labor market institutions. ${ }^{13}$ Like Alvarez and Shimer [2011], workers experience mobility costs as they have to search for a job before switching from one sector to another. ${ }^{14}$ Intuitively, because searching for a job is time-consuming, such an activity is costly in utility terms. As a result, following higher productivity of tradables relative to non tradables, traded firms have to pay higher wages in order to compensate for the workers' costs of switching. Hence, the relative wage of non tradables must fall. Because non traded wages increase less rapidly than traded wages, mobility costs mitigate the appreciation in the relative price of non tradables (see eq. (6)). Since higher prices of non traded goods are not high enough to even lower relative

\footnotetext{
${ }^{11}$ Since series for the unemployment rate differential do not display a unit root process, we express the labor productivity in growth rate. Moreover, on average, the time horizon is too short to recourse to cointegration techniques.

${ }^{12}$ In the second (third) column of Table 3, we include employment protection legislation adjusted with the share of permanent workers (unemployment benefit replacement rate) since these variables are available for a yearly basis. The fourth column shows that results are unchanged when we add two control variables.

${ }^{13} \mathrm{~A}$ convenient shortcut to generate workers' mobility costs is to assume limited substitutability in hours worked across sectors along the lines of Horvath [2000]. Adopting this modelling strategy and calibrating an open economy version of the neoclassical model with tradables and non tradables, Cardi and Restout [2015] find that limited labor mobility is key to generating a less than proportional appreciation in the relative price following a $1 \%$ increase in the productivity of tradables relative to non tradables. Beyond the fact that the causes of workers' mobility costs remain unexplained, by abstracting from search frictions, the authors cannot address the implications of labor market institutions.

${ }^{14}$ From the worker point of view, the mobility costs can be interpreted as psychological costs when switching from one sector to another (see e.g., Dix-Carneiro [2014]), geographic mobility costs (see e.g., Kennan and Walker [2011]) or can be the result of sector-specific human capital (see e.g., Lee and Wolpin $[2006])$.
} 
productivity gains out, traded firms' hire more which results in a larger decline in the unemployment rate in tradables relative to that in non tradables.

A way to gauge the role of labor mobility costs in determining the adjustment of the economy to a productivity differential is to investigate whether elasticities $\beta$, $\gamma$, and $\sigma$ (see (7a)-(8)) vary over time and explore their relationship with the extent of labor reallocation across sectors triggered by higher relative productivity. To perform this experiment, we estimate $\beta, \gamma$, and $\sigma$ in rolling sub-samples. To check results' robustness, we consider different windows' lengths. ${ }^{15}$ As can be seen in the first row of Figure 1 which reports the elasticity of the relative wage to relative productivity (i.e., $\beta$ ) in the solid black line, for all windows' lengths, the response of $\omega$ has increased over time (i.e., $\beta$ becomes less negative). One obvious candidate to explaining such an increase in $\beta$ is the decline in labor mobility costs. If workers incur lower costs of switching sectors, then a productivity differential would result in a greater reallocation of labor between the traded and the non traded sector. ${ }^{16}$ As it clearly stands out, the estimated response of the relative wage tends to increase over time, especially in the nineties, and such a pattern is associated with more labor reallocation following higher relative productivity, in line with our hypothesis. The second row of Figure 1 reveals that as more workers shift from one sector to another following higher productivity gains in tradables relative to non tradables, the relative price appreciates more over time (until the beginning of 2000's), i.e., $\gamma$ takes higher values. Focusing on panels 1(a) and 1(d), the magnitude of labor reallocation reaches a peak at the beginning of 2000's and then tends to be declining. Such a pattern tracks pretty well the fall in $\gamma$ from 2002 onwards and to a lesser extent the merely declining path of $\beta$ which starts later, in 2005. Another piece of evidence which corroborates the role of labor reallocation in shaping the labor market adjustment is the increase in $\sigma$ which captures the response of the unemployment differential to a rise in relative productivity, as can be seen in Figure 1(f). ${ }^{17}$

$<$ Please insert Figure 1 about here $>$

\footnotetext{
${ }^{15}$ When estimating $\beta$ and $\gamma$, we run the same regression as in eqs. (7a)-(7b), except that we consider overlapping subperiods of different fixed lengths, i.e., $T=20, T=25, T=30$ years. More specifically, for $T=20$, we estimate eqs. (7a)-(7b) over 1970-1990, 1971-1991, ...,1987-2007, for $T=25$, over 1970-1995, $\ldots, 1982-2007$, and for $T=30,1970-2000, \ldots, 1977-2007$. To save space, we do not show the results for the relative price when $T=30$.

${ }^{16}$ Following Wacziarg and Wallack [2004], we compute the labor reallocation index in year $t$ for country $i$ denoted by $L R_{i, t}$ by calculating the rate of workers that have shifted from one sector to another over $\tau$ years:

$$
L R_{i, t}(\tau)=\frac{\sum_{j=T}^{N}\left|L_{i, t}^{j}-L_{i, t-\tau}^{j}\right|-\left|\sum_{j=T}^{N} L_{i, t}^{j}-\sum_{j=T}^{N} L_{i, t-\tau}^{j}\right|}{0.5 \sum_{j=T}^{N}\left(L_{i, t-\tau}^{j}+L_{i, t}^{j}\right)} .
$$

where $\tau=5$ and $L_{i, t}^{j}$ denotes employment in sector $j=T, N$. To estimate the effect of higher relative productivity on labor reallocation, we run the following regression in rolling sub-samples:$$
L R_{i, t}=\zeta_{i}+\chi \cdot\left(\hat{a}_{i, t}^{T}-\hat{a}_{i, t}^{N}\right)+\nu_{i, t} .
$$

Since the labor reallocation index is stationary, relative productivity is expressed in growth rate.

${ }^{17}$ When running the regression of the unemployment differential on relative productivity of tradables in growth rate, we add unemployment benefit replacement as a control; due to data availability, we consider one unique window's length (i.e., $T=12$ ) and exclude BEL, DNK, JPN, USA as the time horizon for sectoral unemployment data taken from ILO is too short for these countries.
} 
While above evidence suggests that workers' mobility costs matter in producing a decline in non traded wages relative to traded wages following higher relative productivity of tradables, our estimates also show that the size of the decline in the relative wage varies greatly across countries. Since labor market institutions influence the elasticity of hiring with respect to productivity gains, international differences in labor regulation could be responsible for the cross-country dispersion in the decline in the relative wage. Moreover, by determining the extent of hirings and thus output changes within each sector, the degree of labor market regulation should affect the extent of the decline in the relative unemployment rate of tradables along with the magnitude of the appreciation in the relative price of non tradables following a productivity differential.

As will be clear later when we will further develop the transmission mechanism, labor market regulation influences goods and labor market variables through two distinct channels according to the type of labor market institutions:

- First, we expect the traded wage to increase more and the relative price of non tradables to appreciate less in countries where unemployment benefits are more generous or workers have a larger bargaining power. ${ }^{18}$ As a result, these economies should also experience a larger decline in the unemployment rate of tradables.

- Second, we conjecture that in countries with higher firing costs, the non traded wage should rise less, the unemployment rate of non tradables should decrease by a smaller amount and the relative price should appreciate more. ${ }^{19}$

\subsection{Labor Market Regulation and Cross-Country Differences}

We consider three dimensions of labor market regulation:

- The first aspect is the difficulty of redundancy that we measure by the employment protection legislation (EPL hereafter) index provided by the OECD; this index which captures the strictness of legal protection against dismissals for permanent workers has the advantage to be available for all countries of our sample over the period 19852007. In order to have a more accurate measure of the difficulty of redundancy, we adjust EPL for regular workers with the share of permanent workers in the economy

\footnotetext{
${ }^{18}$ Intuitively, as these economies display a low labor market tightness, hiring is more profitable following productivity gains because it is easier to fulfill job vacancies. As will be detailed subsequently, a larger increase in hirings in the short-run leads a higher rise in net exports in the long-run. Higher demand for tradables tends to mitigate the appreciation in the relative price caused by a productivity differential. Because labor demand in the traded sector is more elastic to productivity gains in countries where the replacement rate or the worker bargaining power is higher, the traded wage is expected to increase by a larger amount. Because traded firms recruit more, $u^{T}$ will decline by a larger amount.

${ }^{19}$ Because a productivity shock tends to lower aggregate labor supply through the positive wealth effect while the non traded sector experiences relatively low productivity gains, the shrinking non traded establishments are subject to the redundancy cost. As a result, they are less prone to recruit more workers when productivity increases. Labor demand in the non traded sector is thus less elastic to productivity gains in countries where employment protection is more pronounced, which mitigates increases in $w^{N}$ and the decline in $u^{N}$. Since traded output increases more relative to non traded output, we expect $p$ to appreciate by a larger amount.
} 
(see Boeri and Van Ours [2008]). The indicator is denoted by $\mathrm{EPL}_{a d j}$.

- The generosity of unemployment benefit systems is measured by using the replacement rate, denoted by $\varrho$. The data we use are taken from the OECD database which calculates the average of the net unemployment benefit for three durations of unemployment (1st year, 2nd and 3rd year, 4th and 5th year).

- In the empirical literature, the worker bargaining power is commonly captured by the bargaining coverage; we thus use this indicator, denoted by BargCov, which gives the proportion of employees covered by collective bargaining. Data are taken from the ICTWSS database (Visser [2009]).

To empirically explore our conjecture according to which the relative wage falls more following a productivity differential between tradables and non tradables in countries with more regulated labor market, we perform a simple split-sample analysis. Hence, we compare the relative wage behavior of 9 countries with high and 9 economies with low labor market regulation by running the regression (7a) of $\omega$ on relative productivity for each sub-sample. We thus expect $\beta^{H}$, which captures the response of $\omega$ to a productivity differential in countries with higher labor market regulation, to be larger (in absolute terms) than $\beta^{L}$ which reflects the reaction of $\omega$ in countries with lower labor market regulation. Because labor market regulation influences the magnitude of responses of labor to productivity gains, labor market institutions should affect the extent of the appreciation in $p$. Adopting the same strategy than that for $\omega$, we run the regression $(7 \mathrm{~b})$ of the relative price on relative productivity for each sub-sample. ${ }^{20}$ More specifically, we investigate whether $p$ appreciates more in countries with stricter legal protection against dismissals (i.e., we expect $\gamma^{H}>\gamma^{L}$ ) and increases less in countries with more generous unemployment benefit scheme or a higher worker bargaining power (i.e., we expect $\gamma^{H}<\gamma^{L}$ ).

The DOLS and FMOLS estimates are reported in Table 4 for countries with high and low labor market regulation. The last two lines of Table 4 gives the sub-sample's average of the corresponding labor market regulation index. As the results in panel A of Table 4 show, the decline in the relative wage is significantly greater for countries with more regulated labor markets, i.e., $\left|\beta^{H}\right|>\left|\beta^{L}\right|$. While countries providing lower unemployment benefits experience a decline in $\omega$ of $-0.16 \%$ approximately, the second set of countries with generous unemployment benefits experience a fall in $\omega$ of $-0.26 \%$. Furthermore, as shown in the second column of Table $4, \omega$ falls by $-0.24 \%$ in countries where the worker bargaining power is relatively higher instead of $-0.18 \%$ in economies with a lower bargaining coverage. A similar pattern emerges when we exploit a third dimension of labor market regulation, namely the strictness of employment protection. Since series for EPL are available over

\footnotetext{
${ }^{20}$ Because the movements in $p$ can be influenced by changes in the cost of entry in product market triggered by competition-oriented policies, we add country-specific linear time trends when we run the regression (7b) for each sub-sample in order to control for these effects.
} 
1985-2007, we run again the regression (7a) for each sub-sample over this period to be consistent. We find that $\omega$ declines by $0.17 \%$ in countries with higher firing costs while $\omega$ declines by only $0.13 \%$ in the second set of countries. Because labor market regulation includes three indicators, we have recourse to a principal component analysis in order to have one overall indicator reflecting all the dimensions of labor market institutions. As displayed in the last column of Table 4, we find that countries with more regulated labor markets experience a larger decline in $\omega$. Finally, we detect a significant difference in the responses of the relative wage between countries with low and high labor market regulation as shown in the third line of Table 4 which indicates that imposing the restriction $\beta^{L}=\beta^{H}$ is strongly rejected at a $1 \%$ significance level.

$<$ Please insert Table 4 about here $>$

Turning to the relative price, the first two columns of panel B of Table 4 show that higher productivity in tradables relative to non tradables causes an appreciation in $p$ which is significantly smaller in countries with more generous unemployment benefits or a higher bargaining coverage. Conversely, as displayed in the third column of Table 4, stricter employment protection legislation tends to amplify the increase in $p$, in line with our conjecture. However, the difference in the relative price responses caused by firing costs between the two sub-samples is not statistically significant. Because $E P L_{a d j}$ does not seem to exert substantial effects on the relative price responses to a productivity differential, it is thus not surprising to find that labor market regulation tends to mitigate the appreciation in $p$ as shown in the last column of Table 4. As discussed later, this finding is in line with our quantitative results which show that large differences in employment protection legislation do not cause marked differences in the relative price adjustment following a productivity differential, the cross-country dispersion in the relative price responses being mostly driven by differences in unemployment benefit replacement rates.

To explore the implications of labor market regulation for the response of the unemployment rate differential, we split our sample into groups with less and more regulated labor markets by using the mean value of the index which encompasses the three dimensions of labor market regulation. Our analysis covers 14 countries out of which 8 are classified as countries with more regulated labor markets. ${ }^{21}$ Contrasting estimates of $\sigma^{H}$ with those of $\sigma^{L}$ shown in the second and third line of Table 3, respectively, a rise in the relative productivity of tradables drives down the relative unemployment rate of tradables, and more so in countries where labor market regulation is higher. More specifically, the unemployment rate of tradables relative to that of non tradables declines by 0.033 and $0.036 \mathrm{ppt}$ in economies

\footnotetext{
${ }^{21}$ Because the effect of an increase in relative productivity of tradables on the unemployment rate differential is small since the latter variable is the difference between two sectoral ratios, we find it convenient to base the split-sample analysis on the mean value instead of the median as we obtain more clear-cut results in this case. In a Technical Appendix, we show that whether we use the median or the mean sample, our split-sample analysis is robust to the threshold used when we explore the implications of three dimensions of labor market regulation for the relative wage and relative price effects of a productivity differential.
} 
with less and more regulated labor markets, respectively. Subsequent columns show that estimated effects between the two subsamples are more distinct; when controlling for the replacement rate and employment protection, the unemployment rate differential falls by 0.032 and $0.041 \mathrm{ppt}$ in countries with low and high labor market regulation, respectively.

In the following, we develop a dynamic general equilibrium model by allowing for search frictions which have two distinct dimensions and assess its ability to account for our evidence. The first cause of search frictions is related to the costs supported by workers when they wish to shift hours worked from one sector to another. We explore the ability of such mobility costs to mitigate the appreciation in $p$ and lower both $\omega$ and the unemployment rate differential $u^{T}-u^{N}$ in line with our evidence. The second cause of search frictions relates to the costs supported by firms when they wish to hire workers. Such costs are influenced by labor market institutions which vary substantially across countries. We investigate whether countries with more regulated labor markets experience a larger decline in both the relative wage and the relative unemployment rate of tradables, and a smaller appreciation in the relative price of non tradables in accordance with our empirical findings.

\section{The Framework}

The country is small in terms of both world goods and capital markets, and faces a given world interest rate, $r^{\star} .{ }^{22}$ The small open economy is populated by a constant number of identical households and firms that have perfect foresight and live forever. Households decide on labor market participation and consumption while firms decide on hirings. The economy consists of two sectors. One sector produces a traded good denoted by the superscript $T$ that can be exported while the other sector produces a non-traded good denoted by the superscript $N$. The setup allows for traded and non-traded goods to be used for consumption. The traded good is chosen as the numeraire. The labor market, in the tradition of Diamond-Mortensen-Pissarides, consists of a matching process within each sector between the firms who post job vacancies and unemployed workers who search for a job. Time is continuous and indexed by $t .^{23}$

\subsection{Households}

At each instant the representative agent consumes traded goods, $C^{T}(t)$, and non-traded goods, $C^{N}(t)$, which are aggregated by a constant elasticity of substitution function:

$$
C\left(C^{T}(t), C^{N}(t)\right)=\left[\varphi^{\frac{1}{\phi}}\left(C^{T}(t)\right)^{\frac{\phi-1}{\phi}}+(1-\varphi)^{\frac{1}{\phi}}\left(C^{N}(t)\right)^{\frac{\phi-1}{\phi}}\right]^{\frac{\phi}{\phi-1}},
$$

\footnotetext{
${ }^{22}$ The price of the traded good is determined on the world market and exogenously given for the small open economy. Hence, real exchange rate movements are exclusively caused by the long-run adjustment in the relative price of non tradables.

${ }^{23}$ Our paper builds on Heijdra and Ligthart [2009]. Unlike the authors, we consider a two-sector framework where the sectoral elasticity of labor supply at the extensive margin determines the transition between the traded and the non traded sector labor force and we explore the implications of labor market regulation.
} 
where $\varphi$ is the weight of the traded good in the overall consumption bundle $(0<\varphi<1)$ and $\phi$ is the intratemporal elasticity of substitution $(\phi>0)$.

The economy that we consider consists of a representative household with a measure one continuum of identical infinitely lived members. At any instant, members in the household derive utility from consumption goods $C$ and experience disutility from working and searching efforts. More precisely, the representative household comprises members who engage in only one of the following activities: working and searching a job in each sector, or enjoying leisure. Assuming that the representative individual is endowed with one unit of time, leisure is defined as $1-F^{T}(t)-F^{N}(t)$, with $F^{j}(t)$ the labor force in sector $j=T, N$ defined as the sum of units of labor time, $L^{j}(t)$, and time spent on searching for a job in sector $j, U^{j}(t)$, i.e., $F^{j}(t)=L^{j}(t)+U^{j}(t)$. Unemployed agents are randomly matched with job vacancies according to a matching function described later. Since the timing of a match is random, agents face idiosyncratic risks. To simplify the analysis, we assume that members in the household perfectly insure each other against variations in labor income.

Because the labor force is not constant, we allow for the transition between employment and unemployment and the transition between leisure and labor force. Since the labor force in sector $j$ is not constant as well, we allow for the transition between the traded and the non traded sector. More specifically, we consider that the utility function is additively separable in the disutility received by working and searching in the two sectors. Such a specification makes it impossible to switch from one sector to another instantaneously without going through a spell of search unemployment, as in Alvarez and Shimer [2011]. This can be justified on the grounds of sector-specific skills as well as geographical or psychological mobility costs. The representative household chooses the time path of consumption and labor force to maximize the following objective function:

$$
\Upsilon=\int_{0}^{\infty}\left\{\frac{1}{1-\frac{1}{\sigma_{C}}} C(t)^{1-\frac{1}{\sigma_{C}}}-\frac{\zeta^{T}}{1+\frac{1}{\sigma_{L}^{T}}} F^{T}(t)^{1+\frac{1}{\sigma_{L}^{T}}}-\frac{\zeta^{N}}{1+\frac{1}{\sigma_{L}^{N}}} F^{N}(t)^{1+\frac{1}{\sigma_{L}^{N}}}\right\} e^{-\beta t} \mathrm{~d} t
$$

where $\zeta^{j}>0$ parametrizes the disutility from working and searching efforts in sector $j=$ $T, N, \beta>0$ is the consumer's subjective time discount rate, and $\sigma_{C}>0$ is the intertemporal elasticity of substitution for consumption; $\sigma_{L}^{j}>0$ is the elasticity of labor supply at the extensive margin in sector $j=T, N$; it measures the extent of workers' moving costs: the smaller the elasticity of labor supply, the larger the utility loss when switching, and thus the lower the degree of labor mobility across sectors. ${ }^{24}$ For later use, we denote by $u^{j}$ the sectoral unemployment rate defined as $u^{j}(t)=U^{j}(t) / F^{j}(t)$.

Denoting by $m^{j}(t)$ the rate at which unemployed agents find jobs and $s^{j}$ the exogenous rate of job separation, employment in sector $j$ evolves gradually according to:

$$
\dot{L}^{j}(t)=m^{j}(t) U^{j}(t)-s^{j} L^{j}(t) .
$$

\footnotetext{
${ }^{24}$ Workers' switching costs are the result of an endogenous sectoral labor force participation decision which implies that the allocation of the labor force across sectors is elastic to the ratio of sectoral reservation wages.
} 
Households supply $L^{j}(t)$ units of labor services in sector $j=T, N$ for which they receive the product wage $W^{j}(t)$. We denote by $A(t)$ the stock of financial wealth held by households which comprises internationally traded bonds, $B(t)$, and shares on domestic firms. Because foreign bonds and domestic shares are perfect substitutes, the stock of financial wealth yields net interest rate earnings $r^{\star} A(t)$. Denoting by $T(t)$ the lump-sum taxes, the flow budget constraint is equal to households' real disposable income less consumption expenditure:

$$
\dot{A}(t)=r^{\star} A(t)+\sum_{j} W^{j}(t) L^{j}(t)+\sum_{j} R^{j} U^{j}(t)-T(t)-P_{C}(P(t)) C(t),
$$

where $P_{C}(P)$ is the consumption price index which is a function of the relative price of non tradables, $P$, and $R^{j}$ represents unemployment benefits received by job seekers in sector $j$.

Denoting by $\lambda(t)$ and $\xi^{j}(t)$ the shadow prices of wealth and finding a job in sector $j$, respectively, the key equations characterizing optimal household behavior are: ${ }^{25}$

$$
\begin{gathered}
C(t)=\left(P_{C}(t) \lambda(t)\right)^{-\sigma_{C}} \\
F^{j}(t)=\left\{\lambda(t)\left[m^{j}\left(\theta^{j}(t)\right) \xi^{j}(t)+R^{j}\right] / \zeta^{j}\right\}^{\sigma_{L}^{j}}, \\
\dot{\lambda}(t)=\lambda(t)\left(\beta-r^{\star}\right), \\
\dot{\xi}^{j}(t)=\left(s^{j}+r^{\star}\right) \xi^{j}(t)-\left[W^{j}(t)-\frac{\zeta^{j}\left(F^{j}(t)\right)^{1 / \sigma_{L}^{j}}}{\lambda(t)}\right],
\end{gathered}
$$

and the appropriate transversality conditions. In order to generate an interior solution, we impose $\beta=r^{\star}$; hence, (14c) implies that $\lambda$ must remain constant over time, i.e., $\lambda(t)=\bar{\lambda}$. Eq. (14b) shows that labor market participation increases with the reservation wage $W_{R}^{j}(t)$, which is defined as the sum of the expected value of a job, $m^{j}(t) \xi^{j}(t)$, and the unemployment benefit, $R^{j}$. For the sake of clarity, we drop the time argument below when this causes no confusion.

Intra-temporal allocation of consumption follows from the following optimal rule:

$$
\left(\frac{1-\varphi}{\varphi}\right) \frac{C^{T}}{C^{N}}=P^{\phi}
$$

An appreciation in the relative price of non tradables $P$ increases expenditure on tradables relative to expenditure on non tradables (i.e. $C^{T} / P C^{N}$ ), only when $\phi>1$. Applying Shephard's lemma and denoting by $\alpha_{C}=\frac{(1-\varphi) P^{1-\phi}}{\varphi+(1-\varphi) P^{1-\phi}}$ the share of non traded goods in consumption expenditure yields expenditure in non tradables and tradables, i.e., $P C^{N}=$ $\alpha_{C} P_{C} C, C^{T}=\left(1-\alpha_{C}\right) P_{C} C$.

\section{$3.2 \quad$ Firms}

Each sector consists of a large number of identical firms which use labor, $L^{j}$, as the sole input in a linear technology, $Y^{j}=A^{j} L^{j}$. Firms post job vacancies $V^{j}$ to hire workers and

\footnotetext{
${ }^{25}$ First-order conditions consist of (14a) and (14c) together with $\zeta^{j}\left(F^{j}\right)^{1 / \sigma_{L}^{j}}=m^{j} \xi^{\prime, j}+R^{j} \lambda$ and $\dot{\xi}^{\prime}=$ $\left(s^{j}+\beta\right) \xi^{\prime, j}-\left[\lambda W^{j}-\zeta^{j}\left(F^{j}\right)^{1 / \sigma_{L}^{j}}\right]$. Denoting by $\xi^{j} \equiv \xi^{\prime, j} / \lambda$, using (14a) and (14c), we get (14b) and $(14 \mathrm{~d})$.
} 
face a cost per job vacancy $\kappa^{j}$ which is assumed to be constant and measured in terms of the traded good. Firms pay the wage $W^{j}$ decided by the generalized Nash bargaining solution. As producers face a labor cost $W^{j}$ per employee and a cost per hiring of $\kappa^{j}$, the profit function of the representative firm in sector $j$ is:

$$
\pi^{j}=\Xi^{j} L^{j}-W^{j} L^{j}-\kappa^{j} V^{j}-x^{j} \cdot \max \left\{0,-\dot{L}^{j}\right\}
$$

where $\Xi^{j}$ is the marginal revenue of labor; $x^{j}$ is a firing tax paid to the government when layoffs are higher than hirings, i.e., if $\dot{L}^{j}<0$ (see e.g., Heijdra and Ligthart [2002], Veracierto [2008]). The firing tax is introduced to capture the strictness of legal protection against dismissals and is modelled as a tax on reducing employment. ${ }^{26}$

Denoting by $f^{j}$ the rate at which a vacancy is matched with unemployed agents, the law of motion for labor is given by:

$$
\dot{L}^{j}=f^{j} V^{j}-s^{j} L^{j}
$$

Denoting by $\gamma^{j}$ the shadow price of employment to the firm, the maximization problem yields the following first-order conditions:

$$
\begin{aligned}
\gamma^{j}+x^{j} & =\frac{\kappa^{j}}{f^{j}\left(\theta^{j}\right)} \\
\dot{\gamma}^{j} & =\gamma^{j}\left(r^{\star}+s^{j}\right)-\left(\Xi^{j}-x^{j} s^{j}-W^{j}\right) .
\end{aligned}
$$

Eq. (18a) requires the marginal cost of vacancy, $\kappa^{j}$, to be equal to the expected marginal benefit of hiring, $f^{j}\left(\gamma^{j}+x^{j}\right)$. Solving (18b) forward and invoking the transversality condition yields:

$$
\gamma^{j}(t)=\int_{t}^{\infty}\left[\Xi^{j}(\tau)-x^{j} s^{j}-W^{j}(\tau)\right] e^{\left(s^{j}+r^{\star}\right)(t-\tau)} \mathrm{d} \tau .
$$

Eq. (19) states that $\gamma^{j}$ is equal to the present discounted value of the cash flow earned on an additional worker, consisting of the excess of marginal revenue of labor $\Xi^{j}$ over the wage $W^{j}$ and the expected firing $\operatorname{cost} x^{j} s^{j}$. Following higher productivity $A^{j}$, the marginal revenue of labor $\Xi^{j}$ rises; hence hiring becomes more profitable which induces firms to post job vacancies, but less so in countries with a higher firing cost $x^{j}$.

\subsection{Matching and Wage Determination}

In each sector, there are job-seeking workers $U^{j}$ and firms with job vacancies $V^{j}$ which are matched in a random fashion. Assuming a constant returns to scale matching function, the number of labor contracts $M^{j}$ concluded per job seeker $U^{j}$ gives the job finding rate $m^{j}$ which is increasing in the labor market tightness $\theta^{j}$ :

$$
m^{j}=M^{j} / U^{j}=X^{j}\left(V^{j} / U^{j}\right)^{\alpha_{V}^{j}}=X^{j}\left(\theta^{j}\right)^{\alpha_{V}^{j}},
$$

\footnotetext{
${ }^{26}$ While employment is lowered, the shrinking establishment is hiring; thus assuming a tax on reducing employment implies that the representative firm simultaneously pays a tax on employment exits and receives a hiring subsidy, the former being higher than the latter amount, i.e., $-x^{j} \dot{L}^{j}=x^{j} s^{j} L^{j}-x^{j} f^{j} V^{j}>0$.
} 
where $\alpha_{V}^{j}$ represents the elasticity of vacancies in job matches and $X^{j}$ corresponds to the matching efficiency. The number of matches $M^{j}$ per job vacancy gives the worker-finding rate for the firm, $f^{j}$, which is decreasing with $\theta^{j}$ :

$$
f^{j}=M^{j} / V^{j}=X^{j}\left(\theta^{j}\right)^{\alpha_{V}^{j}-1} .
$$

When a vacancy and a job-seeking worker meet, a rent is created which is equal to $\xi^{j}+\gamma^{j}+x^{j}$, where $\xi^{j}$ is the value of an additional job, $\gamma^{j}$ is the value of an additional worker, and $x^{j}$ corresponds to the hiring subsidy. ${ }^{27}$ The division of the rent between the worker and the firm determined by generalized Nash bargaining leads to the product wage $W^{j}$ defined as a weighted sum of the labor marginal revenue plus the interest income from the hiring subsidy and the reservation wage:

$$
W^{j}=\alpha_{W}^{j}\left(\Xi^{j}+r^{\star} x^{j}\right)+\left(1-\alpha_{W}^{j}\right) W_{R}^{j}
$$

where $\alpha_{W}^{j}$ and $1-\alpha_{W}^{j}$ correspond to the bargaining power of the worker and the firm.

\subsection{Government}

The final agent in the economy is the government. Unemployment benefits $R^{T} U^{T}+R^{N} U^{N}$ are covered by lump-sum taxes $T$ and the proceeds from the firing $\operatorname{tax} \sum_{j} x^{j} \cdot \max \left\{0,-\dot{L}^{j}\right\}$ according to the following balanced budget constraint: ${ }^{28}$

$$
\sum_{j} x^{j} \cdot \max \left\{0,-\dot{L}^{j}\right\}+T=\sum_{j} R^{j} U^{j}
$$

\subsection{Market Clearing Conditions}

We have to impose the market clearing condition for the non traded good:

$$
Y^{N}(t)=C^{N}(t)
$$

Using the definition of the stock of financial wealth $A(t) \equiv B(t)+\sum_{j} \gamma^{j}(t) L^{j}(t)$, differentiating with respect to time, substituting the accumulation equations of labor (12) and financial wealth (13) together with the dynamic equation for the shadow value of an additional worker (18b), using (23) and (24), the current account is:

$$
\dot{B}(t)=r^{\star} B(t)+Y^{T}(t)-C^{T}(t)-\kappa^{T} V^{T}(t)-\kappa^{N} V^{N}(t) .
$$

\footnotetext{
${ }^{27}$ As mentioned above, the firing tax is modelled as a tax on reducing employment; because firms experience simultaneously outflow and inflow of workers, this shortcut to encompass the strictness of employment protection implies that establishments pay firing taxes and receive hiring subsidies at the same time, the former being larger than the latter amount.

${ }^{28}$ In the numerical analysis, we consider government spending for calibration purpose. In this case, eq. (23) can be rewritten as follows: $\sum_{j} x^{j} \cdot \max \left\{0,-\dot{L}^{j}\right\}+T=\left(R^{T} U^{T}+R^{N} U^{N}\right)+G^{T}+P G^{N}$ where $G^{T}$ and $G^{N}$ government spending on tradables and non tradables, respectively.
} 


\subsection{Steady-State}

We now describe the steady-state of the economy. Due to the lack of empirical estimates at a sectoral level, and to avoid unnecessary complications, we impose $\alpha_{V}^{j}=\alpha_{V}, \alpha_{W}^{j}=\alpha_{W}$, $\sigma_{L}^{j}=\sigma_{L}$ from now on.

First, setting $\dot{B}=0$ into (25), denoting by $v_{N X} \equiv N X / Y^{T}$ the ratio of net exports to traded output, and using (24) yields the goods market equilibrium: ${ }^{29}$

$$
\frac{Y^{T}\left(1-v_{N X}\right)}{Y^{N}}=\frac{\varphi}{1-\varphi} P^{\phi}
$$

where we have inserted the allocation of aggregate consumption expenditure between traded and non traded goods given by (15). According to (26), following a rise in traded output relative to non traded output, the relative price of non tradables, $P$, must appreciate to clear the goods market and all the more so as the elasticity of substitution $\phi$ is smaller.

Second, setting $\dot{\gamma}^{j}=0$ into (18b), using (18a) to eliminate $\gamma^{j}$, and inserting $W^{j}$ given by (22) leads to the vacancy creation equation which states that the marginal benefit of an additional worker to the firm, i.e., $\frac{\left(1-\alpha_{W}\right)}{s^{j}+r^{\star}} \Psi^{j}$ (with $\Psi^{j}$ given by (1)) equalizes the expected costs of recruitment per worker, i.e., $\kappa^{j} / f^{j}$. Inserting (21) and combining hiring decisions for the traded and non traded sectors give:

$$
\frac{\kappa^{T}}{\kappa^{N}} \frac{\left(s^{T}+r^{\star}\right)}{\left(s^{N}+r^{\star}\right)} \frac{X^{N}}{X^{T}}\left(\frac{\theta^{T}}{\theta^{N}}\right)^{1-\alpha_{V}}=\frac{\Xi^{T}+r^{\star} x^{T}-W_{R}^{T}}{\Xi^{N}+r^{\star} x^{N}-W_{R}^{N}},
$$

where $\Xi^{T}=A^{T}$ and $\Xi^{N}=P A^{N}$. According to the vacancy creation equation described by (27), higher productivity in tradables relative to non tradables has an expansionary effect on labor demand in the traded sector and thus pushes up $\theta^{T} / \theta^{N}$ as long as $\phi>1$. Intuitively, higher $A^{T} / A^{N}$ appreciates $P$. If $\phi>1$, the share of tradables rises which in turn stimulates hirings in the traded sector relative to those in the non traded sector.

Third, setting $\dot{\xi}^{j}=0$ into (14d) leads to $\xi^{j}=\frac{\alpha_{W} \Psi^{j}}{s^{j}+r^{\star}}$. Rewriting the latter equation by inserting the vacancy creation equation for sector $j$ to eliminate $\Psi^{j}$ gives the expected value of finding a job, i.e., $m^{j} \xi^{j}=\frac{\alpha_{W}}{1-\alpha_{W}} \kappa^{j} \theta^{j}$. Plugging this equation into (14b) leads to the equality between the utility loss from participating in the labor market in sector $j$, $\frac{\zeta^{j}\left(F^{j}\right)^{\frac{1}{\sigma_{L}}}}{\bar{\lambda}}$, and the marginal benefit from search, $\frac{\alpha_{W}}{1-\alpha_{W}} \kappa^{j} \theta^{j}+R^{j}=W_{R}^{j}$. Combining the decision of search for the traded and the non traded sector gives:

$$
\frac{L^{T}}{L^{N}}=\frac{m^{T}}{m^{N}} \frac{m^{N}+s^{N}}{m^{T}+s^{T}}\left(\frac{W_{R}^{T}}{W_{R}^{N}} \frac{\zeta^{N}}{\zeta^{T}}\right)^{\sigma_{L}},
$$

where we set $\dot{L}^{j}=0$ into (12) to eliminate $U^{j}$. According to (28), a rise in $\theta^{T} / \theta^{N}$ has an expansionary effect on hours worked in the traded sector because more unemployed agents

\footnotetext{
${ }^{29}$ Denoting by $v_{B} \equiv \frac{r^{\star} B}{Y^{T}}$ the ratio of interest receipts to traded output and $v_{V}^{j} \equiv \frac{\kappa^{j} V^{j}}{Y^{T}}$ the ratio of the cost of hiring in sector $j=T, N$ to traded output, the zero current account equation implies $v_{B}-v_{V}^{T}-v_{V}^{N}=$ $-v_{N X}$. While for simplicity purposes, we refer to $v_{N X}$ as the ratio of net exports to traded output, it also includes hiring expenditure, i.e., $N X \equiv Y^{T}-C^{T}=\mathrm{NX}+\kappa^{T} V^{T}+\kappa^{N} V^{N}$ with $\mathrm{NX} \equiv Y^{T}-C^{T}-\kappa^{T} V^{T}-\kappa^{N} V^{N}$ corresponding to the 'true' definition of the trade balance.
} 
find a job while workers are also encouraged to increase their participation to the labor force in this sector, and all the more so as $\sigma_{L}$ is larger.

The long-term equilibrium comprise three equations (26)-(28) which can be solved for relative employment, $L^{T} / L^{N}$, the ratio of sectoral labor market tightness, $\theta^{T} / \theta^{N}$, and the relative price, $P$, as functions of relative productivity, $A^{T} / A^{N}$, and $v_{N X}$. Inserting these solutions into the Nash bargaining wage (22) and the unemployment rate differential (4) allows us to express the relative wage, $\Omega=W^{N} / W^{T}$ and the relative unemployment rate $u^{T} / u^{N}$, in terms of $A^{T} / A^{N}$ and $v_{N X}$. This procedure to solve for the steady-state enables us to break down analytically the effects of a productivity differential between tradables and non tradables into two components as detailed in the next section. ${ }^{30}$

\section{Higher Relative Productivity and Labor Market Frictions}

Since the forces which shape the relative wage and relative price responses to an increase in $A^{T} / A^{N}$ determine the behavior of the unemployment rate differential between tradables and non tradables, we first explore their adjustment. We thus analytically break down the relative wage and relative price effects in two components to shed some light on the transmission mechanism and investigate the implications of labor market institutions. ${ }^{31}$ Then we extend this analysis to the unemployment rate differential between tradables and non tradables and investigate the transitional adjustment of sectoral unemployment rates by using phase diagrams.

\subsection{Inspecting the Transmission Mechanism}

Equating demand (26) and supply (27)-(28) of tradables in terms of non tradables, leads to a relationship between the deviation in percentage of the relative price from its initial steady-state and the productivity differential: ${ }^{32}$

$$
\hat{p}=\frac{\left(1+\Theta^{T}\right) \hat{a}^{T}-\left(1+\Theta^{N}\right) \hat{a}^{N}}{\left(\phi+\Theta^{N}\right)}+\frac{\mathrm{d} \ln \left(1-v_{N X}\right)}{\left(\phi+\Theta^{N}\right)},
$$

\footnotetext{
${ }^{30}$ When solving the steady-state, changes in the net foreign asset position and thus in net exports as reflected by changes in $v_{N X}$ are assumed to be exogenous. Such a procedure allows us to isolate the effects stemming from changes in the trade balance and hiring expenditure. The ratio $v_{N X}$ can be expressed in terms of sectoral productivities by using the intertemporal solvency condition obtained by linearizing (25) and invoking the intertemporal solvency condition. More details can be found in the Technical Appendix.

${ }^{31}$ It compares the steady-state of the model before and after the productivity shock biased towards the traded sector.

${ }^{32}$ Totally differentiating the goods market equilibrium (26) yields: $\left(\hat{y}^{T}-\hat{y}^{N}\right)=\phi \hat{p}-\mathrm{d} \ln \left(1-v_{N X}\right)$. Remembering that $\hat{w}_{R}^{j}=\chi^{j} \hat{\theta}^{j}$ and totally differentiating the vacancy creation equation for sector $j$ gives the deviation in percentage of the sectoral labor market tightness from its initial steady-state, i.e., $\hat{\theta}^{j}=\frac{\Xi^{j} \hat{\Xi}^{j}}{\left[\left(1-\alpha_{V}\right) \Psi^{j}+\chi^{j} W_{R}^{j}\right]}$. Totally differentiating the decision of search equation for sector $j$ leads to $\hat{l}^{j}=\sigma_{L} \hat{\bar{\lambda}}+\left[\alpha_{V} u^{j}+\sigma_{L} \chi^{j}\right] \hat{\theta}^{j}$. Substituting the former into the latter, differentiating the production function to eliminate $\hat{l}^{j}$, and using the fact that $\chi^{j} W_{R}^{j}=\frac{\alpha_{W} \Psi^{j}}{s^{j}+r^{\star}}$ at the steady-state, one obtains $\hat{y}^{j}=\hat{a}^{j}+\Theta^{j} \hat{\Xi}^{j}$ where $\Theta^{j}$ is given by (30). The output differential along the labor market equilibrium is thus given by $\left(\hat{y}^{T}-\hat{y}^{N}\right)=-\Theta^{N} \hat{p}+\left(1+\Theta^{T}\right) \hat{a}^{T}-\left(1+\Theta^{N}\right) \hat{a}^{N}$. Combining the goods with the labor market equilibrium leads to $(29)$.
} 
where we set

$$
\Theta^{j} \equiv \frac{\Xi^{j}\left(s^{j}+r^{\star}\right)\left[\alpha_{V} u^{j}+\sigma_{L} \chi^{j}\right]}{\Psi^{j}\left[\left(1-\alpha_{V}\right)\left(s^{j}+r^{\star}\right)+\alpha_{W} m^{j}\right]},
$$

in order to write expressions in a compact form. The elasticity $\Theta^{j}$ of sectoral employment $L^{j}$ w.r.t. the marginal revenue of labor $\Xi^{j}$ is a measure of the degree of labor mobility across sectors which captures both the size of workers' mobility costs and the extent of search frictions. In order to facilitate the discussion, we assume that $\Theta^{j} \simeq \Theta .{ }^{33}$ Under this assumption, (29) reduces to:

$$
\hat{p}=\frac{(1+\Theta)\left(\hat{a}^{T}-\hat{a}^{N}\right)}{(\phi+\Theta)}+\frac{\mathrm{d} \ln \left(1-v_{N X}\right)}{(\phi+\Theta)},
$$

where $\mathrm{d} \ln \left(1-v_{N X}\right) \simeq-\mathrm{d} v_{N X}$ by using a first-order Taylor approximation.

Eq. (31) breaks down the relative price response into two components: a labor market frictions effect and a labor accumulation effect. The first term on the RHS of (31) corresponds to the labor market frictions effect. Through this channel, higher productivity gains in tradables relative to non tradables tend to appreciate $p$. The reason is that a productivity shock biased toward the traded sector raises traded output relative to non traded output so that $p$ must increase to clear the goods market. Importantly, the size of the relative price appreciation is given by the elasticity $\frac{(1+\Theta)}{(\phi+\Theta)}$. When we let $\sigma_{L}$ tend toward infinity, workers no longer experience a utility loss when shifting from one sector to another; hence the case of perfect mobility of labor across sectors is obtained as reflected by the term $\Theta$ that tends toward infinity; in this configuration, a productivity differential between tradables and non tradables by $1 \%$ appreciates $p$ by $1 \%$ as well. As long as $\sigma_{L}<\infty$, workers experience a mobility cost when moving from one sector to another so that the term $\Theta$ takes finite values. In this configuration, the relative price of non tradables is jointly determined by technological and demand conditions. Hence, the elasticity $\phi$ between traded and non traded goods in consumption plays a pivotal role in the determination of the relative price response. If $\phi>1(\phi<1), p$ appreciates by less (more) than $\hat{a}^{T}-\hat{a}^{N}$.

The second term on the RHS of (31) reveals that a productivity differential between tradables and non tradables also impinges on $p$ by affecting the trade balance and hiring expenditure expressed as a share of traded output, as summarized by $\mathrm{d} v_{N X}$. More precisely, through the labor accumulation channel, higher productivity gains in tradables relative to non tradables increase $v_{N X}$ which exerts a negative impact on $p$ by raising the demand for tradables in the long-run. Intuitively, higher productivity, $A^{j}$, raises the shadow value of an additional worker $\gamma^{j}$ and thus induces firms in both sectors to hire more. Because job vacancies $V^{j}$ are a jump variable, it overshoots on impact. Since hiring is a costly activity, recruiting expenditures rise substantially. While employment builds up, the open economy finances the accelerated hiring process by running a current account deficit in the

\footnotetext{
${ }^{33}$ For the baseline calibration, while labor market parameters are allowed to vary across sectors $\Theta^{T}$ and $\Theta^{N}$ are very similar if not identical. It is only when the firing costs are important that $\Theta^{T}$ and $\Theta^{N}$ differ substantially.
} 
short-run. For the country to remain solvent, the deterioration in the net foreign asset position must be offset by a steady-state increase in net exports. The combined effect of the improvement in the trade balance and the permanently increased hiring expenditure has an expansionary effect on the demand for tradables which drives down $p$, regardless of the value of the elasticity of substitution, $\phi$. To conclude, as long as the elasticity of labor supply takes finite values (i.e., $\sigma_{L}<\infty$ ), we will have to determine numerically if the labor accumulation effect more than offsets the labor market frictions effect when $\phi<1$ so that $\hat{p}<1 \%$ following a rise in the productivity of tradables relative to non tradables by $1 \%$.

We now explore the long-run response of the relative wage of non tradables to a productivity differential. To do so, we first totally differentiate the vacancy creation equation that we substitute into the Nash bargaining wage (22) expressed in rate of change relative to the steady-state: ${ }^{34}$

$$
\hat{w}^{j}=\Omega^{j} \hat{\Xi}^{j}, \quad \Omega^{j} \equiv \frac{\Xi^{j}}{W^{j}} \frac{\alpha_{W}\left[\left(1-\alpha_{V}\right)\left(s^{j}+r^{\star}\right)+m^{j}\right]}{\left[\left(1-\alpha_{V}\right)\left(s^{j}+r^{\star}\right)+\alpha_{W} m^{j}\right]}>0,
$$

where $\hat{\Xi}^{T}=\hat{a}^{T}$ and $\hat{\Xi}^{N}=\hat{p}+\hat{a}^{N}$. Calculating $\hat{\omega} \equiv \hat{w}^{N}-\hat{w}^{T}$ by using (32) and substituting (29) yields the deviation in percentage of the relative wage from its initial steady-state:

$$
\hat{\omega}=\left\{\Omega^{N}\left[\frac{\left(1+\Theta^{T}\right) \hat{a}^{T}+(\phi-1) \hat{a}^{N}}{\left(\phi+\Theta^{N}\right)}\right]-\Omega^{T} \hat{a}^{T}\right\}+\Omega^{N} \frac{\mathrm{d} \ln \left(1-v_{N X}\right)}{\phi+\Theta^{N}} .
$$

Assuming $\Theta^{j} \simeq \Theta$ and $\Omega^{j} \simeq \Omega$ to facilitate the discussion implies that (33) reduces to: ${ }^{35}$

$$
\hat{\omega}=-\Omega\left[\frac{(\phi-1)}{\phi+\Theta}\left(\hat{a}^{T}-\hat{a}^{N}\right)-\frac{\mathrm{d} \ln \left(1-v_{N X}\right)}{\phi+\Theta}\right] .
$$

When assuming perfect mobility of labor across sectors, i.e., if we let $\sigma_{L}$ tend toward infinity, we have $\Theta \rightarrow \infty$; hence (34) shows that a productivity differential leaves unaffected $\omega$. Conversely, as long as workers experience a utility loss when shifting (i.e., assuming $\left.\sigma_{L}<\infty\right)$, higher productivity gains in tradables relative to non tradables impinge on $\omega$ through two channels.

When keeping fixed $v_{N X},(34)$ reduces to $-\Omega \frac{(\phi-1)}{\phi+\Theta}\left(\hat{a}^{T}-\hat{a}^{N}\right)$. Hence, through the labor market frictions channel, a productivity differential between tradables and non tradables lowers the relative wage $\omega$ only if $\phi>1$. With an elasticity of substitution $\phi$ greater than one, the demand for tradables rises more than proportionally. By raising the share of tradables in total expenditure, higher productivity gains in tradables relative to non tradables induce traded firms to hire more which lowers $\omega$. Conversely, with an elasticity $\phi$ smaller than one, the share of non tradables rises which has an expansionary effect on recruitment in the non traded sector. Hence, in this case, $\omega$ increases instead of declining, in contradiction with our empirical findings.

\footnotetext{
${ }^{34}$ Totally differentiating (22) gives $\hat{w}^{j}=\frac{\alpha_{W} \Xi^{j}}{W^{j}} \hat{\Xi}^{j}+\left(1-\alpha_{W}\right) \frac{\chi^{j} W_{R}^{j}}{W^{j}} \hat{\theta}^{j}$. Inserting in the above equation the vacancy creation equation expressed in percentage deviation from initial steady-state, i.e., $\hat{\theta}^{j}=$ $\frac{\Xi^{j} \hat{\Xi}^{j}}{\left[\left(1-\alpha_{V}\right) \Psi^{j}+\chi^{j} W_{R}^{j}\right]}$, and using the fact that at the steady-state, $\chi^{j} W_{R}^{j}=m^{j} \xi^{j}=\frac{m^{j} \alpha_{W} \Psi^{j}}{s^{j}+r^{\star}}$, one obtains (32).

${ }^{35}$ For the baseline scenario of our quantitative analysis, i.e., when calibrating to a typical OECD economy, $\Omega^{T}$ and $\Omega^{N}$ are almost identical.
} 
As captured by the second term on the RHS of (34), a productivity differential between tradables and non tradables also impinges on $\omega$ through a labor accumulation channel. More specifically, higher demand for tradables triggered by the improvement in the trade balance encourages traded firms to hire more which exerts a negative impact on the relative wage.

While $\omega$ unambiguously declines if the elasticity of substitution is larger than one, when $\phi<1$, the relative wage response to a productivity differential is ambiguous. In the latter case, higher productivity in tradables relative to non tradables drives down $\omega$ through the labor accumulation channel while it increases the relative wage through the labor market frictions channel. We address this ambiguity numerically later.

In our model, the elasticity of labor supply at the extensive margin, $\sigma_{L}$, plays a key role in the determination of the relative wage adjustment. When the labor force participation decision is endogenized, the situations of total immobility $\left(\sigma_{L}=0\right)$ and perfect mobility $\left(\sigma_{L} \rightarrow \infty\right)$ of labor emerge as special cases. If we let $\sigma_{L}=0$, the situation of total labor immobility is obtained. Because the mobility costs are prohibitive, the labor force is fixed in both sectors. As will be clear later when discussing quantitative results, such a configuration reduces the likelihood that our model trustfully replicates our empirical findings.

Conversely, when we let $\sigma_{L}$ tend toward infinity, workers are no longer subject to switching costs; in this configuration, we have $\Theta^{j} \rightarrow \infty$ so that $(29)$ reduces to $\hat{p}=\left(\hat{a}^{T}-\hat{a}^{N}\right)$, as in the standard BS model. Inserting the relative price equation into $\hat{\Xi}^{N}=\hat{p}+\hat{a}^{N}$, the deviation in percentage of the relative wage from its initial steady-state (33) can be rewritten as $\hat{\omega}=\left(\Omega^{N}-\Omega^{T}\right) \hat{a}^{T}$. Such an equality reflects the fact that even if mobility costs are absent, technological change biased toward the traded sector may produce different sectoral wage responses because search parameters vary across sectors. However, the quantitative analysis conducted in section 5 reveals that the elasticity $\Omega^{j}$ of sectoral wages w.r.t. the marginal revenue of labor is almost identical across sectors (as long as firing costs are low), i.e., $\Omega^{T} \simeq \Omega^{N}$; hence, if $\sigma_{L} \rightarrow \infty$, we would have $\hat{\omega} \simeq 0$. Standard search frictions are thus insufficient on their own to produce significant long-run movements in the relative wage.

\subsection{Implications of Labor Market Regulation}

We now explore the ability of our model to account for our empirical findings established in section 2.5. So far, we have shown that the relative wage of non tradables no longer remains fixed following higher productivity gains in tradables relative to non tradables because workers experience a mobility cost (as captured by $0<\sigma_{L}<\infty$ ) which must be covered by higher wages. While searching for a job is costly because it is time consuming, in a model with search in the labor market, hiring is also a costly activity. By affecting the marginal benefit of hiring, labor market institutions determine the elasticity of labor demand to productivity gains. Because labor market regulation influences the hiring process 
and the subsequent adjustment of sectoral output to technology shocks, we also address the implications of labor institutions for the relative price adjustment. Since the transmission mechanism varies according to the type of labor market institution, we differentiate between the firing cost on the one hand, the generosity of the unemployment benefit scheme and the worker bargaining power on the other.

\subsubsection{Higher Firing Tax}

In our model, the strictness of legal protection against dismissals is captured by a firing tax denoted by $x^{j}$ paid to the State by the representative firm in the sector which reduces employment. Productivity gains exert two opposite effects on labor $L^{j}$. On the one hand, by producing a positive wealth effect, as reflected by a fall in the shadow value of wealth $\bar{\lambda}$, a higher productivity exerts a negative impact on employment by driving down labor supply (see eq. (14b)). On the other hand, by increasing the marginal revenue of labor, a rise in $A^{j}$ induces firms to recruit more which pushes up employment. Because productivity shocks are biased toward the traded sector, hours worked increase in the traded sector while labor in the non traded sector declines. As non traded establishments are shrinking, firms must pay a firing cost on reducing employment. Thus, according to (19), higher productivity induces non traded firms to post more job vacancies but less so as the firing tax is increased because the surplus from hiring rises by a smaller amount. Since hirings in the non traded sector are relatively less profitable in countries where the firing tax is higher, the labor market tightness $\theta^{N}$ (and thus $W^{N}$ ) increases by a smaller amount.

When $\phi>1$, higher productivity gains in tradables relative to non tradables increases the surplus of hirings in the traded sector relative to that in non traded sector. Hence, the ratio of labor market tightness (i.e., $\theta^{T} / \theta^{N}$ ) rises, and more so as the firing cost paid by non traded firms to the State is higher because hiring in the non traded sector is limited by the firing tax. Consequently, $\omega$ declines more, in line with our empirical findings, through a stronger labor market frictions effect. Because non traded firms tend to recruit less in countries where the firing tax is higher, labor and thus output of non tradables tends to increase by a smaller amount so that the relative price appreciates more. However, a higher firing tax also mitigates the decline in $\omega$ and the appreciation in $p$ since net exports increase less. Intuitively, as recruiting expenditure are curbed by the firing tax, the productivity differential leads to a smaller current account deficit, thus moderating the necessary trade balance improvement.

In terms of (33), a higher firing tax (paid by non traded firms) lowers substantially the term $\Omega^{N}$ which is the elasticity of the non traded wage to the marginal revenue of labor. The term in braces in (33) which captures the labor market frictions channel is thus higher in absolute terms (or more negative) when $\phi>1$. Conversely, when $\phi<1$, the term in braces in (33) becomes positive but smaller as the firing tax $x$ is increased. Regarding the 
relative price equation (29), a stricter employment legislation against dismissals lowers $\Theta^{N}$ and thus amplifies the effect of higher productivity in tradables relative to non tradables on $p$. Moreover, as mentioned above, in countries where the firing tax is higher, net exports increase less which lowers $d v_{N X}>0$ in the last term of (29) and (33). Thus, the firing tax moderates the labor accumulation effect and thus mitigates the negative impact on $p$ and $\omega$.

\subsubsection{Higher Unemployment Benefit Replacement Rate or Worker Bargaining Power}

In our framework, the generosity of the unemployment benefit scheme is captured by the level of $R^{j}$; unemployment benefits are assumed to be a fixed proportion $\varrho$ of the wage rate $W^{j}$, i.e., $R^{j}=\varrho W^{j}$. Additionally, a higher worker bargaining power measured empirically by the bargaining coverage is captured by the parameter $\alpha_{W}$.

In contrast to a firing tax, raising $\varrho$ or $\alpha_{W}$ leads to a larger long-run rise in net exports and thus amplifies the decline in $\omega$ and mitigates the appreciation in the relative price through the labor accumulation channel. The reason is as follows. In countries where unemployment benefits are more generous or the worker bargaining power is larger, there are more job-seeking workers and less job vacancies, thus resulting in lower labor market tightness $\theta^{j}$ in both sectors. Consequently, following higher productivity, firms are more willing to recruit additional workers because hiring is more profitable as the probabilities of fulfilling vacancies $\left(f^{j}\right)$ are much higher. Hence, the open economy experiences a larger current account deficit along the transitional path which must be matched in the long-run by a greater improvement in the balance of trade. By amplifying the rise in net exports and thus the demand for tradables, a productivity shock biased toward the traded sector exerts a larger negative impact on $\omega$ and $p$ in countries with a higher $\varrho$ or a larger $\alpha_{W}$. While a productivity differential lowers further $\omega$ and $p$ through higher net exports, increased labor mobility tends to mitigate the impact of the trade balance. More precisely, larger values of $\varrho$, by reducing the expected cost of hiring (because the probability $f^{j}$ is higher), or higher values of $\alpha_{W}$, by raising the marginal benefit of search, increase the mobility of labor across sectors (captured by $\Theta^{j}$ ). Because workers are more willing to search for a job in countries with higher $\alpha_{W}$ or $\varrho$, larger values of $\Theta^{j}$ mitigate the negative impact of increased net exports on $\omega$ and $p$.

Since it is found analytically that the three dimensions of labor market regulation exert opposite effects on the elasticity of $\omega$ and $p$ to a productivity differential, we conduct a quantitative analysis in section 5.

\subsection{Effects on Sectoral Unemployment Rates}

We now emphasize the implications of labor market frictions for unemployment effects of higher relative productivity. Importantly, our framework is tractable enough to analyze the 
adjustment of sectoral unemployment in the long- and the short-run as well.

We begin with the long-run effect of $A^{T} / A^{N}$ on the unemployment rate differential between tradables and non tradables. Setting $\dot{L}^{j}=0$ into (12) gives us the standard negative relationship between the unemployment rate, $u^{j}$, and labor market tightness, $\theta^{j}$ :

$$
u^{j}=\frac{s^{j}}{s^{j}+m^{j}\left(\theta^{j}\right)} \text {. }
$$

The labor market steady-state in sector $j=T, N$ is described by a decision of search- and a vacancy creation-schedule (henceforth labelled $D S j$ and $V C j$ ), respectively: ${ }^{36}$

$$
\begin{gathered}
L^{j}=\left(1-u^{j}\right)\left(\bar{\lambda} W_{R}^{j} / \zeta^{j}\right)^{\sigma_{L}}, \\
\frac{\kappa^{j}}{f^{j}}=\frac{\left(1-\alpha_{W}\right)}{\left(s^{j}+r^{\star}\right)} \Psi^{j},
\end{gathered}
$$

where $W_{R}^{j}$ and $\Psi^{j}$ are the reservation wage and overall surplus from an additional job in sector $j$. Eqs. (35) and (36a) determine the $D S j$-schedule which is downward-sloping in the $\left(u^{j}, L^{j}\right)$-space. Intuitively, a rise in $\theta^{j}$ raises the probability of finding a job and thereby the marginal benefit of search which increases $L^{j}$ and lowers $u^{j}$. Eqs. (35) and (36b) determine the $V C j$-schedule which is vertical in the traded sector (see Figure 2(a)) and upward-sloping in the non traded sector (see Figure 2(b)). ${ }^{37}$ Intuitively, a rise in $L^{N}$ increases non traded output and thereby exerts a downward pressure on the relative price; because the marginal benefit of hiring falls, $\theta^{N}$ declines, and thus $u^{N}$ increases. Since the terms of trade are fixed, a rise in $L^{T}$ leaves $u^{T}$ unaffected along the $V C T$-schedule.

The initial steady-state is at point $H_{0}^{j}$ in the first row of Figure 2 while the final steadystate is at $H_{1}^{j}$. A rise in relative productivity produces a positive wealth effect which lowers labor supply and thus shifts the $D S j$-schedule downward in sector $j$. At the same time, by raising the surplus from hiring, higher labor productivity shifts the $V C j$-schedule to the left. As firms recruit more, the labor market tightness $\theta^{j}$ increases which lowers the unemployment rate in both sectors. Under certain conditions we detail below, the shift of the $V C j$-schedule to the left is larger in the traded sector which results in a greater decline in $u^{T}$ than in $u^{N}$.

Steady-State Effects. Setting $\Sigma^{j}=\frac{\Xi^{j}}{\left(1-\alpha_{V}\right) \Psi^{j}+\chi^{j} W_{R}^{j}}$, the steady-state change in the labor market tightness is $\hat{\theta}^{j}=\Sigma^{j} \hat{\Xi}^{j}$. Using the latter result, totally differentiating (35) and using (31), subtracting $d u^{N}$ from $d u^{T}$, the change in the unemployment rate differential between tradables and non tradables in percentage point reads as:

$$
d u^{T}-d u^{N}=-\alpha_{V} u(1-u) \Sigma\left[\left(\frac{\phi-1}{\phi+\Theta}\right)\left(\hat{a}^{T}-\hat{a}^{N}\right)-\frac{\mathrm{d} \ln \left(1-v_{N X}\right)}{(\phi+\Theta)}\right],
$$

\footnotetext{
${ }^{36}$ Setting $\dot{L}^{j}=0$ into (12) and $\dot{\xi}^{j}=0$ into (14b) leads to the $D S j$-schedule in sector $j$. Setting $\dot{\gamma}^{j}=0$ into (18b), and inserting $W^{j}$ given by (22) leads to the $V C j$-schedule in sector $j$.

${ }^{37}$ Totally differentiating (35) and (36a) leads to $D S^{j}$-schedule in the $\left(u^{j}, L^{j}\right)$-space, i.e., $\left.\frac{d \ln L^{j}}{d \ln u^{j}}\right|_{\dot{L}^{j}=0}=$ $-\frac{\left[\alpha_{V} u^{j}+\sigma_{L} \chi^{j}\right]}{\alpha_{V}\left(1-u^{j}\right)}<0$. Totally differentiating (35) and (36b) leads to the $V C^{j}$-schedule in the $\left(u^{j}, L^{j}\right)$-space, i.e., $\left.\frac{d \ln L^{j}}{d \ln u^{j}}\right|_{\dot{\theta} j=0}=-\frac{\left(1-\alpha_{V}\right) \Psi^{j}+\chi^{j} W_{R}^{j}}{\alpha_{V}\left(1-u^{j}\right) \Xi_{L^{j}}^{j} L^{j}}>0$ where $\Xi_{L^{j}}^{j}=\partial \Xi^{j} / \partial L^{j} \leq 0$.
} 
where we assume that search parameters are such that $\Theta^{j} \simeq \Theta, u^{j} \simeq u, \Sigma^{j} \simeq \Sigma$ to facilitate the discussion. When we let $\sigma_{L} \rightarrow \infty$, the term $\Theta$ tends toward infinity as well so that the unemployment rate differential remains unchanged. ${ }^{38}$ Intuitively, when job search costs are absent, $p$ appreciates by the same amount as $\hat{a}^{T}-\hat{a}^{N}$ so that the marginal revenue of labor and thus labor market tightness rises evenly across sectors.

As captured by the first term on the RHS of (37), if $\phi<1$, higher $A^{T} / A^{N}$ lowers $u^{T}$ less than $u^{N}$, i.e., $d u^{T}-d u^{N}>0$, through the labor market frictions channel. The second term on the RHS of (37) reveals that the long-run improvement in the balance of trade drives down the unemployment rate differential, i.e., $d u^{T}-d u^{N}<0$, through the labor accumulation channel. Whilst numerical results discussed in the next section show that the latter channel predominates, labor market regulation should amplify the decline in the relative unemployment rate of tradables. Intuitively, in countries where the worker bargaining power or the replacement rate is higher, net exports and thus the demand for tradables increases more. In addition, as employment protection legislation becomes more stringent, $\theta^{N}$ increases less though the labor market frictions channel.

Short-Run Effects. The dynamic effects of a productivity differential on sectoral unemployment rates are depicted in Figure 2(a) and 2(b). The stable branch labelled $X^{j} X^{j}$ is downward-sloping and flatter than the $D S j$-schedule. ${ }^{39}$ Along the stable transitional path, employment and unemployment rate vary in opposite direction. Because labor is a state variable, $L^{j}$ remains unchanged on impact. On the contrary, $U^{j}$, is a control variable which falls sharply on impact since the positive wealth effect encourages agents to reduce time devoted to job search. Thus sectoral unemployment rates decrease at time $t=0$. Graphically, the economy jumps initially at $H^{j, \prime}$.

As can be seen in the first row of Figure $2, u^{N}$ overshoots its new steady-state level and thus should decline more on impact than $u^{T}$. Intuitively, while the positive wealth effect lowers $U^{j}$ in both sectors, higher $A^{T} / A^{N}$ mitigates the decline in $u^{T}$ by exerting a positive impact on the marginal benefit of search. The adjustment in $L^{j}$ along the transitional path reverses this outcome though since the technology shock is biased toward the traded sector. As employment builds up in the traded sector, thus lowering $u^{T}$ along the stable path, the gradual decrease in $L^{N}$ raises $u^{N}$. In the long-run, higher $A^{T} / A^{N}$ lowers the unemployment rate differential, i.e., $d u^{T}-d u^{N}<0$, as long as the labor accumulation channel more than offsets the labor market frictions channel.

$<$ Please insert Figure 2 about here $>$

\footnotetext{
${ }^{38}$ When we let search parameters vary across sectors and $\sigma_{L}$ tend toward infinity, the unemployment rate differential reduces to:$$
\lim _{\sigma_{L} \rightarrow \infty}\left(d u^{T}-d u^{N}\right)=-\alpha_{V}\left[u^{T}\left(1-u^{T}\right) \Sigma^{T}-u^{N}\left(1-u^{N}\right) \Sigma^{N}\right] \hat{a}^{T}
$$

where we used the fact that $\lim _{\sigma_{L} \rightarrow \infty} \hat{p}=\hat{a}^{T}-\hat{a}^{N}$. The term in brackets on the RHS of the above equation is merely positive for the baseline calibration.

${ }^{39}$ The formal proofs can be found in a Technical Appendix.
} 
Implications of labor market regulation for impact effects. Labor market regulation amplifies the rise in $u^{T}(0)-u^{N}(0)$ on impact. In economies where $\varrho$ or $\alpha_{W}$ is higher, $u^{j}$ declines more in both sectors because the wealth effect is greater. At the same time, the greater trade balance improvement further biases firms' hirings toward the traded sector. Because the marginal benefit of search in the traded sector increases more, $U^{N}$ falls by a larger amount relative to $U^{T}$ on impact. Graphically, the $V C N$-schedule shifts less as a result of a smaller appreciation in $p$ in the long-run so that the stable path $X^{N} X^{N}$ is lower in Figure 2(b). As legal protection against dismissals becomes stricter, non traded establishments post less job vacancies and thus agents devote less time to searching for a job in the non traded sector. Since $U^{N}$ decreases more on impact, the fall in $u^{N}$ is larger on impact.

\section{Quantitative Analysis}

In this section, we analyze the effects of a labor productivity differential between tradables and non tradables quantitatively. For this purpose we solve the model numerically. ${ }^{40}$ Therefore, first we discuss parameter values before turning to the quantitative analysis.

\subsection{Calibration}

To calibrate our model, we estimated a set of parameters so that the initial steady state is consistent with the key empirical properties of a representative OECD economy. While at the end of the section we move a step further and calibrate the model for each economy, we first have to evaluate the ability of the two-sector open economy model with labor market frictions to accommodate our evidence. Our sample covers the eighteen OECD economies in our dataset. Since we calibrate a two-sector model with labor market frictions, we pay particular attention to match the labor market differences between the two sectors. To do so, we carefully estimate a set of sectoral labor market parameters shown in Table $6 .{ }^{41}$ Because we consider an open economy setup with traded and non traded goods, we calculate the non-tradable content of employment, consumption, and government spending, and the productivity in tradables in terms of non tradables, for all countries in our sample, as summarized in Table 5. Our reference period for the calibration of the non tradable share given in Table 5 is running from 1990 to 2007 while labor market parameters have been computed over various periods due to data availability. To capture the key properties a typical OECD economy which is chosen as the baseline scenario, we take unweighed average values shown in the last line of Tables 5 and 6 . Some of the values of parameters can be taken directly from the data, but others like $\kappa^{T}, \kappa^{N}, X^{T}, X^{N}, \zeta^{N}, \varphi$, together with initial

\footnotetext{
${ }^{40}$ Technically, the assumption $\beta=r^{\star}$ requires the joint determination of the transition and the steady state.

${ }^{41}$ To calibrate the labor market for the traded and the non traded sector, we need to estimate the job finding and the job destruction rate for each sector. To do so, we apply the methodology developed by Shimer [2012].
} 
conditions $\left(B_{0}, L_{0}^{T}, L_{0}^{N}\right)$, need to be endogenously calibrated to fit a set of labor market and non tradable content features. ${ }^{42}$ We choose the model period to be one month and therefore set the world interest rate, $r^{\star}$, which is equal to the subjective time discount rate, $\beta$, to $0.4 \%$.

We start with the values of the labor market parameters which are chosen so as to match a typical OECD economy. We set the matching efficiency in the traded (non traded) sector $X^{T}\left(X^{N}\right)$ to $0.307(0.262)$ to target a monthly job finding rate $m^{T}\left(m^{N}\right)$ of $17.4 \%$ (17.0\%). In accordance with estimates shown in the last line of column 6 (column 8) of Table 6, the job destruction rate $s^{T}\left(s^{N}\right)$ in the traded (non traded) sector is set to $1.48 \%$ $(1.54 \%)$, which together with the job finding rate $m^{T}\left(m^{N}\right)$ leads to an unemployment rate $u^{T}\left(u^{N}\right)$ of $7.9 \%(8.3 \%)$. We obtain an overall unemployment rate $u$ of $8.1 \%$. To target the labor market tightness in the traded sector, $\theta^{T}=0.24$, and in the non traded sector, $\theta^{N}=0.34$, displayed in the last line of columns 10 and 11 of Table 6 , we set the recruiting cost $\kappa^{T}$ and $\kappa^{N}$ to 1.482 and 0.575 , respectively. ${ }^{43}$

Unemployment benefit replacement rates and the firing cost shown in the latter two columns of Table 6 correspond to averages over 1980-2007 (except Korea: 2001-2007) and 1980-2005, respectively. The unemployment benefits replacement rate, $\varrho$, has been set to $52.4 \%$. To calibrate the firing cost, we take data from FRDB-IMF Labor Institutions Database [2010]; we add the advance notice and the severance payment which are averages after 4 and 20 years of employment. Since the advance notice and the severance payment are both expressed in monthly salary equivalents, we have $x^{j}=\tau W^{j}$ with $\tau \geq 0$. For the baseline calibration, we set the firing tax $\tau$ to $4.2 .{ }^{44}$

Because the features of labor markets vary substantially across OECD economies, we also analyze two different calibrations of the model, one aimed at capturing the U.S. labor market, the other aimed at capturing Europe with its more 'rigid' labor market. To calibrate a typical European labor market, we take the EU-12 unweighed average. ${ }^{45}$

Using U.S. data, Barnichon [2012] reports an elasticity of the matching function with respect to unemployed workers of about 0.6 , an estimate which lies in the middle of the plausible range reported by Petrongolo and Pissarides [2001]. Hence, we set $1-\alpha_{V}$ to 0.6. As it is common in the literature, we impose the Hosios condition, and set the worker

\footnotetext{
${ }^{42}$ As detailed in a Technical Appendix, the steady-state can be reduced to seven equations which jointly determine $\theta^{T}, \theta^{N}, m^{T}, m^{N}, L^{T} / L^{N}$ (and thus $\left.L^{N} / L\right), P$ (and thus $\alpha_{C}$ ), $B$ (and thus $v_{N X}$ ). Among the 20 parameters that the model contains, 14 have empirical counterparts while the remaining 6 parameters, i.e., $\kappa^{T}, \kappa^{N}, X^{T}, X^{N}, \zeta^{N}, \varphi$, together with initial conditions $\left(B_{0}, L_{0}^{T}, L_{0}^{N}\right)$ must be set in order to match $\theta^{T}, \theta^{N}, m^{T}, m^{N}, L^{N} / L, \alpha_{C}, v_{N X}$.

${ }^{43}$ The share of recruiting costs in GDP is $2.3 \%$.

${ }^{44}$ We model firing costs as a tax that firms have to pay to the State when their employment levels decline, i.e., if $\dot{L}^{j}<0$. As mentioned previously, because traded employment monotonically increases while the non traded sector reduces continuously employment following a productivity differential, only the non traded sector is subject to the firing tax.

${ }^{45}$ For sectoral unemployment rates, and monthly job finding and job destruction rates, we take the EU-10 unweighed average due to data availability. See section B.3 that provides the list of countries for EU-12 and EU-10.
} 
bargaining power $\alpha_{W}$ to 0.6 in the baseline scenario.

Next, we turn to the elasticity of labor supply at the extensive margin which is assumed to be symmetric across sectors. We choose $\sigma_{L}$ to be 0.6 in our baseline setting but conduct a sensitivity analysis with respect to this parameter. ${ }^{46}$ Furthermore, in order to target a non tradable content of labor of $66 \%$ which corresponds to the 18 OECD countries' unweighted average shown in the last line of Table 5 , we normalize $\zeta^{T}$ to 1 and choose a value for $\zeta^{N}$ that parametrizes the disutility from working and searching for a job in the non traded sector, of 0.18 (see eq. (11)).

$<$ Please insert Table 5 and Table 6 about here $>$

We now turn to the calibration of consumption-side parameters. Building on our panel data estimations, we set the elasticity of substitution to 1 in the baseline calibration. ${ }^{47}$ But we conduct a sensitivity analysis by considering alternatively a value of $\phi$ smaller or larger than one (i.e., $\phi$ is set to 0.6 and 1.5 , respectively). ${ }^{48}$ The weight of consumption in non tradables $1-\varphi$ is set to 0.42 to target a non-tradable content in total consumption expenditure (i.e., $\alpha_{C}$ ) of $42 \%$, in line with the average of our estimates shown in the last line of Table 5. The intertemporal elasticity of substitution for consumption $\sigma_{C}$ is set to 1 .

For calibration purposes, we introduce government spending on traded and non traded goods in the setup. We set $G^{N}$ and $G^{T}$ so as to yield a non-tradable share of government spending of $90 \%$, and government spending as a share of GDP of $20 \%$. We assume that, in the initial steady-state, net exports are nil and thus choose initial conditions $\left(B_{0}, L_{0}^{T}, L_{0}^{N}\right)$ in order to target $v_{N X}=0$.

We consider a permanent increase in the productivity index $A^{j}$ of both sectors biased towards the traded sector so that the labor productivity differential between tradables and non tradables, i.e., $\hat{a}^{T}-\hat{a}^{N}$, is $1 \%$. While in our baseline calibration we set $\phi=1, \sigma_{L}=0.6$, $\alpha_{W}=0.6, \varrho=0.524, \tau=4.2$, we conduct a sensitivity analysis with respect to these five parameters by setting alternatively: $\phi$ to 0.6 and $1.5, \sigma_{L}$ to $0,0.2$ and $1, \alpha_{W}$ to 0.9 , $\varrho$ to 0.782 , and $\tau$ to $13 .{ }^{49}$ Finally, in the latter two columns of Table 7, we compare the results for the US economy with those obtained for a typical European economy (EU-12).

\footnotetext{
${ }^{46}$ Using data from the Panel Study of Income Dynamics, Fiorito and Zanella [2012] find that aggregate time-series results deliver an extensive margin elasticity in the range 0.8-1.4, which is substantially larger than the corresponding estimate (0.2-0.3) reported by Chetty, Friedman, Manoli, and Weber [2011]. A value of 0.6 is halfway between these two sets of findings.

${ }^{47}$ In Appendix B.2, we describe the empirical strategy to estimate $\phi$. In particular, we derive a testable equation by combining market clearing conditions for tradables and non tradables and the demand for tradables in terms of non tradables. Details of the derivation of the equation we explore empirically can be found in the Technical Appendix of a longer version of the paper. Excluding estimates of $\phi$ for Italy which are negative (see Table 9), column 1 of Table 8 reports consistent estimates for the elasticity of substitution $\phi$ between traded and non traded goods which average to a value close to 1 .

${ }^{48}$ These values for $\phi$ of 0.6 and 1.5 correspond roughly to the averages of estimates of $\phi$ for countries with $\phi<1$ and $\phi>1$, respectively.

${ }^{49}$ When conducting the sensitivity analysis, we raise $\varrho$ from $52.4 \%$ to $78.2 \%$ and $\tau$ from 4.2 to 13 , which correspond to the highest value in our sample of countries for the replacement rate and the firing cost, respectively.
} 


\subsection{Results}

We now assess the ability of the model to account for our empirical findings according to which a productivity differential (by $1 \%$ ) lowers the relative wage (by $0.22 \%$ ), appreciates the relative price (by $0.64 \%$ ), and lowers the unemployment rate of tradables relative to that of non tradables (by $0.034 \mathrm{ppt}$ ). We also investigate the implications of the three dimensions of labor market regulation for the effects of higher $A^{T} / A^{N}$.

No mobility costs. The responses of $\omega$ and $p$ computed numerically are summarized in Table 7. Since the response of $\omega$ is ambiguous when $\phi<1$, it is convenient to first discuss the numerical results in this configuration. Panels D and E of Table 7 report the long-run changes for $\omega$ and $p$ expressed as a percentage. The numbers reported in the first line of each panel give the (overall) responses of these variables to a productivity differential $\hat{a}^{T}-\hat{a}^{N}$ of $1 \%$. Column 1 of Table 7 shows that when abstracting from labor market frictions, i.e., setting $\kappa^{j}=0$ and $\sigma_{L} \rightarrow \infty$, the model cannot account for our empirical evidence.

With mobility costs. Conversely, numerical results summarized in column 2 show that when calibrating to a typical OECD economy, a model with labor market frictions can produce a decline in $\omega$ and a less than proportional increase in $p$ as found in the data. To shed light on the transmission mechanism of higher productivity in tradables relative to non tradables in a model with labor market frictions, we numerically break down the responses into two components: a labor market frictions channel stemming from changes in the share of tradables and a labor accumulation channel triggered by the accelerated hiring process which increases the demand for tradables in the long-run.

As shown in the second line of panels $\mathrm{D}$ and $\mathrm{E}$, a rise by $1 \%$ in the productivity of tradables relative to non tradables raises $\omega$ by $0.29 \%$ and appreciates $p$ by $1.33 \%$ through the labor market frictions effect. Intuitively, when $\phi<1$, a productivity shock biased toward the traded sector raises the share of non tradables into expenditure and thus encourages non traded firms to recruit relatively more than traded firms. To attract workers who experience mobility costs when shifting from one sector to another, $w^{N}$ must rise relative to $w^{T}$. As shown in the third line of panels $\mathrm{D}$ and $\mathrm{E}$, the labor accumulation effect counteracts the labor market frictions effect. More specifically, higher $A^{T} / A^{N}$ also raises net exports which has an expansionary effect on hirings in the traded sector, thus driving down $\omega$ by $0.45 \%$. Higher demand for tradables also depreciates $p$ by $0.47 \%$. Importantly, the labor accumulation effect more than offsets the labor market frictions effect so that $\omega$ declines by $0.16 \%$ and $p$ appreciates by $0.85 \%$, as summarized in the first line of panels D and E.

Our model with search in the labor market and an endogenous sectoral labor force participation sheds light on two sets of factors influencing the mobility of labor across sectors and thus the responses of $\omega$ and $p$ to a productivity differential: the workers' mobility cost reflected by a utility loss when increasing the search intensity for a job in one sector (as 
captured by $\sigma_{L}$ ) and labor market institutions (captured by $\alpha_{W}, \varrho, \tau$ ) determining the elasticity of hiring to labor productivity.

Role of labor supply at the extensive margin. As we move from column 3 to column 5 , the elasticity of labor supply at the extensive margin $\sigma_{L}$ is raised from zero to 1 . Column 3 of panels D and $\mathrm{E}$ of Table 7 shows numerical results if labor is totally immobile across sectors as captured by setting $\sigma_{L}=0$. In this configuration, the labor force is fixed in both sectors because the mobility cost is prohibitive. Since the decision of search is inelastic to the sectoral wage, $\omega$ falls by $0.48 \%$ instead of $0.16 \%$ in the baseline scenario. Hence, such a polar case tends to substantially overstate the decline in $\omega$ and thus confirms the pivotal role of an endogenous labor force participation decision. As shown, in columns 4 and 5 of panels $\mathrm{D}$ and $\mathrm{E}$ of Table 7, raising $\sigma_{L}$ from 0.2 to 1 lowers the utility loss induced by the shift from one sector to another which in turn moderates the decline in $\omega$ and amplifies the appreciation in $p$.

Implications of higher unemployment benefits and worker bargaining power. Scenarios summarized in columns 6 and 7 of Table 7 show that, in line with our evidence, raising the worker bargaining power $\alpha_{W}$ or the unemployment benefit replacement rate $\varrho$ amplifies the decline in $\omega$ from $0.16 \%$ to $0.21 \%$ and $0.25 \%$, respectively. In accordance with our model's predictions, in countries with a higher $\alpha_{W}$ or $\varrho$, higher $A^{T} / A^{N}$ lowers more $\omega$ through the labor accumulation effect, as shown in the third line of panel D. The stronger labor accumulation effect also moderates the appreciation in $p$ from $0.85 \%$ to $0.81 \%$ and $0.76 \%$, respectively, as shown in the first line of panel E, because the demand for tradables increases more than in the baseline scenario. The second line of panel $\mathrm{D}$ also reveals that $\omega$ rises less than in the baseline scenario through the labor market frictions channel because the mobility of labor across sectors rises.

Implications of higher firing costs. Column 8 of Table 7 gives results when the firing cost, $\tau$, is about three times larger than in the baseline scenario. In accordance with our empirical findings, raising $\tau$ drives down further $\omega$ from $-0.16 \%$ to $-0.19 \%$. As shown in the third line of panel $\mathrm{D}$, the labor accumulation channel is merely affected by $\tau$. On the contrary, the second line of panel D reveals that $\omega$ increases by a smaller amount because the firing cost curbs the expansionary effect of higher productivity gains on hiring by non traded firms and thus moderates the rise in $w^{N}$ relative to $w^{T}$ from $0.29 \%$ to $0.25 \%$. Moreover, as shown in the first line of panel E, countries with stringent legal protection against dismissals also experience a larger appreciation in $p$, in line with our empirical findings, because traded output increases more relative to non traded output.

EU-12 vs. USA. The latter two columns of Table 7 compare the responses of $\omega$ and $p$ between a typical European country and the US. Because the legal protection against dismissals is stricter while unemployment benefits are higher, a typical European economy experiences a smaller increase in $w^{N}$ through the labor market frictions channel and a 
larger increase in $w^{T}$ through the labor accumulation channel. As a result, $\omega$ falls by $0.20 \%$ in EU-12 and declines by only $0.09 \%$ in the US. While a higher $\tau$ tends to amplify the appreciation in $p$, a larger $\varrho$ tends to moderate it. The first line of panel D shows that the latter effect dominates so that a productivity differential raises $p$ more in the US $(0.90 \%)$ than in a European economy $(0.82 \%)$.

Implications of $\phi=1$. In panels A and B of Table 7, we consider the scenario $\phi=1$. Keeping fixed net exports, a productivity differential between tradables and non tradables by $1 \%$ would have no effect on $\omega$ while $p$ would appreciate by $1 \%$ if labor market parameters were identical because the share of tradables in total expenditure remains unchanged. As shown in the second line of panel A, $\omega$ falls very slightly because the elasticity of hiring in the traded sector is merely higher than that in the non traded sector. The third line of panel $\mathrm{A}$ and $\mathrm{B}$ reveals that higher $A^{T} / A^{N}$ produces a decline in $\omega$ and a rise in $p$ close to our estimates due to the improvement in the balance of trade.

Unemployment rate differential between tradables and non tradables. We now explore the effects of a rise in $A^{T} / A^{N}$ on the unemployment rate differential between tradables and non tradables shown in panel C of Table 7. Since the transmission mechanism is identical to that described above for $p$ and $\omega$, we focus on the situation of $\phi=1$. This case is particularly interesting for the study of $d u^{T}-d u^{N}$ since the second line of panel $\mathrm{C}$ gives the change in the relative unemployment rate that would prevail if labor mobility costs were absent. ${ }^{50}$ Through the labor market frictions channel, a productivity differential merely influences the relative unemployment rate of tradables. On the contrary, as displayed in the third line of panel $\mathrm{C}$, the unemployment rate differential falls as a result of higher demand for tradables. Intuitively, when workers incur costs of switching sectors, $p$ appreciates by a smaller amount than $\hat{a}^{T}-\hat{a}^{N}$ so that the labor market tightness in the traded sector increases more which produces $d u^{T}-d u^{N}<0$ in line with our empirical findings. Whereas at first sight, the magnitude appears to be small, changes in sectoral unemployment rates are substantial as the aggregate unemployment rate declines by 0.11 percentage point.

Implications of labor market regulation for the unemployment rate differential. Contrasting the figure in column 2 with those in columns 6,7,8, numerical results reveal that the three dimensions of labor market regulation amplifies the decline in the relative unemployment rate of tradables in line with our evidence. While such an amplification operates through higher demand for tradables when $\alpha_{W}$ or $\varrho$ is raised, increasing the firing cost curbs non traded firms' hiring and thus mitigates the rise in $u^{T}-u^{N}$ through the labor market frictions channel.

\footnotetext{
${ }^{50} \mathrm{~A}$ unitary elasticity of substitution between tradables and non tradables implies that the share of non tradables remains fixed and thus neutralizes the labor market frictions channel. In this case, the figures in the second line of panel $\mathrm{C}$ shows the change in the relative unemployment rate due to differences in standard search frictions between the traded and the non traded labor market, i.e., the change in $u^{T}-u^{N}$ that would prevail if labor mobility costs were shut off.
} 
Implications of $\phi>1$. We briefly discuss the scenario $\phi>1$. Panels F and G of Table 7 report the long-run responses of $\omega$ and $p$. Because the labor accumulation channel reinforces the labor market frictions channel, the first line of panel $\mathrm{F}$ reveals that the model tends to overstate the decline in $\omega$ when $\phi>1$. As shown in the first line of panel $G$, the model also tends to understate the rise in $p$ because the relative price appreciates less than proportionately through the labor market frictions effect while the rise in net exports depreciates $p$.

$<$ Please insert Table 7 about here $>$

\subsection{Model Performance}

We now move a step further and compare the predicted values with estimates for each country and the whole sample and thus restrict our attention to relative wage and relative price effects since unemployment differential effects cannot be estimated empirically by country due to data limitation (see Appendix B.3). We use the same baseline calibration for each economy, except for the elasticity of substitution $\phi$ between traded and non traded goods, and labor market parameters which are allowed to vary across countries. More specifically, $\phi$ is set in accordance with its estimates shown in the first column of Table $8 .{ }^{51}$ The parameters which capture the degree of labor market regulation such as the firing cost, $\tau$, and the replacement rate, $\varrho$, are set to their values shown in the latter two columns of Table 6. The matching efficiency $X^{j}$ in sector $j=T, N$ is set to target the job finding rate $m^{j}$ displayed in columns 5 and 7 of Table 6 . The job destruction rate in sector $j, s^{j}$, is set in accordance with its value reported in columns 6 and 8 of Table 6 . The costs per job vacancy $\kappa^{T}$ and $\kappa^{N}$ are chosen to target the aggregate labor market tightness $\theta$ shown in column 13 and the ratio of sectoral labor market tightness $\theta^{T} / \theta^{N}$ obtained by dividing column 10 by column $11 .^{52}$

Before discussing the performance of the model, we relate our analytical results to the elasticity of $p$ and $\omega$ with respect to the productivity differential, i.e., $\gamma$ and $\beta$ (see eqs. (7a)(7b)), which are estimated empirically. When search frictions are similar across sectors, the long-run responses of $p$ and $\omega$ reduce to (31) and (34), respectively. In this configuration, there exists a direct mapping between analytical expressions of $\frac{\hat{p}}{\hat{a}^{T}-\hat{a}^{N}}$ and $\frac{\hat{\omega}}{\hat{a}^{T}-\hat{a}^{N}}$, and empirical estimates of $\gamma$ and $\beta$, respectively. In contrast, when search frictions vary across sectors, we have to correct for the inherent discrepancy between theoretical and empirical values for $\gamma$ and $\beta$. This discrepancy originates from sector-varying $\Theta^{j}$ and $\Omega^{j}$ which makes

\footnotetext{
${ }^{51}$ We also choose the weight of consumption in non tradables $1-\varphi$ to target a non-tradable content in total consumption expenditure (i.e., $\alpha_{C}$ ) for each country in line with our estimates shown in column 2 of Table 5 .

${ }^{52}$ Ideally, the recruiting cost $\kappa^{j}$ would be set in order to target $\theta^{j}$; however, the series for job vacancies by economic activity are available for a maximum of seven years and for a limited number of countries. On the contrary, the OECD provides data for job openings (for the whole economy) over the period 1980-2007 allowing us to calculate the labor market tightness, i.e., $\theta=V / U$, for several countries that we target along with the ratio $\theta^{T} / \theta^{N}$ by choosing $\kappa^{T}$ and $\kappa^{N}$.
} 
the theoretical elasticity of $p$ (resp. $\omega$ ) w.r.t. $\hat{a}^{T}-\hat{a}^{N}$ different. To map the deviation in percentage of $p$ and $\omega$ from their initial steady-state into elasticities estimated empirically, we need to adjust numerically computed values with a term that captures the extent to which search frictions vary across sectors. Once the discrepancy is accounted for, we are able to relate $\gamma$ and $\beta$ estimated empirically to their analytical counterpart which we denote by $\gamma^{\text {predict }}$ and $\beta^{\text {predict }}$, respectively: ${ }^{53}$

$$
\begin{gathered}
\gamma^{\text {predict }}=\left(\frac{1+\Theta^{T}}{\phi+\Theta^{N}}\right)+\frac{1}{\phi+\Theta^{N}} \frac{\mathrm{d} \ln \left(1-v_{N X}\right)}{\hat{a}^{T}-\hat{a}^{N}}, \\
\beta^{\text {predict }}=-\left[\Omega^{T}-\Omega^{N}\left(\frac{1+\Theta^{T}}{\phi+\Theta^{N}}\right)\right]+\frac{\Omega^{N}}{\phi+\Theta^{N}} \frac{\mathrm{d} \ln \left(1-v_{N X}\right)}{\hat{a}^{T}-\hat{a}^{N}},
\end{gathered}
$$

where the second term on the RHS of (38a) and (38b) captures the negative impact on $p$ and $\omega$ of the long-run adjustment in net exports caused by rise in $A^{T} / A^{N}$

Results are shown in Table 8. Columns 2 and 5 of Table 8 give the predicted responses of $\hat{\omega}$ and $\hat{p}$ to a rise in the productivity of tradables relative to non tradables by $1 \%$. Columns 3 and 6 report FMOLS estimates of $\hat{\omega}$ and $\hat{p}$ for each country, EU-12 and the whole sample. ${ }^{54}$ Columns 4 and 7 give the difference between the actual and the predicted values. As can be seen in the last line, the correlation coefficient between simulated and estimated values for the relative wage response is high which indicates that the model generates a cross-country pattern in the relative wage responses which is similar to that in the data. More specifically, column 4 reveals that our model's predictions for $\hat{\omega}$ are relatively close to the evidence for almost half of the countries in our sample, including France, the UK, Ireland, Italy, Japan, the Netherlands, Spain and the United States, and to a lesser extent Germany, Austria and EU-12. The model predicts fairly well the relative price response for nine countries of our sample, including Austria, Belgium, Germany, Finland, Italy, Japan, the Netherlands, Spain, and the UK. The prediction error is also moderate in Denmark and France. However, the correlation coefficient in the last line of the table indicates that the ability of the model to account for the cross-country pattern in the relative price responses is less than that in the relative wage responses. It is worthwhile mentioning that, whether we focus on $\hat{\omega}$ or $\hat{p}$, the prediction error is large for Australia, Canada, and Norway which are important natural resources exporters. Hence, for these three economies, we believe that our assumption of given terms of trade is too strong.

When calibrating to the whole sample, the model predicts remarkably well the relative wage response; we find numerically a decline in $\omega$ of $0.218 \%$ while in the data, $\omega$ falls by $0.223 \%$. When we turn to the relative price, the prediction error increases substantially as our model produces an appreciation of $0.778 \%$ while we find empirically a rise of $0.636 \%$.

\footnotetext{
${ }^{53}$ The correction term for $p$ and $\omega$ is $\left(\frac{1+\Theta^{T}}{\phi+\Theta^{N}}\right)\left[1-\left(\frac{1+\Theta^{N}}{1+\Theta^{T}}\right)\right] \hat{a}^{N}$ and $-\left\{\left[\Omega^{T}-\Omega^{N}\left(\frac{1+\Theta^{T}}{\phi+\Theta^{N}}\right)\right]-\left[\Omega^{N}-\Omega^{N}\left(\frac{1+\Theta^{N}}{\phi+\Theta^{N}}\right)\right]\right\} \hat{a}^{N}$, respectively. It is worth mentioning that the magnitude of the bias originating from sector-varying search frictions is quantitatively low.

${ }^{54}$ We reach similar conclusions when using DOLS estimates.
} 
We now investigate whether the long-run response in $\omega$ is more pronounced and $p$ appreciates less in countries where labor markets are more regulated, in line with our empirical findings documented in subsection 2.5. In Figure 3, we plot the simulated responses of the relative wage on the vertical axis against the employment protection legislation index adjusted with the share of permanent workers in the economy in Figure 3(a). Figure 3(b) plots simulated responses of the relative wage against an indicator of labor market regulation which encompasses two dimensions, namely the generosity of the unemployment benefit scheme and the extent of the worker bargaining power. ${ }^{55}$ Despite the wide dispersion in the relative wage responses that our model generates, the trend line in Figure 3(a) reveals that the relative wage falls more in countries where legal protection against dismissals is stricter. In Figure 3(b) countries where unemployment benefits are more generous or the worker bargaining power is higher also experience a larger decline in the relative wage. In sum, while productivity gains biased toward the traded sector drive down non traded wages relative to traded wages as the result of job search costs experienced by workers, international differences in hiring costs and thus in the degree of labor market regulation can account for the dispersion in the relative wage responses across countries.

Figure 3(c) plots the simulated responses for the relative price against our measure of labor market regulation which encompasses the extent of the worker bargaining power, the generosity of the unemployment benefit scheme and the strictness of legal protection against dismissals. While both empirical and numerical results show that higher firing costs put upward pressure on the relative price, the trend line in Figure 3(c) indicates that more generous unemployment benefits exert a stronger influence. More specifically, in line with the evidence documented in section 2.5, we find quantitatively that the relative price of non tradables tends to appreciate less in countries with more regulated labor markets.

$<$ Please insert Table 8 and Figure 3 about here $>$

\subsection{Long- and Short-Run Adjustment of Sectoral Unemployment Rates}

An additional major implication of our two-sector model with search frictions is that higher relative productivity leads to a decline in the unemployment rate differential in the longrun as long as the effect of increased demand for tradables is larger than the impact of changes in the share of tradables when $\phi<1$. Column 8 of Table 8 reports the numerical counterpart of $\sigma$ which corresponds to the estimated effect of higher relative productivity on the unemployment rate differential adjusted with the bias originating from sector-varying search frictions, i.e.,

$$
\sigma^{\text {predict }}=-\alpha_{V} \Delta^{T}+\alpha_{V} u^{N}\left(1-u^{N}\right) \frac{\Sigma^{N}}{\phi+\Theta^{N}} \frac{\mathrm{d} \ln \left(1-v_{N X}\right)}{\hat{a}^{T}-\hat{a}^{N}}
$$

\footnotetext{
${ }^{55}$ The labor market regulation index in Figure 3(b) is obtained by using a principal component analysis over the period 1980-2007 which corresponds to the reference period for the calibration of labor market institutions variables.
} 
where $\Delta^{T}=\left[u^{T}\left(1-u^{T}\right) \Sigma^{T}-u^{N}\left(1-u^{N}\right) \Sigma^{N}\left(\frac{1+\Theta^{T}}{\phi+\Theta^{N}}\right)\right]$. As shown in column 8 of Table 8 , the unemployment rate differential falls by $0.011 \mathrm{ppt}$ for an average OECD economy. Column 9 of Table 8 shows the adjustment of the unemployment rate differential that would prevail if labor mobility costs were absent, i.e., if $\sigma_{L} \rightarrow \infty$. In this situation, the unemployment rate differential increases in a representative OECD economy along with most of the countries in our sample as its response is only driven by differences in standard search frictions between the traded and non traded labor markets.

While the baseline model (for an average OECD economy) tends to understate the magnitude of the decrease in $u^{T}$ relative to $u^{N}$ we estimate empirically (see the first row of Table 3), its decline remains substantial though in Belgium, Denmark, France, Germany, Spain where $d u^{T}-d u^{N}$ varies from -0.061 to $-0.022 \mathrm{ppt}$. In this regard, Figure $3(\mathrm{~d})$ reveals that the long-run adjustment of the unemployment rate differential to a rise in $A^{T} / A^{N}$ is quite distinct between countries with low and high labor market regulation. In line with our evidence, $u^{T}$ falls more than $u^{N}$ in economies with higher labor market regulation.

While so far we have investigated the long-run effects, Figure 2(c) plots the dynamics for sectoral unemployment rates and contrasts the results for a representative OECD economy (shown in solid lines) with those obtained for an economy with more regulated labor markets (shown in dashed lines). ${ }^{56}$ Focusing first on a representative OECD economy, the first conclusion that emerges is that the adjustment is rapid, the sectoral unemployment rates reaching their steady-state values after 3 years approximately. Secondly, whilst in the longrun sectoral unemployment rates decline by about $0.12 \mathrm{ppt}$ with $d u^{T}<d u^{N}<0$, the fall in job search in the non traded sector is such that $u^{N}$ decreases by 0.24 ppt on impact, thus reversing $d u^{T}-d u^{N}$ in the short-run. Thirdly, labor market regulation slows down the transitional adjustment toward the steady-state because the probability of finding a job is much lower in countries where $\varrho$ and/or $\tau$ is higher. Fourthly, as can be seen in dashed lines in Figure 2(c), the change in the unemployment rate differential is amplified both in the short- and the long-run. Because labor market regulation further biases the positive impact of the technology shock on traded firms' hiring, less agents search for a job in the non traded sector on impact while along the transitional path, recruitment by traded firms lowers $u^{T}$.

\section{Conclusion}

While the literature exploring the implications of higher productivity in tradables relative to non tradables commonly assumes frictionless labor markets, our empirical results show that the non traded wage tends to decline relative to the traded wage. Because the non traded wage increases at a lower speed than the traded wage, it is found empirically that

\footnotetext{
${ }^{56}$ When we consider an OECD economy with high labor market regulation, we set $\varrho$ to $78.2 \%$ and the firing tax to 13 months, these two figures corresponding to the highest values in our sample.
} 
the relative price appreciates less than that predicted by the standard neoclassical model abstracting from labor market frictions. Our estimates also reveal that the unemployment rate of tradables falls more than that of non tradables since the appreciation in the relative price of non tradables does not compensate for lower productivity gains. We also report evidence suggesting that such responses to a productivity differential have increased as the result of decreasing labor mobility costs. Whilst time-varying costs of switching sectors can rationalize the rise in the responses of variables to higher relative productivity, our estimates reveal that their adjustment is quite distinct whether labor market regulation is high or low. We report results which indicate that both the relative wage and the unemployment differential fall more while the relative price appreciates less in countries with more regulated labor markets.

To account for the evidence, we develop a two-sector open economy model with search in the labor market and an endogenous sectoral labor force participation decision. As in Alvarez and Shimer [2011], workers cannot reallocate hours worked from one sector to another without searching for a job in this sector. Because such an activity is costly in utility terms, workers experience a switching cost. We find analytically that two sets of parameters play a pivotal role in the determination of the relative wage and relative price responses to higher productivity in tradables relative to non tradables: i) preference parameters such as the elasticity of labor supply at the extensive margin and the elasticity of substitution in consumption between tradables and non tradables, ii) parameters capturing labor market institutions such as the firing tax, the unemployment benefit replacement rate and the worker bargaining power.

Our quantitative analysis indicates that, regardless of the value of the elasticity of substitution between tradables and non tradables, when the elasticity of labor at the extensive margin takes finite values, the relative wage falls while workers' mobility costs curtail the appreciation in the relative price following a productivity differential, thus producing a fall in the unemployment rate differential between tradables and non tradables. On the contrary, the situations of total immobility or perfect mobility of labor across sectors that emerge as special cases cannot account for the evidence. When we investigate the impact of labor market institutions, we find that the relative price appreciates less when raising the replacement rate or the worker bargaining power because net exports and thus demand for tradables increase more. Moreover, the relative wage falls by a larger amount because traded firms are encouraged to hire more, thus amplifying the rise in the traded wage along with the decline in the relative unemployment rate of tradables. Increasing the firing cost curbs hiring in the non traded sector, and thus produces a larger decline in the relative wage, in accordance with our evidence. Because strictness of legal protection against dismissals further biases the positive influence of the productivity shock on traded firms' hirings, the unemployment rate of tradables decreases more relative to that of non tradables. Since non 
traded output increases less, the relative price of non tradables must appreciate more to clear the goods market.

To explore quantitatively the implications of labor market institutions for the crosscountry dispersion in the estimated effects, we calibrate the model to country-specific data. We thus allow for the elasticity of substitution between tradables and non tradables and labor market parameters to vary across countries. Whilst simulated responses display a wide dispersion across countries, both the relative wage and the unemployment rate differential decline more in countries where labor market regulation is higher, in line with the evidence. The relative price of non tradables also appreciates less in countries where labor markets are more regulated, in accordance with the empirical findings, the strictness of legal protection against dismissals playing a secondary role in determining the movements in the relative price.

\section{References}

Alvarez, Fernando and Robert Shimer (2011) Search and Rest Unemployment. Econometrica, 79, pp. $75-122$.

Andolfatto, David (1996) Business Cycles and Labor-Market Search. American Economic Review 86(1), pp. 112-132.

Artuç, Erhan, Shubham Chaudhuri, and John McLaren (2010) Trade Shocks and Labor Adjustment: A Structural Empirical Approach. American Economic Review, 100(3), pp. 1008-45.

Balassa, Bela (1964) The Purchasing Power Parity Doctrine: a Reappraisal. Journal of Political Economy, 72, pp. 584-596.

Barnichon, Regis (2012) Vacancy Posting, Job Separation and Unemployment Fluctuations. Journal of Economic Dynamics and Control, 36(3), pp. 315-330.

Bergin Paul R., Reuven Glick and Alan M. Taylor (2006) Productivity, Tradability, and the Long-Run Price Puzzle. Journal of Monetary Economics, vol. 53(8), 2041-2066.

Boeri and Van Ours (2008) The Economics of Imperfect Labor Markets. Second edition. Princeton University Press.

Canzoneri, Matthew B., Robert E. Cumby and Behzad Diba (1999) Relative Labor Productivity and the Real Exchange Rate in the Long Run: Evidence for a Panel of OECD Countries. Journal of International Economics, vol. 47, 245-266.

Cardi, Olivier, and Romain Restout (2015) Imperfect Mobility of Labor across Sectors: A Reappraisal of the Balassa-Samuelson Effect. Journal of International Economics, 97(2), pp. 249-265.

Chang, Briana (2012) A Search Theory of Sectoral Reallocation. mimeo, University of Wisconsin.

Chetty, Raj, Adam Guren, Day Manoli, and Andrea Weber (2011) Are Micro and Macro Labor Supply Elasticities Consistent? A Review of Evidence on the Intensive and Extensive Margins. American Economic Review: Papers \& Proceedings, 101 (3), 471-475.

Curuk, Malik and Vannoorenberghe, Gonzague (2017) Inter-Sectoral Labor Reallocation in the Short Run: The Role of Occupational Similarity. Journal of International Economics, 108, pp. $20-36$.

Christopoulos, Dimitris K., Karine Gente and León-Ledesma, Miguel A. (2012) Net Foreign Assets, Productivity and Real Exchange Rates in Constrained Economies. European Economic Review, 56(3), pp. 295-316.

Cosar, Kerem (2013) Adjusting to Trade Liberalization: Reallocation and Labor Market Policies. mimeo University of Chicago.

De Gregorio, Jose, Alberto Giovannini and Holger C. Wolf (1994) International Evidence on Tradables and Nontradables Inflation. European Economic Review, 38, pp. 1225-1244.

Dix-Carneiro, Rafael (2014) Trade Liberalization and Labor Market Dynamics. Econometrica, 82(3), pp. 825-885.

Dix-Carneiro, Rafael, and Brian Kovak (2017) Trade Reform and Regional Dynamics: Evidence from 25 Years of Brazilian Matched Employer-Employee Data. American Economic Review, forthcoming. 
Dutt, Pushan, Devashish Mitra, and Priya Ranjan (2009) International Trade and Unemployment: Theory and Cross-National Evidence. Journal of International Economics 78, 32-44.

European Union KLEMS (2011) Growth and Productivity Accounts.

Fiorito, Riccardo and Giulio Zanella (2012) The Anatomy of the Aggregate Labor Supply Elasticity Review of Economic Dynamics, 15(2), pp. 171-187.

Fondazione Rodolfo Debenedetti-IMF Labour Institutions Database (1980-2005). http://www. frdb.org/page/data/categoria/international-data

Ghironi, Fabio and Marc J. Melitz (2005) International Trade and Macroeconomic Dynamics with Heterogenous Firms. Quarterly Journal of Economics, 120(3), pp. 865-915.

Heer, Burkhard and Stefan F. Schubert (2012) Unemployment and Debt Dynamics in a Highly Indebted Small Open Economy. Journal of International Money and Finance, 31(6), pp. 13921413.

Heijdra, Ben J., and Jenny E. Ligthart (2002) The Hiring Subsidy cum Firing Tax in a Search Model of Unemployment. Economics Letters, 75, pp. 97-108.

Heijdra, Ben J., and Jenny E. Ligthart (2009) Labor Tax Reform, Unemployment and Search. International Tax and Public Finance, 16, pp. 82-104.

Hobijn, Bart and Aysegül Sahin (2009) Job-Finding and Separation Rates in the OECD. Economics Letters, 104(3), pp. 107-111.

Horvath, Michael (2000) Sectoral Shocks and Aggregate Fluctuations. Journal of Monetary Economics, 45, pp. 69-106.

Jensen, Bradford J., and Lori G. Kletzer, (2006) Offshoring White-Collar Work, in Susan M. Collins and Lael Brainard, eds., Brookings Trade Forum 2005, Offshoring White-Collar Work. Brookings Institution: Washington, DC, pp. 75-134.

Kakkar, Vikas (2003) The Relative Price of Nontraded Goods and Sectoral Total Factor Productivity: an Empirical Investigation. The Review of Economics and Statistics, 85(2), pp. 444-452.

Kambourov, Gueorgui (2009) Labour Market Regulations and the Sectoral Reallocation of Workers: The Case of Trade Reforms. The Review of Economic Studies, 76, pp. 1321-1358.

Kennan, John K., and James W. Walker (2011) The Effect of Expected Income on Individual Migration Decisions. Econometrica, 79(1), pp. 211-251.

Lane, Philip R., and Gian Maria Milesi-Ferretti (2004) The Transfer Problem Revisited: Net Foreign Assets and Real Exchange Rates. The Review of Economics and Statistics, 86(4), pp. 841-857.

Lee, Donghoon and Kenneth I. Wolpin (2006) Intersectoral Labor Mobility and the Growth of the Service Sector. Econometrica, 74, pp. 1-46.

Matsuyama, Kiminori (1992) A Simple Model of Sectoral Adjustment. The Review of Economic Studies, 59(2), pp. 375-387.

Merz, Monika, (1995) Search in the Labor Market and the Real Business Cycle. Journal of Monetary Economics 36(2), pp. 269-300.

Pedroni, Peter (2000) Fully Modified OLS for Heterogeneous Cointegrated Panels. Advances in Econometrics, vol. 15, edited in B. Baltagi: Nonstationary Panels, Panel Cointegration and Dynamic Panels, 93-130.

Pedroni, Peter (2001) Purchasing Power Parity Tests in Cointegrated Panels. The Review of Economics and Statistics, 83(4), pp. 727-731.

Petrongolo, Barbara and Christopher A. Pissarides (2001) Looking Into the Black Box: A Survey of the Matching Function. Journal of Economic Literature, 39(2), pp. 390-431.

Phelan, Christopher, and Alberto Trejos (2000) The Aggregate Effects of Sectoral Reallocations. Journal of Monetary Economics, 45(2), pp. 249-268.

Samuelson Paul A. (1964) Theoretical Notes on Trade Problems. The Review of Economics and Statistics, 46, pp. 145-164.

Shi, Shouyong, and Quan Wen (1999) Labor Market Search and the Dynamic Effects of Taxes and Subsidies. Journal of Monetary Economics, 43, 457-495.

Shimer, Robert (2012) Reassessing the Ins and Outs of Unemployment. The Review of Economic Dynamics, 15(2), pp. 127-148.

Veracierto, Marcelo (2008) Firing Costs And Business Cycle Fluctuations. International Economic Review, vol. 49(1), pages 1-39.

Visser, Jelle (2009), ICTWSS Database, Database on Institutional Characteristics of Trade Unions, Wage Setting, State Intervention and Social Pacts in 34 countries between 1960 and 2007, Institute for Advanced Labour Studies, AIAS, University of Amsterdam, Amsterdam. http://www. uva-aias.net/207

Wacziarg, Romain and Jessica S. Wallack (2004) Trade Liberalization and Intersectoral Labor Movements. Journal of International Economics, 64, pp. 411-439. 
Table 1: Panel Cointegration Estimates of $\beta$ and $\gamma$ for the Whole Sample (eqs. (7))

\begin{tabular}{l|c|c||c|c}
\hline \multirow{2}{*}{$\left(a^{T}-a^{N}\right)$} & \multicolumn{2}{|c||}{ Relative wage eq. (7a) } & \multicolumn{2}{c}{ Relative price eq. (7b) } \\
\cline { 2 - 5 } & DOLS & FMOLS & DOLS & FMOLS \\
\cline { 2 - 5 }$t(\beta)=0$ & $\begin{array}{c}-0.223^{a} \\
(-29.72)\end{array}$ & $\begin{array}{c}-0.223^{a} \\
(-33.85)\end{array}$ & $\begin{array}{c}0.646^{a} \\
(76.54)\end{array}$ & $\begin{array}{c}0.636^{a} \\
(83.01)\end{array}$ \\
\cline { 2 - 5 }$t(\gamma)=1$ & 0.000 & 0.000 & & \\
\hline Number of countries & 18 & 18 & 0.000 & 0.000 \\
Number of observations & 680 & 680 & 680 & 18 \\
\hline
\end{tabular}

Notes: all regressions include country fixed effects. Heteroskedasticity and autocorrelation consistent t-statistics are reported in parentheses. ${ }^{a}$ denotes significance at $1 \%$ level. The rows $t(\beta)=0$ and $t(\gamma)=1$ report the p-value of the test of $H_{0}: \beta=0$ and $H_{0}: \gamma=1$ respectively.

Table 2: Panel Cointegration Estimates of $\beta_{i}$ and $\gamma_{i}$ for Each Country (eqs. (7))

\begin{tabular}{|c|c|c|c|c|}
\hline & \multicolumn{2}{|c|}{ Relative wage equation } & \multicolumn{2}{|c|}{ Relative price equation } \\
\hline Country & $\hat{\beta}_{i}^{D O L S}$ & $\hat{\beta}_{i}^{F M O L S}$ & $\hat{\gamma}_{i}^{D O L S}$ & $\hat{\gamma}_{i}^{F M O L S}$ \\
\hline AUS & $\begin{array}{c}-0.047 \\
(-1.51)\end{array}$ & $\begin{array}{c}-0.062^{b} \\
(-2.19)\end{array}$ & $\begin{array}{c}0.567^{a} \\
(10.95)\end{array}$ & $\begin{array}{c}0.559^{a} \\
(10.88)\end{array}$ \\
\hline AUT & $\begin{array}{c}-0.220^{a} \\
(-12.62)\end{array}$ & $\begin{array}{c}-0.231^{a} \\
(-13.95)\end{array}$ & $\begin{array}{c}0.687^{a} \\
(20.14)\end{array}$ & $\begin{array}{c}0.689^{a} \\
(21.89)\end{array}$ \\
\hline BEL & $\begin{array}{c}-0.150^{a} \\
(-6.36)\end{array}$ & $\begin{array}{c}-0.135^{a} \\
(-5.74)\end{array}$ & $\begin{array}{c}0.732^{a} \\
(17.49)\end{array}$ & $\begin{array}{c}0.740^{a} \\
(17.52)\end{array}$ \\
\hline CAN & $\begin{array}{c}-0.298^{a} \\
(-6.11)\end{array}$ & $\begin{array}{c}-0.299^{a} \\
(-7.19)\end{array}$ & $\begin{array}{c}0.549^{a} \\
(4.95)\end{array}$ & $\begin{array}{c}0.524^{a} \\
(5.19)\end{array}$ \\
\hline DEU & $\begin{array}{c}-0.502^{a} \\
(-20.60)\end{array}$ & $\begin{array}{r}-0.493^{a} \\
(-22.90)\end{array}$ & $\begin{array}{c}0.532^{a} \\
(9.76)\end{array}$ & $\begin{array}{c}0.517^{a} \\
(10.70)\end{array}$ \\
\hline DNK & $\begin{array}{c}-0.366^{a} \\
(-4.96)\end{array}$ & $\begin{array}{c}-0.355^{a} \\
(-5.86)\end{array}$ & $\begin{array}{c}0.361^{a} \\
(9.51)\end{array}$ & $\begin{array}{c}0.357^{a} \\
(12.63)\end{array}$ \\
\hline ESP & $\begin{array}{c}-0.231^{a} \\
(-8.30)\end{array}$ & $\begin{array}{c}-0.236^{a} \\
(-11.10)\end{array}$ & $\begin{array}{c}0.689^{a} \\
(19.14)\end{array}$ & $\begin{array}{c}0.709^{a} \\
(21.50)\end{array}$ \\
\hline FIN & $\begin{array}{c}-0.197^{a} \\
(-11.14)\end{array}$ & $\begin{array}{c}-0.193^{a} \\
(-12.99)\end{array}$ & $\begin{array}{c}0.645^{a} \\
(19.98)\end{array}$ & $\begin{array}{c}0.628^{a} \\
(23.02)\end{array}$ \\
\hline FRA & $\begin{array}{c}-0.396^{a} \\
(-6.56)\end{array}$ & $\begin{array}{c}-0.395^{a} \\
(-7.00)\end{array}$ & $\begin{array}{c}0.787^{a} \\
(29.79)\end{array}$ & $\begin{array}{c}0.790^{a} \\
(31.01)\end{array}$ \\
\hline GBR & $\begin{array}{c}-0.152^{b} \\
(-2.35)\end{array}$ & $\begin{array}{c}-0.161^{a} \\
(-2.94)\end{array}$ & $\begin{array}{c}0.842^{a} \\
(6.63)\end{array}$ & $\begin{array}{c}0.810^{a} \\
(7.41)\end{array}$ \\
\hline IRL & $\begin{array}{c}-0.187^{a} \\
(-3.64)\end{array}$ & $\begin{array}{c}-0.193^{a} \\
(-4.20)\end{array}$ & $\begin{array}{l}0.554^{a} \\
(18.09)\end{array}$ & $\begin{array}{l}0.562^{a} \\
(19.20)\end{array}$ \\
\hline ITA & $\begin{array}{c}-0.265^{a} \\
(-10.04)\end{array}$ & $\begin{array}{c}-0.282^{a} \\
(-11.74)\end{array}$ & $\begin{array}{c}0.761^{a} \\
(23.91)\end{array}$ & $\begin{array}{c}0.727^{a} \\
(23.34)\end{array}$ \\
\hline JPN & $\begin{array}{c}-0.161^{a} \\
(-8.05)\end{array}$ & $\begin{array}{c}-0.157^{a} \\
(-9.29)\end{array}$ & $\begin{array}{c}0.879^{a} \\
(42.50)\end{array}$ & $\begin{array}{c}0.898^{a} \\
(41.06)\end{array}$ \\
\hline KOR & $\begin{array}{c}-0.403^{a} \\
(-10.77)\end{array}$ & $\begin{array}{c}-0.393^{a} \\
(-12.53)\end{array}$ & $\begin{array}{c}0.529^{a} \\
(40.46)\end{array}$ & $\begin{array}{c}0.532^{a} \\
(45.58)\end{array}$ \\
\hline NLD & $\begin{array}{c}-0.331^{a} \\
(-5.90)\end{array}$ & $\begin{array}{c}-0.307^{a} \\
(-5.82)\end{array}$ & $\begin{array}{l}0.724^{a} \\
(15.95)\end{array}$ & $\begin{array}{l}0.731^{a} \\
(18.04)\end{array}$ \\
\hline NOR & $\begin{array}{c}-0.071^{a} \\
(-5.84)\end{array}$ & $\begin{array}{c}-0.081^{a} \\
(-6.17)\end{array}$ & $\begin{array}{c}0.094 \\
(0.75)\end{array}$ & $\begin{array}{c}0.034 \\
(0.29)\end{array}$ \\
\hline SWE & $\begin{array}{c}-0.020 \\
(-0.66)\end{array}$ & $\begin{array}{c}-0.009 \\
(-0.52)\end{array}$ & $\begin{array}{c}0.908^{a} \\
(11.23)\end{array}$ & $\begin{array}{c}0.882^{a} \\
(18.13)\end{array}$ \\
\hline USA & $\begin{array}{c}-0.017 \\
(-0.69)\end{array}$ & $\begin{array}{c}-0.033 \\
(-1.47)\end{array}$ & $\begin{array}{l}0.784^{a} \\
(23.50)\end{array}$ & $\begin{array}{l}0.765^{a} \\
(24.80)\end{array}$ \\
\hline EU-12 & $\begin{array}{c}-0.252^{a} \\
(-26.89)\end{array}$ & $\begin{array}{c}-0.249^{a} \\
(-30.24)\end{array}$ & $\begin{array}{l}0.685^{a} \\
(58.20)\end{array}$ & $\begin{array}{c}0.679^{a} \\
(64.78)\end{array}$ \\
\hline All sample & $\begin{array}{c}-0.223^{a} \\
(-29.72)\end{array}$ & $\begin{array}{c}-0.223^{a} \\
(-33.85)\end{array}$ & $\begin{array}{c}0.646^{a} \\
(76.54)\end{array}$ & $\begin{array}{c}0.636^{a} \\
(83.01)\end{array}$ \\
\hline
\end{tabular}


Table 3: Panel OLS Estimates of $\sigma$ for the Whole and Sub-Samples (eq. (8))

\begin{tabular}{l|c|c|c|c}
\hline \multirow{2}{*}{} & \multicolumn{4}{|c}{ Relative unemployment eq. (8) } \\
\hline \multirow{4}{*}{$\sigma$} & Without control & with $E P L_{a d j}$ & with $\varrho$ & with $E P L_{a d j}$ and $\varrho$ \\
\multirow{3}{*}{$\sigma^{H}$} & $(1)$ & $(2)$ & $(3)$ & $(4)$ \\
\cline { 2 - 5 }$\sigma^{L}$ & $-0.034^{a}$ & $-0.034^{a}$ & $-0.037^{a}$ & $-0.037^{a}$ \\
& $(-2.58)$ & $(-2.62)$ & $(-2.85)$ & $(-2.64)$ \\
\cline { 2 - 5 } & $-0.036^{c}$ & $-0.036^{c}$ & $-0.040^{c}$ & $-0.041^{c}$ \\
\hline Number of observations & $(-1.77)$ & $(-1.71)$ & $(-1.90)$ & $(-1.95)$ \\
Number of countries & $-0.033^{c}$ & $-0.031^{c}$ & $-0.034^{c}$ & $-0.032^{c}$ \\
\hline & $(-1.86)$ & $(-1.72)$ & $(-1.89)$ & $(-1.68)$ \\
\hline
\end{tabular}

Notes: all regressions include country fixed effects. ${ }^{a}\left({ }^{c}\right)$ denotes significance at $1 \%$ (10\%) level. We split the sample of 14 OECD countries into two subsamples on the basis of the mean sample of the labor market regulation ('LMR') index obtained by using a principal component analysis. The number of observations of the sub-sample of countries with high (low) labor market regulation is $94(70)$. We estimate eq. (8) for the high and low labor market regulation countries without (column 1) or with one (columns 2 and 3) or two (column 4) labor market control variable; coefficient $\sigma^{H}\left(\sigma^{L}\right)$ captures the response of the unemployment rate differential between tradables and non tradables in countries with high (low) labor market regulation. ' $\mathrm{EPL}_{a d j}$ ' is the strictness of employment protection against dismissals adjusted with the share of permanent workers, ' $\varrho$ ' is the unemployment benefits replacement rate.

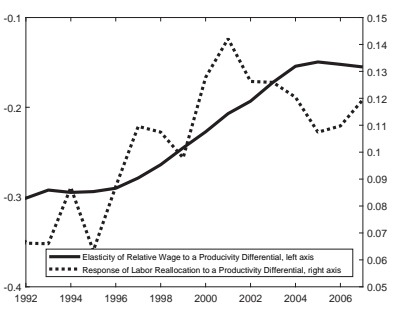

(a) $\beta$ (window's length $T=20)$

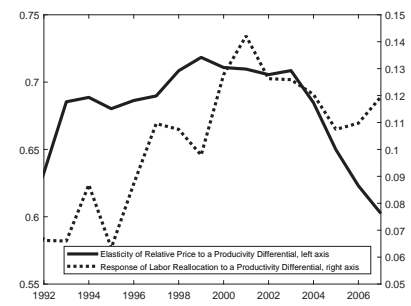

(d) $\gamma$ (window's length $T=20)$

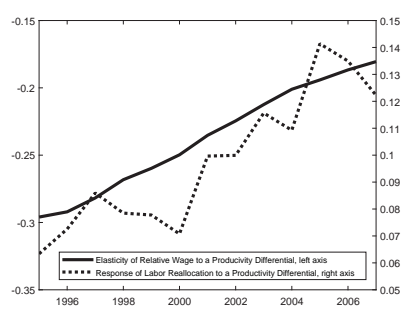

(b) $\quad \beta$ (window's length $T=25)$

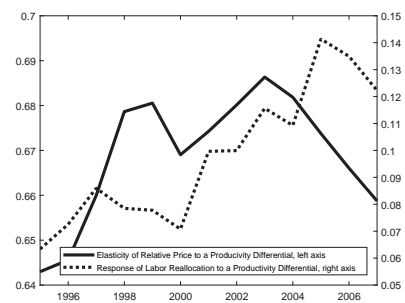

(e) $\quad \gamma$ (window's length $T=25)$

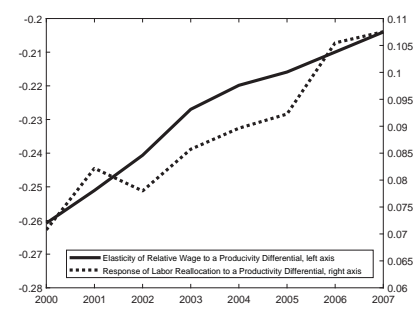

(c) $\beta$ (window's length $T=30)$

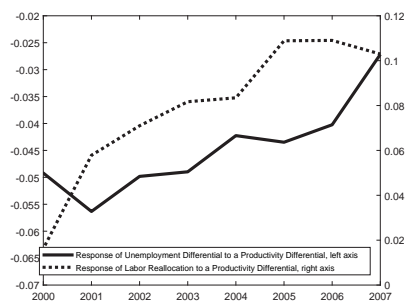

(f) $\quad \sigma$ (window's length $T=12)$

Figure 1: Plot of Estimates of $\beta, \gamma$, and $\sigma$ in Rolling Sub-Samples against the Magnitude of Intersectoral Labor Reallocation Caused by Higher Productivity Gains in Tradables Notes: We estimate $\beta$ (see eq. (7a)), $\gamma$ (see eq. (7b)), $\sigma$ (see eq. (8)), and the extent of labor reallocation following higher relative productivity in rolling sub-samples. The first row of Figure 1 plots FMOLS estimates for the response of the relative wage to a rise in the relative productivity of tradables (shown in the solid line) against the magnitude of intersectoral labor reallocation following a rise in the productivity differential (shown in the dashed line). The first two figures in the second row of Figure 1 plot FMOLS estimates for the response of the relative price to a rise in the relative productivity of tradables (shown in the solid line) against the magnitude of intersectoral labor reallocation following a rise in the productivity differential (shown in the dashed line). Sample: 18 OECD countries, $1970-2007$. Figure 1(f) plots the estimated response of the unemployment rate differential to a rise in the productivity differential (shown in the solid line) against the magnitude of intersectoral labor reallocation following a rise in the productivity differential (shown in the dashed line). Sample: 10 OECD countries, 1987-2007. 
Table 4: Panel Cointegration Estimates of $\beta$ and $\gamma$ for Sub-Samples

\begin{tabular}{|c|c|c|c|c|c|c|c|c|}
\hline LMR & \multicolumn{2}{|c|}{$\varrho$} & \multicolumn{2}{|c|}{ BargCov } & \multicolumn{2}{|c|}{$\mathrm{EPL}_{a d j}$} & \multicolumn{2}{|c|}{ LMR } \\
\hline & DOLS & FMOLS & DOLS & FMOLS & DOLS & FMOLS & DOLS & FMOLS \\
\hline $\begin{array}{l}\text { A.Relative Wage } \\
\beta^{H}\end{array}$ & $\begin{array}{l}-0.261^{a} \\
(-23.04)\end{array}$ & $\begin{array}{l}-0.255^{a} \\
(-25.65)\end{array}$ & $\begin{array}{l}-0.242^{a} \\
(-22.18)\end{array}$ & $\begin{array}{l}-0.238^{a} \\
(-24.91)\end{array}$ & $\begin{array}{l}-0.165^{a} \\
(-30.29)\end{array}$ & $\begin{array}{l}-0.172^{a} \\
(-32.59)\end{array}$ & $\begin{array}{l}-0.166^{a} \\
(-31.68)\end{array}$ & $\begin{array}{l}-0.173^{a} \\
(-33.20)\end{array}$ \\
\hline$\beta^{L}$ & $\begin{array}{c}-0.158^{a} \\
(-16.34)\end{array}$ & $\begin{array}{c}-0.166^{a} \\
(-19.14)\end{array}$ & $\begin{array}{c}-0.180^{a} \\
(-17.25)\end{array}$ & $\begin{array}{c}-0.185^{a} \\
(-19.93)\end{array}$ & $\begin{array}{c}-0.130^{a} \\
(-13.97)\end{array}$ & $\begin{array}{c}-0.130^{a} \\
(-11.57)\end{array}$ & $\begin{array}{c}-0.113^{a} \\
(-10.74)\end{array}$ & $\begin{array}{c}-0.112^{a} \\
(-8.26)\end{array}$ \\
\hline$t\left(\hat{\beta}^{L}=\hat{\beta}^{H}\right)$ & 0.000 & 0.000 & 0.000 & 0.000 & 0.000 & 0.011 & 0.000 & 0.000 \\
\hline B.Relative Price & & & & & & & & \\
\hline$\gamma^{H}$ & $\begin{array}{l}0.791^{a} \\
(6.37)\end{array}$ & $\begin{array}{c}0.776^{a} \\
(7.15)\end{array}$ & $\begin{array}{l}0.555^{a} \\
(8.76)\end{array}$ & $\begin{array}{l}0.566^{a} \\
(9.41)\end{array}$ & $\begin{array}{l}0.501^{a} \\
(5.37)\end{array}$ & $\begin{array}{l}0.414^{a} \\
(4.75)\end{array}$ & $\begin{array}{l}0.257^{a} \\
(3.10)\end{array}$ & $\begin{array}{l}0.186^{b} \\
(2.02)\end{array}$ \\
\hline$\gamma^{L}$ & $\begin{array}{l}1.123^{a} \\
(12.81)\end{array}$ & $\begin{array}{c}1.037^{a} \\
(13.60)\end{array}$ & $\begin{array}{l}1.388^{a} \\
(10.28)\end{array}$ & $\begin{array}{l}1.273^{a} \\
(11.21)\end{array}$ & $\begin{array}{c}0.205^{b} \\
(2.40)\end{array}$ & $\begin{array}{c}0.236^{a} \\
(2.91)\end{array}$ & $\begin{array}{c}0.502^{a} \\
(4.91)\end{array}$ & $\begin{array}{c}0.524^{a} \\
(6.01)\end{array}$ \\
\hline$t\left(\hat{\gamma}^{L}=\hat{\gamma}^{H}\right)$ & 0.000 & 0.000 & 0.000 & 0.000 & 1.000 & 0.987 & 0.011 & 0.000 \\
\hline Time period & 1970 & 2007 & 1970 & 2007 & 198 & 2007 & 1985 & 2007 \\
\hline Countries & & & & & & & & \\
\hline Observations & & & & & & & & \\
\hline mean LMR (high) & & & & & & & & \\
\hline mean LMR (low) & & & & & & & & \\
\hline
\end{tabular}

Notes: ${ }^{a}$ denotes significance at $1 \%$ level. To investigate whether labor market regulation influences the responses of the relative wage, $\beta$, and the relative price, $\gamma$, to a productivity differential, we split the sample of 18 OECD countries into two subsamples and run the regressions (7a)-(7b) for the high and low-labor market regulation countries. $\beta^{H}\left(\beta^{L}\right)$ and $\gamma^{H}\left(\gamma^{L}\right)$ capture the responses of the relative wage and the relative price, respectively, in countries with high (low) labor market regulation. The row $t\left(\hat{\beta}^{L}=\hat{\beta}^{H}\right)$ $\left(t\left(\hat{\gamma}^{L}=\hat{\gamma}^{H}\right)\right)$ reports the p-value of the test of $H_{0}: \hat{\beta}^{L}=\hat{\beta}^{H}\left(\hat{\gamma}^{L}=\hat{\gamma}^{H}\right)$. ' $\varrho$ ' is the unemployment benefits replacement rate, 'EPL $\mathrm{Ldj}$ ' the strictness of employment protection against dismissals adjusted with the share of permanent workers, 'BargCov' the bargaining coverage and 'LMR' the labor market regulation index obtained by using a principal component analysis.

Table 5: Data to Calibrate the Two-Sector Model (1990-2007)

\begin{tabular}{|l|ccc|ccc|c|}
\hline \multirow{2}{*}{ Countries } & \multicolumn{3}{|c|}{ Non tradable Share } & \multicolumn{3}{c|}{$G^{j} / Y^{j}$} & Relative Productivity \\
\cline { 2 - 7 } & Labor & Consumption & Gov. Spending & $G / Y$ & $G^{T} / Y^{T}$ & $G^{N} / Y^{N}$ & $A^{T} / A^{N}$ \\
& $(1)$ & $(2)$ & $(3)$ & $(4)$ & $(5)$ & $(6)$ & $(7)$ \\
\hline AUS & 0.68 & 0.43 & n.a. & 0.18 & n.a. & n.a. & 1.30 \\
AUT & 0.64 & 0.42 & 0.90 & 0.19 & 0.05 & 0.27 & 1.05 \\
BEL & 0.68 & 0.42 & 0.91 & 0.22 & 0.06 & 0.30 & 1.28 \\
CAN & 0.69 & 0.43 & 0.91 & 0.20 & 0.05 & 0.30 & 1.32 \\
DEU & 0.65 & 0.40 & 0.91 & 0.19 & 0.05 & 0.27 & 1.00 \\
DNK & 0.68 & 0.42 & 0.94 & 0.26 & 0.05 & 0.36 & 1.17 \\
ESP & 0.66 & 0.46 & 0.88 & 0.18 & 0.06 & 0.24 & 1.18 \\
FIN & 0.63 & 0.43 & 0.89 & 0.22 & 0.06 & 0.34 & 1.47 \\
FRA & 0.69 & 0.40 & 0.94 & 0.23 & 0.05 & 0.31 & 1.05 \\
GBR & 0.70 & 0.40 & 0.93 & 0.20 & 0.04 & 0.29 & 1.54 \\
IRL & 0.62 & 0.43 & 0.89 & 0.17 & 0.04 & 0.28 & 1.83 \\
ITA & 0.63 & 0.37 & 0.91 & 0.19 & 0.05 & 0.27 & 1.00 \\
JPN & 0.64 & 0.43 & 0.86 & 0.16 & 0.06 & 0.22 & 0.96 \\
KOR & 0.58 & 0.44 & 0.76 & 0.12 & 0.06 & 0.18 & 1.53 \\
NLD & 0.70 & 0.40 & 0.90 & 0.23 & 0.07 & 0.32 & 1.38 \\
NOR & 0.66 & 0.39 & 0.88 & 0.21 & 0.06 & 0.34 & 1.44 \\
SWE & 0.68 & 0.45 & 0.92 & 0.27 & 0.06 & 0.39 & 1.42 \\
USA & 0.73 & 0.51 & 0.90 & 0.16 & 0.05 & 0.20 & 1.12 \\
EU-12 & 0.66 & 0.42 & 0.91 & 0.21 & 0.05 & 0.30 & 1.28 \\
Mean & 0.66 & 0.42 & 0.90 & 0.20 & 0.05 & 0.29 & 1.28 \\
\hline
\end{tabular}




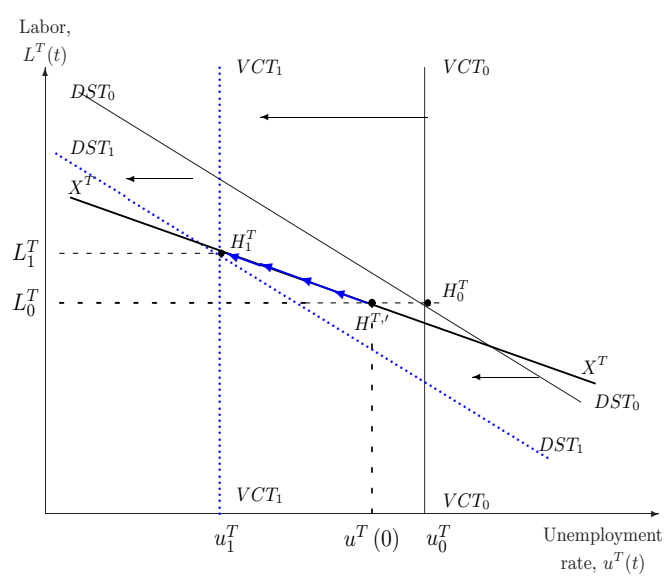

(a) $\left(u^{T}, L^{T}\right)$-space

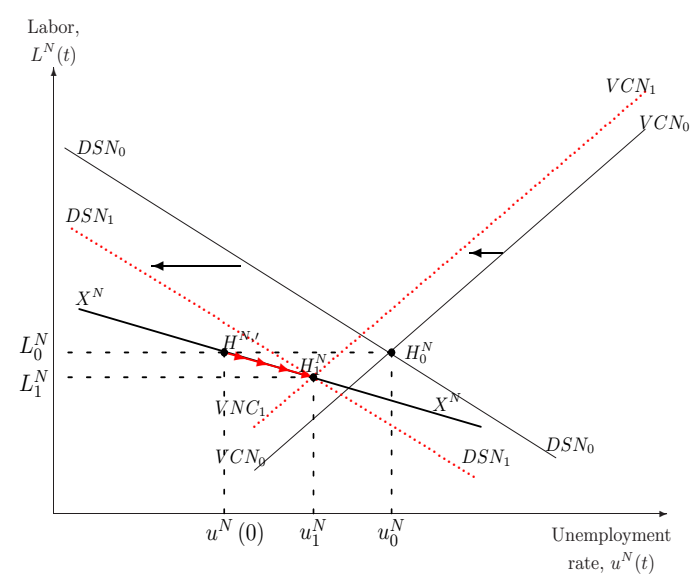

(b) $\left(u^{N}, L^{N}\right)$-space

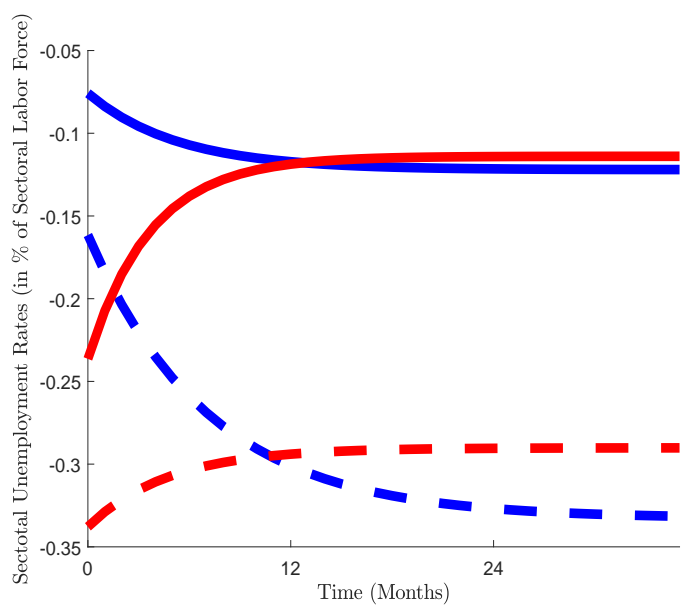

(c) Dynamics for $u^{T}(t)$ and $u^{N}(t)$

Figure 2: Theoretical and Numerically Computed Adjustment of Sectoral Unemployment Rates. Notes: Figure 2(c) plots the dynamics of unemployment rates of tradables (shown in the blue line) and non tradables (shown in the red line) for a representative OECD economy (shown in solid lines) and contrast them with those for an OECD economy with high labor market regulation (shown in dashed lines), i.e., we set the unemployment benefit replacement rate to $78.2 \%$ and the firing tax to 13 months. 


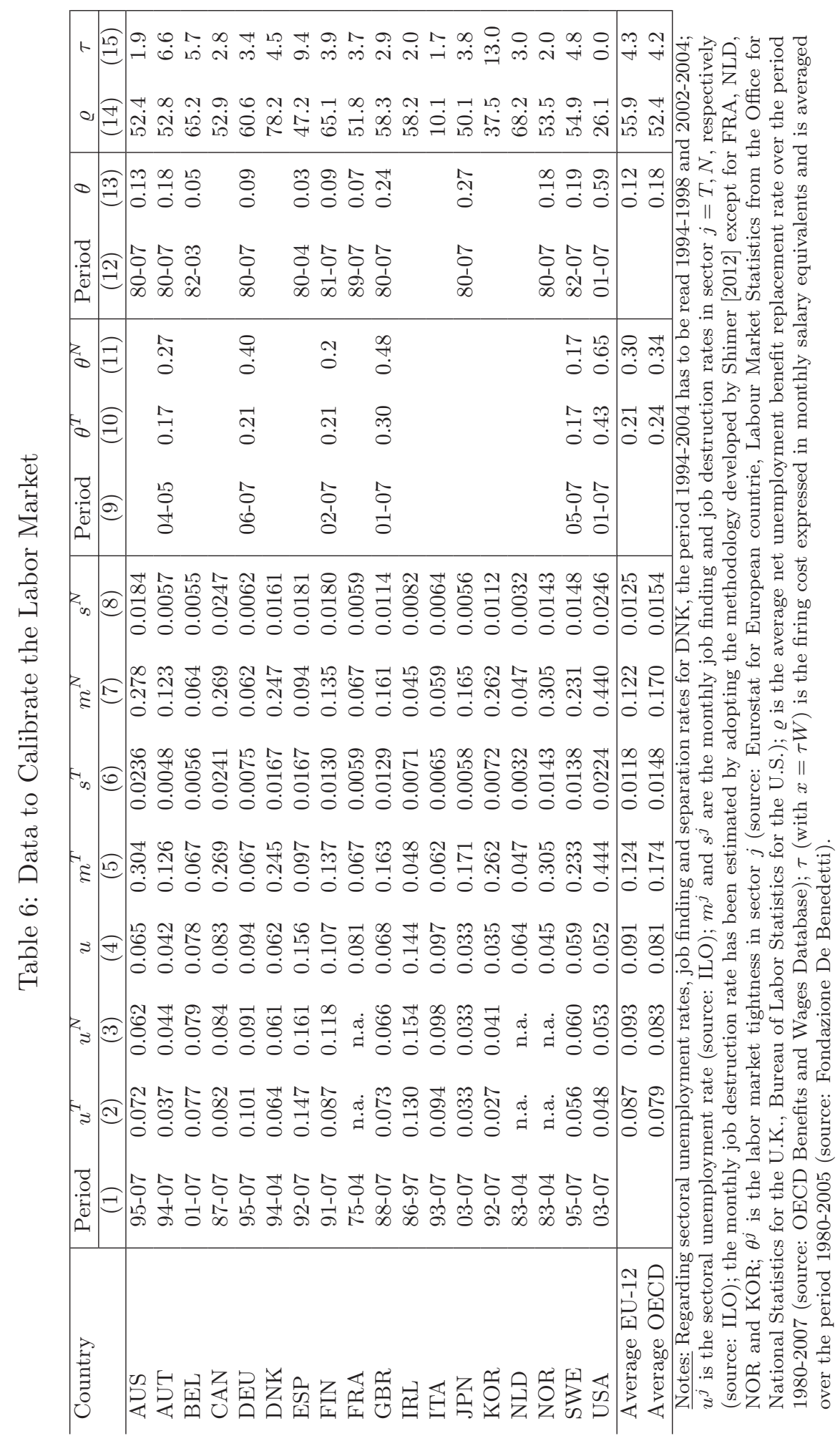




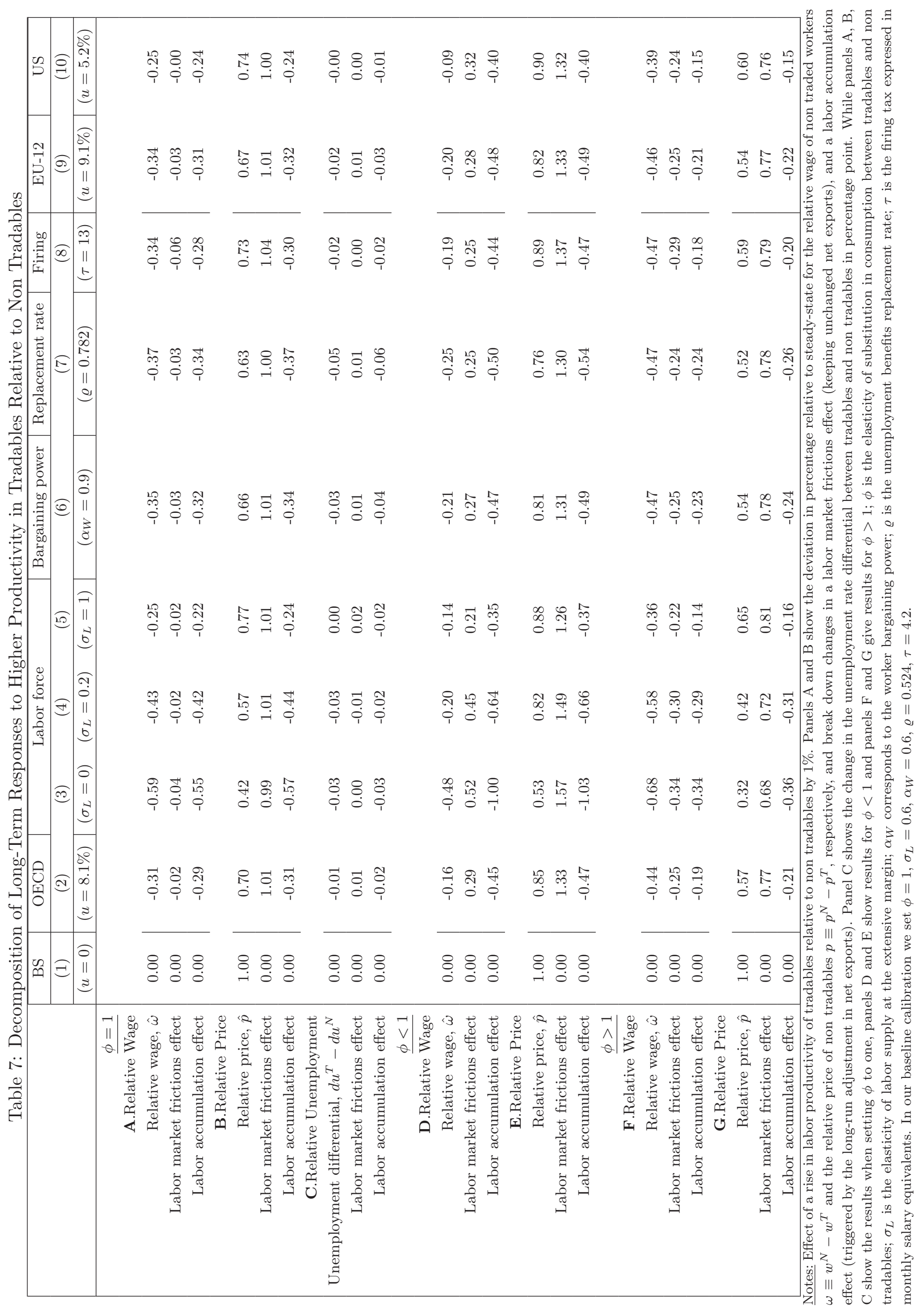




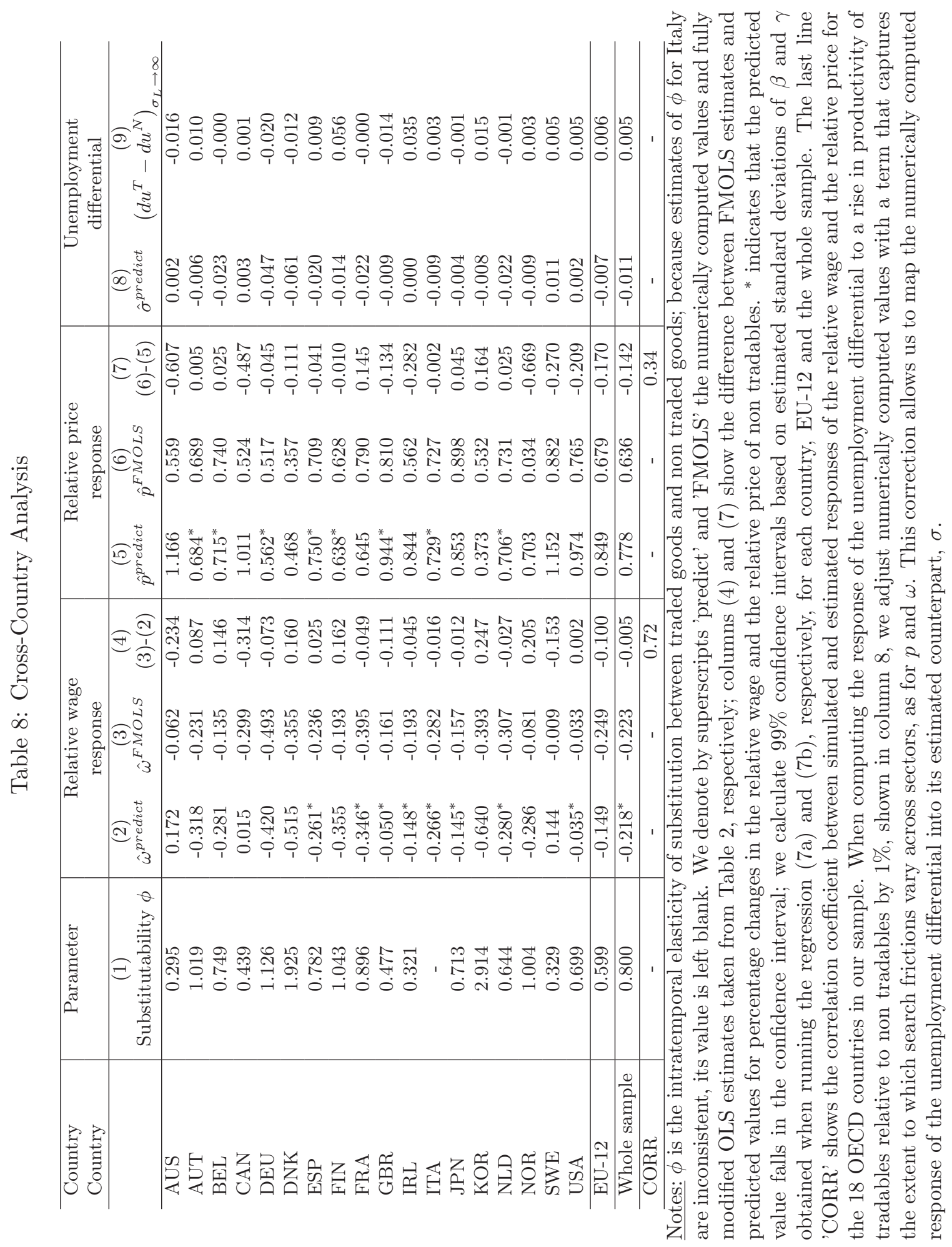




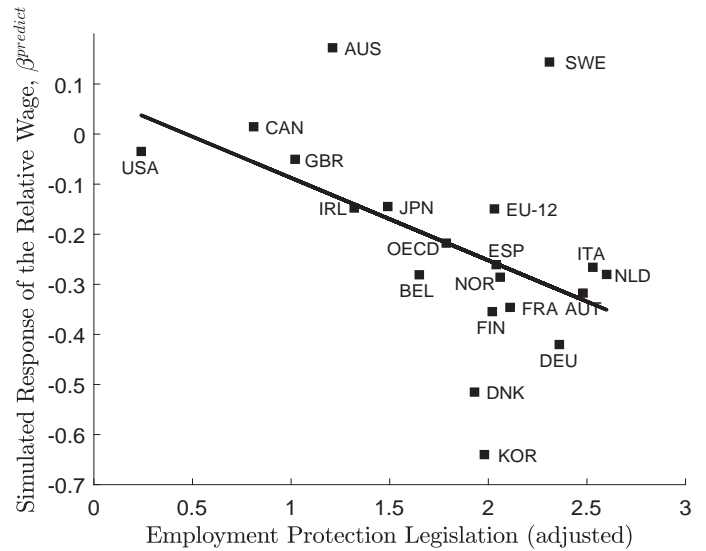

(a) Relative Wage Responses against $\mathrm{EPL}_{a d j}$

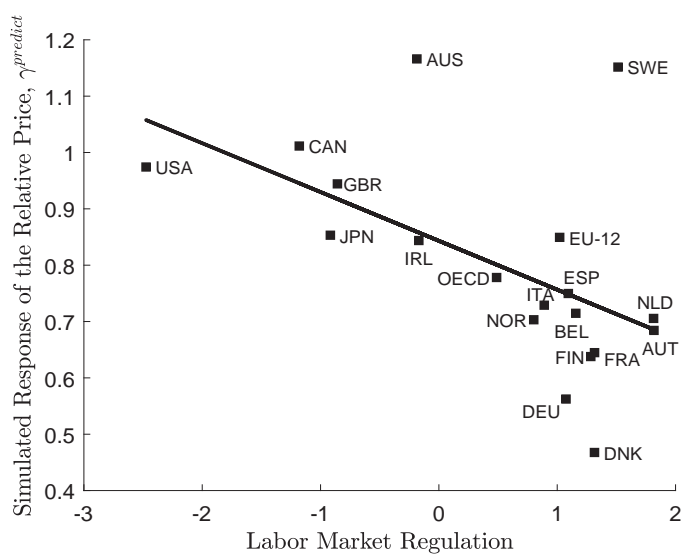

(c) Relative Price Responses against Labor Market Regulation

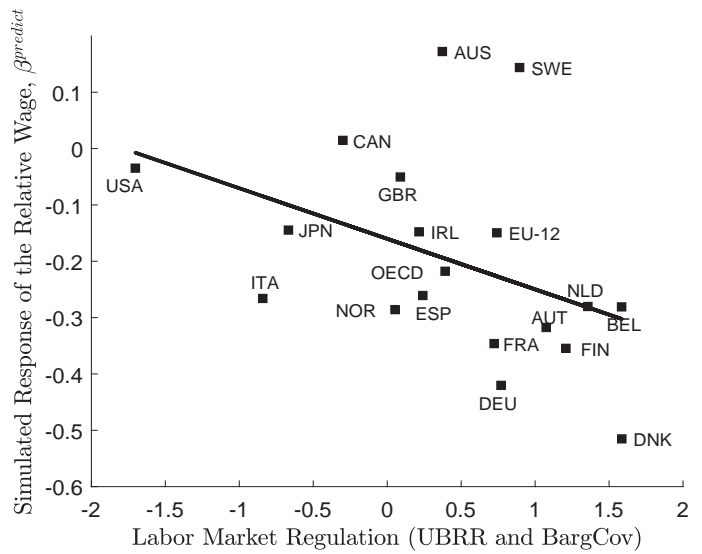

(b)

Relative Wage Responses against Unemployment Benefits and Bargaining Coverage

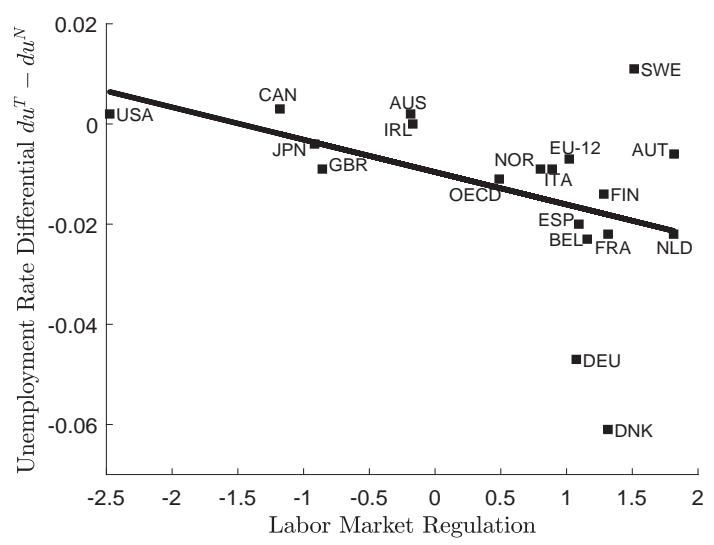

(d) Unemployment Rate Differential against Labor Market Regulation

Figure 3: Cross-Country Relationship between Simulated Responses to Higher Relative Productivity and Labor Market Regulation. Notes: Horizontal axes display the indicators of labor market regulation: the top-left panel shows the employment protection legislation index adjusted with the share of permanent workers (i.e., $\mathrm{EPL}_{a d j}$ ), the top-right panel shows a labor market regulation index obtained by using a principal component analysis which encompasses both the generosity of the unemployment benefit scheme (UBRR) and the extent of the worker bargaining power (BargCov), the bottom panels show the labor market regulation index which encompasses the three dimensions of labor market institutions. Vertical axes in the top panels report simulated long-run responses of the relative wage to higher relative productivity from the baseline model with search frictions and an endogenous labor force participation decision. Vertical axes in bottom panels report simulated longrun responses of the relative price and unemployment rate differential to higher relative productivity. 


\section{A Data for Empirical Analysis}

Country Coverage: Our sample consists of a panel of 18 OECD countries: Australia (AUS), Austria (AUT), Belgium (BEL), Canada (CAN), Germany (DEU), Denmark (DNK), Spain (ESP), Finland (FIN), France (FRA), the United Kingdom (GBR), Ireland (IRL), Italy (ITA), Japan (JPN), Korea (KOR), the Netherlands (NLD), Norway (NOR), Sweden (SWE), and the United States (USA).

Period Coverage: The period is running from 1970 to 2007, except for Japan (1974-2007).

Sources: We use the EU KLEMS [2011] database (the March 2011 data release) for all countries of our sample with the exceptions of Canada and Norway. For these two countries, sectoral data are taken from the Structural Analysis (STAN) database provided by the OECD [2011]. Both the EU KLEMS and STAN databases provide annual data at the ISIC-rev.3 1-digit level for eleven industries.

The eleven industries are split into tradables and non tradables sectors. To do so, we adopt the classification proposed by De Gregorio et al. [1994]. Following Jensen and Kletzer [2006], we have updated this classification by treating "Financial Intermediation" as a traded industry. We construct traded and non traded sectors as follows (EU KLEMS codes are given in parentheses):

- Traded Sector: "Agriculture, Hunting, Forestry and Fishing" (A-B), "Mining and Quarrying" (C), "Total Manufacturing" (D), "Transport, Storage and Communication" (I) and "Financial Intermediation" (J).

- Non Traded Sector: "Electricity, Gas and Water Supply" (E), "Construction" (F), "Wholesale and Retail Trade" (G), "Hotels and Restaurants" (H), "Real Estate, Renting and Business Services" (K) and "Community Social and Personal Services" (L-Q).

Once industries have been classified as traded or non traded, for any macroeconomic variable $X$, its sectoral counterpart $X^{j}$ for $j=T, N$ is constructed by adding the $X_{k}$ of all sub-industries $k$ classified in sector $j=T, N$ as follows $X^{j}=\sum_{k \in j} X_{k}$. In the following, we provide details on data construction (mnemonics are in parentheses):

- Relative wage of non tradables, $\Omega$, is calculated as the ratio of the nominal wage in the non traded sector $W^{N}$ to the nominal wage in the traded sector $W^{T}$, i.e., $\Omega=W^{N} / W^{T}$. The sectoral nominal wage $W^{j}$ for sector $j=T, N$ is calculated by dividing labor compensation in sector $j$ (LAB) by total hours worked by persons engaged (H_EMP) in that sector.

- Relative price of non tradables, $P$, corresponds to the ratio of the value added deflator of non traded goods $P^{N}$ to the value added deflator of traded goods $P^{T}$, i.e., $P=P^{N} / P^{T}$. The value added deflator $P^{j}$ for sector $j=T, N$ is calculated by dividing value added at current prices by value added at constant prices in sector $j$. Series for sectoral value added at current prices (VA) (constant prices (VA_QI) resp.) are constructed by adding value at current (constant resp.) prices of all sub-industries in sector $j=T, N$.

- Relative productivity of tradables, $A^{T} / A^{N}$, is calculated as the ratio of traded real labor productivity $A^{T}$ to the non traded real labor productivity $A^{N}$. To measure real labor productivity in sector $j=T, N$, we divide value-added at constant prices in sector $j$ (VA_QI) by total hours worked by persons engaged (H_EMP) in that sector.

- The construction of sectoral unemployment rates is detailed below in subsection B.3.

To empirically assess the role of labor market regulation in the determination of the relative price and relative wage responses to higher productivity in tradables relative to non tradables, we use a number of indicators which capture the extent of rigidity of labor markets. We detail below the sources:

- Employment protection legislation, denoted by $E P L$, is an index available on an annual basis developed by the OECD which is designed as a multi-dimensional indicator of the strictness of a comprehensive set of legal regulations governing hiring and firing employees on regular contracts. Source: OECD Labour Market Statistics database. Data coverage: 1985-2007 (1990-2007 for KOR). Because the legal protection for workers with temporary contracts has been eased in most European countries, we follow Boeri and Van Ours [2008] and construct an alternative index in order to have a more accurate measure of employment protection. This indicator, denoted by $\mathrm{EPL}_{a d j}$, is computed by adjusting EPL with the share of permanent workers in the economy ( share $_{\text {perm }}$ ) according to $\mathrm{EPL}_{a d j}=\mathrm{EPL} \times$ share $_{\text {perm }}$.

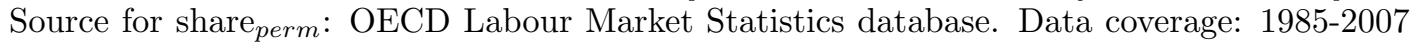
(1990-2007 for KOR).

- The generosity of the unemployment benefit scheme is commonly captured by the unemployment benefit replacement rate. The replacement rate, denoted by $\varrho$, measure is defined as 
the average of the net unemployment benefit (including social assistance and housing benefit) replacement rates for two earnings levels and three family situations, and for three durations of unemployment (1 year, $2 \& 3$ years, $4 \& 5$ years). Source: OECD, Benefits and Wages Database. Data coverage: 2001-2007. In order to have longer time series, we calculated $\varrho$ over the period running from 1970 to 2000 , by using the growth rate of the historic OECD measure of benefit entitlements which is defined as the average of the gross unemployment benefit replacement rates for two earnings levels, three family situations and three durations of unemployment. Source: OECD, Benefits and Wages Database. Data coverage: 1970-2001 for all countries while data are unavailable for Korea.

- The worker bargaining power is measured by the collective bargaining coverage which corresponds to the employees covered by collective wage bargaining agreements as a proportion of all wage and salary earners in employment with the right to bargaining. This time-varying indicator is denoted by BargCov. Source: Data Base on Institutional Characteristics of Trade Unions, Wage Setting, State Intervention and Social Pacts, 1960-2009 (ICTWSS), version 3.0, Jelle Visser [2009]. Data coverage: 1970-2007 for AUS, AUT, CAN, DEU, DNK, FIN, GBR, IRL, ITA, JPN, SWE and USA, 1970-2005 for NLD and NOR, 1970-2002 for BEL and FRA, 1977-2004 for ESP and 2002-2006 for KOR.

Figures 4(a), 4(b), 4(c) plot the absolute values of FMOLS estimates for the relative wage responses, $\beta_{i}$, taken from Table 2 against the EPL index adjusted with the share of permanent workers, the net unemployment benefit replacement rates, and the bargaining coverage, respectively. Because time series for the unemployment benefit replacement rate and bargaining coverage are available only from the beginning of the 2000's for Korea and thus are too short, we exclude this country from Figures 4(b) and 4(c). In line with our conjecture, the trend lines in Figures 4(a), 4(b), 4(c) show that the estimated responses of the relative wage and our three measures of labor market regulation are positively related across countries. We also we have recourse to a principal component analysis to construct an indicator that gives a more accurate measure of the degree of labor market regulation. Figure 4(d) displays the traditional distinction between English-speaking and Continental European economies, labor markets being much less regulated in the former than the latter countries. Importantly, in accordance with our conjecture, the trend line is upward sloping, thus suggesting that higher productivity in tradables relative to non tradables lowers the relative wage more in countries where labor market regulation is more pronounced.

\section{B Data for Calibration}

\section{B.1 Non Tradable Share}

Table 5 shows the non-tradable content of labor, consumption, government spending, and gives the share of government spending on the traded and non traded goods in the sectoral output. The last column of Table 5 also shows the ratio of traded real labor productivity to the non traded real labor productivity, $A^{T} / A^{N}$. Our sample consists of 18 OECD countries mentioned in section A, including 12 European countries plus Australia, Canada, Korea, Japan, Norway, the United-States. Our reference period for the calibration corresponds to the period 1990-2007. The choice of this period has been dictated by data availability.

To calculate the non tradable share of employment we split the eleven industries into traded and non traded sectors by adopting the classification proposed by De Gregorio et al. [1994] and updated by Jensen and Kletzer [2006] (Source: EU KLEMS [2011]). The non-tradable share of labor, shown in column 1 of Table 5 averages to $66 \%$.

To split consumption expenditure (at current prices) into consumption in traded and non traded goods, we made use of the Classification of Individual Consumption by Purpose (COICOP) published by the United Nations (Source: United Nations [2011]). Among the twelve items, the following ones are treated as consumption in traded goods: "Food and Non-Alcoholic Beverages", "Alcoholic Beverages Tobacco and Narcotics", "Clothing and Footwear", "Furnishings, Household Equipment", "Transport", "Miscellaneous Goods and Services". The remaining items are treated as consumption in non traded goods: "Housing, Water, Electricity, Gas and Fuels", "Health", "Communication", "Education", "Restaurants and Hotels". Because the item "Recreation and Culture" is somewhat problematic, we decided to consider it as both tradable (50\%) and non tradable (50\%) with equal shares. Data coverage: 1990-2007 for AUS, AUT, CAN, DNK, FIN, FRA, GBR, ITA, JPN, KOR, NLD, NOR, and USA, 1991-2007 for DEU, 1993-2007 for SWE, 1995-2007 for BEL and ESP and 1996-2007 for IRL. Note that the non-tradable share of consumption shown in column 2 of Table 5 averages to $42 \%$.

Sectoral government expenditure data (at current prices) were obtained from the Government Finance Statistics Yearbook (Source: IMF [2011]) and the OECD General Government Accounts database (Source: OECD [2012b]). Adopting Morshed and Turnovsky's [2004] methodology, the 


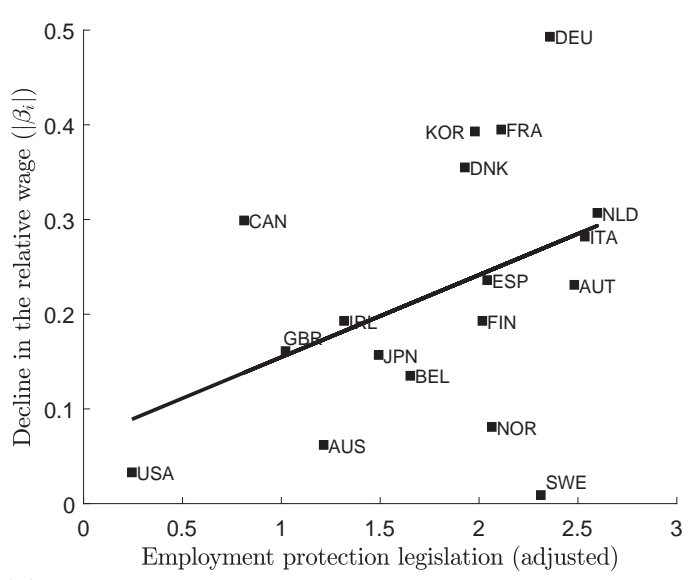

(a) Relative Wage Responses against Firing Cost

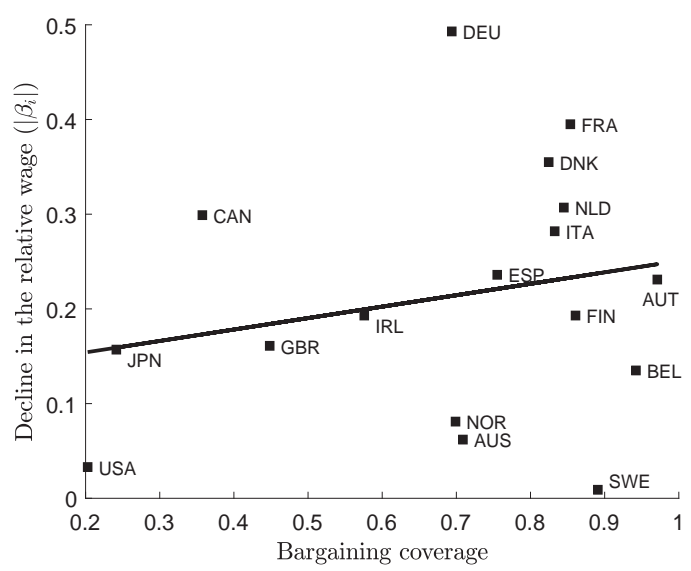

(c) Relative Wage Responses against Worker Bargaining Power

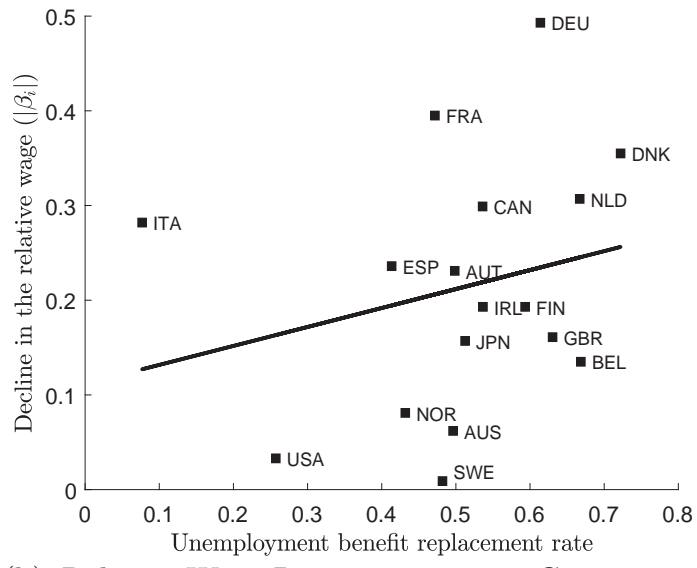

(b) Relative Wage Responses against Generosity of Unemployment Benefit Scheme

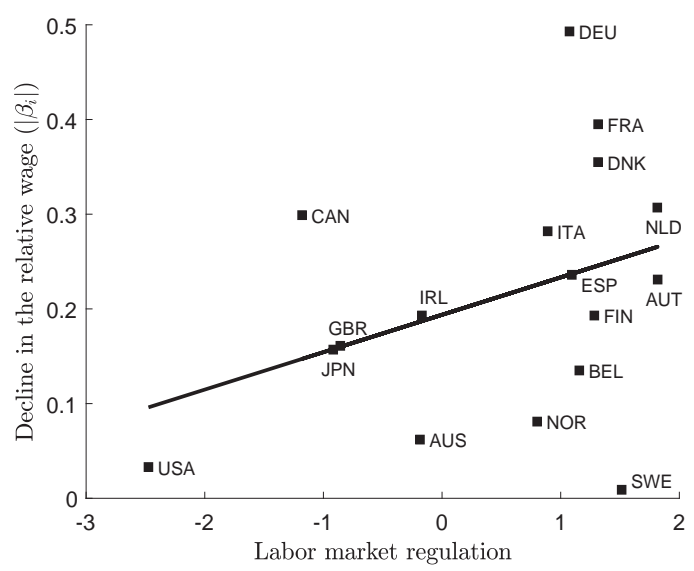

(d) Relative Wage Responses against Labor Market Regulation Index

Figure 4: Labor Market Regulation and The Relative Wage Response to Higher Productivity of Tradables relative to Non Tradables Notes: Figure 4 plots fully modified OLS estimates of relative wage responses to a labor productivity differential against indicators of labor market regulation. Horizontal axis displays the FMOLS estimates for each country which are taken from Table 2. For easier reading, we show the absolute value of the change in the relative wage (i.e., $\left.\left|\beta_{i}\right|\right)$. Firing cost is captured by the employment protection legislation index adjusted with the share of permanent workers in the economy (source: OECD); the generosity of unemployment benefit scheme is measured by the average of net unemployment benefit replacement rates for three duration of unemployment (source: OECD); the worker bargaining power is measured by the bargaining coverage (source: Visser [2009]); in Figure 4(d), we have recourse to a principal component analysis in order to have one overall indicator encompassing the three dimensions of labor market regulation. 
following four items were treated as traded: "Fuel and Energy", "Agriculture, Forestry, Fishing, and Hunting", "Mining, Manufacturing, and Construction", "Transport and Communications". Items treated as non traded are: "Government Public Services", "Defense", "Public Order and Safety", "Education", "Health", "Social Security and Welfare", "Environment Protection", "Housing and Community Amenities", "Recreation Cultural and Community Affairs". Data coverage: 1990-2007 for BEL, DNK, FIN, GBR, IRL, ITA, JPN, NOR and USA, 1990-2006 for CAN, 1991-2007 for DEU, 1995-2007 for AUT, ESP, FRA, NLD and SWE and 2000-2007 for KOR (data are not available for AUS). The non-tradable component of government spending shown in column 3 of Table 5 averages to $90 \%$. While government spending as a share in GDP is shown in column 4, the proportion of government spending on the traded and non traded good (i.e., $G^{T} / Y^{T}$ and $G^{N} / Y^{N}$ ) are shown in columns 5 and 6 of Table 5 . They average $5 \%$ and $29 \%$, respectively.

The last column of Table 5 displays the ratio of labor productivity of tradables relative to non tradables $\left(A^{T} / A^{N}\right)$ averaged over the period 1990-2007 for all countries. Source: the EU KLEMS [2011] and STAN database. As shown in column 7, the traded sector is in average 28 percent more productive than the non traded sector.

\section{B.2 Elasticity of Substitution in consumption $(\phi)$}

To estimate the elasticity of substitution in consumption $\phi$ between traded and non traded goods, we first derive a testable equation by inserting the optimal rule for intra-temporal allocation of consumption (15) into the goods market equilibrium which gives $\frac{C^{T}}{C^{N}}=\frac{Y^{T}-N X-E^{T}}{Y^{N}-E^{N}}$ where $N X \equiv$ $\dot{B}-r^{\star} B$ is net exports, $E^{T} \equiv G^{T}+I^{T}+F$ (with $\left.F \equiv \kappa^{T} V^{T}+\kappa^{N} V^{N}\right)$ and $E^{N} \equiv G^{N}+I^{N}$; note that we include investment in order to be consistent with accounting identities. Inserting the optimal rule for intra-temporal allocation of consumption (15) into the goods market equilibrium, and denoting the ratio of $E^{T}$ to traded value added adjusted with net exports at current prices by $v_{E^{T}}=\frac{P^{T} E^{T}}{P^{T} Y^{T}-P^{T} N X}$, and the ratio of $E^{N} \equiv G^{N}+I^{N}$ to non traded value added at current prices by $v_{E^{N}}=\frac{P^{N} E^{N}}{P^{N} Y^{N}}$, the goods market equilibrium can be rewritten as follows $\frac{\left(Y^{T}-N X\right)\left(1-v_{E^{T}}\right)}{Y^{N}\left(1-v_{E^{N}}\right)}=$ $\left(\frac{\varphi}{1-\varphi}\right) P^{\phi}$. Isolating $\left(Y^{T}-N X\right) / Y^{N}$ and taking logarithm yields $\ln \left(\frac{Y^{T}-N X}{Y^{N}}\right)=\alpha+\phi \ln P$ where $\alpha \equiv \ln \left(\frac{1-v_{E}^{N}}{1-v_{E}^{T}}\right)+\ln \left(\frac{\varphi}{1-\varphi}\right)$. Adding an error term $\mu$, we estimate $\phi$ by running the regression of the (logged) output of tradables adjusted with net exports at constant prices in terms of output of non tradables on the (logged) relative price of non tradables:

$$
\ln \left(\frac{Y^{T}-N X}{Y^{N}}\right)_{i, t}=f_{i}+f_{t}+\alpha_{i} t+\phi_{i} \ln P_{i, t}+\mu_{i, t},
$$

where $f_{i}$ and $f_{t}$ are the country fixed effects and time dummies, respectively. Because the term $\alpha$ is composed of ratios which may display a trend over time, we add country-specific linear trends, as captured by $\alpha_{i} t$.

Instead of using time series for sectoral value added, we can alternatively make use of series for sectoral labor compensation. Multiplying both sides of $\frac{\left(Y^{T}-N X\right)\left(1-v_{E^{T}}\right)}{Y^{N}\left(1-v_{E^{N}}\right)}=\left(\frac{\varphi}{1-\varphi}\right) P^{\phi}$ by $\frac{P^{T}}{P^{N}}$ and then by $\frac{\rho^{T}}{\rho^{N}}$ with $\rho^{j}=\frac{W^{j} L^{j}}{P^{j} Y^{j}}$, denoting by $\gamma^{T}=\left(W^{T} L^{T}-\rho^{T} P^{T} N X\right)$ (with $\left.\rho_{T} \equiv \frac{W^{T} L^{T}}{P^{T} Y^{T}}\right)$ and $\gamma^{N}=W^{N} L^{N}$, and taking logarithm yields $\ln \left(\frac{\gamma^{T}}{\gamma^{N}}\right)=\eta+(\phi-1) \ln P$ where $\eta$ is a term composed of both preference (i.e., $\varphi$ ) and production (i.e., $\rho^{j}$ ) parameters, and the (logged) ratio of $E^{T}\left(E^{N}\right)$ to $W^{T} L^{T}-\rho^{T} P^{T} N X\left(W^{N} L^{N}\right)$. We thus estimate $\phi$ by exploring alternatively the following empirical relationship:

$$
\ln \left(\gamma^{T} / \gamma^{N}\right)_{i, t}=g_{i}+g_{t}+\eta_{i} t+\delta_{i} \ln P_{i, t}+\zeta_{i, t},
$$

where $\delta_{i}=\left(\phi_{i}-1\right) ; g_{i}$ and $g_{t}$ are the country fixed effects and time dummies, respectively; we add country-specific trends, as captured by $\eta_{i} t$, because $\eta$ is composed of ratios that may display a trend over time.

Time series for sectoral value added at constant prices, labor compensation, and the relative price of non tradables are taken from EU KLEMS [2011] (see section A). Net exports correspond to the external balance of goods and services at current prices taken from OECD Economic Outlook Database. To construct time series for net exports at constant prices $N X$, data are deflated by the traded value added deflator of traded goods (i.e., $P^{T}$ ).

Since the LHS term of (40) and (41) and the relative price of non tradables as well display trends, we ran unit root and then cointegration tests. Having verified that these two assumptions are empirically supported, we estimate the cointegrating relationships by using DOLS and FMOLS estimators for cointegrated panel proposed by Pedroni [2000], [2001]. DOLS and FMOLS estimates are reported in Table 9, considering alternatively eq. (40) or eq. (41). Estimates of $\phi$ are reported in column 1 of Table 8 when calibrating the model for each country. As a reference model, we 
Table 9: Estimates of the Elasticity of Substitution in Consumption between Tradables and Non Tradables $(\phi)$

\begin{tabular}{|c|c|c|c|c|}
\hline Country & $\hat{\phi}_{i}^{D O L S}$ & $\hat{\phi}_{i}^{F M O L S}$ & $\hat{\phi}_{i}^{D O L S}$ & $\hat{\phi}_{i}^{F M O L S}$ \\
\hline & $\begin{array}{c}\text { eq. (40) } \\
(1)\end{array}$ & $\begin{array}{c}\text { eq. }(40) \\
(2)\end{array}$ & $\begin{array}{c}\text { eq. (41) } \\
(3)\end{array}$ & $\begin{array}{c}\text { eq. (41) } \\
(4)\end{array}$ \\
\hline AUS & $\begin{array}{l}0.081 \\
(0.74)\end{array}$ & $\begin{array}{c}0.295^{a} \\
(3.09)\end{array}$ & $\begin{array}{l}0.011 \\
(0.08)\end{array}$ & $\begin{array}{c}0.375^{b} \\
(2.39)\end{array}$ \\
\hline AUT & $\begin{array}{c}0.574 \\
(1.62)\end{array}$ & $\begin{array}{c}1.019^{a} \\
(2.99)\end{array}$ & $\begin{array}{c}0.910^{a} \\
(3.77)\end{array}$ & $\begin{array}{l}1.414^{a} \\
(4.98)\end{array}$ \\
\hline BEL & $\begin{array}{c}-0.268 \\
(-1.58)\end{array}$ & $\begin{array}{l}0.034 \\
(0.17)\end{array}$ & $\begin{array}{c}0.393^{a} \\
(3.41)\end{array}$ & $\begin{array}{c}0.749^{a} \\
(4.60)\end{array}$ \\
\hline $\mathrm{CAN}$ & $\begin{array}{c}0.308^{b} \\
(2.04)\end{array}$ & $\begin{array}{c}0.439^{a} \\
(3.75)\end{array}$ & $\begin{array}{c}0.332^{b} \\
(2.18)\end{array}$ & $\begin{array}{c}0.569^{a} \\
(4.94)\end{array}$ \\
\hline DEU & $\begin{array}{c}0.976^{a} \\
(3.46)\end{array}$ & $\begin{array}{c}1.126^{a} \\
(2.99)\end{array}$ & $\begin{array}{c}1.190^{a} \\
(4.34)\end{array}$ & $\begin{array}{c}1.363^{a} \\
(3.47)\end{array}$ \\
\hline DNK & $\begin{array}{l}1.243 \\
(1.24)\end{array}$ & $\begin{array}{c}1.925^{a} \\
(2.76)\end{array}$ & $\begin{array}{c}1.698^{b} \\
(2.35)\end{array}$ & $\begin{array}{c}1.320^{a} \\
(2.73)\end{array}$ \\
\hline ESP & $\begin{array}{c}0.527^{a} \\
(3.31)\end{array}$ & $\begin{array}{c}0.782^{a} \\
(4.71)\end{array}$ & $\begin{array}{l}0.177 \\
(0.90)\end{array}$ & $\begin{array}{c}0.355^{c} \\
(1.71)\end{array}$ \\
\hline FIN & $\begin{array}{l}1.556^{a} \\
(10.13)\end{array}$ & $\begin{array}{c}1.043^{a} \\
(9.30)\end{array}$ & $\begin{array}{c}2.061^{a} \\
(8.62)\end{array}$ & $1_{(8.45)}^{1.412^{a}}$ \\
\hline FRA & $\begin{array}{c}0.880^{a} \\
(4.75)\end{array}$ & $\begin{array}{c}0.896^{a} \\
(6.29)\end{array}$ & $\begin{array}{c}1.169^{a} \\
(4.46)\end{array}$ & $\begin{array}{l}1.048^{a} \\
(5.58)\end{array}$ \\
\hline GBR & $\begin{array}{c}0.688^{a} \\
(8.76)\end{array}$ & $\begin{array}{c}0.477^{a} \\
(9.57)\end{array}$ & $\begin{array}{l}1.424^{a} \\
(14.39)\end{array}$ & $\begin{array}{l}1.183^{a} \\
(15.03)\end{array}$ \\
\hline IRL & $\begin{array}{c}0.074 \\
(0.28)\end{array}$ & $\begin{array}{l}0.321 \\
(1.48)\end{array}$ & $\begin{array}{l}0.485 \\
(0.89)\end{array}$ & $\begin{array}{l}0.126 \\
(0.28)\end{array}$ \\
\hline ITA & $\begin{array}{c}-0.365^{a} \\
(-3.44)\end{array}$ & $\begin{array}{l}-0.260 \\
(-1.50)\end{array}$ & $\begin{array}{c}-0.427^{a} \\
(-3.04)\end{array}$ & $\begin{array}{c}-0.206 \\
(-1.17)\end{array}$ \\
\hline JPN & $\begin{array}{c}0.832^{a} \\
(3.96)\end{array}$ & $\begin{array}{c}0.713^{a} \\
(3.25)\end{array}$ & $0.681^{a}$ & $\begin{array}{c}0.655^{a} \\
(4.55)\end{array}$ \\
\hline $\mathrm{KOR}$ & $\begin{array}{l}0.626 \\
(0.52)\end{array}$ & $\begin{array}{l}2.914^{a} \\
(4.16)\end{array}$ & $\begin{array}{l}1.006 \\
(1.26)\end{array}$ & $\begin{array}{l}2.237^{a} \\
(4.60)\end{array}$ \\
\hline NLD & $\begin{array}{c}0.832^{a} \\
(2.65)\end{array}$ & $\begin{array}{c}0.644^{c} \\
(1.93)\end{array}$ & $\begin{array}{c}0.523^{c} \\
(1.92)\end{array}$ & $\begin{array}{l}0.412 \\
(1.10)\end{array}$ \\
\hline NOR & $\begin{array}{c}1.138^{a} \\
(7.26)\end{array}$ & $\begin{array}{c}1.004^{a} \\
(9.81)\end{array}$ & $\begin{array}{l}2.080^{a} \\
(14.42)\end{array}$ & $\begin{array}{l}2.056^{a} \\
(13.51)\end{array}$ \\
\hline SWE & $\begin{array}{c}0.364^{b} \\
(2.24)\end{array}$ & $\begin{array}{c}0.329^{a} \\
(3.52)\end{array}$ & $\begin{array}{l}1.073^{a} \\
(5.85)\end{array}$ & $\begin{array}{l}0.915^{a} \\
(7.16)\end{array}$ \\
\hline USA & $\begin{array}{l}0.486 \\
(1.37) \\
\end{array}$ & $\begin{array}{c}0.699^{a} \\
(3.27)\end{array}$ & $\begin{array}{l}0.571 \\
(0.90) \\
\end{array}$ & $\begin{array}{c}0.804^{b} \\
(2.07)\end{array}$ \\
\hline EU-12 & $\begin{array}{c}0.590^{a} \\
(9.65)\end{array}$ & $\begin{array}{c}0.599^{a} \\
(11.84)\end{array}$ & $\begin{array}{c}0.890^{a} \\
(26.17)\end{array}$ & $\begin{array}{c}0.832^{a} \\
(16.18)\end{array}$ \\
\hline Whole sample & $\begin{array}{c}0.586^{a} \\
(11.63)\end{array}$ & $\begin{array}{c}0.800^{a} \\
(16.86)\end{array}$ & $\begin{array}{c}0.853^{a} \\
(24.52)\end{array}$ & $\begin{array}{c}0.933^{a} \\
(28.55)\end{array}$ \\
\hline
\end{tabular}

Notes: Data coverage: 1970-2007 (except Japan: 1974-2007). All regressions include country fixed effects, time dummies and country specific trends. ${ }^{a},{ }^{b}$ and ${ }^{c}$ denote significance at $1 \%, 5 \%$ and $10 \%$ levels. Heteroskedasticity and autocorrelation consistent t-statistics are reported in parentheses.

consider FMOLS estimates when exploring the empirical relationship (40); running regression (40) gives an estimate for the whole sample of 0.800 which is close to the value documented by Mendoza [1995] who reports an estimate of 0.74. As shown in Table 9, the estimated value of $\phi$ for Belgium is statistically significant only when exploring the empirical relationship (41) for this economy; in column 1 of Table 8, we set $\phi$ to 0.749 for Belgium. Because estimates for Italy are negative by using alternatively eq. (40) or eq. (41), the estimate of $\phi$ for this country is left blank in column 1 of Table 8 and $\phi$ is set to our panel data estimation for EU-12, i.e., 0.599, when calibrating the model for each country.

\section{B.3 Labor Market Variables}

We now describe the data employed to calibrate the model, focusing on labor market variables. To begin with, EU-10 refers to the following ten European countries: Austria, Belgium, Germany, Denmark, Spain, Finland, the United Kingdom, Ireland, Italy, Sweden; EU-12 includes EU-10 along with France and the Netherlands.

We construct the following labor market variables:

- Sectoral unemployment rate denoted by $u^{j}(j=T, N)$ is the number of unemployed workers $U^{j}$ in sector $j$ as a share of the labor force $F^{j} \equiv L^{j}+U^{j}$ in this sector. LABORSTA database from ILO provides series for unemployed workers by economic activity for fifteen OECD countries out of eighteen in our sample. The longest available period ranges from 1987 to 2007. On average, our data covers 12.8 years per country. Series cover 18 sectors, according to ISIC Rev.3.1 classification. To construct $L^{j}$ and $U^{j}$ for $j=T, N$, we map the classifica- 
tion used previously to compute series for sectoral wages, prices and real labor productivity indexes (see section A) into the 1-digit ISIC-rev.3 classification. The mapping was clear for all industries except for "Not classifiable by economic activity" (1-digit ISIC-Rev.3, code: X) when constructing $L^{j}$ and $U^{j}$, and, "Unemployed seeking their first job" to identify $U^{j}$. These two categories have been split between tradables and non tradables according to the shares of total unemployment (excluding the two categories) between tradables and non tradables by year and country. In a few rare cases, the sum of sectoral employment provided by ILO did not correspond to total unemployment. These differences were usually due to missing data for some industries in the sectoral databases. In these cases, we added these differences in level, keeping however the share of each sector constant. In Table 10 we provide an overview of the classifications used to construct traded and non traded sectors variables. Once industries have been classified as traded or non traded, series for unemployed and employed workers are constructed by adding unemployed and employed workers of all sub-industries $k$ in sector $j=T, N$ in the form $U^{j}=\sum_{k \in j} U_{k}$ and $L^{j}=\sum_{k \in j} L_{k}$. Data coverage: AUS (1995-2007), AUT (1994-2007), BEL (2001-2007), CAN (1987-2007), DEU (1995-2007), DNK (1994-1998 and 2002-2004), ESP (1992-2007), FIN (1995-2007), GBR (1988-2007), IRL (1986-1997), ITA (1993-2007), JPN (2003-2007), KOR (1992-2007), SWE (1995-2007) and USA (2003-2007). Data for unemployed workers by economic activity are not available for FRA, NLD and NOR.

- Sectoral labor market tightness denoted by $\theta^{j}(j=T, N)$ is calculated as the ratio of job vacancies in sector $j\left(V^{j}\right)$ to the number of unemployed workers in that sector $\left(U^{j}\right)$. To construct $\theta^{j}$, we collect information on job vacancies and unemployed workers by economic activity. Sources for $V^{j}$ : Job Openings and Labor Turnover Survey (JOLTS) provided by the Bureau of Labor Statistics (BLS) for USA, Eurostat database (NACE 1-digit) for a range of European Countries, Labour Market Statistics from the Office for National Statistics for the UK. Sources for $U^{j}$ : Current Population Survey (CPS) published by the BLS for USA and LABORSTA (ILO) for European Countries. ${ }^{57}$ As shown in Table 10, the level of detail in the definition of traded and non traded sectors differs across databases in two dimensions. First, the number of items to split disaggregated data varies across nomenclatures from a low eleven categories in the Eurostat database to a high of eighteen items in the LABORSTA database. Second, the definitions of items are not harmonized across the different sets of data. To generate sectoral variables in a consistent and uniform way, series on disaggregated data for vacancies and unemployed workers are added up to form traded and non traded sectors following, as close as possible, the classification we used for value added, hours worked and labor compensation. Once industries have been classified as traded or non traded, series for employment vacancies (unemployed workers resp.) are constructed by adding job openings (unemployed workers resp.) of all sub-industries $k$ in sector $j=T, N$ in the form $V^{j}=$ $\sum_{k \in j} V_{k}\left(U^{j}=\sum_{k \in j} U_{k}\right.$ resp.). Data coverage for $V^{j}$ and $U^{j}$ : AUT (2004-2005), DEU (2006-2007), FIN (2002-2007), GBR (2001-2007), SWE (2005-2007) and USA (2001-2007).

- Aggregate labor market tightness denoted by $\theta$ is also computed because series for $\theta^{j}$ are available over a too short time horizon and for a few countries only; $\theta$ is calculated as the ratio of job vacancies to registered unemployment. Source: Registered Unemployed and Job Vacancies Dataset, OECD. Coverage: AUS (1980-2007), BEL (1982-2003), DEU (1980-2007), ESP (1980-2004), FIN (1981-2007), GBR (1980-2007), NOR (1980-2007), SWE (1982-2007).

- Job finding rate denoted by $m^{j}(j=T, N)$ is computed at a sectoral level by adopting the methodology proposed by Shimer [2012]. As Shimer [2012], we ignore movements in and out of the overall labor force. Since we compute the job finding rate for the traded and the non traded sector, we have to further assume that labor force is fixed at a sectoral level, i.e., we ignore reallocation of labor across sectors. More details on the model and the derivation of the results below can be found in the Technical Appendix. The monthly job finding rate $m^{j,<1}(t)$ for sector $j$ at time $t$ is computed as follows:

$$
m^{j,<1}(t)=-\ln \left(1-M^{j,<1}(t)\right),
$$

where $t$ indexes months and the probability of finding a job $M^{j,<1}$ within one month is given by

$$
M^{j,<1}(t)=1-\left[\frac{\left(1-\alpha^{<1}(t)\right) U^{j}(t)}{U^{j}(t-1)}\right],
$$

with $\alpha^{j,<1}(t)=\frac{U^{j,<1}(t)}{U^{j}(t)}$ the share of unemployment less than one month $\left(U^{j,<1}(t)\right)$ among total monthly unemployment $\left(U^{j}(t)\right)$ in sector $j$. Source: LABORSTA database from ILO for

\footnotetext{
${ }^{57}$ The JOLTS and CPS databases provide (not seasonally adjusted) monthly data on vacancies and unemployed workers. We convert monthly data series into annual data series by summing the twelve monthly data points.
} 
data on employment and unemployment at the sectoral level, and, OECD for unemployment by duration.

- Job destruction rate denoted by $s^{j}(j=T, N)$ is estimated by solving this equation:

$$
U^{j}(t)=\psi^{j}(t) \frac{s^{j}(t)}{s^{j}(t)+m^{j,<1}(t)}\left(U^{j}(t)+L^{j}(t)\right)+\left(1-\psi^{j}(t)\right) U^{j}(t-1),
$$

where $\psi^{j}$ is the monthly rate of convergence to the long-run sectoral unemployment rate:

$$
\psi^{j}(t)=1-e^{-\left(s^{j}(t)+m^{j,<1}(t)\right)} .
$$

When estimating $s^{j}$ by using (44), the unemployment rate has not necessarily reached its longrun equilibrium. Since we calibrate the model so that the initial steady state is consistent with the empirical properties of each OECD economy, we have computed values for $s^{j}$ which are consistent with the steady-state sectoral unemployment rate $u^{j}=\frac{s^{j}}{s^{j}+m^{j}}$ where $u^{j}$ is the actual value taken from the data and $m^{j}$ is computed by using (42). Reassuringly, average values for job destruction rates obtained from eq. (44) are close to those derived from the long-run equilibrium of the unemployment rate. More details can be found in the Technical Appendix.

- Unemployment benefit net replacement rate denoted by $\varrho$ is shown in column 14 of Table 6 and is defined in section A. Replacement rates are averaged over 1980-2007 for all countries except Korea (2001-2007). Average EU-12 unemployment benefit replacement rate shown in Table 6 is the unweighted average of twelve EU members' replacement rates. Source: OECD, Benefits and Wages Database.

- Firing cost denoted by $\tau$ is shown in the last column of Table 6 is a measure of the strictness of legal protection against dismissals captured by the firing tax $x=\tau . W$ in our model; it is calculated as the sum of the average advance notice and average severance payment after 4 and 20 years of employment. $\tau$ is expressed in monthly salary equivalents and is averaged over the period 1980-2005. Source: Fondazione de Benedetti.

Series of employment and unemployment by economic activity provided by ILO are not available for France, the Netherlands, Norway; while such data is available for Korea, unemployment by duration provided by the OECD is not available and thus prevents the estimation of the monthly job finding and job destruction rates. For these four countries, we proceeded as follows:

- Monthly job finding rates denoted by $m$ come from Hobijn and Sahin [2009] who give average values for France (1975-2004), the Netherlands (1983-2004), Norway (1983-2004). For Korea, we average the job finding rates taken from Chang et al. [2004] over 1993-1994.

- Unemployment rate denoted by $u$ is is the number of unemployed people as a percentage of the labor force. Coverage: FRA (1975-2004), the NLD (1983-2004), NOR (1983-2004). Source: OECD, LFS database.

- Monthly job separation rate denoted by $s$ is computed so as to be consistent with the steady-state unemployment rate given by $u=\frac{s}{s+m}$.

\section{References}

Chang, Yongsung, Jaeryang Nam, and Changyong Rhee (2004) Trends in Unemployment Rates in Korea: A Search-Matching Model Interpretation. Journal of the Japenese and the International Economies, 18(2), pp. 241-263.

International Monetary Fund (2011), Government Finance Statistics Yearbook, IMF, Washington D.C.

Mendoza, Enrique, G. (1995) The Terms of Trade, Real Exchange Rate and Economic Fluctuations. International Economic Review, 36, pp. 101-137.

Organization for Economic Cooperation and Development (2012), Input-Output Database, OECD, Paris.

Organization for Economic Cooperation and Development (2012), National Accounts: General Government Accounts, OECD, Paris.

Organization for Economic Cooperation and Development (2011), Structural Analysis Database, OECD, Paris.

Organization for Economic Cooperation and Development (2013), Annual National Accounts, OECD, Paris.

United Nations Statistics Division (2011) Classification of individual consumption by purpose. 


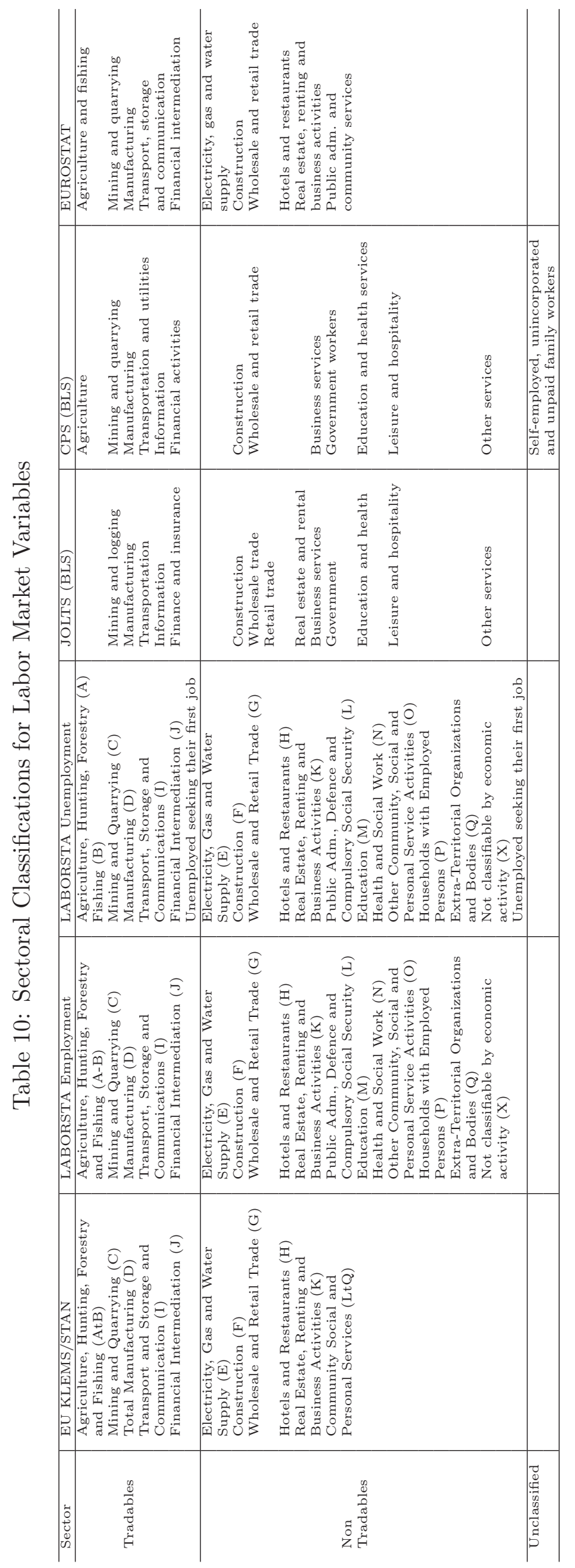




\title{
RELATIVE PRODUCTIVITY AND SEARCH UNEMPLOYMENT IN AN OPEN ECONOMY
}

\author{
TECHNICAL APPENDIX
}

NOT MEANT FOR PUBLICATION

- Section A presents the source and construction of the data used in the empirical and quantitative analysis, and provides summary statistics as well.

- Section B starts with a quick look at the data and provides additional empirical results related to panel unit root and cointegration tests and shows alternative cointegration estimates as well. The section also gives more details and results on the split-sample analysis.

- Sections C-E give more details on the model. Section C develops an open economy version of the neoclassical model with search frictions and sectoral endogenous labor supply, and derives first-order conditions. Section D presents the matching process and derives the Nash bargaining wage. Section $\mathrm{E}$ sets out the approach taken to solve the model, analyzes equilibrium dynamics, and provides formal solutions.

- Section F provides the main steps leading to equations in the main text of section 2.1.

- Section G characterizes the initial steady-state and the transitional paths by using phase diagrams.

- In section $\mathrm{H}$, we derive analytically the steady-state effects of higher productivity in tradables relative to non tradables and investigate the adjustment along the stable path by using phase diagrams whose constructions are presented in section G. In section I, we describe the graphical framework which allows us to characterize initial steady-state values for the relative wage and the relative price.

- In section J, we decompose analytically the steady-state changes in the relative wage and the relative price following higher relative productivity of tradables. In section L, we break down the change in the unemployment rate differential into labor market frictions and labor accumulation effects.

- In section K, we analyze graphically the long-term adjustment in the relative price, the relative wage, and the unemployment differential following a productivity shock biased toward the traded sector and investigate the implications of labor market regulation.

- In section M, we explore the case of total immobility and perfect mobility as well in order to highlight the role of the elasticity of the labor supply at the extensive margin.

- Section $\mathrm{N}$ gives more details about the calibration of the model to data. 


\section{A Data Description}

\section{A.1 Data for Empirical Analysis: Source and Construction}

Country Coverage: Our sample consists of a panel of 18 countries: Australia (AUS), Austria (AUT), Belgium (BEL), Canada (CAN), Germany (DEU), Denmark (DNK), Spain (ESP), Finland (FIN), France (FRA), the United Kingdom (GBR), Ireland (IRL), Italy (ITA), Japan (JPN), Korea (KOR), the Netherlands (NLD), Norway (NOR), Sweden (SWE), and the United States (USA). These countries have the most extensive coverage of variables of our interest.

Period Coverage: The period is running from 1970 to 2007, except for Japan (1974-2007).

Sources: We use the EU KLEMS [2011] database (the March 2011 data release) for all countries of our sample with the exceptions of Canada and Norway. For these two countries, sectoral data are taken from the Structural Analysis (STAN) database provided by the OECD [2011]. Both the EU KLEMS and STAN databases provide annual data at the ISIC-rev.3 1-digit level for eleven industries.

The eleven 1-digit ISIC-rev.3 industries are split into tradables and non tradables sectors. To do so, we adopt the classification proposed by De Gregorio et al. [1994] who treat an industry as traded when it exports at least $10 \%$ of its output. Following Jensen and Kletzer [2006], we have updated the classification suggested by De Gregorio et al. [1994] by treating "Financial Intermediation" as a traded industry. Jensen and Kletzer [2006] use the geographic concentration of service activities within the United States to identify which service activities are traded domestically. The authors classify activities that are traded domestically as potentially traded internationally. The idea is that when a good or a service is traded, the production of the activity is concentrated in a particular region to take advantage of economies of scale in production.

Jensen and Kletzer [2006] use the two-digit NAICS (North American Industrial Classification System) to identify tradable and non tradable sectors. We map their classification into the NACEISIC-rev.3 used by the EU KLEMS database. The mapping was clear for all sectors except for "Real Estate, Renting and Business Services". According to the EU KLEMS classification, the industry labelled "Real Estate, Renting and Business Services" is an aggregate of five sub-industries: "Real estate activities" (NACE code: 70), "Renting of Machinery and Equipment" (71), "Computer and Related Activities" (72), "Research and Development" (73) and "Other Business Activities" (74). While Jensen and Kletzer [2006] find that industries 70 and 71 can be classified as tradable, they do not provide information for industries 72, 73 and 74. We decided to classify "Real Estate, Renting and Business Services" as non tradable.

Traded Sector comprises the following industries: Agriculture, Hunting, Forestry and Fishing; Mining and Quarrying; Total Manufacturing; Transport, Storage and Communication; and Financial Intermediation.

Non Traded Sector comprises the following industries: Electricity, Gas and Water Supply; Construction; Wholesale and Retail Trade; Hotels and Restaurants; Real Estate, Renting and Business Services; and Community Social and Personal Services.

Relevant to our work, the EU KLEMS and STAN database provides series, for each industry and year, on value added at current and constant prices, permitting the derivation of sectoral deflators of value added, as well as details on labor compensation and employment data, allowing the construction of sectoral wage rates. We describe below the construction for the data employed in Section 2 (mnemonics are given in parentheses):

- Sectoral value-added deflator $P_{t}^{j}$ for $j=T, N$ : value added at current prices (VA) over value added at constant prices (VA_QI) in sector $j$. Source: EU KLEMS database. The relative price of non tradables $P_{t}$ corresponds to the ratio of the value added deflator of non traded goods to the value added deflator of traded goods: $P_{t}=P_{t}^{N} / P_{t}^{T}$.

- Sectoral labor $L_{t}^{j}$ for $j=T, N$ : total hours worked by persons engaged (H_EMP) in sector $j$. Source: EU KLEMS database.

- Sectoral nominal wage $W_{t}^{j}$ for $j=T, N$ : labor compensation in sector $j$ (LAB) over total hours worked by persons engaged (H_EMP) in that sector. Source: EU KLEMS database. The relative wage, $\Omega_{t}$ is calculated as the ratio of the nominal wage in the non traded sector $W^{N}$ to the nominal wage in the traded sector: $\Omega_{t}=W_{t}^{N} / W_{t}^{T}$.

- The construction of sectoral unemployment rates is detailed below in section A.2.

Because data source and construction are heterogenous across variables as a result of different nomenclatures, Table 11 provides a summary of the classification adopted to split value added and its demand components as well into traded and non traded goods.

Summary statistics of the data used in the empirical analysis are displayed in Table 12. As shown in the first three columns, all countries of our sample experience higher productivity gains in tradables relative to non tradables, an appreciation in the relative price of non tradables (except for Norway) and a decline in the ratio of the non traded wage relative to the traded wage. 


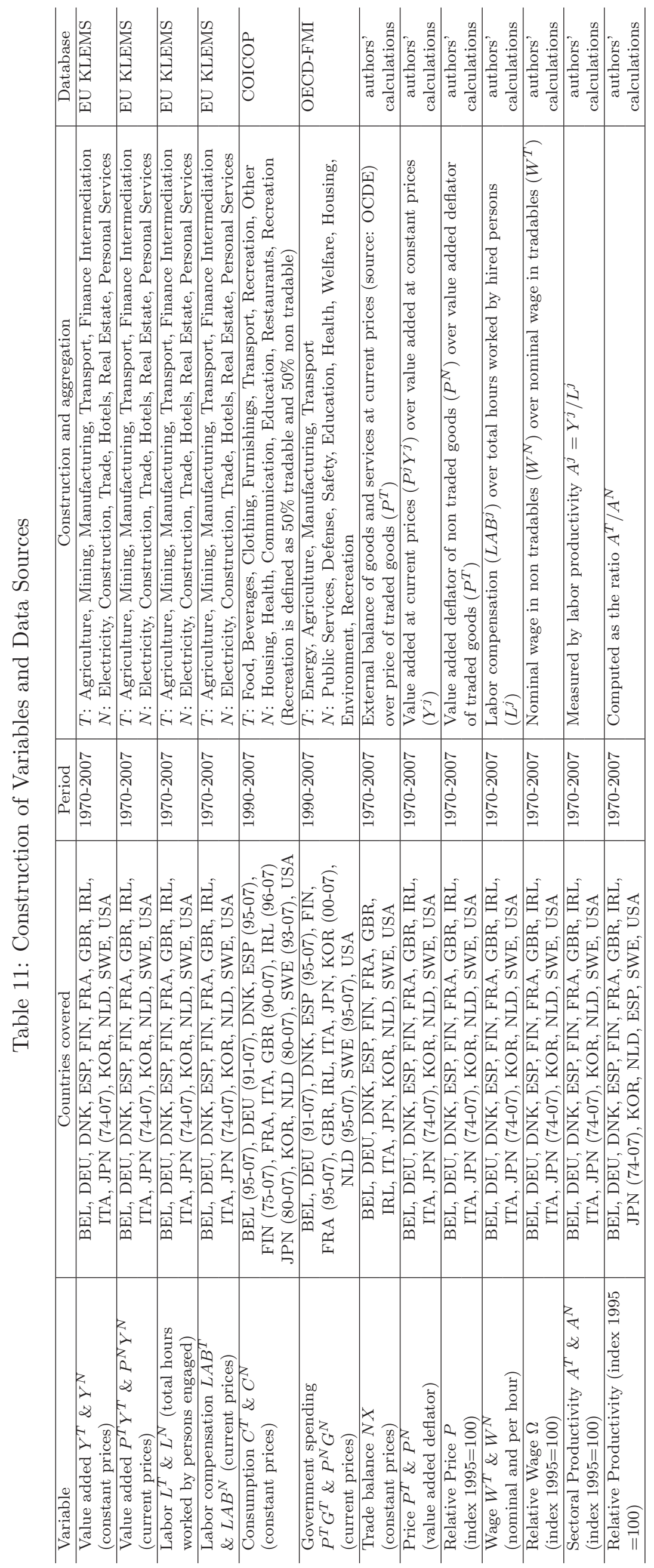


To empirically assess the role of labor market institutions in the determination of the relative wage response to higher productivity in tradables relative to non tradables, we use three indicators aimed at capturing the stringency of labor market regulation. We detail below the construction and the source of these three indicators:

- The strictness of legal protection against dismissals for permanent workers is measured by the employment protection legislation index, $\mathrm{EPL}_{i, t}$ in country $i$ at time $t$, provided by OECD. Source for $\mathrm{EPL}_{i, t}$ : OECD Labour Market Statistics database. Data coverage: 1985-2007 (1990-2007 for KOR). This index can be misleading since regulation was eased for temporary contracts (in Spain) while the regulation for workers with permanent contracts hardly changed. To have a more accurate measure of legal protection against dismissals, we construct a new index denoted by $\operatorname{EPLadj}_{i, t}$ in country $i$ at time $t$ by adjusting $\mathrm{EPL}_{i, t}$ for regular workers with the share share $\operatorname{perm}_{i, t}$ of permanent workers in the economy, i.e., $\operatorname{EPLadj}_{i, t}=\mathrm{EPL}_{i, t} \times$ share perm $_{i, t}$. Source for share perm ${ }_{i, t}:$ OECD Labour Market Statistics database. Data coverage: 1985-2007 (1990-2007 for KOR).

- The generosity of the unemployment benefit scheme, $\varrho_{i, t}$ in country $i$ at time $t$, is commonly captured by the unemployment benefit replacement rate. It is worthwhile noticing that the unemployment benefit rates are very similar across counties when considering shortterm unemployment (less than one year) but display considerable heterogeneity for long-term unemployment. To have a more accurate measure of the generosity of the unemployment benefit scheme, we calculate $\varrho$ as the average of the net unemployment benefit (including social assistance and housing benefit) replacement rates (for two earnings levels and three family situations) for three durations of unemployment ( 1 year, $2 \& 3$ years, $4 \& 5$ years). Source: OECD, Benefits and Wages Database. Data coverage: 2001-2007. In order to have longer time series, we calculated $\varrho$ over the period running from 1970 to 2000 , by using the growth rate of the historic OECD measure of benefit entitlements which is defined as the average of the gross unemployment benefit replacement rates for two earnings levels, three family situations and three durations of unemployment. Source: OECD, Benefits and Wages Database. Data coverage: 1970-2001 for all countries while data are unavailable for Korea.

- The worker bargaining power is measured by the collective bargaining coverage, $\mathrm{BargCov}_{i, t}$, which corresponds to the employees covered by collective wage bargaining agreements as a proportion of all wage and salary earners in employment with the right to bargaining. Source: Data Base on Institutional Characteristics of Trade Unions, Wage Setting, State Intervention and Social Pacts, 1960-2010 (ICTWSS), version 3.0, Jelle Visser [2009]. Data coverage: 19702007 for AUS, AUT, CAN, DEU, DNK, FIN, GBR, IRL, ITA, JPN, SWE and USA, 1970-2005 for NLD and NOR, 1970-2002 for BEL and FRA, 1977-2004 for ESP and 2002-2006 for KOR.

Summary statistics of the labor market regulation indicators used in the empirical analysis are displayed in the three last columns Table 12.

\section{A.2 Calibration of the Labor Market}

To calibrate the labor market for the traded and the non traded sector, we need to estimate the sectoral unemployment rate, the job finding and the job destruction rate for each sector, and the sectoral labor market tightness. We provide below the source and construction of the data.

\section{A.2.1 Source and Construction of Data}

In this subsection, we first describe the data employed to calibrate some key features of OECD labor markets. Then, we present the dataset we use to estimate a set of sectoral search unemployment parameters. Summary statistics for the key indicators of the labor market are displayed in Table 13.

- Sectoral unemployment rate, $u^{j}$, is the number of unemployed workers $U^{j}$ in sector $j=T, N$ as a share of the labor force $L^{j}+U^{j}$ in this sector. LABORSTA database from the International Labour Organization (ILO) provides annual data for unemployed and employed workers at the 1-digit ISIC-rev.3 level. To construct $L^{j}$ and $U^{j}$ for $j=T, N$, we map the classification used previously to compute series for sectoral wages, prices and real labor productivity indexes (see section A.1) into the 1-digit ISIC-rev.3 classification used by the LABORSTA database. The mapping was clear for all industries except for "Not classifiable by economic activity" (1-digit ISIC-Rev.3 code: X) when constructing $L^{j}$ and $U^{j}$, and, "Unemployed seeking their first job" to identify $U^{j}$. These two categories have been split between tradables and non tradables according to the shares of total unemployment (excluding the two sectors) between tradables and non tradables by year and country. In a few rare 
Table 12: Summary Statistics per Country

\begin{tabular}{l|c|c|c|c|c|c}
\hline \multirow{2}{*}{ Countries } & \multicolumn{7}{|c}{ Variables } \\
\cline { 2 - 7 } & $\hat{p}$ & $\hat{\omega}$ & $\hat{a}^{T}-\hat{a}^{N}$ & $\varrho$ & BargCov & EPL $_{\text {adj }}$ \\
& $(1)$ & $(2)$ & $(3)$ & $(4)$ & $(5)$ & $(6)$ \\
\hline AUS & 0.91 & -0.27 & 1.83 & 0.50 & 0.71 & 1.21 \\
AUT & 1.97 & -0.72 & 2.89 & 0.50 & 0.97 & 2.48 \\
BEL & 2.26 & -0.04 & 2.53 & 0.67 & 0.94 & 1.65 \\
CAN & 0.54 & -0.42 & 1.55 & 0.54 & 0.36 & 0.81 \\
DEU & 0.85 & -0.62 & 1.62 & 0.72 & 0.69 & 2.36 \\
DNK & 0.78 & -0.91 & 2.21 & 0.61 & 0.82 & 1.93 \\
ESP & 2.62 & -0.97 & 3.67 & 0.41 & 0.76 & 2.04 \\
FIN & 2.56 & -0.78 & 4.22 & 0.59 & 0.86 & 2.02 \\
FRA & 2.14 & -0.98 & 2.68 & 0.47 & 0.85 & 2.11 \\
GBR & 1.57 & -0.50 & 2.31 & 0.63 & 0.45 & 1.02 \\
IRL & 2.55 & -0.88 & 4.37 & 0.54 & 0.58 & 1.32 \\
ITA & 2.02 & -0.92 & 3.05 & 0.08 & 0.83 & 2.53 \\
JPN & 2.60 & -0.44 & 2.68 & 0.51 & 0.24 & 1.49 \\
KOR & 3.35 & -2.15 & 6.49 & 0.38 & 0.11 & 1.98 \\
NLD & 1.86 & -0.39 & 2.38 & 0.67 & 0.85 & 2.60 \\
NOR & -0.37 & -0.39 & 1.96 & 0.43 & 0.70 & 2.06 \\
SWE & 2.34 & -0.11 & 2.76 & 0.48 & 0.89 & 2.31 \\
USA & 1.74 & -0.23 & 2.64 & 0.26 & 0.20 & 0.24 \\
Average & 1.79 & -0.65 & 2.88 & 0.50 & 0.66 & 1.79 \\
\hline NOt & &
\end{tabular}

Notes: $\hat{p}$ is the relative price of non tradables average growth rate, $\hat{\omega}$ is the relative wage of non tradables average growth rate and $\left(\hat{a}^{T}-\hat{a}^{N}\right)$ is the average growth rate of the labor productivity differential between tradables and non tradables. Data coverage for $\hat{p}, \hat{\omega}$ and $\left(\hat{a}^{T}-\hat{a}^{N}\right)$ is $1970-2007$ (1974-2007 for Japan). $\varrho$ is the unemployment benefit replacement rate. Data coverage: 1970-2007 (2001-2007 for KOR). BargCov is the collective bargaining coverage. Data coverage: 1970-2007 for AUS, AUT, CAN, DEU, DNK, FIN, GBR, IRL, ITA, JPN, SWE and USA, 1970-2005 for NLD and NOR, 1970-2002 for BEL and FRA, 1977-2004 for ESP and 2002-2006 for $\mathrm{KOR}$. $\mathrm{EPL}_{a d j}$ is the employment protection legislation index adjusted with the share of permanent workers in the economy. Data coverage: 1985-2007 (1990-2007 for KOR).

cases, the sum of sectoral employment provided by ILO did not correspond to total unemployment. These differences were usually due to missing data for some industries in the sectoral databases. In these cases, we added these differences in level, keeping however the share of each sector constant. In Table 13 we provide a overview of the classifications used to construct traded and non traded sectors variables. Once industries have been classified as traded or non traded, series for unemployed and employed workers are constructed by adding unemployed and employed workers of all sub-industries $k$ in sector $j=T, N$ in the form $U^{j}=\sum_{k \in j} U_{k}$ and $L^{j}=\sum_{k \in j} L_{k}$. Data coverage: AUS (1995-2007), AUT (1994-2007), BEL (2001-2007), CAN (1987-2007), DEU (1995-2007), DNK (1994-1998 and 2002-2004), ESP (1992-2007), FIN (1995-2007), GBR (1988-2007), IRL (1986-1997), ITA (1993-2007), JPN (2003-2007), KOR (1992-2007), SWE (1995-2007) and USA (2003-2007). Data for unemployed workers by economic activity are not available for FRA, NLD and NOR.

- Labor market tightness, $\theta^{j}$ for $j=T, N$, is calculated as the ratio of employment vacancies in sector $j\left(V^{j}\right)$ to the number of unemployed workers in that sector $\left(U^{j}\right)$. To construct the variables $\theta^{j}$, we collect information on job vacancies and unemployed workers by economic activity. Sources for $V^{j}$ : Job Openings and Labor Turnover Survey (JOLTS) provided by the Bureau of Labor Statistics (BLS) for USA and Eurostat database (NACE 1-digit) for a range of European Countries, Labour Market Statistics from the Office for National Statistics for the UK. Sources for $U^{j}$ : Current Population Survey (CPS) published by the BLS for USA and LABORSTA (ILO) for European Countries. ${ }^{58}$ As shown in Table 13, the level of detail in the definition of traded and non traded sectors differs across databases in two dimensions. First, the number of items to split disaggregated data varies across nomenclatures from a low eleven categories in the Eurostat database to a high of eighteen items in the LABORSTA

\footnotetext{
${ }^{58}$ The JOLTS and CPS databases provide (not seasonally adjusted) monthly data on vacancies and unemployed workers. We convert monthly data series into a annual data series by summing the twelve monthly data points.
} 
database. Second, the definitions of items are not harmonized across the different sets of data. To generate sectoral variables in a consistent and uniform way, series on disaggregated data for vacancies and unemployed workers are added up to form traded and non traded sectors following, as close as possible, the classification we used for value added, hours worked and labor compensation. Once industries have been classified as traded or non traded, series for employment vacancies (unemployed workers resp.) are constructed by adding job openings (unemployed workers resp.) of all sub-industries $k$ in sector $j=T, N$ in the form $V^{j}=$ $\sum_{k \in j} V_{k}$ (U $U^{j}=\sum_{k \in j} U_{k}$ resp.). Data coverage for $V^{j}$ and $U^{j}$ : AUT (2004-2005), DEU (2006-2007), FIN (2002-2007), GBR (2001-2007), SWE (2005-2007) and USA (2001-2007).

For reason of space, Table 13 does not provide the classification between tradables and non tradables for job vacancies for the United Kingdom. The classification is detailed below. The Office for National Statistics provides series for the UK that cover 19 sectors, according to SIC 2007 classification. Sectors have been aggregated into tradables (Financial and insurance activities; Information and communication; Manufacturing; Mining and quarrying; Transport and storage) and non tradables (Accomodation and food service activities; Administrative and support service activities; Arts, entertainment and recreation; Construction; Education; Electricity, gas, steam and air conditioning supply; Human health and social work activities; Other service activities; Public administration and defense; Compulsory social security; Real estate activities; Water supply, sewerage, waste and remediation activities; Wholesale and retail trade; repair of motor vehicles and motor cycles).

\section{A.2.2 The Methodology}

In this section, we present the approach we adopted to measure the job finding and employment exit rates by using readily accessible data. We apply the methodology developed by Shimer [2012] who assume that the labor force is fixed. Applying the same logic to our two-sector model, we need to impose that the labor force $F^{j}$ is fixed at a sectoral level. The implication of such an assumption is twofold. First, we explicitly assume that there are no movements into and out of the labor force at an aggregate level. Second, we assume that there are no movements between the traded and the non traded sectors. Reassuringly, Shimer [2012] shows that a two-state model where workers simply transit between employment and unemployment does a good job of capturing unemployment fluctuations. Because the reallocation of labor across sectors is relatively low, the second assumption should not substantially affect the results. In particular, Shimer [2012] finds that the job finding rate to worker averaged 0.44 over the post-war period for the U.S., while our own estimates indicate that the job finding rate averages about 0.40 from 2003 to 2007.

The presentation below borrows heavily from Elsby, Hobijn, and Sahin [2013]. We assume that during period $t$, all unemployed workers find a job according to a Poisson process with arrival rate $m^{j}(t)=-\ln \left(1-M^{j}(t)\right)$ and all employed workers lose their job according to a Poisson process with arrival rate $s^{j}(t)=-\ln \left(1-S^{j}(t)\right)$. We refer to $m^{j}(t)$ and $s^{j}(t)$ as the job finding and job destruction rates in sector $j$ and to $M^{j}(t)$ and $S^{j}(t)$ as the corresponding probabilities.

The evolution over time of the unemployed workers, which we denote by $U^{j}(t)$, can be written as:

$$
\dot{U}^{j}(t)=s^{j}(t) L^{j}(t)-m^{j}(t) U^{j}(t)
$$

where $L^{j}(t)$ is employment in sector $j$; the evolution over time of the unemployed workers can be written alternatively by using the fact that $L^{j}(t)=F^{j}-U^{j}(t)$ :

$$
\dot{U}^{j}(t)=s^{j}(t)\left(F^{j}-U^{j}(t)\right)-m^{j}(t) U^{j}(t)
$$

where $s^{j}(t)$ is the monthly rate of inflow into unemployment, $m^{j}(t)$ is the monthly outflow rate from unemployment, and $t$ indexes months.

Collecting terms, assuming that the job destruction rate and the job finding rate are constant within years and solving eq. (47), pre-multiplying by $e^{-(m+s) \tau}$, and integrating over the time interval $[t-12, t]$, leads to the temporal path for unemployed workers:

$$
U^{j}(t)=\psi^{j}(t) \tilde{u}^{j}(t) F^{j}(t)+(1-\psi(t)) U^{j}(t-12),
$$

where $\tilde{u}^{j}$ is the long-run unemployment rate in sector $j$ :

$$
\tilde{u}^{j}(t)=\frac{s^{j}(t)}{s^{j}(t)+m^{j}(t)},
$$

and $\psi^{j}$ is the annual rate of convergence to the long-run sectoral unemployment rate:

$$
\psi^{j}(t)=1-e^{-\left(s^{j}(t)+m^{j}(t)\right) 12} .
$$




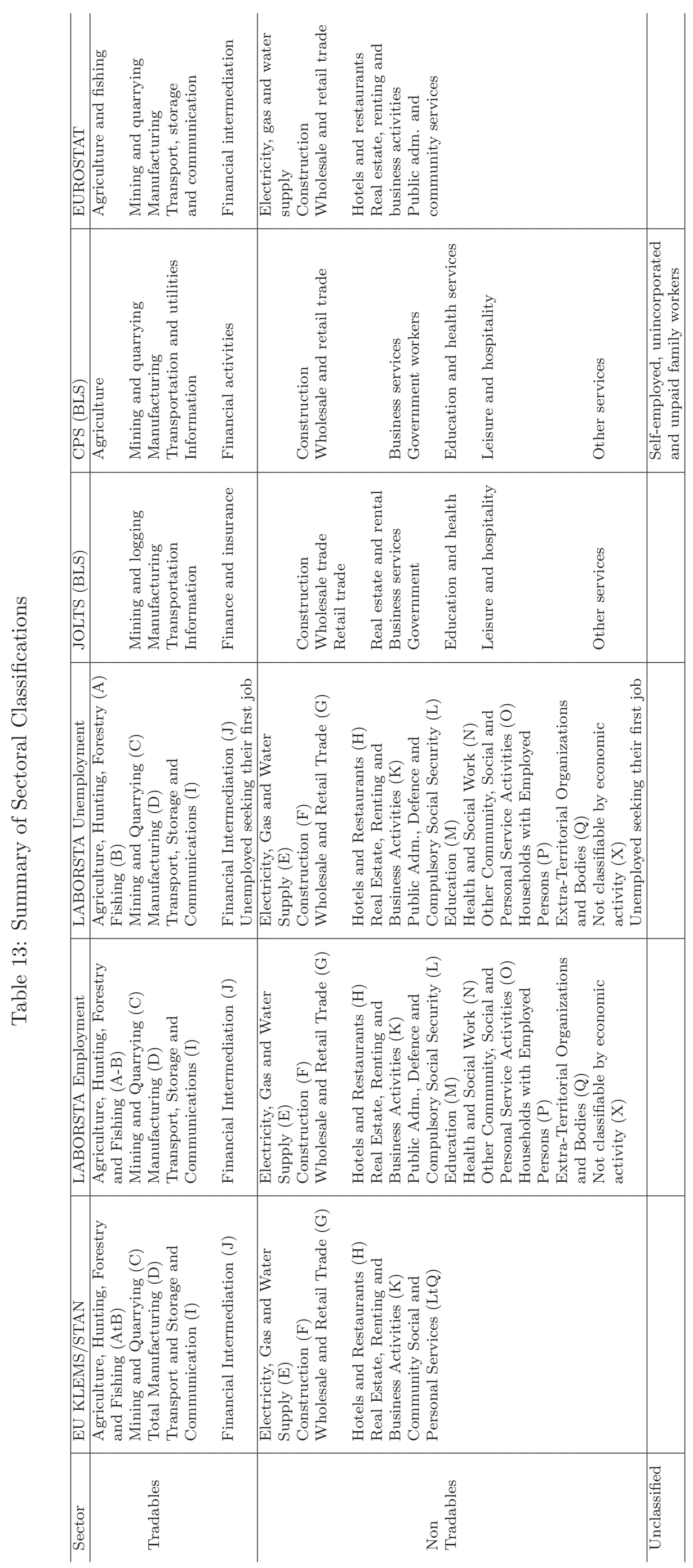


To infer the monthly outflow probability $M^{j}(t)$ and then the monthly job finding rate $m^{j}(t)$, we follow Shimer [2012] and write the dynamic equations of sectoral unemployment and sectoral short term unemployment, i.e.,

$$
\begin{gathered}
\dot{U}^{j}(t+d)=s^{j}(t) L^{j}(t)-m^{j}(t) U^{j}(t),, \\
\dot{U}^{j,<d}(t+d)=s^{j}(t) L^{j}(t)-m^{j}(t) U^{j,<d}(t),
\end{gathered}
$$

where $U^{j,<d}(t+d)$ denotes short-term unemployment, i.e., the stock of unemployed workers who are employed at some time $\tau \in] t, t+d]$ but lose their job and thus are unemployed at time $t+d$; hence, by construction, $U^{j,<d}(t)=0$ since all short-term unemployed workers were employed at time $t$. Combining (51a) and (51b) to eliminate $s^{j}(t) L^{j}(t)$ leads to a dynamic equation relating changes of unemployment to changes of short-term unemployment:

$$
\dot{U}^{j}(t+d)=\dot{U}^{j,<d}(t+d)-m^{j}(t)\left(U^{j}(t)-U^{j,<d}(t)\right) .
$$

Solving eq. (52) above by integrating over $[t-d, t]$, and using the fact that at time $t$, short-term unemployment is such that $U^{j,<d}(t)=0$, leads to:

$$
U^{j}(t+d)=U^{j,<d}(t+d)+e^{-m^{j}(t) \cdot d} U^{j}(t) .
$$

Inserting $e^{-m^{j}(t) \cdot d}=\left(1-M^{j,<d}(t)\right)$ where $M^{j,<d}$ is the probability that an unemployed worker exits unemployment within $d$ months, one obtains:

$$
U^{j}(t+d)-U^{j}(t)=U^{j,<d}(t+d)-M^{j,<d}(t) U^{j}(t)
$$

Eq. (53) states that the change of unemployment in sector $j$ is equal to the inflows into unemployment $U^{j,<d}(t+d)$ of workers who were employed at time $t$ but are unemployed at time $t+d$ less the number of unemployed workers who find a job $M^{j,<d}(t) U^{j}(t)$. Solving (53) for $M^{j,<d}(t)$, it is possible to write the probability that an unemployed worker exits unemployment within $d$ months as

$$
M^{j,<d}(t)=1-\left[\frac{U^{j}(t+d)-U^{j,<d}(t+d)}{U^{j}(t)}\right] .
$$

The probability of finding a job within $d$ months given by eq. (54) can be mapped as the monthly job finding rate for unemployment duration $d=1,3,6,12$ :

$$
m^{j,<d}(t)=-\frac{1}{d} \ln \left(1-M^{j,<d}(t)\right) .
$$

To estimate the monthly job finding rate, we use the duration of unemployment lower than one month. In this configuration, the probability of finding a job can be rewritten as follows:

$$
M^{j,<1}(t)=1-\left[\frac{U^{j}(t)-U^{j,<1}(t)}{U^{j}(t-1)}\right]
$$

or alternatively

$$
1-M^{j,<1}(t)=\frac{U^{j}(t)-U^{j,<1}(t)}{U^{j}(t-1)} .
$$

Since $U^{j}(t-1)$ corresponds to monthly unemployment, we have to convert annual data on a monthly basis:

$$
U^{j}(t-1)=\left(U^{j}(t-12)\right)^{1 / 12}\left(U^{j}(t)\right)^{11 / 12} .
$$

Using (55) with $d=1$, the monthly job finding rate is:

$$
m^{j,<1}(t)=-\ln \left(U^{j}(t)-U^{j,<1}(t)\right)+\ln \left(U^{j}(t-1)\right),
$$

where the construction of $U^{j}(t-1)$ is given by eq. (57) while the same logic applies to $U^{j}(t)$.

Since series for unemployment by duration are expressed in percentage, we define $\alpha^{j,<1}(t)$ the share of unemployment less than one month among total unemployment as follows:

$$
\alpha^{j,<1}(t)=\frac{U^{j,<1}(t)}{U^{j}(t)} .
$$

Because the share of short-term unemployment is not available by economic activity, we assume that $\alpha^{j,<1}(t)$ is identical across sectors:

$$
\alpha^{j,<1}(t)=\alpha^{T,<1}(t)=\alpha^{N,<1}(t) .
$$

The job destruction rate can be estimated by solving this equation:

$$
U^{j}(t)=\psi^{j}(t) \frac{s^{j}(t)}{s^{j}(t)+m^{j,<1}(t)}\left(U^{j}(t)+L^{j}(t)\right)+\left(1-\psi^{j}(t)\right) U^{j}(t-1),
$$

where $\psi^{j}$ is the monthly rate of convergence to the long-run sectoral unemployment rate:

$$
\psi^{j}(t)=1-e^{-\left(s^{j}(t)+m^{j,<1}(t)\right)} .
$$




\section{A.2.3 Computation of the job finding rate and the job separation rate at a sectoral level}

To estimate the monthly job finding rate, $m^{j,<1}$, and the job destruction rate, $s^{j}$, for $j=T, N$, we proceed as follows:

- We estimate $\alpha^{<1}(t)=\alpha^{j,<1}(t)=\frac{U^{<1}(t)}{U(t)}$ where $U^{<1}(t)$ is unemployment of duration less than one month.

- Using the fact that $U^{j,<1}(t)=\alpha^{<1}(t) U^{j}(t)$, the probability of finding a job is

$$
M^{j,<1}(t)=1-\left[\frac{\left(1-\alpha^{<1}(t)\right) U^{j}(t)}{U^{j}(t-1)}\right],
$$

where $U^{j}(t-1)$ corresponds to monthly unemployment which is calculated as follows $U^{j}(t-$ 1) $=\left(U^{j}(t-12)\right)^{1 / 12}\left(U^{j}(t)\right)^{11 / 12}$ by using annual data.

- The monthly job finding rate is:

$$
m^{j,<1}(t)=-\ln \left(1-M^{j,<1}(t)\right)
$$

- The job destruction rate can be estimated by solving the following equation:

$$
U^{j}(t)=\psi^{j}(t) \frac{s^{j}(t)}{s^{j}(t)+m^{j,<1}(t)}\left(U^{j}(t)+L^{j}(t)\right)+(1-\psi(t)) U^{j}(t-1),
$$

where $\psi^{j}$ is the monthly rate of convergence to the long-run sectoral unemployment rate:

$$
\psi^{j}(t)=1-e^{-\left(s^{j}(t)+m^{j}(t)\right)} .
$$

To compute $m^{j,<1}$ and $s^{j}$, we need series for unemployment by economic activity in order to construct $U^{j}$, and unemployment less than 1 month in order to estimate $\alpha^{<1}(t)$. For unemployment at the sectoral level, data are taken from ILOSTAT database (ILO) while unemployment less than one month is provided by OECD which gives unemployment by duration. Data coverage: AUS (19952007), AUT (1994-2007), BEL (2001-2007), CAN (1987-2007), DEU (1995-2007), DNK (1994-1998 and 2002-2004), ESP (1992-2007), FIN (1991-2007), GBR (1988-2007), IRL (1986-1997), ITA (19932007), JPN (2003-2007), SWE (1995-2007) and USA (2003-2007). Because we calibrate the model so that the initial steady state is consistent with the empirical properties of each OECD economy while the series for the sectoral job separation rates are computed when the economy is out of the steady-state, we need to compute values for $s^{j}$ which are consistent with the steady-state sectoral unemployment rate $\tilde{u}^{j}=\frac{s^{j}}{s^{j}+m^{j}}$ given the computed value for $m^{j}$. The two first columns in Table 14 show the actual values for the sectoral unemployment rates while columns 3 and 4 give the values for steady-state sectoral unemployment rates computed by using its long-run equilibrium $\tilde{u}^{j}=\frac{s^{j}}{m^{j}+s^{j}}$ where the job finding rate $m^{j}$ is taken from columns 5 and 7 of Table 6 and the job destruction rate has been computed by solving eq. (65). The two last columns of Table 14 show the difference between the actual and the predicted value. Reassuringly, because computed values for $m^{j}$ and $s^{j}$ by using (64) and (65) are averaged over a long enough time horizon so that the unemployment rate should have reached its long-run value, actual and predicted values are close in most of the cases, except for Sweden, Australia and Italy (for $u^{T}$ ), and Ireland (for $u^{N}$ ). The values for sectoral job destruction rates shown in columns 6 and 8 of Table 6 are thus calculated by using the long-run equilibrium expression for the sectoral unemployment rate, i.e.,

$$
s^{j}=\frac{m^{j} u^{j}}{1-u^{j}},
$$

where $u^{j}$ is taken from columns 2 and 3 of Table 6 and $m^{j}$ is taken from columns 5 and 7 of Table 6. Computed values for $s^{j}$ using (67) are shown in columns 6 and 8 of Table 6 .

For France, Korea, the Netherlands, and Norway, data are not available to compute the job finding and the job separation rate. We proceed as follows to get estimates of $m$ and $s$ when calibrating the model for each economy:

- Because data for unemployment by economic activity are not available for FRA, NLD, and NOR, estimates for the job finding rate $m=m^{j}$ are taken from Hobijn and Sahin [2009]. Note that estimates are not available at a sectoral level so that we have to assume that the job finding rate is identical across sectors, i.e., $m^{j}=m$. Building on estimates by Hobijn and Sahin [2009], we set $m=6.7 \%$ for France (1975-2004), $m=4.7 \%$ for the Netherlands (19832004 ), and $m=30.5 \%$ for Norway (1983-2004). To compute the job separation rate, we use 
Table 14: Comparison of Actual Values with Calculated Values for the Sectoral Unemployment Rates

\begin{tabular}{l|cc|cc|cc}
\hline Country & \multicolumn{2}{|c|}{ Actual } & \multicolumn{2}{c|}{ Calculated } & \multicolumn{2}{c}{ Error } \\
\hline & $u^{T}$ & $u^{N}$ & $\tilde{u}^{T}$ & $\tilde{u}^{N}$ & $u^{T}-\tilde{u}^{T}$ & $u^{N}-\tilde{u}^{N}$ \\
& $(1)$ & $(2)$ & $(3)$ & $(4)$ & $(5)$ & $(6)$ \\
AUS & 0.072 & 0.062 & 0.084 & 0.066 & -0.012 & -0.004 \\
AUT & 0.037 & 0.044 & 0.036 & 0.037 & 0.001 & 0.007 \\
BEL & 0.077 & 0.079 & 0.075 & 0.078 & 0.002 & 0.001 \\
CAN & 0.082 & 0.084 & 0.086 & 0.086 & -0.004 & -0.002 \\
DEU & 0.101 & 0.091 & 0.100 & 0.094 & 0.001 & -0.003 \\
DNK & 0.064 & 0.061 & 0.067 & 0.060 & -0.003 & 0.001 \\
ESP & 0.147 & 0.161 & 0.146 & 0.155 & 0.001 & 0.006 \\
FIN & 0.087 & 0.118 & 0.088 & 0.119 & -0.001 & -0.001 \\
GBR & 0.073 & 0.066 & 0.071 & 0.068 & 0.002 & -0.002 \\
IRL & 0.130 & 0.154 & 0.132 & 0.144 & -0.002 & 0.010 \\
ITA & 0.094 & 0.098 & 0.104 & 0.097 & -0.010 & 0.001 \\
JPN & 0.033 & 0.033 & 0.024 & 0.025 & 0.009 & 0.008 \\
SWE & 0.056 & 0.060 & 0.043 & 0.045 & 0.013 & 0.015 \\
USA & 0.048 & 0.053 & 0.047 & 0.052 & 0.001 & 0.001 \\
\hline
\end{tabular}

the steady-state expression for the unemployment rate $u=\frac{s}{s+m}$ where the unemployment rate is averaged over the appropriate period, i.e., 1975-2004 for France, 1983-2004 for the Netherlands and 1983-2004 for Norway. Series for harmonized unemployment rates are taken from Labor Force Survey, OECD.

- While we can construct series for unemployment by economic activity for Korea, series for unemployment by duration is not provided by the OECD for this economy. We thus average the job finding rates taken from Chang et al. [2004] over 1993-1994, i.e., $m=26.2 \%$ and compute the job destruction rate by using the steady-expression for the unemployment rate $u^{j}=\frac{s^{j}}{s^{j}+m}$ where $u^{j}$ is the sectoral unemployment rate calculated by using the LABORSTA database from ILO.

\section{A.3 Elasticity of substitution in consumption $(\phi)$ : Empirical Strategy}

When including physical capital investment and denoting recruiting costs by $F \equiv \kappa^{T} V^{T}+\kappa^{N} V^{N}$, according to the goods market equilibrium, we have:

$$
\frac{Y^{T}-N X-I^{T}-G^{T}-F}{Y^{N}-I^{N}-G^{N}}=\frac{C^{T}}{C^{N}}
$$

where we used the fact that $\dot{B}-r^{\star} B=N X$ with $B$ the net foreign asset position and $N X$ net exports. Inserting the optimal rule for intra-temporal allocation of consumption (15), i.e., $\frac{C^{T}}{C^{N}}=\left(\frac{\varphi}{1-\varphi}\right) P^{\phi}$, into (68) leads to

$$
\frac{Y^{T}-N X-I^{T}-G^{T}-F}{Y^{N}-I^{N}-G^{N}}=\left(\frac{\varphi}{1-\varphi}\right) P^{\phi} .
$$

According to the market clearing condition, we could alternatively use data for consumption or for sectoral value added along with times series for its demand components to estimate $\phi$. Unfortunately, classifications for valued added by industry and for consumption by items are different (because nomenclatures are different) and thus it is most likely that $C^{T}$ differs from $Y^{T}-N X-G^{T}-I^{T}-F$, and $C^{N}$ from $Y^{N}-G^{N}-I^{N}$ as well. Because time series for traded and non traded consumption display a short time horizon for half countries of our sample while data for sectoral value added and net exports are available for the 18 OECD countries of our sample over the period running from 1970 to 2007 (except for Japan: 1974-2007), we find appropriate to estimate $\phi$ by computing $Y^{T}-N X-E^{T}$ and $Y^{N}-E^{N}$ where $E^{T} \equiv G^{T}+I^{T}+F$ and $E^{N} \equiv G^{N}+I^{N}$. Yet, a difficulty shows up because the classification adopted to split government spending and investment expenditure into traded and non traded items is different from that adopted to break down value added into traded and non traded components. Moreover, the time horizon is short at a disaggregated level for most of the countries, especially for time series of $G^{j}$. To overcome these difficulties, we proceed as follows. Denoting the ratio of $E^{T} \equiv G^{T}+I^{T}+F$ to traded value added adjusted with net exports at current prices by $v_{E^{T}}=\frac{P^{T} E^{T}}{P^{T} Y^{T}-P^{T} N X}$, and denoting the ratio of $E^{N} \equiv G^{N}+I^{N}$ to non traded value added 
at current prices by $v_{E^{N}}=\frac{P^{N} E^{N}}{P^{N} Y^{N}}$, the goods market equilibrium (69) can be rewritten as follows:

$$
\frac{\left(P^{T} Y^{T}-P^{T} N X\right)\left(1-v_{E^{T}}\right)}{P^{N} Y^{N}\left(1-v_{E^{N}}\right)}=\left(\frac{\varphi}{1-\varphi}\right) P^{\phi-1},
$$

or alternatively

$$
\frac{\left(Y^{T}-N X\right)\left(1-v_{E^{T}}\right)}{Y^{N}\left(1-v_{E^{N}}\right)}=\left(\frac{\varphi}{1-\varphi}\right) P^{\phi} .
$$

Setting

$$
\alpha \equiv \ln \frac{\left(1-v_{E^{N}}\right)}{\left(1-v_{E^{T}}\right)}+\ln \left(\frac{\varphi}{1-\varphi}\right),
$$

and taking logarithm, eq. (70) can be rewritten as follows:

$$
\ln \left(\frac{Y^{T}-N X}{Y^{N}}\right)=\alpha+\phi \ln P .
$$

Indexing time by $t$ and countries by $i$, and adding an error term $\mu$, we estimate $\phi$ by exploring the following empirical relationship:

$$
\ln \left(\frac{Y^{T}-N X}{Y^{N}}\right)_{i, t}=f_{i}+f_{t}+\alpha_{i} t+\phi_{i} \ln P_{i, t}+\mu_{i, t},
$$

where $f_{i}$ captures the country fixed effects, $f_{t}$ are time dummies, and $\mu_{i, t}$ are the i.i.d. error terms. Because the term (71) is composed of ratios which may display a trend over time, we add country-specific trends, as captured by $\alpha_{i} t$. Eq. (73) corresponds to eq. (40) in the text.

Instead of using time series for sectoral value added, we can alternatively make use of series for sectoral labor compensation. Multiplying both sides by $\frac{P^{T}}{P^{N}}$ and then by $\frac{\rho^{T}}{\rho^{N}}$ with $\rho^{j}=\frac{W^{j} L^{j}}{P^{j} Y^{j}}$ the sectoral labor income share, eq. (70) can be rewritten as follows

$$
\ln \left(\frac{W^{T} L^{T}-\rho^{T} P^{T} N X}{W^{N} L^{N}}\right)=\eta+(\phi-1) \ln P .
$$

where

$$
\eta \equiv \ln \frac{\left(1-v_{E^{N}}\right)}{\left(1-v_{E^{T}}\right)}+\ln \left(\frac{\varphi}{1-\varphi}\right)+\ln \frac{\rho^{T}}{\rho^{N}}
$$

Indexing time by $t$ and countries by $i$, and adding an error term $\mu$, we estimate $\phi$ by exploring the following empirical relationship:

$$
\ln \left(\gamma^{T} / \gamma^{N}\right)_{i, t}=g_{i}+g_{t}+\eta_{i} t+\delta_{i} \ln P_{i, t}+\zeta_{i, t},
$$

where $\delta_{i}=\left(\phi_{i}-1\right) ; g_{t}$ are time dummies which capture common macroeconomic shocks. Because $\eta_{i}$ is composed of preference parameters (i.e., $\varphi$ ), and (logged) ratios which may display trend over time, we introduce country fixed effects $g_{i}$, and add country-specific trends, as captured by $\eta_{i} t$. Once we have estimated $\delta_{i}$, we can compute $\hat{\phi}_{i}=\hat{\delta}_{i}+1$ where a hat refers to point estimate in this context. Eq. (76) corresponds to eq. (41) in the text.

\section{B Empirical results}

\section{B.1 A First Glance at the Data}

We begin by examining the data for the 18 OECD economies over the period 1970-2007. Figure 5 plots the average relative price growth against the average relative wage growth which have been scaled (i.e., divided) by the average productivity growth differential between tradables and non tradables. Quantitatively, the BS model predicts that a productivity differential between tradables and non tradables of $1 \%$ leaves unaffected the relative wage of non tradables and appreciates the relative price of non tradables by $1 \%$. Hence, according to the BS model, all countries should be positioned at point BS along the $\mathrm{X}$-axis with coordinates $(1,0)$. However, we find that all countries are positioned to the south-west of point BS. Quantitatively, we find that a productivity differential between tradables and non tradables by $1 \%$ is associated with a fall in the relative wage which varies between $-0.02 \%$ for Belgium and $-0.41 \%$ for Denmark. Regarding the relative price, we find that its appreciation varies between $0.34 \%$ for Canada to $0.97 \%$ for Japan while Norway experiences a fall in the relative price of non tradables due to the large increase of prices in traded industries such as 'Mining and Quarrying' (which accounts for about one fourth of GDP) over 1995-2007. 


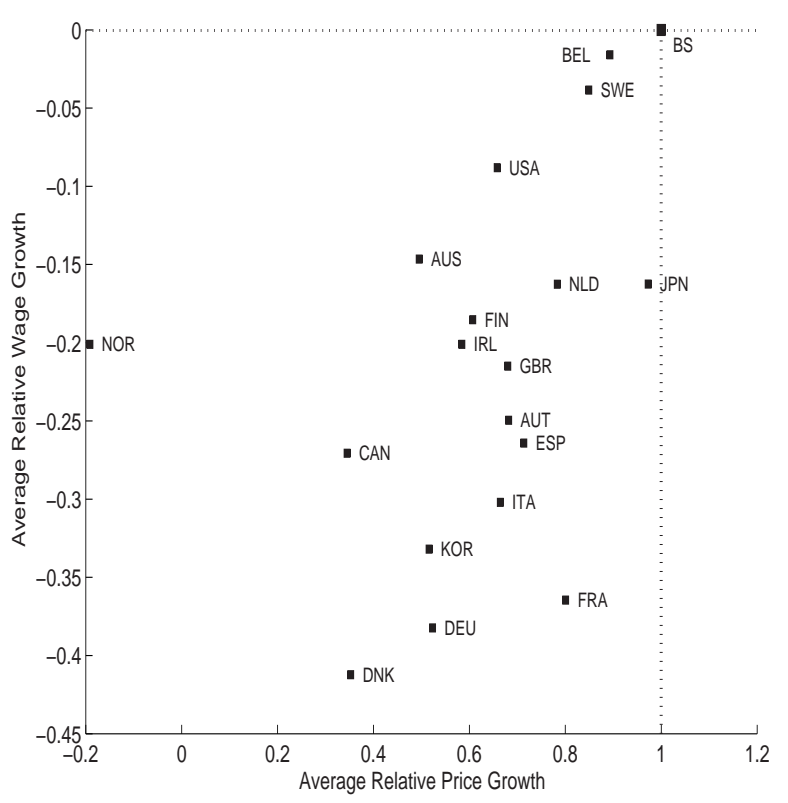

Figure 5: The Relative Price and the Relative Wage Growth. Notes: Figure 5 plots the annual average growth of the relative price of non tradables and the relative wage of non tradables, both scaled by the average productivity growth differential between tradables and non tradables, for each country of our sample over 1970-2007.

The data seem to challenge the conventional wisdom that labor mobility would gradually eliminate wage differences across sectors. If it were the case, the ratio of the non traded wage to the traded wage would remain unchanged. However, we observe that the relative wage tends to fall. Moreover, because non traded wages increase by a smaller amount that if labor were perfectly mobile, the relative price of non tradables appreciates by a smaller amount than suggested by the standard BS model. To confirm these findings, in the following, we have recourse to panel data unit root tests and cointegration methods.

\section{B.2 Panel Unit Root Tests}

We test for the presence of unit roots in the logged relative wage $\omega$ (i.e., $w^{N}-w^{T}$ ) and in the difference between the $(\log )$ relative price $p$ (i.e., $p^{N}-p^{T}$ ) and the $(\log )$ relative productivities (i.e., $a^{T}-a^{N}$ ). If the wage equalization hypothesis was right, sectoral wages would increase at the same speed so that the relative wage of non tradables would be stationary. As a result, the non tradable unit labor cost would rise by the same amount as the productivity differential. Hence, the difference between the (logged) relative price and the (logged) relative productivity should be stationary as well.

We consider five panel unit root tests among those most commonly used in the literature: i) Levin, Lin and Chu's [2002] test based on a homogenous alternative assumption, ii) a t-ratio type test statistic by Breitung [2000] for testing a panel unit root based on alternative detrending methods, iii) Im, Pesaran and Shin's [2003] test that allows for a heterogeneous alternative, iv) Fisher type test by Maddala and Wu [1999], and v) Hadri [2000] who proposes a test of the null of stationarity against the alternative of a unit root in the panel data. Results are summarized in Table 15. We ran these five panel unit root tests for sectoral unemployment rates along with the unemployment rate differential.

As shown in the first column Table 15, all panel unit root tests, reveal that the relative wage variable is non-stationary at a $5 \%$ significance level. This finding suggests that labor market frictions prevent wage equalization across sectors in the long run. Regarding the relative price of non tradables and the productivity of tradables relative to productivity of non tradables, these variables are found to be non-stationary. As shown in the last column, the difference between the relative price of non tradables and the relative productivity is integrated of order one which implies that the productivity differential is not fully reflected in the non tradable unit labor cost and thus the relative price. As can be seen in The first two columns of Table 17, sectoral unemployment rates are stationary, except for Hadri's [2000] test.

The common feature of first generation tests is the restriction that all cross-sections are independent. We also consider some second generation unit root tests that allow cross-unit dependencies. We consider the tests developed by: i) Bai and $\mathrm{Ng}$ [2002] based on a dynamic factor model, ii) Choi [2001] based on an error-component model, iii) Pesaran [2007] based on a dynamic factor model 
Table 15: Panel Unit Root Tests (p-values) for eqs. (7a)-(7b) involving the relative wage and the relative price

\begin{tabular}{l} 
Test \\
\cline { 3 - 6 }
\end{tabular}

Table 16: Panel Unit Root Tests (second generation) for eqs. (7a)-(7b) involving the relative wage and the relative price

\begin{tabular}{l|l|c|c|c|c}
\hline \multirow{2}{*}{ Test } & \multirow{2}{*}{ Stat } & \multicolumn{4}{|c}{ Variables } \\
\cline { 3 - 6 } & & $\omega$ & $p$ & $a^{T}-a^{N}$ & $p-\left(a^{T}-a^{N}\right)$ \\
\hline Bai and Ng [2002] & $Z_{\hat{e}}^{c}$ & 0.267 & 0.151 & 0.038 & 0.530 \\
& $P_{\hat{e}}^{c}$ & 0.251 & 0.150 & 0.050 & 0.498 \\
Choi [2001] & $P_{m}$ & 0.000 & 0.988 & 0.992 & 0.407 \\
& $Z$ & 0.053 & 1.000 & 1.000 & 0.653 \\
Pesaran [2007] & $L^{\star}$ & 0.047 & 1.000 & 1.000 & 0.662 \\
Chang [2002] & CIPS & 0.010 & 0.320 & 0.450 & 0.015 \\
& CIPS & 0.010 & 0.320 & 0.450 & 0.015 \\
& $S_{N}$ & 1.000 & 1.000 & 1.000 & 1.000
\end{tabular}

Notes: For all tests, the null of a unit root is not rejected if p-value $\geq 0.05$ at a $5 \%$ significance level. $\hat{r}$ is the estimated number of common factors. For the idiosyncratic components, $P_{\hat{e}}^{c}$ is a Fisher's type statistic based on p-values of the individual ADF tests. Under $H_{0}, P_{\hat{e}}^{c}$ has a $\chi^{2}$ distribution. $Z_{\hat{e}}^{c}$ is the standardized Choi's type statistic. Under $H_{0}, Z_{\hat{e}}^{c}$ has a $N(0,1)$ distribution. For the idiosyncratic components, the estimated number of independent stochastic trends in the common factors is reported. The first estimated value is derived from the filtered test $M Q_{c}$ and the second one is derived from the corrected test $M Q_{f}$. The $P_{m}$ test is a modified Fisher's inverse chi-square test. The $Z$ test is an inverse normal test. The $L^{\star}$ test is a modified logit test. All these three statistics have a standard normal distribution under $H_{0}$. CIPS is the mean of individual Cross sectionally ADF statistics (CADF). CIP $S^{\star}$ denotes the mean of truncated individual CADF statistics. The $S_{N}$ statistic corresponds to the average of individual non-linear IV t-ratio statistics. It has a $N(0,1)$ distribution under $H_{0}$. Corresponding $p$-values are in parentheses.

and iv) Chang [2002] who proposes the instrumental variable nonlinear test. The results of second generation unit root tests are shown in Table 16.

In all cases, except for the Choi [2001] and Pesaran's [2007] tests applied to $\omega$ and $p-\left(a^{T}-a^{N}\right)$, we fail to reject the presence of a unit root in the relative price, the relative wage, the productivity differential, and the difference $p-\left(a^{T}-a^{N}\right)$, when cross-unit dependencies are taken into account.

\section{B.3 Cointegration Tests and Alternative Cointegration Estimates}

To begin with, we report the results of parametric and non parametric cointegration tests developed by Pedroni ([1999]), ([2004]). Cointegration tests are based on the estimated residuals of equations (5) and (6). Table 18 reports the tests of the null hypothesis of no cointegration. All Panel tests reject the null hypothesis of no cointegration between $p$ and $a^{T}-a^{N}$ at the $1 \%$ significance level while three Panel tests reject the null hypothesis of no cointegration between $\omega$ and $a^{T}-a^{N}$ at the $5 \%$ significance level. Group-mean parametric t-test confirm cointegration between $p$ and the labor productivity differential and between $\omega$ and $a^{T}-a^{N}$ at $5 \%$ and $1 \%$ significance level, respectively, while group-mean non parametric t-tests are somewhat less pervasive. Pedroni [2004] explores finite sample performances of the seven statistics. The results reveal that group-mean parametric t-test is more powerful than other tests in finite samples. By and large, panel cointegration tests provide evidence in favor of cointegration between the relative price and relative productivity, and between the relative wage and relative productivity.

As robustness checks, we compare our group-mean FMOLS estimates and group-mean DOLS estimates with one lag $(q=1)$, with alternative estimators. First, we consider the group-mean DOLS 
Table 17: Panel Unit Root Tests (p-values) for eq. (8) involving sectoral unemployment rates

\begin{tabular}{l|l|c|c|c}
\hline Test & \multirow{2}{*}{ Stat } & \multicolumn{3}{|c}{ Variables } \\
\cline { 3 - 5 } & & $d u^{T}$ & $d u^{N}$ & $d u^{T}-d u^{N}$ \\
\hline Levin et al. [2002] & t-stat & 0.000 & 0.000 & 0.000 \\
Breitung [2000] & t-stat & 0.049 & 0.045 & 0.000 \\
Im et al. [2003] & W-stat & 0.000 & 0.003 & 0.000 \\
Maddala and Wu [1999] & ADF & 0.000 & 0.003 & 0.000 \\
& PP & 0.000 & 0.000 & 0.000 \\
Hadri [2000] & $Z_{\mu}$-stat & 0.074 & 0.051 & 0.013 \\
\hline
\end{tabular}

Notes: For all tests, except for Hadri [2000], the null of a unit root is not rejected if p-value $\geq 0.05$ at a $5 \%$ significance level. For Hadri [2000], the null of stationarity is rejected if p-value $\leq 0.05$ at a $5 \%$ significance level. ADF and PP are the Maddala and Wu's [1999] $P$ test based on Augmented Dickey-Fuller and Phillips-Perron $p$-values respectively.

Table 18: Panel cointegration tests results (p-values)

\begin{tabular}{l|c|c}
\hline \multirow{2}{*}{ Panel tests } & wage equation & price equation \\
\cline { 2 - 3 } Non-parametric $\nu$ & eq. (5) & eq. (6) \\
\cline { 2 - 3 } Non-parametric $\rho$ & 0.000 & 0.000 \\
Non-parametric $t$ & 0.012 & 0.003 \\
Parametric $t$ & 0.004 & 0.002 \\
Group-mean tests & 0.046 & 0.000 \\
Non-parametric $\rho$ & 0.388 & 0.449 \\
Non-parametric $t$ & 0.167 & 0.220 \\
Parametric $t$ & 0.016 & 0.001 \\
\hline Notes: The null hypothesis of no cointegration is rejected if the p-value
\end{tabular}

is below 0.05 (0.10 resp.) at 5\% (10\% resp.) significance level. 
Table 19: Alternative Cointegration Estimates of $\beta$ and $\gamma$

\begin{tabular}{|c|c|c|c|c|}
\hline & \multicolumn{2}{|c|}{ Relative wage eq. (5) } & \multicolumn{2}{|c|}{ Relative price eq. (6) } \\
\hline & $\hat{\beta}$ & $t(\beta=0)$ & $\hat{\gamma}$ & $t(\gamma=1)$ \\
\hline $\operatorname{DOLS}(q=2)$ & $\begin{array}{l}-0.223^{a} \\
(-27.69)\end{array}$ & 0.000 & $\begin{array}{l}0.658^{a} \\
(77.95)\end{array}$ & 0.000 \\
\hline $\operatorname{DOLS}(q=3)$ & $\begin{array}{l}-0.220^{a} \\
(-26.77)\end{array}$ & 0.000 & $\begin{array}{l}0.673^{a} \\
(79.22)\end{array}$ & 0.000 \\
\hline $\operatorname{DOLS}(q=4)$ & $\begin{array}{l}-0.218^{a} \\
(-26.51)\end{array}$ & 0.000 & $\begin{array}{l}0.678^{a} \\
(84.96)\end{array}$ & 0.000 \\
\hline DFE & $\begin{array}{l}-0.105^{b} \\
(-2.51)\end{array}$ & 0.006 & $\begin{array}{l}0.697^{a} \\
(13.55)\end{array}$ & 0.000 \\
\hline MG & $\begin{array}{l}-0.145^{a} \\
(-7.43)\end{array}$ & 0.000 & $\begin{array}{l}0.608^{a} \\
(17.25)\end{array}$ & 0.000 \\
\hline PMG & $\begin{array}{l}-0.164^{a} \\
(-10.59)\end{array}$ & 0.000 & $\begin{array}{l}0.668^{a} \\
(31.03)\end{array}$ & 0.000 \\
\hline Panel DOLS $(q=1)$ & $\begin{array}{l}-0.214^{a} \\
(-6.32)\end{array}$ & 0.000 & $\begin{array}{l}0.621^{a} \\
(22.39)\end{array}$ & 0.000 \\
\hline Panel DOLS $(q=2)$ & $\begin{array}{l}-0.216^{a} \\
(-6.85)\end{array}$ & 0.000 & $\begin{array}{l}0.620^{a} \\
(22.62)\end{array}$ & 0.000 \\
\hline Panel DOLS $(q=3)$ & $\begin{array}{l}-0.213^{a} \\
(-6.42)\end{array}$ & 0.000 & $\begin{array}{l}0.624^{a} \\
(23.88)\end{array}$ & 0.000 \\
\hline
\end{tabular}

Notes: All regressions include country fixed effects. Heteroskedasticity and autocorrelation consistent t-statistics are reported in parentheses. ${ }^{a}$ denotes significance at $1 \%$ level. The columns $t(\beta)=0$ and $t(\gamma)=1$ report the p-value of the test of $H_{0}: \beta=0$ and $H_{0}: \gamma=1$ respectively.

estimator with 2 lags $(q=2)$ and 3 lags $(q=3)$. Second, we estimate cointegration relationships (7a) and (7b) using the panel DOLS estimator (Mark and Sul [2003]). We also use alternative econometric techniques to estimate cointegrating relationships (3): the dynamic fixed effects estimator (DFE), the mean group estimator (MG, Pesaran and Smith [1995]), the pooled mean group estimator (PMG, Pesaran et al. [1999]). All results are displayed in Table 19 and show that estimates of $\hat{\beta}$ and $\hat{\gamma}$ are close to those shown in Table 1 of the paper, except for the dynamic fixed effects estimator which suggests a fall in $\omega$ of $0.1 \%$ instead of $0.2 \%$.

\section{B.4 Split-Sample Analysis}

In this subsection, we provide more details about the split-sample analysis we perform in the main text in order to differentiate the effects of a productivity differential according to the degree of labor market regulation.

\section{B.4.1 Relative Wage and Relative Price Effects of Higher Relative Productiv- ity of Tradables: Implications of Labor Market Regulation}

To empirically explore the implications of labor market regulation for the effects of a productivity differential between tradables and non tradables, we apply cointegration techniques and perform a simple split-sample analysis. We consider three indicators which capture the extent of regulation on labor markets: the unemployment benefit replacement rate, the collective bargaining coverage, and the employment protection legislation index. We also we have recourse to a principal component analysis to construct an indicator that gives a more accurate measure of the degree of labor market regulation. Source and data construction are detailed in section A. We take the median to split the sample of 18 countries in 9 countries with high and 9 economies with low labor market regulation. Table 20 shows values of each labor market indicator for each country. For each indicator, countries are ranked in decreasing order.

We first compare the relative wage behavior of 9 countries with high and 9 economies with low labor market regulation by running the regression of the relative wage on relative productivity for each sub-sample:

$$
\omega_{i, t}=\delta_{i}+\beta^{c}\left(a_{i, t}^{T}-a_{i, t}^{N}\right)+v_{i, t}, \quad c=H, L,
$$

where $\beta^{H}\left(\beta^{L}\right)$ captures the response of the relative wage to a productivity differential in countries with higher (lower) labor market regulation.

We adopt a similar approach for the relative price. Because the movements in the relative price of non tradables can be influenced by changes in the cost of entry in product market triggered by competition-oriented policies, we add country-specific linear time trends when we run the regression for each sub-sample in order to control for these effects:

$$
p_{i, t}=\delta_{i}+\gamma^{c}\left(a_{i, t}^{T}-a_{i, t}^{N}\right)+u_{i, t}, \quad c=H, L,
$$


where $\gamma^{H}\left(\gamma^{L}\right)$ captures the response of the relative price to a productivity differential in countries where the index that captures the extent of labor market regulation is above (below) the median.

Building on our model's predictions, we expect the relative wage to decline more (i.e., $\left|\beta^{H}\right|$ is expected to take higher values) and the relative price to appreciate less (i.e., $\left|\gamma^{H}\right|$ is expected to take lower values) in countries where the unemployment benefit scheme is more generous (i.e., $\varrho$ is higher) or the collective bargaining coverage is greater (i.e., BargCov is higher). While we expect the relative wage to decline more in countries with strictness legislation against dismissals (i.e., $E P L_{a d j}$ takes higher values), the relative price should appreciate by a larger amount. While estimates summarized in Table 4 in the main text corroborate all of our conjectures related to the implications of labor market regulation for the relative wage and relative price effects of a productivity differential, Table 21 shows results when we base the split-sample analysis on sample mean for the three dimensions of labor market regulation. Reassuringly, all of our conclusions hold when we base the split of the sample of 18 OECD countries on sample mean. In a nutshell, our results are robust to the threshold used to perform the split-sample analysis.

Table 20: Split-Sample Analysis: Labor Market Indicators

\begin{tabular}{cc|cc|cc|cc}
\hline \multicolumn{2}{c}{$\begin{array}{c}\text { Collective Bargaining } \\
\text { Coverage }\end{array}$} & \multicolumn{2}{c}{$\begin{array}{c}\text { Unemployment Benefit } \\
\text { Replacement Rate }\end{array}$} & \multicolumn{2}{c}{$\begin{array}{c}\text { Employment Protection } \\
\text { Legislation }\end{array}$} & \multicolumn{2}{c}{$\begin{array}{c}\text { Labor Market } \\
\text { Regulation }\end{array}$} \\
$(1)$ & $(2)$ & $(3)$ & $(4)$ & $(5)$ & $(6)$ & $(7)$ & $(8)$ \\
\hline AUT & 97.10 & DNK & 72.21 & NLD & 2.60 & AUT & 1.82 \\
BEL & 94.22 & BEL & 66.86 & ITA & 2.53 & NLD & 1.81 \\
SWE & 89.08 & NLD & 66.70 & AUT & 2.48 & SWE & 1.51 \\
FIN & 86.07 & GBR & 63.04 & DEU & 2.36 & FRA & 1.32 \\
FRA & 85.38 & DEU & 61.39 & SWE & 2.31 & DNK & 1.31 \\
NLD & 84.50 & FIN & 59.33 & FRA & 2.11 & FIN & 1.28 \\
ITA & 83.26 & IRL & 53.65 & NOR & 2.06 & BEL & 1.16 \\
DNK & 82.45 & CAN & 53.60 & ESP & 2.04 & ESP & 1.09 \\
ESP & 75.51 & JPN & 51.24 & FIN & 2.02 & DEU & 1.07 \\
AUS & 70.89 & AUT & 49.85 & KOR & 1.98 & ITA & 0.89 \\
NOR & 69.89 & AUS & 49.62 & DNK & 1.93 & NOR & 0.80 \\
DEU & 69.38 & SWE & 48.19 & BEL & 1.65 & IRL & -0.17 \\
IRL & 57.58 & FRA & 47.18 & JPN & 1.49 & AUS & -0.19 \\
GBR & 44.83 & NOR & 43.18 & IRL & 1.32 & GBR & -0.86 \\
CAN & 35.75 & ESP & 41.34 & AUS & 1.21 & JPN & -0.92 \\
JPN & 24.15 & KOR & 37.51 & GBR & 1.02 & CAN & -1.18 \\
USA & 20.28 & USA & 25.72 & CAN & 0.81 & USA & -2.47 \\
KOR & 10.50 & ITA & 7.68 & USA & 0.24 & KOR & n.a. \\
\hline Mean & 65.60 & Mean & 49.91 & Mean & 1.79 & Mean & 0.40 \\
\hline
\end{tabular}

Notes: Data coverage for Unemployment benefit replacement rate: 1970-2007 (2001-2007 for KOR). Data coverage for collective bargaining coverage: 1970-2007 for AUS, AUT, CAN, DEU, DNK, FIN, GBR, IRL, ITA, JPN, SWE and USA, 1970-2005 for NLD and NOR, 1970-2002 for BEL and FRA, 1977-2004 for ESP and 2002-2006 for KOR. Data coverage for the employment protection legislation index adjusted with the share of permanent workers in the economy: 1985-2007 (1990-2007 for KOR). The labor market regulation index is obtained by using a principal component analysis and thus the data coverage corresponds to the shortest period among the three indicators used.

\section{B.4.2 Effect on Unemployment Rate Differential of Higher Relative Produc- tivity of Tradables: Implications of Labor Market Regulation}

One prediction of the two-sector model with search frictions developed in the paper is that a productivity differential between tradables and non tradables lowers the unemployment rate in both the traded and non traded sector, the decline of the former being larger than that of the latter. When we investigate the implications of labor market regulation, our model also predicts that the decline in the unemployment rate differential between tradables and non tradables following higher relative productivity of tradables is more pronounced in countries where labor markets are more regulated. To test these predictions, we proceed in two stages.

Firstly, indexing countries and time by $i$ and $t$ respectively, we explore the following relationship empirically:

$$
d u_{i, t}^{T}-d u_{i, t}^{N}=\eta_{i}+\sigma \cdot\left(\hat{a}_{i, t}^{T}-\hat{a}_{i, t}^{N}\right)+\lambda \cdot L M R_{i, t}+z_{i, t},
$$

where $\eta_{i}$ are the country fixed effects and $z_{i, t}$ are i.i.d. error terms. The dependent variable is the difference between the change in the unemployment rate in the traded sector and the change in the unemployment rate in the non traded sector (so that the unemployment rate differential is expressed 
Table 21: Panel Cointegration Estimates of $\beta$ and $\gamma$ for Sub-Samples

\begin{tabular}{|c|c|c|c|c|c|c|c|c|}
\hline \multirow[t]{2}{*}{ LMR } & \multicolumn{2}{|c|}{$\varrho$} & \multicolumn{2}{|c|}{ BargCov } & \multicolumn{2}{|c|}{$\mathrm{EPL}_{a d j}$} & \multicolumn{2}{|c|}{ LMR } \\
\hline & DOLS & FMOLS & DOLS & FMOLS & DOLS & FMOLS & DOLS & FMOLS \\
\hline A.Relative Wage & & & & & & & & \\
\hline$\beta^{H}$ & $\begin{array}{l}-0.261^{a} \\
(-23.04)\end{array}$ & $\begin{array}{l}-0.255^{a} \\
(-25.65)\end{array}$ & $\begin{array}{l}-0.233^{a} \\
(-27.28)\end{array}$ & $\begin{array}{l}-0.232^{a} \\
(-30.59)\end{array}$ & $\begin{array}{c}-0.168^{a} \\
(-30.76)\end{array}$ & $\begin{array}{l}-0.176^{a} \\
(-33.77)\end{array}$ & $\begin{array}{l}-0.160^{a} \\
(-30.37)\end{array}$ & $\begin{array}{l}-0.164^{a} \\
(-32.12)\end{array}$ \\
\hline$\beta^{L}$ & $\begin{array}{c}-0.158^{a} \\
(-16.34)\end{array}$ & $\begin{array}{c}-0.166^{a} \\
(-19.14)\end{array}$ & $\begin{array}{c}-0.163^{a} \\
(-9.32)\end{array}$ & $\begin{array}{c}-0.168^{a} \\
(-11.23)\end{array}$ & $\begin{array}{c}-0.116^{a} \\
(-11.63)\end{array}$ & $\begin{array}{c}-0.113^{a} \\
(-7.74)\end{array}$ & $\begin{array}{c}-0.107^{a} \\
(-10.08)\end{array}$ & $\begin{array}{c}-0.108^{a} \\
(-6.72)\end{array}$ \\
\hline$t\left(\hat{\beta}^{L}=\hat{\beta}^{H}\right)$ & 0.000 & 0.000 & 0.000 & 0.000 & 0.000 & 0.000 & 0.000 & 0.000 \\
\hline B.Relative Price & & & & & & & & \\
\hline$\gamma^{H}$ & $\begin{array}{l}0.791^{a} \\
(6.37)\end{array}$ & $\begin{array}{c}0.776^{a} \\
(7.15)\end{array}$ & $\begin{array}{c}0.754^{a} \\
(10.19)\end{array}$ & $\begin{array}{l}0.713^{a} \\
(10.90)\end{array}$ & $\begin{array}{l}0.442^{a} \\
(5.85)\end{array}$ & $\begin{array}{l}0.353^{a} \\
(4.76)\end{array}$ & $\begin{array}{l}0.464^{a} \\
(6.15)\end{array}$ & $\begin{array}{c}0.371^{a} \\
(5.14)\end{array}$ \\
\hline$\gamma^{L}$ & $\begin{array}{l}1.123^{a} \\
(12.81)\end{array}$ & $\begin{array}{c}1.037^{a} \\
(13.60)\end{array}$ & $\begin{array}{l}1.410^{a} \\
(8.96)\end{array}$ & $\begin{array}{l}1.346^{a} \\
(9.92)\end{array}$ & $\begin{array}{l}0.214 \\
(1.48)\end{array}$ & $\begin{array}{l}0.281^{a} \\
(2.72)\end{array}$ & $\begin{array}{l}0.206 \\
(1.14)\end{array}$ & $\begin{array}{l}0.296^{b} \\
(2.46)\end{array}$ \\
\hline$t\left(\hat{\gamma}^{L}=\hat{\gamma}^{H}\right)$ & 0.000 & 0.000 & 0.000 & 0.000 & 0.723 & 0.999 & 0.804 & 1.000 \\
\hline Time period & 197 & 2007 & 1970 & 2007 & 198 & 2007 & 198 & 2007 \\
\hline Countries & & & & & & & & \\
\hline Observations & & & & & & & & \\
\hline mean LMR (high) & & & & & & & & \\
\hline mean LMR (low) & & & & & & & & \\
\hline
\end{tabular}

Notes: ${ }^{a}$ and ${ }^{b}$ denote significance at $1 \%$ and $5 \%$ levels. To investigate whether labor market regulation influences the responses of the relative wage, $\beta$, and the relative price, $\gamma$, to a productivity differential, we split the sample of 18 OECD countries into two subsamples and run the regressions (7a)-(7b) for the high and low-labor market regulation countries. $\beta^{H}\left(\beta^{L}\right)$ and $\gamma^{H}\left(\gamma^{L}\right)$ capture the responses of the relative wage and the relative price, respectively, in countries with high (low) labor market regulation. The row $t\left(\hat{\beta}^{L}=\hat{\beta}^{H}\right)\left(t\left(\hat{\gamma}^{L}=\hat{\gamma}^{H}\right)\right)$ reports the p-value of the test of $H_{0}: \hat{\beta}^{L}=\hat{\beta}^{H}\left(\hat{\gamma}^{L}=\hat{\gamma}^{H}\right)$. ' $\varrho^{\prime}$ is the unemployment benefits replacement rate, 'EPL adj' the strictness of employment protection against dismissals adjusted with the share of permanent workers, 'BargCov' the bargaining coverage and 'LMR' the labor market regulation index obtained by using a principal component analysis.

in percentage point); we construct the productivity differential by taking growth rates in order to remove the time trend, i.e., $\hat{a}_{i, t}^{T}-\hat{a}_{i, t}^{N}$, since $a_{i t}^{T}-a_{i t}^{N}$ displays a unit root process, see section B.2.

Since sectoral unemployment rates can be directly affected by labor market regulation, we add a control $L M R_{i t}$ which varies over time. Since bargaining coverage is available on a yearly basis for four countries only, whilst data availability is erratic for the rest of countries, we do not include this indicator in our analysis. On the contrary, the adjusted employment protection legislation index, $E L P_{a d j}$, and the unemployment benefit replacement rate, $\varrho$, are available on a yearly basis since 1985, except Korea. While in the baseline regression, we add $E P L_{a d j}$ as a control variable in the baseline regression, we conducted a robustness check and replaced it with the unemployment benefit replacement rate. Our results are merely quantitatively affected.

Turning to the implications of labor market regulation, we perform a split-sample analysis on the basis of the labor market regulation index, $L M R_{i t}$, shown in the last column of Table 20 which is an overall indicator reflecting all the dimensions of labor market institutions obtained by running a principal component analysis. We explore the following relationship empirically for each sub-sample:

$$
d u_{i, t}^{T}-d u_{i, t}^{N}=\delta_{i}+\sigma^{k} \cdot\left(\hat{a}_{i, t}^{T}-\hat{a}_{i, t}^{N}\right)+\lambda^{k} \cdot \mathrm{LMR}_{i, t}+z_{i, t}, \quad k=H, L,
$$

where $\sigma^{H}\left(\sigma^{L}\right)$ captures the response of the relative unemployment rate of tradables to a rise in the productivity differential in countries where the labor market regulation index, $L M R_{i t}$, is above (below) the mean.

Results are shown in Table 22 which reports both estimated values for $\sigma$ and $\lambda$. In accordance with our model's predictions, estimated values of $\sigma$ in eq. (79) are negative across all specifications, i.e., higher productivity of tradables relative to non tradables lowers more the unemployment rate of tradables than that of non tradables. When we run the regression (80), we also find empirically that the unemployment rate of tradables falls more relative to the unemployment rate of non tradables in countries where labor market regulation is more pronounced, i.e., $\sigma^{H}<\sigma^{L}$.

\section{First-Order Conditions}

It is worthwhile noticing that we employ below in the formal analysis the term "short-run static solutions". This terminology refers to solutions of static optimality conditions which are inserted in dynamic optimality conditions in order to analyze the equilibrium dynamics. The term "short-run" refers to first-order conditions, and the term "static" indicates that the solution holds at each instant of time, and thus in the long-run. 


\begin{tabular}{|c|c|c|c|c|}
\hline \multirow[b]{3}{*}{$\sigma$} & \multicolumn{4}{|c|}{ Unemployment differential eqs. (79)-(80) } \\
\hline & $\begin{array}{c}\text { Without Control } \\
\text { (1) }\end{array}$ & $\begin{array}{l}\text { with } E P L_{a d j} \\
(2)\end{array}$ & $\begin{array}{c}\text { with } \varrho \\
(3)\end{array}$ & $\begin{array}{c}\text { with } E P L_{a d j} \text { and } \varrho \\
(4)\end{array}$ \\
\hline & $\begin{array}{c}-0.034^{a} \\
(-2.58)\end{array}$ & $\begin{array}{c}-0.034^{b} \\
(-2.57)\end{array}$ & $\begin{array}{c}-0.037^{a} \\
(-2.76)\end{array}$ & $\begin{array}{c}-0.037^{a} \\
(-2.75)\end{array}$ \\
\hline$\lambda_{E P L}$ & & $\begin{array}{l}-0.001 \\
(-0.05)\end{array}$ & & $\begin{array}{l}-0.001 \\
(-0.24)\end{array}$ \\
\hline$\lambda_{\varrho}$ & & & $\begin{array}{c}-0.016 \\
(-1.60)\end{array}$ & $\begin{array}{c}-0.016 \\
(-1.61)\end{array}$ \\
\hline$\sigma^{H}$ & $\begin{array}{c}-0.036^{c} \\
(-1.77)\end{array}$ & $\begin{array}{c}-0.036^{c} \\
(-1.71)\end{array}$ & $\begin{array}{c}-0.040^{c} \\
(-1.90)\end{array}$ & $\begin{array}{c}-0.041^{c} \\
(-1.95)\end{array}$ \\
\hline$\lambda_{E P L}^{H}$ & & $\begin{array}{l}0.001 \\
(0.01)\end{array}$ & & $\begin{array}{c}-0.001 \\
(-0.20)\end{array}$ \\
\hline$\lambda_{\varrho}^{H}$ & & & $\begin{array}{l}-0.016 \\
(-1.23)\end{array}$ & $\begin{array}{l}-0.016 \\
(-1.23)\end{array}$ \\
\hline & $\begin{array}{c}-0.033^{c} \\
(-1.86)\end{array}$ & $\begin{array}{l}-0.031^{c} \\
(-1.72)\end{array}$ & $\begin{array}{c}-0.034^{c} \\
(-1.89)\end{array}$ & $\begin{array}{c}-0.032^{c} \\
(-1.68)\end{array}$ \\
\hline$\lambda_{E P L}^{L}$ & & $\begin{array}{l}-0.004 \\
(-0.40)\end{array}$ & & $\begin{array}{l}-0.005 \\
(-0.56)\end{array}$ \\
\hline$\lambda_{\varrho}^{L}$ & & & $\begin{array}{l}-0.015 \\
(-0.94)\end{array}$ & $\begin{array}{l}-0.016 \\
(-1.00)\end{array}$ \\
\hline Number of observations & 164 & 164 & 164 & 164 \\
\hline Number of countries & 14 & 14 & 14 & 14 \\
\hline
\end{tabular}

\section{C.1 Households}

We set

$$
\rho(t) \equiv \frac{1}{1-\frac{1}{\sigma_{C}}} C(t)^{1-\frac{1}{\sigma_{C}}}+v^{T}\left(L^{T}(t)+U^{T}(t)\right)+v^{N}\left(L^{N}(t)+U^{N}(t)\right),
$$

where $v^{j}\left(L^{j}(t)+U^{j}(t)\right)$ is the disutility function from working and searching efforts. We drop the time index when it is obvious. The current-value Hamiltonian for the representative household's optimization problem is:

$$
\begin{aligned}
\mathcal{H}^{H} & =\rho+\lambda\left[r^{\star} A+W^{T} L^{T}+W^{N} L^{N}+R^{T} U^{T}+R^{N} U^{N}-P_{C} C-T\right] \\
& +\xi^{T, \prime}\left[m^{T} U^{T}-s^{T} L^{T}\right]+\xi^{N, \prime}\left[m^{N} U^{N}-s^{N} L^{N}\right]
\end{aligned}
$$

where $A, L^{j}(j=T, N)$ are state variables; $\lambda, \xi^{j, \prime}$ (with $j=T, N$ ) are the corresponding co-state variables; $C$ and $U^{j}$ are the control variables.

Assuming that the representative agent takes $m$ as given, first-order conditions for households are:

$$
\begin{gathered}
C=\left(P_{C} \lambda\right)^{-\sigma_{C}}, \\
-v_{F}^{T}\left(L^{T}+U^{T}\right)=m^{T} \xi^{T, \prime}+R^{T} \lambda, \\
-v_{F}^{N}\left(L^{N}+U^{N}\right)=m^{N} \xi^{N, \prime}+R^{N} \lambda, \\
\dot{\lambda}=\lambda\left(\beta-r^{\star}\right), \\
\dot{\xi}^{T, \prime}=\left(s^{T}+\beta\right) \xi^{T, \prime}-\left[\lambda W^{T}+v_{F}^{T}\left(L^{T}+U^{T}\right)\right], \\
\dot{\xi}^{N, \prime}=\left(s^{N}+\beta\right) \xi^{N, \prime}-\left[\lambda W^{N}+v_{F}^{N}\left(L^{N}+U^{N}\right)\right],
\end{gathered}
$$

where $\xi^{j, \prime}$ (with $j=T, N$ ) is the utility value of the marginal job and $\lambda$ the marginal utility of wealth.

Since $\xi^{j, \prime}$ represents the utility value from an additional job and $\bar{\lambda}$ corresponds to the marginal utility of wealth, the pecuniary value of the marginal job is $\xi^{j}(\tau) \equiv \frac{\xi^{j, \prime}(\tau)}{\bar{\lambda}}$ for $\tau \in[t, \infty)$. Using this definition, we can rewrite $(83 \mathrm{~d})$ as follows:

$$
\dot{\xi}^{j}=\left(s^{j}+r^{\star}\right) \xi^{j}-\left(W^{j}+\frac{v_{F}^{j}}{\bar{\lambda}}\right) .
$$


Abstracting from search costs implies that the marginal rate of substitution between labor and consumption, $-\frac{v_{F}^{j}}{\bar{\lambda}}$, has to be equal to the wage rate $W^{j}$. In this case, the shadow price of employment $\xi^{j}$ is null. As long as agents face search costs, the real wage rate must exceed the disutility from entering the labor force $-\frac{v_{F}^{j}}{\bar{\lambda}}$. Since the quantity $-\frac{v_{F}^{j}}{\bar{\lambda}}$ can be viewed as being the worker's reservation wage, we will refer to $W^{j}+\frac{v_{F}^{j}}{\lambda}$ as the worker's surplus (by keeping in mind that $v_{F}^{j}<0$ ).

Solving (84) forward and using the transversality condition $\lim _{t \rightarrow \infty} \xi^{j} L^{j} \exp \left(-\left(r^{\star}+s^{j}\right) t\right)=0$, we get:

$$
\xi^{j}(t)=\int_{t}^{\infty}\left[W^{j}(\tau)-W_{R}^{j}(\tau)\right] e^{\left(s^{j}+r^{\star}\right)(t-\tau)} \mathrm{d} \tau
$$

where $W_{R}^{j}$ is the reservation wage given by

$$
W_{R}^{j} \equiv-\frac{v_{F}^{j}}{\bar{\lambda}}=m^{j}\left(\theta^{j}\right) \xi^{j}+R^{j}
$$

Differentiating $\xi^{j}(t) L^{j}(t)$ w. r. t. time and substituting the law of motion for employment $\dot{L}^{j}(t)$ (12) and the dynamic optimality condition (84) yields:

$$
\begin{aligned}
\frac{\mathrm{d}}{\mathrm{d} t}\left(\xi^{j} L^{j}\right) & =\dot{\xi}^{j} L^{j}+\xi^{j} \dot{L}^{j}=\left(s^{j}+r^{\star}\right) \xi^{j} L^{j}-\left(W^{j}+\frac{v_{F}^{j}}{\bar{\lambda}}\right) L^{j}+\xi^{j}\left(m^{j} U^{j}-s^{j} L^{j}\right) \\
& =r^{\star} \xi^{j} L^{j}-\left[\left(W^{j}+\frac{v_{F}^{j}}{\bar{\lambda}}\right) L^{j}-\xi^{j} m^{j} U^{j}\right], \\
& =r^{\star} \xi^{j} L^{j}-\left(W^{j} L^{j}+R^{j} U^{j}+\frac{v_{F}^{j}}{\bar{\lambda}} F^{j}\right),
\end{aligned}
$$

where $F^{j} \equiv L^{j}+U^{j}$ is the labor force and we have inserted eqs. (83b)-(83c), i.e., we used the fact that $m^{j} \xi^{j}=-\frac{v_{F}^{j}}{\bar{\lambda}}-R^{j}$. Solving forward, making use of the transversality condition, we get:

$$
\xi^{j}(t) L^{j}(t)=\int_{t}^{\infty}\left[\left(W^{j} L^{j}+R^{j} U^{j}\right)+\frac{v_{F}^{j}}{\bar{\lambda}} F^{j}\right] e^{-r^{\star}(\tau-t)} \mathrm{d} \tau .
$$

Differentiating $\frac{v_{F}^{j}\left(U^{j}+L^{j}\right)}{\bar{\lambda}}=m^{j}\left(\theta^{j}\right) \xi^{j}+R^{j}$ w. r. t. time and inserting (84), we can derive the dynamic equation for job seekers in sector $j$ :

$$
\begin{aligned}
-\frac{v_{F F}^{j}}{\bar{\lambda}} \dot{U}^{j} & =m^{j}\left(\theta^{j}\right) \dot{\xi}^{j}+\alpha_{V}^{j} m^{j}\left(\theta^{j}\right) \xi^{j} \frac{\dot{\theta}^{j}}{\theta^{j}}+\frac{v_{F F}^{j}}{\bar{\lambda}} \dot{L}^{j} \\
& =\left[\left(s^{j}+r^{\star}\right)+\alpha_{V}^{j} \frac{\dot{\theta}^{j}}{\theta^{j}}\right] m^{j}\left(\theta^{j}\right) \xi^{j}-m^{j}\left(\theta^{j}\right)\left(W^{j}+\frac{v_{F}^{j}}{\bar{\lambda}}\right)+\frac{v_{F F}^{j}}{\bar{\lambda}} \dot{L}^{j}
\end{aligned}
$$

where we used the fact that $\frac{\left(m^{j}\right)^{\prime} \theta^{j}}{m^{j}}=\alpha_{V}^{j}$. Substituting $m^{j} \xi^{j}=-\frac{v_{F}^{j}}{\lambda}-R^{j}$, we get:

$$
\frac{v_{F F}^{j}}{\bar{\lambda}} \dot{U}^{j}=\left(\frac{v_{F}^{j}}{\bar{\lambda}}+R^{j}\right)\left[\left(s+r^{\star}\right)+\alpha_{V}^{j} \frac{\dot{\theta}^{j}}{\theta^{j}}\right]+m^{j}\left(\theta^{j}\right)\left(W^{j}+\frac{v_{F}^{j}}{\bar{\lambda}}\right)-\frac{v_{F F}^{j}}{\bar{\lambda}} \dot{L}^{j} .
$$

\section{C.2 Firms}

We consider a traded sector which produces a good denoted by the superscript $T$ that can be exported or consumed domestically. We also consider a non traded sector which produces a good denoted by the superscript $N$ that can be consumed only domestically. Each sector consists of a large number of identical firms. Both the traded and non-traded sectors use labor, $L^{T}$ and $L^{N}$, according to constant returns to scale production functions:

$$
Y^{T}=A^{T} L^{T}, \quad \text { and } \quad Y^{N}=A^{N} L^{N} .
$$

Firms post job vacancies $V^{j}$ to hire workers and face a cost per job vacancy $\kappa^{j}$ which is assumed to be constant and measured in terms of the traded good. Firms pay the wage $W^{j}$ decided by the generalized Nash bargaining solution. We also consider that firms must pay a firing tax $x^{j}$ per job loss which captures the extent of employment protection legislation (see e.g., Heijdra and Ligthart [2002], Veracierto [2008]). 
As producers face a labor cost $W^{j}$ per employee, a cost per hiring of $\kappa^{j}$, the profit function of the representative firm in the traded sector is:

$$
\pi^{T}=A^{T} L^{T}-W^{T} L^{T}-\kappa^{T} V^{T}-x^{T} \cdot \max \left\{0,-\dot{L}^{T}\right\}
$$

where $x^{T}$ is a firing tax in the traded sector when $\dot{L}^{T}<0$ otherwise $x^{T}=0$.

Symmetrically, denoting by $P$ the price of non traded goods in terms of traded goods, the profit function of the representative firm in the non traded sector is:

$$
\pi^{N}=P A^{N} L^{N}-W^{N} L^{N}-\kappa^{N} V^{N}-x^{N} \cdot \max \left\{0,-\dot{L}^{N}\right\}
$$

where $x^{N}$ is a firing tax in the non traded sector when $\dot{L}^{N}<0$ otherwise $x^{N}=0$.

Denoting by $f^{j}$ the rate at which a vacancy is matched with unemployed agents, the law of motion for labor is given by:

$$
\dot{L}^{j}=f^{j}\left(\theta^{j}\right)-s^{j} L^{j}
$$

where $f^{j} V^{j}$ represents the flow of job vacancies which are fulfilled; note that $f^{j}$ decreases with labor tightness $\theta^{j}$.

The current-value Hamiltonian for the sector $j$ 's representative firm optimization problem is:

$$
\mathcal{H}^{j}=\Xi^{j} L^{j}-W^{j} L^{j}-\kappa^{j} V^{j}+\left(\gamma^{j}+x^{j}\right)\left(f^{j} V^{j}-s^{j} L^{j}\right),
$$

where $\Xi^{j}$ is the marginal revenue of labor with $\Xi^{T} \equiv A^{T}$ and $\Xi^{N} \equiv P A^{N}$ and $\gamma^{j}$ is the co-state variable associated to the labor motion equation (92).

First-order conditions can be written as follows:

$$
\begin{aligned}
\gamma^{j}+x^{j} & =\frac{\kappa^{j}}{f^{j}\left(\theta^{j}\right)}, \\
\dot{\gamma}^{j} & =\gamma^{j}\left(r^{\star}+s^{j}\right)-\left(\Xi^{j}-x^{j} s^{j}-W^{j}\right),
\end{aligned}
$$

where $\gamma^{j}$ represents the pecuniary value of an additional job to the representative firm of sector $j=T, N$. This can be seen more formally by solving (94b) forward and using the appropriate transversality condition. This yields:

$$
\gamma^{j}(t)=\int_{t}^{\infty}\left[\Xi^{j}(\tau)-W^{j}(\tau)-x^{j} s^{j}\right] e^{\left(s^{j}+r^{\star}\right)(t-\tau)} \mathrm{d} \tau .
$$

Differentiating $\gamma^{j}(t) L^{j}(t)$ w. r. t. time and inserting the law of motion for employment $\dot{L}^{j}(t)$ together with the dynamic optimality condition (94b), we obtain:

$$
\begin{aligned}
\frac{\mathrm{d}}{\mathrm{d} t}\left(\gamma^{j} L^{j}\right) & =\dot{\gamma}^{j} L^{j}+\gamma^{j} \dot{L}^{j}=\gamma^{j}\left(r^{\star}+s^{j}\right) L^{j}+x^{j} s^{j} L^{j}-\left(\Xi^{j}-W^{j}\right) L^{j}+\gamma^{j}\left(f^{j} V^{j}-s^{j} L^{j}\right), \\
& =r^{\star} \gamma^{j} L^{j}-\left[\Xi^{j} L^{j}-W^{j} L^{j}-\gamma^{j} f^{j} V^{j}-x^{j} s^{j} L^{j}\right]=r^{\star} \gamma^{j} L^{j}-\pi^{j},
\end{aligned}
$$

where we used the fact that $\gamma^{j}=\kappa^{j} / f^{j}-x^{j}, \pi^{j}=\Xi^{j} L^{j}-W^{j} L^{j}+x^{j} \dot{L}^{j}-\kappa^{j} V^{j}$ and $\dot{L}^{j}=f^{j} \theta^{j}-s^{j} L^{j}$. Using the first-order condition (94a) and solving forward, making use of the transversality condition, we get:

$$
\begin{aligned}
\gamma^{j}(t) L^{j}(t) & =\int_{t}^{\infty}\left[\Xi^{j} L^{j}-W^{j} L^{j}-\kappa^{j} V^{j}-x^{j} \cdot \max \left\{0,-\dot{L}^{j}\right\}\right] e^{-r^{\star}(\tau-t)} \mathrm{d} \tau \\
& =\int_{t}^{\infty} \pi^{j} e^{-r^{\star}(\tau-t)} \mathrm{d} \tau
\end{aligned}
$$

\section{Matching and Wage Determination}

In each sector, there are job-seeking workers $U^{j}$ and firms with job vacancies $V^{j}$ which are matched in a random fashion. Assuming a constant returns to scale matching function, the number of labor contracts $M^{j}$ concluded per job seeker $U^{j}$ gives the job finding rate $m^{j}$ which is increasing in the labor market tightness $\theta^{j}$ :

$$
m^{j}=\frac{M^{j}}{U^{j}}=X^{j}\left(\frac{V^{j}}{U^{j}}\right)^{\alpha_{V}^{j}}=X^{j}\left(\theta^{j}\right)^{\alpha_{V}}, \quad \alpha_{V}^{j} \in(0,1),
$$

where $\alpha_{V}^{j}$ represents the elasticity of vacancies in job matches and $X^{j}$ corresponds to the matching efficiency. ${ }^{59}$ The number of matches $M^{j}$ per job vacancy gives the worker-finding rate for the firm:

$$
f^{j}=\frac{M^{j}}{V^{j}}=X^{j}\left(\theta^{j}\right)^{\alpha_{V}^{j}-1}
$$

\footnotetext{
${ }^{59}$ Note that the flows of workers in and out of employment are equal to each other in any symmetric equilibrium, i.e., $m^{j} U^{j}=f^{j} V^{j}$. Hence equations $\dot{L}^{j}=f^{j} V^{j}-s^{j} L^{j}$ and $\dot{L}^{j}=m^{j} U^{j}-s^{j} L^{j}$ indicate that the demand for labor indeed equates the supply.
} 
Eq. (98) shows that the instantaneous probability of the firm finding a worker is higher the lower the labor market tightness $\theta^{j}$.

The representative firm of sector $j$ posts job vacancies in order to hire workers. We assume that the wage rate is derived from a bargaining between the firm and the worker. The wage rate $W^{j}$ is set so as to maximize the following expression:

$$
W^{j}(t)=\operatorname{argmax} \mathcal{H}_{W}^{j}=\operatorname{argmax}\left(\xi^{j}(t)\right)^{\alpha_{W}^{j}}\left(\gamma^{j}(t)+x^{j}\right)^{1-\alpha_{W}^{j}}, \quad 0 \leq \alpha_{W}^{j} \leq 1,
$$

where $\alpha_{W}^{j}$ and $1-\alpha_{W}^{j}$ correspond to the bargaining power of the worker and the firm, respectively. The first-order condition determining the current wage, $w(t)$ writes as follows:

$$
\frac{\partial \mathcal{H}_{W}^{j}}{\partial W^{j}(t)}=\frac{\alpha_{W}^{j} \mathcal{H}_{W}^{j}}{\xi^{j}(t)} \frac{\partial \xi^{j}(t)}{\partial W^{j}(t)}+\frac{\left(1-\alpha_{W}^{j}\right) \mathcal{H}_{W}^{j}}{\gamma^{j}(t)+x^{j}} \frac{\partial \gamma^{j}(t)}{\partial W^{j}(t)}=0 .
$$

Differentiating (85) and (95) w.r.t. the wage rate $W^{j}$, we get: $\frac{\partial \xi^{j}(t)}{\partial W^{j}(t)}=1$ and $\frac{\partial \gamma^{j}(t)}{\partial W^{j}(t)}=-1$; inserting these into (100):

$$
\alpha_{W}^{j}\left(\gamma^{j}(t)+x^{j}\right)=\left(1-\alpha_{W}^{j}\right) \xi^{j}(t)
$$

By differentiating (101) w. r. t. time, inserting the dynamic equations for $\xi^{j}$ given by (84) and for $\gamma^{j}$ given by (94b), bearing in mind that $\gamma^{j}+x^{j}=\frac{1-\alpha_{W}^{j}}{\alpha_{W}^{j}} \xi^{j}$ (see eq. (100)), rearranging terms, leads to the wage rate:

$$
W^{j}=\alpha_{W}^{j}\left(\Xi^{j}+r^{\star} x^{j}\right)+\left(1-\alpha_{W}^{j}\right) W_{R}^{j}
$$

where $W_{R}^{j}=-v_{F}^{j} / \bar{\lambda}$ represents the reservation wage.

An alternative expression for the reservation wage $W_{R}^{j}$ which is equal to $-v_{F}^{j} / \bar{\lambda}=m^{j}\left(\theta^{j}\right) \xi^{j}+$ $R^{j}$ can be derived as follows. Eliminating $\xi^{j}$ from (100) by making use of (116a), i.e., $\xi^{j}=$ $\frac{\alpha_{W}^{j}}{1-\alpha_{W}^{j}}\left(\gamma^{j}+x^{j}\right)$, inserting (94a), i.e., $\gamma^{j}+x^{j}=\kappa^{j} / f^{j}$, and using the fact that $m^{j} / f^{j}=\theta^{j}$, the reservation wage can be rewritten as follows:

$$
\begin{aligned}
W_{R}^{j} & =m^{j}\left(\theta^{j}\right) \xi^{j}+R^{j} \\
& =m^{j} \frac{\alpha_{W}^{j}}{1-\alpha_{W}^{j}} \frac{\kappa^{j}}{f^{j}}+R^{j} \\
& =\frac{\alpha_{W}^{j}}{1-\alpha_{W}^{j}} \kappa^{j} \theta^{j}+R^{j}
\end{aligned}
$$

\section{E Solving the Model}

\section{E.1 Short-Run Static Solutions}

In this subsection, we compute short-run static solutions for consumption and the relative price of non tradables. Static efficiency condition (83a) can be solved for consumption which of course must hold at any point of time:

$$
C=C(\bar{\lambda}, P)
$$

with

$$
\begin{aligned}
C_{\bar{\lambda}} & =\frac{\partial C}{\partial \bar{\lambda}}=-\sigma_{C} \frac{C}{\bar{\lambda}}<0 \\
C_{P} & =\frac{\partial C}{\partial P}=-\alpha_{C} \sigma_{C} \frac{C}{P}<0
\end{aligned}
$$

where $\sigma_{C}$ corresponds to the intertemporal elasticity of substitution for consumption.

Denoting by $\phi$ the intratemporal elasticity of substitution between the tradable and the non tradable good and inserting short-run solution for consumption (83a) into intra-temporal allocations between non tradable and tradable goods, i.e., $C^{N}=P_{C}^{\prime} C$ and $C^{T}=\left[P^{C}-P P_{C}^{\prime}\right] C$, allows us to solve for $C^{T}$ and $C^{N}$ :

$$
C^{T}=C^{T}(\bar{\lambda}, P), \quad C^{N}=C^{N}(\bar{\lambda}, P)
$$


where the partial derivatives are:

$$
\begin{aligned}
C_{\bar{\lambda}}^{T} & =-\sigma_{C} \frac{C^{T}}{\bar{\lambda}}<0, \\
C_{P}^{T} & =\alpha_{C} \frac{C^{T}}{P}\left(\phi-\sigma_{C}\right) \lessgtr 0, \\
C_{\bar{\lambda}}^{N} & =-\sigma_{C} \frac{C^{N}}{\bar{\lambda}}<0, \\
C_{P}^{N} & =-\frac{C^{N}}{P}\left[\left(1-\alpha_{C}\right) \phi+\alpha_{C} \sigma_{C}\right]<0,
\end{aligned}
$$

where we use the fact that $-\frac{P_{C}^{\prime \prime} P}{P_{C}^{\prime}}=\phi\left(1-\alpha_{C}\right)>0$ and $P_{C}^{\prime} C=C^{N}$.

Inserting the short-run static solution for consumption in non tradables $C^{N}(\bar{\lambda}, P)$ given by (106) into the market clearing condition for non tradables (24) allows us to solve for the relative price of non tradables:

$$
P=P\left(L^{N}, \bar{\lambda}, A^{N}\right)
$$

where

$$
\begin{aligned}
P_{L^{N}} & =\frac{\partial P}{\partial L^{N}}=\frac{A^{N}}{C_{P}^{N}}<0, \\
P_{\bar{\lambda}} & =\frac{\partial P}{\partial \bar{\lambda}}=-\frac{C_{\bar{\lambda}}^{N}}{C_{P}^{N}}<0, \\
P_{A^{N}} & =\frac{\partial P}{\partial A^{N}}=\frac{L^{N}}{C_{P}^{N}}<0 .
\end{aligned}
$$

Inserting (109) into (106), the short-run static solutions for $C^{T}$ and $C^{N}$ become:

$$
C^{T}=C^{T}\left(L^{N}, \bar{\lambda}, A^{N}\right), \quad C^{N}=C^{N}\left(L^{N}, \bar{\lambda}, A^{N}\right),
$$

where the partial derivatives are:

$$
\begin{aligned}
\frac{\hat{C}^{T}}{\hat{\bar{\lambda}}} & =-\frac{\sigma_{C} \phi}{\left[\left(1-\alpha_{C}\right) \phi+\alpha_{C} \sigma_{C}\right]}<0, \\
\frac{\hat{C}^{T}}{\hat{L}^{N}} & =\frac{\hat{C}^{T}}{\hat{A}^{N}}=-\frac{\left(\phi-\sigma_{C}\right)}{\left[\left(1-\alpha_{C}\right) \phi+\alpha_{C} \sigma_{C}\right]} \frac{\omega_{N}}{\omega_{C}} \lessgtr 0, \\
\frac{\hat{C}^{N}}{\hat{\bar{\lambda}}} & =-\sigma_{C}+\sigma_{C}=0, \\
\frac{\hat{C}^{N}}{\hat{L}^{N}} & =\frac{\hat{C}^{N}}{\hat{A^{N}}}=\frac{\omega_{N}}{\omega_{C}}>0 .
\end{aligned}
$$

We denote by a hat the rate of change of the variable and rewrite $\frac{C^{N}}{A^{N} L^{N}}=\frac{P C^{N}}{P_{C} C} \frac{P_{C} C}{Y} \frac{Y}{P A^{N} L^{N}}=\frac{\alpha_{C} \omega_{C}}{\omega_{N}}$ with $\alpha_{C}$ the non tradable content of consumption expenditure, $\omega_{C}$ the GDP share of consumption expenditure and $\omega_{N}$ the non tradable content of GDP.

\section{E.2 Derivation of the Dynamic Equation of the Current Account}

Using the fact that $A \equiv B+\gamma^{T} L^{T}+\gamma^{N} L^{N}$, differentiating with respect to time, noticing that $\left(\gamma^{j} L^{j}\right)=r^{\star} \gamma^{j} L^{j}-\pi^{j}$, the accumulation equation of traded bonds is given by:

$$
\begin{aligned}
\dot{B} & =\dot{A}-\dot{\gamma}^{T} L^{T}-\gamma^{T} \dot{L}^{T}-\dot{\gamma}^{N} L^{N}-\gamma^{N} \dot{L}^{N}, \\
& =r^{\star}\left(A-\gamma^{T} L^{T}-\gamma^{N} L^{N}\right)+\pi^{T}+\pi^{N}+W^{T} L^{T}+W^{N} L^{N}+R^{T} U^{T}+R^{N} U^{N}-T-P_{C} C .
\end{aligned}
$$

Remembering that $\pi^{j}=\Xi^{j}-W^{j} L^{j}-\kappa^{j} V^{j}-x^{j} \cdot \max \left\{0,-\dot{L}^{j}\right\}$, inserting the market clearing condition for the non traded good (24) and the balanced government budget (23), the current account equation reduces to:

$$
\dot{B}(t)=r^{\star} B(t)+A^{T} L^{T}(t)-C^{T}(t)-G^{T}-\kappa^{T} V^{T}(t)-\kappa^{N} V^{N}(t) .
$$




\section{E.3 Equilibrium Dynamics and Formal Solutions}

\section{E.3.1 Dynamic System}

Differentiating (94a) w. r. t. time, using (94b) yields

$$
\frac{\dot{\theta}^{j}}{\theta^{j}}=\frac{1}{1-\alpha_{V}^{j}} \frac{\dot{\gamma}^{j}}{\gamma^{j}+x^{j}} .
$$

Eliminating $\gamma^{j}+x^{j}$ by using (94a), leads to the dynamic equation for labor market tightness $\theta^{j}$ :

$$
\dot{\theta}^{j}(t)=\frac{\theta^{j}(t)}{\left(1-\alpha_{V}^{j}\right)}\left\{\left(s^{j}+r^{\star}\right)-\frac{f^{j}\left(\theta^{j}(t)\right)}{\kappa^{j}}\left[\left(\Xi^{j}+r^{\star} x^{j}\right)-W^{j}\right]\right\} .
$$

Setting the overall surplus from an additional job in sector $j$ :

$$
\Psi^{j}(t)=\left(\Xi^{j}(t)+r^{\star} x^{j}\right)+\frac{v_{F}^{j}(t)}{\bar{\lambda}} .
$$

Inserting the Nash bargaining wage $W^{j}$ given by (102) into $\left[\left(\Xi^{j}+r^{\star} x^{j}\right)-W^{j}\right]$, the dynamic equation for labor market tightness $\theta^{j}$ can be rewritten as follows:

$$
\dot{\theta}^{j}(t)=\frac{\theta^{j}(t)}{\left(1-\alpha_{V}^{j}\right)}\left\{\left(s^{j}+r^{\star}\right)-\frac{f^{j}\left(\theta^{j}(t)\right)\left(1-\alpha_{W}^{j}\right) \Psi^{j}(t)}{\kappa^{j}}\right\} .
$$

The overall surplus from an additional job in the traded and the non traded sector, respectively, is given by:

$$
\Psi^{T}=\left(A^{T}+r^{\star} x^{T}\right)+\frac{v_{F}^{T}}{\bar{\lambda}}, \quad \Psi^{N}=\left[P\left(L^{N}, \bar{\lambda}, A^{N}\right) A^{N}+r^{\star} x^{N}\right]+\frac{v_{F}^{N}}{\bar{\lambda}},
$$

where the short-run static solution for the relative price of non tradables (108) has been inserted into the overall surplus from a match into the non traded sector. Partial derivatives are given by:

$$
\begin{aligned}
\Psi_{L^{T}}^{T} & =\Psi_{U^{T}}^{T}=\frac{v_{F F}^{T}}{\bar{\lambda}}<0, \\
\Psi_{L^{N}}^{N} & =P_{L^{N}} A^{N}+\frac{v_{F F}^{N}}{\bar{\lambda}}<0 \\
\Psi_{U^{N}}^{N} & =\frac{v_{F F}^{N}}{\bar{\lambda}}<0 \\
\Psi_{A^{N}}^{N} & =P_{A^{N}} A^{N}+P=\frac{A^{N} L^{N}}{C_{P}^{N}}+P, \\
& =\frac{A^{N} L^{N}}{C_{P}^{N}}\left\{1-\left[\left(1-\alpha_{C}\right) \phi+\alpha_{C} \sigma_{C}\right] \frac{\alpha_{C} \omega_{C}}{\omega_{N}}\right\}<0, \\
\Psi_{\bar{\lambda}}^{N} & =P_{\bar{\lambda}} A^{N}-\frac{v_{F}^{N}}{(\bar{\lambda})^{2}}, \\
& =-\frac{1}{\bar{\lambda}}\left\{\frac{\sigma_{C} P A^{N}}{\left[\left(1-\alpha_{C}\right) \phi+\alpha_{C} \sigma_{C}\right]}+\frac{v_{F}^{N}}{\bar{\lambda}}\right\}<0,
\end{aligned}
$$

where $P_{L^{N}}<0, C_{P}^{N}<0$, and we use the fact that $\frac{C^{N}}{A^{N} L^{N}}=\frac{P C^{N}}{P_{C} C} \frac{P_{C} C}{Y} \frac{Y}{P A^{N} L^{N}}=\frac{\alpha_{C} \omega_{C}}{\omega_{N}}$.

The adjustment of the open economy towards the steady-state is described by a dynamic system which comprises six equations. We consider that the utility function is additively separable in the disutility received by working and searching in the two sectors. Such a specification makes it impossible to switch from one sector to another instantaneously without going through a spell of search unemployment, as in Alvarez and Shimer [2011]. Because workers must search for a job to switch from one sector to another, i.e., cannot relocate hours worked from one sector to another instantaneously, the dynamic system is block recursive. The first (second) dynamic system consists of the law of motion of employment in the traded (non traded) sector described by (12), the dynamic equations for labor tightness and job seekers given by (114) and (88), respectively. We denote the steady-state value with a tilde.

\section{Traded Sector}

Linearizing the accumulation equation for traded labor (12) by setting $j=T$ and the dynamic equations for labor market tightness (114) and job seekers (88) in the traded sector, we get in matrix form:

$$
\left(\dot{L}^{T}, \dot{\theta}^{T}, \dot{U}^{T}\right)^{T}=J^{T}\left(L^{T}(t)-\tilde{L}^{T}, \theta^{T}(t)-\tilde{\theta}^{T}, U^{T}(t)-\tilde{U}^{T}\right)^{T}
$$


where $J^{T}$ is given by

$$
J^{T} \equiv\left(\begin{array}{ccc}
-s^{T} & \left(m^{T}\right)^{\prime} \tilde{U}^{T} & m^{T}\left(\tilde{\theta}^{T}\right) \\
-\frac{1-\alpha_{W}^{T}}{1-\alpha_{V}^{T}} \frac{\tilde{m}^{T}}{\kappa^{T}} \frac{v_{F F}^{T}}{\lambda} & \left(s^{T}+r^{\star}\right) & -\frac{1-\alpha_{W}^{T}}{1-\alpha_{V}^{T}} \frac{\tilde{m}^{T}}{\kappa^{T}} \frac{v_{F F}^{T}}{\lambda} \\
\left(2 s^{T}+r^{\star}\right)+\frac{\alpha_{W}^{T} \tilde{m}^{T}}{1-\alpha_{V}^{T}} & -\left(m^{T}\right)^{\prime} \tilde{U}^{T} & \left(s^{T}+r^{\star}\right)-\tilde{m}^{T}+\frac{\alpha_{W}^{T}}{1-\alpha_{V}^{T}} \tilde{m}^{T}
\end{array}\right),
$$

and where we used the fact that:

$$
\begin{aligned}
& \frac{\tilde{f}^{T}\left(1-\alpha_{W}^{T}\right) \tilde{\Psi}^{T}}{s^{T}+r^{\star}}=\kappa^{T}, \\
& \frac{v_{F}^{T}}{\bar{\lambda}}+R^{T}=-\tilde{m}^{T} \tilde{\xi}^{T}=-\frac{\tilde{m}^{T} \alpha_{W}^{T} \tilde{\Psi}^{T}}{s^{T}+r^{\star}}, \\
& 1+\frac{\alpha_{V}^{T}}{1-\alpha_{V}^{T}} \frac{\tilde{f}^{T}\left(1-\alpha_{W}^{T}\right) \tilde{\Psi}^{T}}{\kappa^{T}\left(s^{T}+r^{\star}\right)}=\frac{1}{1-\alpha_{V}^{T}} .
\end{aligned}
$$

The trace denoted by $\operatorname{Tr}$ of the linearized $3 \times 3$ matrix (118) is given by:

$$
\operatorname{Tr} J^{T}=\left(s^{T}+r^{\star}\right)+r^{\star}+\frac{\tilde{m}^{T}}{1-\alpha_{V}^{T}}\left[\alpha_{W}^{T}-\left(1-\alpha_{V}^{T}\right)\right] .
$$

The determinant denoted by Det of the linearized $3 \times 3$ matrix (118) is unambiguously negative:

$$
\operatorname{Det} J^{T}=-\left(s^{T}+r^{\star}\right)\left(s^{T}+\tilde{m}^{T}\right)\left[\left(s^{T}+r^{\star}\right)+\frac{\alpha_{W}^{T}}{1-\alpha_{V}^{T}} \tilde{m}^{T}\right]<0 .
$$

Assuming that the Hosios condition holds, i.e., setting $\alpha_{W}^{T}=1-\alpha_{V}^{T}$, the trace reduces to:

$$
\operatorname{Tr} J^{T}=\left(s^{T}+r^{\star}\right)+r^{\star},
$$

while the determinant is given by:

$$
\operatorname{Det} J^{T}=-\left(s^{T}+r^{\star}\right)\left(s^{T}+r^{\star}+\tilde{m}^{T}\right)\left(s^{T}+\tilde{m}^{T}\right)<0 .
$$

From now on, for clarity purpose, we impose the Hosios condition in order to avoid unnecessary complications. We relax this assumption when analyzing steady-state effects and conducting a quantitative exploration of the effects of higher productivity of tradables relative to non tradables. Note that all conclusions related to the analysis of equilibrium dynamics hold whether the Hosios conditions is imposed or not.

Denoting by $\nu^{T}$ the eigenvalue in the traded sector, the characteristic equation for the matrix $J$ (118) of the linearized system writes as follows:

$$
\left(s^{T}+r^{\star}-\nu_{i}^{T}\right)\left\{\left(\nu_{i}^{T}\right)^{2}-r^{\star} \nu_{i}^{T}+\frac{\operatorname{Det} J^{T}}{s^{T}+r^{\star}}\right\}=0 .
$$

The characteristic roots obtained from the characteristic polynomial of degree two can be written as follows:

$$
\nu_{i}^{T} \equiv \frac{1}{2}\left\{r^{\star} \pm \sqrt{\left(r^{\star}\right)^{2}-4 \frac{\operatorname{Det} J^{T}}{s^{T}+r^{\star}}}\right\} \gtrless 0, \quad i=1,2 .
$$

We denote by $\nu_{1}^{T}<0$ and $\nu_{2}^{T}>0$ the stable and unstable eigenvalues respectively which satisfy:

$$
\nu_{1}^{T}<0<r^{\star}<\nu_{2}^{T} .
$$

Let $\nu_{3}^{T}$ be the second unstable characteristic root which writes as:

$$
\nu_{3}^{T}=s^{T}+r^{\star}>0 .
$$

Since the system features one state variable, $L^{T}$, and one negative eigenvalue, two jump variables, $\theta^{T}$ and $U^{T}$, and two positive eigenvalues, the equilibrium yields a unique one-dimensional saddle-path. Inserting (119) and (120) into (124), the stable and unstable eigenvalues reduce to:

$$
\nu_{1}^{T}=-\left(s^{T}+\tilde{m}^{T}\right), \quad \nu_{2}^{T}=\left(s^{T}+r^{\star}+\tilde{m}^{T}\right) .
$$

\section{Non Traded Sector}


Linearizing the accumulation equation for non traded labor (12) by setting $j=N$ and the dynamic equations for labor market tightness (114) and job seekers (88) in the non traded sector, we get in matrix form:

$$
\left(\dot{L}^{N}, \dot{\theta}^{N}, \dot{U}^{N}\right)^{T}=J^{N}\left(L^{N}(t)-\tilde{L}^{N}, \theta^{N}(t)-\tilde{\theta}^{N}, U^{N}(t)-\tilde{U}^{N}\right)^{T}
$$

where $J^{N}$ is given by

$$
J^{N} \equiv\left(\begin{array}{ccc}
-s^{N} & \left(m^{N}\right)^{\prime} \tilde{U}^{N} & m^{N}\left(\tilde{\theta}^{N}\right) \\
-\frac{1-\alpha_{W}^{N}}{1-\alpha_{V}^{N}} \frac{\tilde{m}^{N}}{\kappa^{N}}\left(P_{L^{N}} A^{N}+\frac{v_{F F}^{N}}{\lambda}\right) & \left(s^{N}+r^{\star}\right) & -\frac{1-\alpha_{W}^{N}}{1-\alpha_{V}^{N}} \frac{\tilde{m}^{N}}{\kappa^{N}} \frac{v_{F F}^{N}}{\lambda} \\
\left(2 s^{N}+r^{\star}\right)+\frac{\alpha_{W}^{N} \tilde{m}^{N}}{1-\alpha_{V}^{N}}\left(P_{L^{N}} A^{N} \frac{\bar{\lambda}}{v_{F F}^{N}}+1\right) & -\left(m^{N}\right)^{\prime} \tilde{U}^{N} & \left(s^{N}+r^{\star}\right)-\tilde{m}^{N}+\frac{\alpha_{W}^{N}}{1-\alpha_{V}^{N}} \tilde{m}^{N}
\end{array}\right),
$$

and where we used the fact that:

$$
\begin{aligned}
& \frac{\tilde{f}^{N}\left(1-\alpha_{W}^{N}\right) \tilde{\Psi}^{N}}{s^{N}+r^{\star}}=\kappa^{N}, \\
& \frac{v_{F}^{N}}{\bar{\lambda}}+R^{N}=-\tilde{m}^{N} \tilde{\xi}^{N}=-\frac{\tilde{m}^{N} \alpha_{W}^{N} \tilde{\Psi}^{N}}{s^{N}+r^{\star}}, \\
& 1+\frac{\alpha_{V}^{N}}{1-\alpha_{V}^{N}} \frac{\tilde{f}^{N}\left(1-\alpha_{W}^{N}\right) \tilde{\Psi}^{N}}{\kappa^{N}\left(s^{N}+r^{\star}\right)}=\frac{1}{1-\alpha_{V}^{N}} .
\end{aligned}
$$

The trace denoted by $\operatorname{Tr}$ of the linearized $3 \times 3$ matrix (129) is given by:

$$
\operatorname{Tr} J^{N}=\left(s^{N}+r^{\star}\right)+r^{\star}+\frac{\tilde{m}^{N}}{1-\alpha_{V}^{N}}\left[\alpha_{W}^{N}-\left(1-\alpha_{V}\right)\right] .
$$

The determinant denoted by Det of the linearized $3 \times 3$ matrix (129) is unambiguously negative:

$$
\begin{aligned}
\operatorname{Det} J^{N} & =-\left(s^{N}+r^{\star}\right)\left\{\left(s^{N}+\tilde{m}^{N}\right)\left[\left(s^{N}+r^{\star}\right)+\frac{\alpha_{W}^{N}}{1-\alpha_{V}^{N}} \tilde{m}^{N}\right]\right. \\
& \left.+\frac{1-\alpha_{W}^{N}}{1-\alpha_{V}^{N}} \frac{\tilde{m}^{N}}{\kappa^{N}} P_{L^{N}} A^{N} \frac{\tilde{m}^{N}}{\theta^{N}}\left(\frac{\alpha_{W}^{N}}{1-\alpha_{W}^{N}} \kappa^{N} \tilde{\theta}^{N} \frac{\bar{\lambda}}{v_{F F}^{N}}-\alpha_{V} \tilde{U}^{N}\right)\right\}<0,
\end{aligned}
$$

where $P_{L^{N}}<0$.

Assuming that the Hosios condition holds, i.e., setting $\alpha_{W}^{N}=1-\alpha_{V}^{N}$, the trace reduces to:

$$
\operatorname{Tr} J^{N}=\left(s^{N}+r^{\star}\right)+r^{\star},
$$

while the determinant is given by:

$\operatorname{Det} J^{N}=-\left(s^{N}+r^{\star}\right)^{2}\left(s^{N}+\tilde{m}^{N}\right)\left\{\frac{\left(s^{N}+r^{\star}+\tilde{m}^{N}\right)}{\left(s^{N}+r^{\star}\right)}-\frac{P_{L^{N}} \tilde{L}^{N}}{\tilde{P}} \frac{\tilde{P} A^{N}}{\left(1-\alpha_{V}^{N}\right) \tilde{\Psi}^{N}}\left(\tilde{\chi}^{N} \sigma_{L}^{N}+\alpha_{V} \tilde{u}^{N}\right)\right\}<0$,

where we have rewritten the last term as follows:

$$
\begin{aligned}
& \frac{1-\alpha_{W}^{N}}{1-\alpha_{V}^{N}} \frac{\tilde{m}^{N}}{\kappa^{N}} P_{L^{N}} A^{N} \frac{\tilde{m}^{N}}{\theta^{N}}\left(\frac{\alpha_{W}^{N}}{1-\alpha_{W}^{N}} \kappa^{N} \tilde{\theta}^{N} \frac{\bar{\lambda}}{v_{F F}^{N}}-\alpha_{V} \tilde{U}^{N}\right) \\
= & -\frac{1-\alpha_{W}^{N}}{1-\alpha_{V}^{N}} \frac{\tilde{m}^{N}}{\kappa^{N}} P_{L^{N}} A^{N} \tilde{f}^{N} \tilde{F}^{N}\left(\tilde{\chi}^{N} \sigma_{L}^{N}+\alpha_{V} \tilde{u}^{N}\right), \\
= & -\frac{s^{N}}{\tilde{u}^{N}\left(1-\alpha_{V}^{N}\right)} P_{L^{N}} \tilde{L}^{N} A^{N} \frac{\left(s^{N}+r^{\star}\right)}{\tilde{\Psi}^{N}}\left(\tilde{\chi}^{N} \sigma_{L}^{N}+\alpha_{V} \tilde{u}^{N}\right), \\
= & -\left(s^{N}+r^{\star}\right)\left(s^{N}+\tilde{m}^{N}\right) \frac{P_{L^{N}} \tilde{L}^{N}}{\tilde{P}} \frac{\tilde{P} A^{N}}{\left(1-\alpha_{V}^{N}\right) \tilde{\Psi}^{N}}<0,
\end{aligned}
$$

and where we used the fact that $\frac{\alpha_{W}^{N}}{1-\alpha_{W}^{N}} \kappa^{N} \tilde{\theta}^{N}=-\tilde{\chi}^{N} \frac{v_{F}^{N}}{\lambda}, \tilde{f}^{N}=\tilde{m}^{N} / \tilde{\theta}^{N}$, and $\frac{v_{F}^{N}}{v_{F F}^{N} \tilde{F}^{N}}=\sigma_{L}^{N}$ to get the second line, $\frac{\tilde{f}^{N}\left(1-\alpha_{W}^{N}\right)}{\kappa^{N}}=\frac{\left(s^{N}+r^{\star}\right)}{\tilde{\Psi}^{N}}, \tilde{m}^{N} \tilde{U}^{N}=s^{N} \tilde{L}^{N}$, and $\tilde{U}^{N} / \tilde{F}^{N}=\tilde{u}^{N}$ to get the third line, $\tilde{u}^{N}=\frac{s^{N}}{s^{N}+\tilde{m}^{N}}$, multiplying the numerator and the denominator by $\tilde{P}$ and rearranging terms to get the last line.

We impose the Hosios condition in order to avoid unnecessary complications. Denoting by $\nu^{N}$ the eigenvalue, the characteristic equation for the matrix $J$ (129) of the linearized system writes as follows:

$$
\left(s^{N}+r^{\star}-\nu_{i}^{N}\right)\left\{\left(\nu_{i}^{N}\right)^{2}-r^{\star} \nu_{i}^{N}+\frac{\operatorname{Det} J^{N}}{s^{N}+r^{\star}}\right\}=0 .
$$


The characteristic roots obtained from the characteristic polynomial of degree two write as follows:

$$
\nu_{i}^{N} \equiv \frac{1}{2}\left\{r^{\star} \pm \sqrt{\left(r^{\star}\right)^{2}-4 \frac{\operatorname{Det} J^{N}}{s^{N}+r^{\star}}}\right\} \gtrless 0, \quad i=1,2 .
$$

We denote by $\nu_{1}^{N}<0$ and $\nu_{2}^{N}>0$ the stable and unstable eigenvalues respectively which satisfy:

$$
\nu_{1}^{N}<0<r^{\star}<\nu_{2}^{N} .
$$

As it will become useful later, $\nu_{1}^{N}\left(r^{\star}-\nu_{1}^{N}\right)=\frac{\operatorname{Det} J^{N}}{s^{N}+r^{\star}}$ which can be rewritten as follows

$$
\begin{aligned}
\frac{\operatorname{Det} J^{N}}{s^{N}+r^{\star}} & =-\left(s^{N}+r^{\star}\right)\left(s^{N}+\tilde{m}^{N}\right)\left\{\frac{\left(s^{N}+r^{\star}+\tilde{m}^{N}\right)}{\left(s^{N}+r^{\star}\right)}+\frac{\omega_{N}}{\alpha_{C} \omega_{C}\left[\left(1-\alpha_{C}\right) \phi+\alpha_{C} \sigma_{C}\right]}\right. \\
& \left.\times \frac{\tilde{P} A^{N}}{\left(1-\alpha_{V}^{N}\right) \tilde{\Psi}^{N}}\left(\tilde{\chi}^{N} \sigma_{L}^{N}+\alpha_{V}^{N} \tilde{u}^{N}\right)\right\}<0 .
\end{aligned}
$$

where we used the fact that $\frac{C^{N}}{A^{N} L^{N}}=\frac{\alpha_{C} \omega_{C}}{\omega_{N}}$ and $P_{L^{N}}=\frac{A^{N}}{C_{P}^{N}}<0$.

Let $\nu_{3}^{N}$ be the second unstable characteristic root which writes as:

$$
\nu_{3}^{N}=s^{N}+r^{\star}>0 .
$$

Since the system features one state variable, $L^{N}$, and one negative eigenvalue, two jump variables, $\theta^{N}$ and $U^{N}$, and two positive eigenvalues, the equilibrium yields a unique one-dimensional saddlepath.

\section{E.4 Formal Solutions for $\theta^{T}(t)$ and $U^{T}(t)$}

Setting the constant $D_{2}^{T}=0$ to insure a converging adjustment for all macroeconomic aggregates, the stable paths are given by :

$$
\begin{aligned}
L^{T}(t)-\tilde{L}^{T} & =D_{1}^{T} e^{\nu_{1}^{T} t} \\
\theta^{T}(t)-\tilde{\theta}^{T} & =\omega_{21}^{T} D_{1}^{T} e^{\nu_{1}^{T} t} \\
U^{T}(t)-\tilde{U}^{T} & =\omega_{31}^{T} D_{1}^{T} e^{\nu_{1}^{T} t}
\end{aligned}
$$

where $D_{1}^{T}=L_{0}^{T}-\tilde{L}^{T}$, and elements $\omega_{21}^{T}$ and $\omega_{31}^{T}$ of the eigenvector (associated with the stable eigenvalue $\nu_{1}^{T}$ ) are given by:

$$
\begin{aligned}
\omega_{21}^{T} & =\frac{\frac{1-\alpha_{W}^{T}}{1-\alpha_{V}^{T}} \frac{\tilde{m}^{T}}{\kappa^{T}} \frac{v_{F F}^{T}}{\lambda}\left(\tilde{m}^{T}+s^{T}+\nu_{1}^{T}\right)}{\tilde{m}^{T}\left(s^{T}+r^{\star}-\nu_{1}^{T}\right)+\frac{1-\alpha_{W}^{T}}{1-\alpha_{V}^{T}} \frac{\tilde{m}^{T}}{\kappa^{T}} \frac{v_{F F}^{T}}{\lambda}\left(m^{T}\right)^{\prime} \tilde{U}^{T}} \lessgtr 0, \\
\omega_{31}^{T} & =\left(\frac{s^{T}+\nu_{1}^{T}}{\tilde{m}^{T}}\right)-\frac{\left(m^{T}\right)^{\prime} \tilde{U}^{T}}{\tilde{m}^{T}} \omega_{21}^{T} \lessgtr 0 .
\end{aligned}
$$

We have normalized $\omega_{11}^{T}$ to unity. Inserting $\nu_{1}^{T}=s^{T}+\tilde{m}^{T}$ (see (127)) into (141a) and (141b), eigenvectors reduce to:

$$
\omega_{21}^{T}=0, \quad \omega_{31}^{T}=-1
$$

From (142), the dynamics for labor market tightness $\theta^{T}$ degenerate while job seekers are negatively correlated with employment along a stable transitional path.

\section{E.5 Formal Solutions for $\theta^{N}(t)$ and $U^{N}(t)$}

Setting the constant $D_{2}^{N}=0$ to insure a converging adjustment for all macroeconomic aggregates, the stable paths are given by:

$$
\begin{aligned}
L^{N}(t)-\tilde{L}^{N} & =D_{1}^{N} e^{\nu_{1}^{N} t}, \\
\theta^{N}(t)-\tilde{\theta}^{N} & =\omega_{21}^{N} D_{1}^{N} e^{\nu_{1}^{N} t}, \\
U^{N}(t)-\tilde{U}^{N} & =\omega_{31}^{N} D_{1}^{N} e^{\nu_{1}^{N} t},
\end{aligned}
$$

where $D_{1}^{N}=L_{0}^{N}-\tilde{L}^{N}$, and elements $\omega_{21}^{N}$ and $\omega_{31}^{N}$ of the eigenvector (associated with the stable eigenvalue $\nu_{1}^{N}$ ) are given by:

$$
\begin{aligned}
\omega_{21}^{N} & =\frac{\frac{1-\alpha_{W}^{N}}{1-\alpha_{V}^{N}} \frac{\tilde{m}^{N}}{\kappa^{N}}\left[\tilde{m}^{N}\left(P_{L^{N}} A^{N}+\frac{v_{F F}^{N}}{\lambda}\right)+\left(s^{N}+\nu_{1}^{N}\right) \frac{v_{F F}^{N}}{\lambda}\right]}{\tilde{m}^{N}\left(s^{N}+r^{\star}-\nu_{1}^{N}\right)+\frac{1-\alpha_{W}^{N}}{1-\alpha_{V}^{N}} \frac{\tilde{m}^{N}}{\kappa^{N}} \frac{v_{F F}^{N}}{\bar{\lambda}}\left(m^{N}\right)^{\prime} \tilde{U}^{N}} \lessgtr 0, \\
\omega_{31}^{N} & =\left(\frac{s^{N}+\nu_{1}^{N}}{\tilde{m}^{N}}\right)-\frac{\left(m^{N}\right)^{\prime} \tilde{U}^{N}}{\tilde{m}^{N}} \omega_{21}^{N} \lessgtr 0 .
\end{aligned}
$$


We have normalized $\omega_{11}^{N}$ to unity. The signs of (144a) and (144b) will be determined later.

\section{E.6 Formal Solution for the Stock of Foreign Bonds $B(t)$}

Substituting first the short-run static solutions for consumption in tradables given by (110), and using the fact that $V^{j}=U^{j} \theta^{j}$, the accumulation equation for traded bonds (112) can be written as follows:

$$
\dot{B}(t)=r^{\star} B(t)+A^{T} L^{T}(t)-C^{T}\left(L^{N}(t), \bar{\lambda}, A^{N}\right)-G^{T}-\kappa^{T} \theta^{T}(t) U^{T}(t)-\kappa^{N} \theta^{N}(t) U^{N}(t) .
$$

Linearizing (145) in the neighborhood of the steady-state and inserting stable solutions given by (140) and (143) yields:

$$
\dot{B}(t)=r^{\star}(B(t)-\tilde{B})+\Lambda^{T}\left(L^{T}(t)-\tilde{L}^{T}\right)+\Lambda^{N}\left(L^{N}(t)-\tilde{L}^{N}\right),
$$

where we set:

$$
\begin{aligned}
\Lambda^{T} & =A^{T}-\kappa^{T} \tilde{U}^{T} \omega_{21}^{T}-\kappa^{T} \tilde{\theta}^{T} \omega_{31}^{T}=A^{T}+\kappa^{T} \tilde{\theta}^{T}>0 \\
\Lambda^{N} & =-C_{L^{N}}^{T}-\kappa^{N} \tilde{U}^{N} \omega_{21}^{N}-\kappa^{N} \tilde{\theta}^{N} \omega_{31}^{N} \\
& =-C_{L^{N}}^{T}-\kappa^{N} \tilde{U}^{N}\left(1-\alpha_{V}^{N}\right) \omega_{21}^{N}-\frac{\kappa^{N} \tilde{\theta}^{N}\left(s^{N}+\nu_{1}^{N}\right)}{\tilde{m}^{N}}>0
\end{aligned}
$$

where we have inserted (144b) and used the fact that $\left(m^{N}\right)^{\prime} \theta^{N} / m^{N}=\alpha_{V}^{N}$ to get (147b); note that $C_{L^{N}}^{T} \simeq 0$ because our estimates of $\phi$ average about 1 while we set $\sigma_{C}$ to one. The sign of $(147 \mathrm{~b})$ follows from the fact that $\omega_{21}^{N}<0$ (see (189)) and $s^{N}+\nu_{1}^{N}<0$; the latter result stems from the fact that $\nu_{1}^{T}=-\left(s^{T}+\tilde{m}^{T}\right)$; because we have the following set of inequalities $\frac{\operatorname{Det} J^{N}}{s^{N}+r^{N}}<\frac{\operatorname{Det} J^{T}}{s^{T}+r^{\star}}<0$, $\nu_{1}^{N}<-\left(s^{N}+\tilde{m}^{N}\right)<0$ and thereby $s^{N}+\nu_{1}^{N}<0$.

Solving the differential equation (146) yields:

$$
B(t)=\tilde{B}+\left[\left(B_{0}-\tilde{B}\right)-\frac{\Lambda^{T} D_{1}^{T}}{\nu_{1}^{T}-r^{\star}}-\frac{\Lambda^{N} D_{1}^{N}}{\nu_{1}^{N}-r^{\star}}\right] e^{r^{\star} t}+\frac{\Lambda^{T} D_{1}^{T}}{\nu_{1}^{T}-r^{\star}} e^{\nu_{1}^{T} t}+\frac{\Lambda^{N} D_{1}^{N}}{\nu_{1}^{N}-r^{\star}} e^{\nu_{1}^{N} t} .
$$

Invoking the transversality condition for intertemporal solvency, and using the fact that $D_{1}^{T}=$ $L_{0}^{T}-\tilde{L}^{T}$ and $D_{1}^{N}=L_{0}^{N}-\tilde{L}^{N}$, we obtain the linearized version of the nation's intertemporal budget constraint:

$$
\tilde{B}-B_{0}=\Phi^{T}\left(\tilde{L}^{T}-L_{0}^{T}\right)+\Phi^{T}\left(\tilde{L}^{N}-L_{0}^{N}\right)
$$

where we set

$$
\Phi^{T} \equiv \frac{\Lambda^{T}}{\nu_{1}^{T}-r^{\star}}=-\frac{\left(A^{T}+\kappa^{T} \tilde{\theta}^{T}\right)}{\left(s^{T}+\tilde{m}^{T}+r^{\star}\right)}<0, \quad \Phi^{N} \equiv \frac{\Lambda^{N}}{\nu_{1}^{N}-r^{\star}}<0 .
$$

Equation (150) can be solved for the stock of foreign bonds:

$$
\tilde{B}=B\left(\tilde{L}^{T}, \tilde{L}^{N}\right), \quad B_{L^{T}}=\Phi^{T}<0, \quad B_{L^{N}}=\Phi^{N}<0 .
$$

For the national intertemporal solvency to hold, the terms in brackets of equation (148) must be zero so that the stable solution for net foreign assets finally reduces to:

$$
B(t)-\tilde{B}=\Phi^{T}\left(L^{T}(t)-\tilde{L}^{T}\right)+\Phi^{N}\left(L^{N}(t)-\tilde{L}^{N}\right)
$$

\section{F Revisiting the Theory Developed by Balassa [1964] and Samuelson [1964]: Derivation of Equations in Section 2.1}

This Appendix presents the formal analysis underlying the results described in section 2.1. For simplicity purposes, we abstract from firing costs. Additionally, we assume that the worker bargaining power $\alpha_{W}^{j}$ is symmetric across sectors.

As defined by eq. (113) that we repeat for convenience, the overall surplus from hiring in sector $j, \Psi^{j}$, is defined as the difference between the marginal product of labor $\left(\Xi^{j}\right)$ and the reservation wage $\left(W_{R}^{j}\right)$ :

$$
\Psi^{j}=\Xi^{j}-W_{R}^{j}
$$

Eq. (153) corresponds to eq. (1) in the text. The reservation wage, $W_{R}^{j}$, is equal to the expected value of a job, i.e., $m^{j} \xi^{j}$ with $m^{j}$ the probability of finding a job, plus the unemployment benefit $R^{j}$ :

$$
W_{R}^{j}=\frac{\alpha_{W}}{1-\alpha_{W}} \kappa^{j} \theta^{j}+R^{j}
$$


where we used the fact that $m^{j} \xi^{j}=\frac{\alpha_{W}}{1-\alpha_{W}} \kappa^{j} \theta^{j}$. Totally differentiating eq. (154), the change of the reservation wage in percentage is proportional to the labor market tightness:

$$
\hat{w}_{R}^{j}=\chi^{j} \hat{\theta}^{j}
$$

where $\chi^{j} \equiv \frac{m^{j} \xi^{j}}{W_{R}^{j}}$ corresponds to the share of the surplus associated with a labor contract; the share $\chi^{j}$ is smaller than one as long as job seekers receive unemployment benefits, $R^{j}$, from the State since $W_{R}^{j}=m^{j} \xi^{j}+R^{j}$.

The product wage $W^{j}$ paid to the worker in sector $j$ is equal to the reservation wage $W_{R}^{j}$ plus a share $\alpha_{W}$ of the overall surplus $\Psi^{j}$ :

$$
W^{j}=\alpha_{W} \Psi^{j}+W_{R}^{j}
$$

Eq. (156) corresponds to eq. (2) in the text. Totally differentiating (156), the change in the product wage in percentage is proportional to the changes in the labor market tightness and the overall surplus from an additional job:

$$
\begin{aligned}
\hat{w}^{j} & =\frac{\alpha_{W} \Psi^{j}}{W^{j}} \hat{\Psi}^{j}+\frac{W_{R}^{j}}{W^{j}} \hat{W}_{R}^{j}, \\
& =\frac{\alpha_{W} \Psi^{j}}{W^{j}} \hat{\Psi}^{j}+\frac{W_{R}^{j} \chi^{j}}{W^{j}} \hat{\theta}^{j},
\end{aligned}
$$

where we substituted (155) to get the last line. Subtracting $\hat{w}^{T}$ from $\hat{w}^{N}$ yields the wage differential between the non traded and the traded sector:

$$
\begin{aligned}
\hat{w}^{N}-\hat{w}^{T} & =\frac{\alpha_{W} \Psi^{N}}{W^{N}} \hat{\Psi}^{N}+\frac{W_{R}^{N}}{W^{N}} \hat{W}_{R}^{N}-\frac{\alpha_{W} \Psi^{T}}{W^{T}} \hat{\Psi}^{T}+\frac{W_{R}^{T}}{W^{T}} \hat{W}_{R}^{T}, \\
& =-\frac{\chi W_{R}}{W}\left(\hat{\theta}^{T}-\hat{\theta}^{N}\right)-\frac{\alpha_{W} \Psi}{W}\left(\hat{\Psi}^{T}-\hat{\Psi}^{N}\right),
\end{aligned}
$$

where we assume that initially, sectoral wages, $W^{j}$, the share of the surplus associated with a labor contract, $\chi^{j}$, reservation wages, $W_{R}^{j}$, and overall surpluses, $\Psi^{j}$, are similar across sectors, i.e., $W^{j} \simeq W, \chi^{j} W_{R}^{j} \simeq \chi W_{R}$ and $\Psi^{j} \simeq \Psi$. Eq. (158) corresponds to eq. (3) in the text.

Denoting the job destruction rate by $s^{j}$ and the job finding rate by $m^{j}$, and using the fact at the steady-state, the flow of unemployed workers who find a job is equalized with the flow of employed workers who lose their job, the unemployment rate $u^{j}$ in sector $j$ reads as:

$$
u^{j}=\frac{s^{j}}{s^{j}+m^{j}\left(\theta^{j}\right)} .
$$

Totally differentiating (159) and assuming that the elasticity of vacancies in job matches, denoted by $\alpha^{V}$, is symmetric across sectors, the change in unemployment rate in sector $j$ reads as:

$$
\begin{aligned}
d u^{j} & =-\alpha_{V} u^{j} \frac{m^{j}}{s^{j}+m^{j}\left(\theta^{j}\right)} \hat{\theta}^{j} \\
& =-\alpha_{V} u^{j}\left(1-u^{j}\right) \hat{\theta}^{j}
\end{aligned}
$$

where we used the fact that $1-u^{j}=\frac{m^{j}}{s^{j}+m^{j}\left(\theta^{j}\right)}$. Subtracting $d u^{T}$ from $d u^{N}$ yields negative relationship between the unemployment rate differential between tradables and non tradables and the percentage change in labor market tightness in the traded relative to the non traded sector:

$$
d u^{T}-d u^{N}=-\alpha_{V} u(1-u)\left(\hat{\theta}^{T}-\hat{\theta}^{N}\right)
$$

where we assume that at the initial steady-state, search parameters are such that $u^{j} \equiv u$. Eq. (161) corresponds to eq. (4) in the text.

When a labor contract is concluded, a surplus $\Psi^{j}$ is created. The firm obtains a share $1-\alpha_{W}$ of the surplus which is equal to the difference between the marginal product of labor and the Nash bargaining wage $W^{j}$ :

$$
\left(1-\alpha_{W}\right) \Psi^{j}=\Xi^{j}-W^{j} .
$$

The equation above can be rewritten as follows:

$$
\Xi^{j}=\left(1-\alpha_{W}\right) \Psi^{j}+W^{j}
$$

Eq. (162) corresponds to eq. (5) in the text. According to the definition of the representative firm's profit (16), i.e., $\pi^{j}=\Xi^{j} L^{j}-W^{j} L^{j}-\kappa^{j} V^{j}$ (we set $x^{j}=0$ since we abstract from the firing 
cost in this section for simplicity purposes), the share of the surplus obtained by the firm is equal to the dividend plus the hiring cost per worker:

$$
\left(1-\alpha_{W}\right) \Psi^{j}=\frac{\pi^{j}+\kappa^{j} V^{j}}{L^{j}} .
$$

Totally differentiating (162) yields the change of the marginal revenue of labor in percentage:

$$
\hat{\Xi}^{j}=\frac{\left(1-\alpha_{W}\right) \Psi^{j}}{\Xi^{j}} \hat{\Psi}^{j}+\frac{W^{j}}{\Xi^{j}} \hat{w}^{j} .
$$

Subtracting $\hat{\Xi}^{T}$ from $\hat{\Xi}^{N}$ while assuming that initially $W^{j} \simeq W, \Xi^{j} \simeq \Xi, \Psi^{j} \simeq \Psi$, leads to:

$$
\hat{\Xi}^{N}-\hat{\Xi}^{T}=-\frac{\left(1-\alpha_{W}\right) \Psi}{\Xi}\left(\hat{\Psi}^{T}-\hat{\Psi}^{N}\right)+\frac{W}{\Xi}\left(\hat{w}^{N}-\hat{w}^{T}\right) .
$$

Using the fact that $\hat{\Xi}^{N}=\hat{p}+\hat{a}^{N}$ and $\hat{\Xi}^{T}=\hat{a}^{T}$, one obtains a relationship between the relative price growth and both the productivity and the wage differential:

$$
\hat{p}=\hat{a}^{T}-\hat{a}^{N}-\frac{\left(1-\alpha_{W}\right) \Psi}{\Xi}\left(\hat{\Psi}^{T}-\hat{\Psi}^{N}\right)+\frac{W}{\Xi}\left(\hat{w}^{N}-\hat{w}^{T}\right) .
$$

Eq. (166) corresponds to eq. (6) in the text.

\section{G Graphical Apparatus}

Before turning to the derivation of steady-state effects, we investigate graphically the long-run effects of a productivity differential.

\section{G.1 Steady-State}

Using (103), the steady-state of the open economy is described by the following set of equations:

$$
\begin{gathered}
\tilde{C}=\left[P_{C}(\tilde{P}) \bar{\lambda}\right]^{-\sigma_{C}}, \\
s^{T} \tilde{L}^{T}=m^{T}\left(\tilde{\theta}^{T}\right) \tilde{U}^{T}, \\
s^{N} \tilde{L}^{N}=m^{N}\left(\tilde{\theta}^{N}\right) \tilde{U}^{N}, \\
\left(\tilde{L}^{T}+\tilde{U}^{T}\right)=\left[\bar{\lambda}\left(\frac{\alpha_{W}^{T}}{1-\alpha_{W}^{T}} \kappa^{T} \tilde{\theta}^{T}+R^{T}\right)\right]^{\sigma_{L}^{T}}, \\
\left(\tilde{L}^{N}+\tilde{U}^{N}\right)=\left[\bar{\lambda}\left(\frac{\alpha_{W}^{N}}{1-\alpha_{W}^{N}} \kappa^{N} \tilde{\theta}^{N}+R^{N}\right)\right]^{\sigma_{L}^{N}}, \\
\frac{\kappa^{T}}{f^{T}\left(\tilde{\theta}^{T}\right)}=\frac{\left(1-\alpha_{W}^{T}\right) \tilde{\Psi}^{T}}{s^{T}+r^{\star}}, \\
\frac{\kappa^{N}}{f^{N}\left(\tilde{\theta}^{N}\right)}=\frac{\left(1-\alpha_{W}^{N}\right) \tilde{\Psi}^{N}}{s^{N}+r^{\star}}, \\
A^{N} \tilde{L}^{N}=\tilde{C}^{N}, \\
r^{\star} \tilde{B}+A^{T} \tilde{L}^{T}-\tilde{C}^{T}-\kappa^{T} \tilde{\theta}^{T} \tilde{U}^{T}-\kappa^{N} \tilde{\theta}^{N} \tilde{U}^{N}, \\
\text { and the intertemporal solvency condition } \\
\tilde{B}-B_{0}=\Phi^{T}\left(\tilde{L}^{T}-L_{0}^{T}\right)+\Phi^{T}\left(\tilde{L}^{N}-L_{0}^{N}\right),
\end{gathered}
$$

where $C^{N}=P_{C}^{\prime} C$ and $C^{T}=\left(1-\alpha_{C}\right) P_{C} C$ and we used the fact that $V^{j}=U^{j} \theta^{j}$. The steady-state equilibrium defined by ten equations jointly determines $\tilde{C}, \tilde{L}^{T}, \tilde{L}^{N} \tilde{U}^{T}, \tilde{U}^{N}, \tilde{\theta}^{T}, \tilde{\theta}^{N}, \tilde{P}, \tilde{B}, \bar{\lambda}$.

\section{G.2 Isoclines and Stable Path in the $\left(\theta^{T}, L^{T}\right)$-space}

The labor market in the traded sector can be summarized graphically by Figure 6(a) that traces out two schedules in the $\left(\theta^{T}, L^{T}\right)$-space. More precisely, eliminating $\tilde{U}^{T}$ from eq. (167d) by using 
(167b), i.e., $\tilde{U}^{T}=\frac{s^{T} \tilde{L}^{T}}{\tilde{m}^{T}}$, the system which comprises eqs. (167b), (167d) and (167f) can be reduced to two equations:

$$
\begin{aligned}
\tilde{L}^{T} & =\frac{\tilde{m}^{T}}{\tilde{m}^{T}+s^{T}}\left[\bar{\lambda}\left(\frac{\alpha_{W}^{T}}{1-\alpha_{W}^{T}} \kappa^{T} \tilde{\theta}^{T}+R^{T}\right)\right]^{\sigma_{L}^{T}}, \\
\frac{\kappa^{T}}{f^{T}\left(\tilde{\theta}^{T}\right)} & =\frac{\left(1-\alpha_{W}^{T}\right)}{\left(s^{T}+r^{\star}\right)} \tilde{\Psi}^{T},
\end{aligned}
$$

where $\tilde{m}^{T}=m^{T}\left(\tilde{\theta}^{T}\right)$ and $\tilde{f}^{T}=f^{T}\left(\tilde{\theta}^{T}\right)$; using the fact the reservation wage $W_{R}^{T}=-\frac{v_{F}^{T}}{\lambda}$ is equal to $\left(\frac{\alpha_{W}^{T}}{1-\alpha_{W}^{T}} \kappa^{T} \tilde{\theta}^{T}+R^{T}\right)$ (see eq. (103)), the overall surplus from hiring in the traded sector is given by:

$$
\tilde{\Psi}^{T} \equiv\left(A^{T}+r^{\star} x^{T}\right)-\left(\frac{\alpha_{W}^{T}}{1-\alpha_{W}^{T}} \kappa^{T} \tilde{\theta}^{T}+R^{T}\right)
$$

Totally differentiating eq. (168a) yields

$$
\hat{\tilde{L}}^{T}=\sigma_{L}^{T} \hat{\bar{\lambda}}+\left[\alpha_{V}^{T} \tilde{u}^{T}+\sigma_{L}^{T} \tilde{\chi}^{T}\right] \hat{\tilde{\theta}}^{T}
$$

where $\tilde{u}^{T}=\frac{s^{T}}{s^{T}+\tilde{m}^{T}}$ and $0<\tilde{\chi}^{T}=\frac{\frac{\alpha_{W}^{T}}{1-\alpha_{W}^{T}} \kappa^{T} \tilde{\theta}^{T}}{W_{R}^{T}}<1$. The slope of the $\dot{L}^{T}=0$ schedule in the $\left(\theta^{T}, L^{T}\right)$-space writes as:

$$
\left.\frac{\hat{\tilde{L}}^{T}}{\hat{\tilde{\theta}}^{T}}\right|_{\dot{L}^{T}=0}=\left[\alpha_{V}^{T} \tilde{u}^{T}+\sigma_{L}^{T} \tilde{\chi}^{T}\right]>0 .
$$

Hence the decision of search (henceforth labelled $D S T$ ) schedule is upward-sloping in the $\left(\theta^{T}, L^{T}\right)$ space. According to (170), a fall in the marginal utility of wealth $\bar{\lambda}$ shifts downward the DSTschedule.

Totally differentiating eq. (168b) yields

$$
\hat{\tilde{\theta}}^{T}\left[\left(1-\alpha_{V}^{T}\right) \tilde{\Psi}^{T}+\tilde{\chi}^{T} \tilde{W}_{R}^{T}\right]=A^{T} \hat{a}^{T}
$$

where we used (167f) and the fact that $-\left(f^{T}\right)^{\prime} \theta^{T} / f^{T}=\left(1-\alpha_{V}^{T}\right)$. The slope of the $\dot{\theta}^{T}=0$ schedule in the $\left(\theta^{T}, L^{T}\right)$-space can be written as:

$$
\left.\frac{\hat{\tilde{L}}^{T}}{\hat{\tilde{\theta}}^{T}}\right|_{\dot{\theta}^{T}=0}=+\infty
$$

Hence the vacancy creation (henceforth labelled $V C T$ ) schedule is a vertical line in the $\left(\theta^{T}, L^{T}\right)$ space. According to (172), a rise in labor productivity in the traded sector $A^{T}$ shifts to the right the $V C T$-schedule.

Having determined the patterns of isoclines in the $\left(\theta^{T}, L^{T}\right)$-space, we now analyze the slope of the stable path. To determine the pattern of the stable path, we have to estimate:

$$
\frac{\frac{L^{T}(t)-\tilde{L}^{T}}{\tilde{L}^{T}}}{\frac{\theta^{T}(t)-\tilde{\theta}^{T}}{\tilde{\theta}^{T}}}=\frac{1}{\omega_{21}^{T}} \frac{\tilde{\theta}^{T}}{\tilde{L}^{T}} .
$$

Using the fact that $\omega_{21}^{T}=0$ (see (142)), the slope of the stable branch labelled $S S^{T}$ in the $(\theta, L)$-space rewrites as:

$$
\left.\frac{\hat{\tilde{L}}^{T}}{\hat{\tilde{\theta}}^{T}}\right|_{S S^{T}}=+\infty .
$$

According to (175), the stable branch coincides with the $V C T$-schedule (see Figure 6(a)) as the dynamics for $\theta^{T}$ degenerate.

\section{G.3 Isoclines and Stable Path in the $\left(\theta^{N}, L^{N}\right)$-space}

The labor market in the non traded sector can be summarized graphically by Figure 6(b) that traces out two schedules in the $\left(\theta^{N}, L^{N}\right)$-space. More precisely, eliminating $\tilde{U}^{N}$ from eq. (167e) by using (167c), i.e., $\tilde{U}^{N}=\frac{s^{N} \tilde{L}^{N}}{\tilde{m}^{N}}$, and inserting the short-run static solution for the relative price of non 


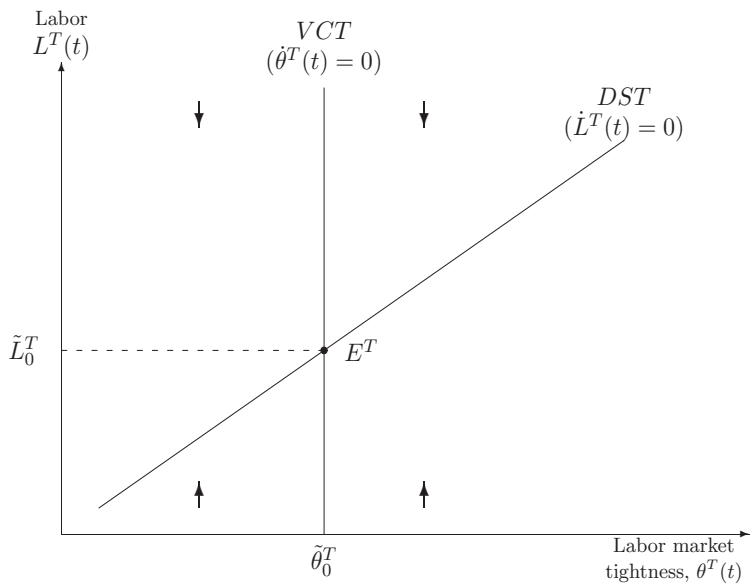

(a) $\left(\theta^{T}, L^{T}\right)$-space

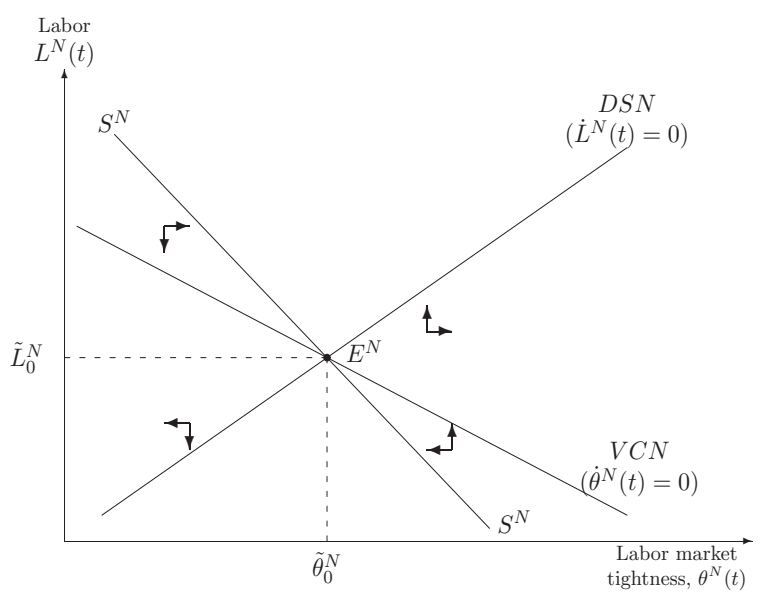

(b) $\left(\theta^{N}, L^{N}\right)$-space

Figure 6: Phase Diagrams in the $\left(\theta^{j}, L^{j}\right)$-space 
tradables given by (108) implies that the system which comprises eqs. (167c), (167e), (167g), and (167h) can be reduced to two equations:

$$
\begin{aligned}
\tilde{L}^{N} & =\frac{\tilde{m}^{N}}{\tilde{m}^{N}+s^{N}}\left[\bar{\lambda}\left(\frac{\alpha_{W}^{N}}{1-\alpha_{W}^{N}} \kappa^{N} \tilde{\theta}^{N}+R^{N}\right)\right]^{\sigma_{L}^{N}}, \\
\frac{\kappa^{N}}{f^{N}\left(\tilde{\theta}^{N}\right)} & =\frac{\left(1-\alpha_{W}^{N}\right)}{\left(s^{N}+r^{\star}\right)} \tilde{\Psi}^{N},
\end{aligned}
$$

where $\tilde{m}^{N}=m^{N}\left(\tilde{\theta}^{N}\right)$ and $\tilde{f}^{N}=f^{N}\left(\tilde{\theta}^{N}\right)$; using the fact the reservation wage $W_{R}^{N}=-\frac{v_{F}^{N}}{\bar{\lambda}}$ is equal to $\left(\frac{\alpha_{W}^{N}}{1-\alpha_{W}^{N}} \kappa^{N} \tilde{\theta}^{N}+R^{N}\right)$ (see eq. (103)), the overall surplus from hiring in the non traded sector is given by:

$$
\tilde{\Psi}^{N} \equiv\left[\left(P\left(\bar{\lambda}, L^{N}, A^{N}\right) A^{N}+r^{\star} x^{N}\right)\right]-\left(\frac{\alpha_{W}^{N}}{1-\alpha_{W}^{N}} \kappa^{N} \tilde{\theta}^{N}+R^{N}\right)
$$

Totally differentiating eq. (176a) yields

$$
\hat{\tilde{L}}^{N}=\sigma_{L}^{N} \hat{\bar{\lambda}}+\left[\alpha_{V}^{N} \tilde{u}^{N}+\sigma_{L}^{N} \tilde{\chi}^{N}\right] \hat{\tilde{\theta}}^{N}
$$

where $\tilde{u}^{N}=\frac{s^{N}}{s^{N}+\tilde{m}^{N}}$ and $0<\tilde{\chi}^{N}=\frac{\frac{\alpha_{W}^{N}}{1-\alpha_{W}^{N} \kappa^{N} \tilde{\theta}^{N}}}{W_{R}^{N}}<1$. The slope of the $\dot{L}^{N}=0$ schedule in the $\left(\theta^{N}, L^{N}\right)$-space writes as:

$$
\left.\frac{\hat{\tilde{L}}^{N}}{\hat{\tilde{\theta}}^{N}}\right|_{\dot{L}^{N}=0}=\left[\alpha_{V}^{N} \tilde{u}^{N}+\sigma_{L}^{N} \tilde{\chi}^{N}\right]>0
$$

Hence the decision of search (henceforth labelled $D S N)$ schedule is upward-sloping in the $\left(\theta^{N}, L^{N}\right)$ space. According to (178), a fall in the marginal utility of wealth $\bar{\lambda}$ shifts downward the $D S N$ schedule.

Totally differentiating eq. (176b) yields

$$
\begin{aligned}
& \hat{\tilde{\theta}}^{N}\left[\left(1-\alpha_{V}^{N}\right) \tilde{\Psi}^{N}+\tilde{\chi}^{N} W_{R}^{N}\right] \\
= & -\frac{\tilde{P} A^{N}\left\{\omega_{N} \hat{\tilde{L}}^{N}+\sigma_{C} \alpha_{C} \omega_{C} \hat{\bar{\lambda}}+\left[\omega_{N}-\omega_{C} \alpha_{C}\left(\left(1-\alpha_{C}\right) \phi+\alpha_{C} \sigma_{C}\right)\right] \hat{a}^{N}+\right\}}{\alpha_{C} \omega_{C}\left[\left(1-\alpha_{C}\right) \phi+\alpha_{C} \sigma_{C}\right]},
\end{aligned}
$$

where we used $(167 \mathrm{~g})$ and the fact that $-\left(f^{N}\right)^{\prime} \theta^{N} / f^{N}=\left(1-\alpha_{V}^{N}\right)$. The slope of the $\dot{\theta}^{N}=0$ schedule in the $\left(\theta^{N}, L^{N}\right)$-space is:

$$
\left.\frac{\hat{\tilde{L}}^{N}}{\hat{\tilde{\theta}}^{N}}\right|_{\dot{\theta}^{N}=0}=-\frac{\left[\left(1-\alpha_{V}^{N}\right) \tilde{\Psi}^{N}+\tilde{\chi}^{N} W_{R}^{N}\right]}{P A^{N}} \frac{\alpha_{C} \omega_{C}\left[\left(1-\alpha_{C}\right) \phi+\alpha_{C} \sigma_{C}\right]}{\omega_{N}}<0 .
$$

Hence the vacancy creation (henceforth labelled $V C N)$ schedule is downward-sloping in the $\left(\theta^{N}, L^{N}\right)$ space. According to $(181)$, since $\left[\omega_{N}-\omega_{C} \alpha_{C}\left(\left(1-\alpha_{C}\right) \phi+\alpha_{C} \sigma_{C}\right)\right] \gtreqless 0$, a rise in labor productivity in the non traded sector $A^{N}$ may shift to the left or to the right the $V C N$-schedule depending on whether $\phi$ takes high or low values; it is worthwhile mentioning that higher productivity in tradables relative to non tradables shifts to the right the $V C N$-schedule by appreciating the relative price and thus by raising the marginal revenue of labor in the non traded sector, i.e., by increasing $\Xi^{N} \equiv P A^{N}$. Moreover, a fall in the marginal utility of wealth $\bar{\lambda}$ shifts to the right the $V C N$-schedule by appreciating the relative price of non tradables.

Having determined the patterns of isoclines in the $\left(\theta^{N}, L^{N}\right)$-space, we now analyze the slope of the stable path. To do so, we use the third line of the Jacobian matrix (129) to rewrite the element $\omega_{2 i}^{N}$ of the eigenvector:

$$
\omega_{2 i}^{N}=\frac{\left(2 s^{N}+r^{\star}\right)+\left(s^{N}+r^{\star}-\nu_{i}^{N}\right)\left(\frac{s^{N}+\nu_{i}^{N}}{\tilde{m}^{N}}\right)+\tilde{m}^{N}\left(P_{L^{N}} A^{N} \frac{\bar{\lambda}}{v_{F F}^{N}}+1\right)}{\frac{\left(m^{N}\right)^{\prime} \tilde{U}^{N}}{\tilde{m}^{N}}\left(s^{N}+\tilde{m}^{N}+r^{\star}-\nu_{i}^{N}\right)} .
$$

The first two terms in the numerator of (182) can be rewritten as follows:

$$
\left(2 s^{N}+r^{\star}\right)+\left(s^{N}+r^{\star}-\nu_{i}^{N}\right)\left(\frac{s^{N}+\nu_{i}^{N}}{s^{N}}\right)=s^{N}+\frac{\left(s^{N}+r^{\star}\right)\left(s^{N}+\tilde{m}^{N}\right)+\nu_{i}^{N}\left(r^{\star}-\nu_{i}^{N}\right)}{\tilde{m}^{N}},
$$


where $\nu_{i}^{N}\left(r^{\star}-\nu_{i}^{N}\right)$ is equal to the determinant of the Jacobian matrix (129) given by (134). To determine the pattern of the stable path in the $\left(\theta^{N}, L^{N}\right)$-space, we have to estimate:

$$
\frac{\frac{L^{N}(t)-\tilde{L}^{N}}{\tilde{L}^{N}}}{\frac{\theta^{N}(t)-\tilde{\theta}^{N}}{\tilde{\theta}^{N}}}=\frac{1}{\omega_{21}^{N}} \frac{\tilde{\theta}^{N}}{\tilde{L}^{N}} .
$$

Inserting (138) into (184), the slope of the stable branch labelled $S^{N} S^{N}$ in the $\left(\theta^{N}, L^{N}\right)$-space can be rewritten as follows:

$$
\left.\frac{\hat{\tilde{L}}^{N}}{\hat{\tilde{\theta}}^{N}}\right|_{S^{N} S^{N}}=\frac{1}{\omega_{21}^{N}} \frac{\tilde{\theta}^{N}}{\tilde{L}^{N}}=-\frac{\left(s^{N}+\tilde{m}^{N}+r^{\star}-\nu_{1}^{N}\right)}{\left(s^{N}+r^{\star}\right)} \frac{\left(1-\alpha_{V}^{N}\right) \tilde{\Psi}^{N}}{\tilde{P} A^{N}} \frac{\alpha_{C} \omega_{C}\left[\left(1-\alpha_{C}\right) \phi+\alpha_{C} \sigma_{C}\right]}{\omega_{N}}<0,
$$

where we denote by a hat the rate of change relative to initial steady-state. According to (185), the stable branch $S S^{N}$ is downward-sloping in the $\left(\theta^{N}, L^{N}\right)$-space.

To get (185), we proceed as follows. We first have rewritten the numerator of eigenvector $\omega_{21}^{N}$ given by (182) (set $i=1$ ) by using (183) and by inserting $\frac{\text { Det } J^{N}}{s^{N}+r^{\star}}$ (which is equal to $\nu_{1}^{N}\left(r^{\star}-\nu_{1}^{N}\right)$ ) given by (138):

$$
\begin{aligned}
& s^{N}+\frac{\left(s^{N}+r^{\star}\right)\left(s^{N}+\tilde{m}^{N}\right)-\left(s^{N}+r^{\star}+\tilde{m}^{N}\right)\left(s^{N}+\tilde{m}^{N}\right)}{\tilde{m}^{N}}+\tilde{m}^{N}\left(P_{L^{N}} A^{N} \frac{\bar{\lambda}}{v_{F F}^{N}}+1\right) \\
- & \frac{\omega_{N} \tilde{P} A^{N}}{\alpha_{C} \omega_{C}\left[\left(1-\alpha_{C}\right) \phi+\alpha_{C} \sigma_{C}\right]} \frac{\left(s^{N}+r^{\star}\right)\left(s^{N}+\tilde{m}^{N}\right)\left(\tilde{\chi}^{N} \sigma_{L}^{N}+\alpha_{V}^{N} \tilde{u}^{N}\right)}{\left(1-\alpha_{V}^{N}\right) \tilde{\Psi}^{N} \tilde{m}^{N}} \\
= & -\frac{\omega_{N} \tilde{P} A^{N}}{\alpha_{C} \omega_{C}\left[\left(1-\alpha_{C}\right) \phi+\alpha_{C} \sigma_{C}\right]} \frac{\left(s^{N}+r^{\star}\right)\left(s^{N}+\tilde{m}^{N}\right) \alpha_{V}^{N} \tilde{u}^{N}}{\left(1-\alpha_{V}^{N}\right) \tilde{\Psi}^{N} \tilde{m}^{N}} .
\end{aligned}
$$

To get the last line, we computed the following term $\tilde{m}^{N}\left(P_{L^{N}} A^{N} \frac{\bar{\lambda}}{v_{F F}^{N}}+1\right)$ as follows:

$$
\begin{aligned}
& \tilde{m}^{N}\left(P_{L^{N}} A^{N} \frac{\bar{\lambda}}{v_{F F}^{N}}+1\right)=\tilde{m}^{N}\left(\frac{P_{L^{N}} \tilde{L}^{N}}{\tilde{P}} \frac{\tilde{P} A^{N}}{\tilde{L}^{N}} \tilde{F}^{N} \sigma_{L}^{N} \frac{\bar{\lambda}}{v_{F}^{N}}+1\right), \\
= & \tilde{m}^{N}\left\{\frac{\omega_{N} \tilde{P} A^{N}}{\alpha_{C} \omega_{C}\left[\left(1-\alpha_{C}\right) \phi+\alpha_{C} \sigma_{C}\right]} \frac{s^{N}+\tilde{m}^{N}}{\tilde{m}^{N}} \frac{\left(s^{N}+r^{\star}\right) \sigma_{L}^{N} \tilde{\chi}^{N}}{\alpha_{W}^{N} \tilde{\Psi}^{N} \tilde{m}^{N}}+1\right\},
\end{aligned}
$$

where we used the fact that $\frac{v_{F}^{N}}{v_{F F}^{N} \tilde{F}^{N}}=\sigma_{L}^{N}$ to get the first line, $\frac{\tilde{L}^{N}}{\tilde{F}^{N}}=\frac{\tilde{m}^{N}}{s^{N}+\tilde{m}^{N}}$ and $\frac{P_{L^{N}} \tilde{L}^{N}}{\tilde{P}}=$ $\frac{\omega_{N} \tilde{P} A^{N}}{\alpha_{C} \omega_{C}\left[\left(1-\alpha_{C}\right) \phi+\alpha_{C} \sigma_{C}\right]}$ to get the second line, $\tilde{m}^{N} \tilde{\xi}^{N}=\tilde{m}^{N} \frac{\alpha_{W}^{N} \tilde{\Psi}^{N}}{\left(s^{N}+r^{\star}\right)}=-\tilde{\chi}^{N} \frac{v_{F}^{N}}{\lambda}$ to get (188). Inserting (188) into (186), rearranging terms, we get (187).

Inserting first (188), and multiplying $\omega_{21}^{N}$ (setting setting $i=1$ into (182)) by $\tilde{L}^{N} / \tilde{\theta}^{N}$, we get:

$$
\begin{aligned}
\omega_{21}^{N} \frac{\tilde{L}^{N}}{\tilde{\theta}^{N}}= & -\frac{\frac{\omega_{N} \tilde{P} A^{N}}{\alpha_{C} \omega_{C}\left[\left(1-\alpha_{C}\right) \phi+\alpha_{C} \sigma_{C}\right]} \frac{\left(s^{N}+r^{\star}\right)\left(s^{N}+\tilde{m}^{N}\right)}{\left(1-\alpha_{V}^{N}\right) \tilde{\Psi}^{N} \tilde{m}^{N}} \frac{\tilde{L}^{N}}{\tilde{F}^{N}}}{\left(s^{N}+\tilde{m}^{N}+r^{\star}-\nu_{1}^{N}\right)}, \\
= & -\frac{\frac{\omega_{N} \tilde{P} A^{N}}{\alpha_{C} \omega_{C}\left[\left(1-\alpha_{C}\right) \phi+\alpha_{C} \sigma_{C}\right]} \frac{\left(s^{N}+r^{\star}\right)}{\left(1-\alpha_{V}^{N}\right) \tilde{\Psi}^{N}}}{\left(s^{N}+\tilde{m}^{N}+r^{\star}-\nu_{1}^{N}\right)}<0,
\end{aligned}
$$

where we used the fact that $\left(m^{N}\right)^{\prime} \theta^{N} / m^{N}=\alpha_{V}^{N}$ and $\tilde{u}^{N}=\tilde{U}^{N} / \tilde{F}^{N}$ to get the first line, $\frac{\tilde{L}^{N}}{\tilde{F}^{N}}=$ $\frac{\tilde{m}^{N}}{s^{N}+\tilde{m}^{N}}$ to get (189).

Because both the $V C N$-schedule and the stable branch $S^{N} S^{N}$ are downward sloping, we have now to determine whether the stable branch $S^{N} S^{N}$ is steeper or flatter than the $V C N$-schedule. To do so, we compute the following term which shows up in eq. (181):

$$
\left(1-\alpha_{V}^{N}\right) \tilde{\Psi}^{N}+\tilde{\chi}^{N} W_{R}^{N}=\left(1-\alpha_{V}^{N}\right) \tilde{\Psi}^{N} \frac{\left(s^{N}+\tilde{m}^{N}+r^{\star}\right)}{\left(s^{N}+r^{\star}\right)},
$$

where we used the fact that $\tilde{\chi}^{N} W_{R}^{N}=\frac{\tilde{m}^{N} \alpha_{W}^{N} \tilde{\Psi}^{N}}{s^{N}+r^{\star}}=\frac{\tilde{m}^{N}\left(1-\alpha_{V}^{N}\right) \tilde{\Psi}^{N}}{s^{N}+r^{\star}}$. Since $\frac{\left(s^{N}+\tilde{m}^{N}+r^{\star}-\nu_{1}^{N}\right)}{\left(s^{N}+r^{\star}\right)}>$ $\frac{\left(s^{N}+\tilde{m}^{N}+r^{\star}\right)}{\left(s+r^{\star}\right)}$, inspection of (181) and (185) implies that the $S^{N} S^{N}$-schedule is steeper than the $V C N$-schedule (see Figure 6(b)).

We turn now to the transitional adjustment along the stable path in the $\left(L^{N}, U^{N}\right)$-space by making use of (144b):

$$
U^{N}(t)-\tilde{U}^{N}=\omega_{31}^{N}\left(L^{N}(t)-\tilde{L}^{N}\right)
$$


where $\omega_{31}^{N}$ is given by eq. (144b). To sign the slope of the transitional path in the $\left(L^{N}, U^{N}\right)$-space, we use the third line of the Jacobian matrix (129) to rewrite the element $\omega_{21}^{N}$ of the eigenvector:

$$
\omega_{21}^{N}=\frac{\left(2 s^{N}+r^{\star}\right)+\left(s^{N}+r^{\star}-\nu_{1}^{N}\right)\left(\frac{s^{N}+\nu_{1}^{N}}{\tilde{m}^{N}}\right)+\frac{\tilde{m}^{N} \tilde{\Psi}_{L^{N}}}{\tilde{\Psi}_{U^{N}}}}{\frac{\left(m^{N}\right)^{\prime} \tilde{U}^{N}}{\tilde{m}^{N}}\left(s^{N}+\tilde{m}^{N}+r^{\star}-\nu_{1}^{N}\right)} .
$$

where $\tilde{\Psi}_{L^{N}}$ and $\tilde{\Psi}_{U^{N}}$ and the partial derivatives (evaluated at the steady-state) of the overall surplus from an additional job $\Psi^{N}$ in the non traded sector:

$$
\begin{array}{r}
\Psi_{L^{N}}^{N}=\frac{\partial \Psi^{N}}{\partial L^{N}}=P_{L^{N}} A^{N}+\frac{v_{F F}^{N}}{\bar{\lambda}}<0, \\
\Psi_{U^{N}}^{N}=\frac{\partial \Psi^{N}}{\partial U^{N}}=\frac{v_{F F}^{N}}{\bar{\lambda}}<0 .
\end{array}
$$

Inserting (192) into (144b) allows to rewrite $\omega_{31}^{N}$ as follows:

$$
\begin{aligned}
\omega_{31}^{N} & =\left(\frac{s^{N}+\nu_{1}^{N}}{\tilde{m}^{N}}\right)-\frac{\left(m^{N}\right)^{\prime} \tilde{U}^{N}}{\tilde{m}^{N}} \omega_{21}^{N}, \\
& =\left(\frac{s^{N}+\nu_{1}^{N}}{\tilde{m}^{N}}\right)-\frac{\left(2 s^{N}+r^{\star}\right)+\left(s^{N}+r^{\star}-\nu_{1}^{N}\right)\left(\frac{s^{N}+\nu_{1}^{N}}{\tilde{m}^{N}}\right)+\frac{\tilde{m}^{N} \tilde{\Psi}_{L^{N}}}{\tilde{\Psi}_{U^{N}}}}{\left(s^{N}+\tilde{m}^{N}+r^{\star}-\nu_{1}^{N}\right)}, \\
& =\frac{\left(s^{N}+\nu_{1}^{N}\right)-\left(2 s^{N}+r^{\star}\right)-\frac{\tilde{m}^{N} \tilde{\Psi}_{L^{N}}}{\tilde{\Psi}_{U^{N}}}}{\left(s^{N}+\tilde{m}^{N}+r^{\star}-\nu_{1}^{N}\right)}, \\
& =-\frac{\left[\left(s^{N}+r^{\star}-\nu_{1}^{N}\right)+\frac{\tilde{m}^{N} \tilde{\Psi}_{L^{N}}}{\tilde{\Psi}_{U^{N}}}\right]}{\left(s^{N}+\tilde{m}^{N}+r^{\star}-\nu_{1}^{N}\right)}<0,
\end{aligned}
$$

where $\nu_{1}^{N}<0$ is the stable root for the non traded labor market. Since according to (193), $\tilde{\Psi}_{L^{N}}<0$ and $\tilde{\Psi}_{U^{N}}<0$, we have $\omega_{31}^{N}<0$. Hence, as employment declines in the non traded sector, job seekers increase in this sector.

\section{G.4 Isoclines and Stable Path in the $\left(u^{T}, L^{T}\right)$-space}

One can alternatively analyze the transitional adjustment in the $\left(u^{T}, L^{T}\right)$-space. To do so, we first determine the slopes of the isoclines $\dot{L}^{T}=0$ and $\dot{\theta}^{T}=0$ in the $\left(u^{T}, L^{T}\right)$-space. Hence, we first determine the relationship between labor market tightness and the unemployment rate by using the definition of the latter, i.e. $\tilde{u}^{T}=\frac{s^{T}}{s^{T}+m^{T}\left(\tilde{\theta}^{T}\right)}$. To alleviate the notation, we assume:

$$
\alpha_{V}=\alpha_{V}^{j}, \quad \sigma_{L}=\sigma_{L}^{j} .
$$

Totally differentiating the equation that describes the steady-state level of the unemployment rate, we have:

$$
\hat{\tilde{\theta}}^{T}=-\frac{1}{\alpha_{V}}\left(\frac{s^{T}+\tilde{m}^{T}}{\tilde{m}^{T}}\right) \hat{\tilde{u}}^{T} .
$$

The slope of the $\dot{L}^{T}=0$ schedule in the $\left(u^{T}, L^{T}\right)$-space writes as:

$$
\left.\frac{\hat{\tilde{L}}^{T}}{\hat{\tilde{u}}^{T}}\right|_{\dot{L}^{T}=0}=-\left[\alpha_{V} \tilde{u}^{T}+\sigma_{L} \tilde{\chi}^{T}\right] \frac{1}{\alpha_{V}}\left(\frac{s^{T}+\tilde{m}^{T}}{\tilde{m}^{T}}\right)<0 .
$$

Hence the $D S T$-schedule is downward-sloping in the $\left(u^{T}, L^{T}\right)$-space, as displayed in Figure $7($ a) .

Using eq. (172) together with eq. (196), we have:

$$
-\frac{1}{\alpha_{V}}\left(\frac{s^{T}+\tilde{m}^{T}}{\tilde{m}^{T}}\right) \hat{\tilde{u}}^{T}\left[\left(1-\alpha_{V}^{T}\right) \tilde{\Psi}^{T}+\tilde{\chi}^{T} \tilde{W}_{R}^{T}\right]=A^{T} \hat{a}^{T} .
$$

The slope of the $\dot{\theta}^{T}=0$ schedule in the $\left(u^{T}, L^{T}\right)$-space thus reads as:

$$
\left.\frac{\hat{\tilde{L}}^{T}}{\hat{\tilde{u}}^{T}}\right|_{\dot{\theta}^{T}=0}=+\infty
$$

As a result, the $V C T$-schedule is a vertical line in the $\left(u^{T}, L^{T}\right)$-space, as displayed in Figure 7 (a). 
Having determined that the patterns of isoclines, we turn now to the transitional adjustment along the stable path labelled $X X^{T}$. We begin by linearizing $u^{j}(t)=\frac{s^{j}}{s^{j}+m^{j}\left(\theta^{j}(t)\right)}$ in the neighborhood of the steady-state which leads to:

$$
\begin{aligned}
u^{j}(t)-\tilde{u}^{j} & =\frac{1}{\tilde{F}^{j}}\left[\left(1-\tilde{u}^{j}\right)\left(U^{j}(t)-\tilde{U}^{j}\right)-\tilde{u}^{j}\left(L^{j}(t)-\tilde{L}^{j}\right)\right], \\
& =\frac{1}{\tilde{F}^{j}}\left[\left(1-\tilde{u}^{j}\right) \omega_{31}^{j}-\tilde{u}^{j}\right] D_{1}^{j} e^{\nu_{1}^{j} t} .
\end{aligned}
$$

where we used the stable paths for $L^{j}(t)$ and $U^{j}(t)$. Using $(199)$ and the fact that $\left(L^{j}(t)-\tilde{L}^{j}\right)=$ $D_{1}^{j} e^{\nu_{1}^{j} t}$, the slope of the stable path in the $\left(u^{j}, L^{j}\right)$-space,

$$
\begin{aligned}
\left.\frac{\frac{L^{j}(t)-\tilde{L}^{j}}{\tilde{L}^{j}}}{\frac{u^{j}(t)-\tilde{u}^{j}}{\tilde{u}^{j}}}\right|_{X X^{j}} & =-\tilde{F}^{j} \frac{\tilde{u}^{j}}{\tilde{L}^{j}} \frac{1}{\left[\left(1-\tilde{u}^{j}\right) \omega_{31}^{j}-\tilde{u}^{j}\right]}, \\
& =\frac{s^{j}}{\tilde{m}^{j}} \frac{1}{\left[\left(1-\tilde{u}^{j}\right) \omega_{31}^{j}-\tilde{u}^{j}\right]},
\end{aligned}
$$

where we used the fact that:

$$
\begin{aligned}
\tilde{F}^{j} \frac{\tilde{u}^{j}}{\tilde{L}^{j}} & =\frac{\tilde{U}^{j}}{\tilde{L}^{j}}, \\
& =\frac{\frac{s^{j}}{s^{j}+\tilde{m}^{j}}}{\frac{\tilde{m}^{j}}{s^{j}+\tilde{m}^{j}}} \\
& =\frac{s^{j}+\tilde{m}^{j}}{\tilde{m}^{j}} \tilde{u}^{j}=\frac{s^{j}}{\tilde{m}^{j}},
\end{aligned}
$$

since $\tilde{U}^{j} / \tilde{L}^{j}=s^{j} / \tilde{m}^{j}$.

Focusing on the traded sector, inserting the stable path (see section E.4) for job seekers, i.e., $U^{T}(t)-\tilde{U}^{T}=\omega_{31}^{T} D_{1} e^{\nu_{1}^{T} t}$ with $\omega_{31}^{T}=-1$ (see eq. (142)), the stable path $X X^{T}$ shown in Figure $7(\mathrm{a})$ is described by:

$$
\begin{aligned}
\left.\frac{\hat{L}^{T}(t)}{\hat{u}^{T}(t)}\right|_{X X^{T}} & =-\frac{s^{T}+\tilde{m}^{T}}{\tilde{m}^{T}} \tilde{u}^{T}<0, \\
& =-\frac{\tilde{u}^{T}}{1-\tilde{u}^{T}} .
\end{aligned}
$$

Eq. (202) reveals that in countries where the unemployment benefit scheme is more generous (i.e., $\varrho$ takes higher values) or worker bargaining power is greater (i.e., $\alpha_{W}$ takes higher values), the stable path becomes steeper since labor market tightness is initially low and thus the unemployment rate $u^{T}$ is high.

We now demonstrate that the slope of the eigenvector $(202)$ in the $\left(u^{T}, L^{T}\right)$-space is larger (i.e., less negative) than the slope of the $D S T$-schedule described by eq. (197):

$$
\begin{aligned}
& 0>-\frac{s^{T}+\tilde{m}^{T}}{\tilde{m}^{T}} \tilde{u}^{T}>-\left[\alpha_{V} \tilde{u}^{T}+\sigma_{L} \tilde{\chi}^{T}\right] \frac{1}{\alpha_{V}}\left(\frac{s^{T}+\tilde{m}^{T}}{\tilde{m}^{T}}\right), \\
& 0>-\frac{\sigma_{L} \tilde{\chi}^{T}\left(s^{T}+\tilde{m}^{T}\right)}{\alpha_{V}} .
\end{aligned}
$$

Since the term on the RHS of inequality is unambiguously negative, the stable branch which corresponds to the $X X^{T}$-schedule is flatter than the $D S T$-schedule.

The adjustment of labor and unemployment rate in the traded sector is depicted in Figure 2(a). Following an increase in productivity of tradables relative to non tradables, the decision of search-schedule shifts (slightly) to the left as a result of the positive wealth effect (captured by a decline in $\bar{\lambda}$, see eq. (170)); at the same time, the vacancy creation-schedule which is vertical also shifts to the left (see eq. (172)) as a result of the rise in $A^{T}$ which encourages firms to post more job vacancies; as a result, $\theta^{T}$ increases which raises the probability of finding a job and thus lowers unemployment. The unemployment rate declines on impact. Along the stable path, $u^{T}$ falls while employment builds up.

\section{G.5 Isoclines and Stable Path in the $\left(u^{N}, L^{N}\right)$-space}

The steady-state level of the non traded sector is described by:

$$
\tilde{u}^{N}=\frac{s^{N}}{s^{N}+m^{N}\left(\tilde{\theta}^{N}\right)}
$$




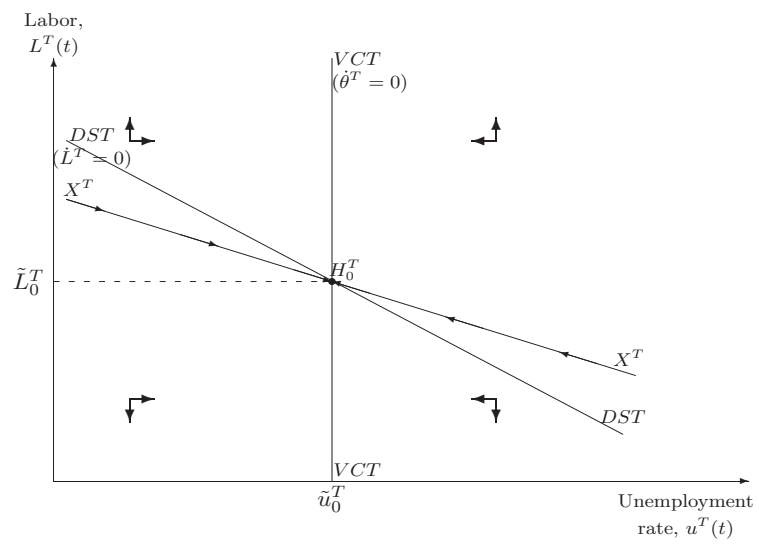

(a) $\left(u^{T}, L^{T}\right)$-space

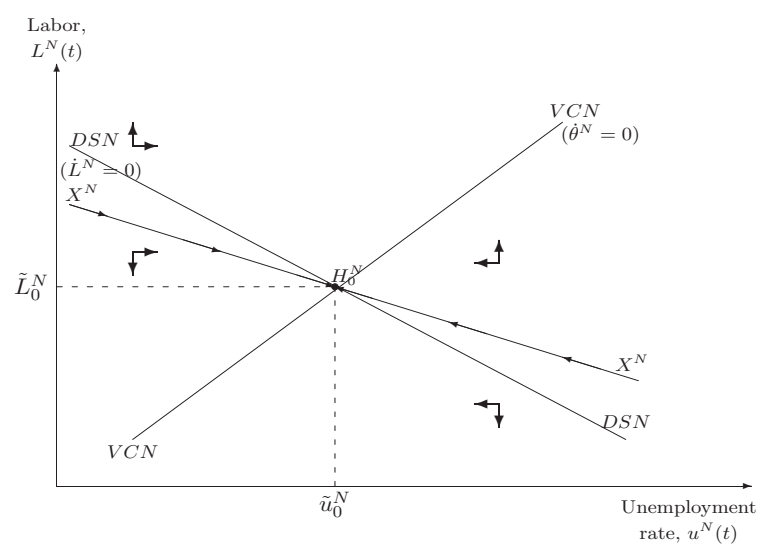

(b) $\left(u^{N}, L^{N}\right)$-space

Figure 7: Phase Diagrams in the $\left(u^{j}, L^{j}\right)$-space 
Totally differentiating eq. (204) leads to:

$$
\hat{\tilde{\theta}}^{N}=-\frac{1}{\alpha_{V}}\left(\frac{s^{N}+\tilde{m}^{N}}{\tilde{m}^{N}}\right) \hat{\tilde{u}}^{N} .
$$

The slope of the $\dot{L}^{N}=0$ schedule in the $\left(u^{N}, L^{N}\right)$-space reads as:

$$
\left.\frac{\hat{\tilde{L}}^{N}}{\hat{\tilde{u}}^{N}}\right|_{\dot{L}^{N}=0}=-\left[\alpha_{V} \tilde{u}^{N}+\sigma_{L} \tilde{\chi}^{N}\right] \frac{1}{\alpha_{V}}\left(\frac{s^{N}+\tilde{m}^{N}}{\tilde{m}^{N}}\right)<0 .
$$

Hence the $D S N$-schedule is downward-sloping in the $\left(u^{N}, L^{N}\right)$-space, as displayed in Figure $7(\mathrm{~b})$.

Inserting first (108) and totally differentiating eq. (176b) leads to:

$$
\left[\left(1-\alpha_{V}\right) \tilde{\Psi}^{N}+\chi^{N} \tilde{W}_{R}^{N}\right] \hat{\tilde{\theta}}^{N}=P_{\bar{\lambda}} A^{N} d \bar{\lambda}+P_{L^{N}} A^{N} d L^{N}+\left(P_{A^{N}} A^{N}+\tilde{P}\right) d A^{N},
$$

where $P_{L^{N}}<0$. space:

Inserting eq. (205) into eq. (207) gives us the slope of of the $\dot{\theta}^{N}=0$ schedule in the $\left(u^{N}, L^{N}\right)$ -

$$
\left.\frac{\hat{\tilde{L}}^{N}}{\hat{\tilde{u}}^{N}}\right|_{\dot{\theta}^{N}=0}=-\frac{\left[\left(1-\alpha_{V}\right) \tilde{\Psi}^{N}+\chi^{N} \tilde{W}_{R}^{N}\right]}{\alpha_{V} P_{L^{N}} A^{N} L^{N}}\left(\frac{s^{N}+\tilde{m}^{N}}{\tilde{m}^{N}}\right)>0 .
$$

where the positive sign of eq. (208) follows from eq. (110) indicating that $P_{L^{N}}<0$. As a result, the $V C N$-schedule is an upward-sloping line in the $\left(u^{N}, L^{N}\right)$-space, as displayed in Figure $7(\mathrm{~b})$.

Having determined the patterns of isoclines, we turn now to the transitional adjustment along the stable path labelled $X X^{N}$ by making use of (200):

$$
\left.\frac{\frac{L^{N}(t)-\tilde{L}^{N}}{\tilde{L}^{N}}}{\frac{u^{N}(t)-\tilde{u}^{N}}{\tilde{u}^{N}}}\right|_{X X^{N}}=\frac{\tilde{U}^{N}}{\tilde{L}^{N}} \frac{1}{\left[\left(1-\tilde{u}^{N}\right) \omega_{31}^{N}-\tilde{u}^{N}\right]} .
$$

As will be useful, we first determine the expression of eigenvector $\omega_{31}^{N}$ by inserting eq. (182) into $(144 b)$ :

$$
\omega_{31}^{N}=-\frac{\left(s^{N}+r^{\star}-\nu_{1}^{N}\right)+\tilde{m}^{N}\left(P_{L^{N}} A^{N} \frac{\bar{\lambda}}{v_{F F}^{N}}+1\right)}{\left(s^{N}+\tilde{m}^{N}+r^{\star}-\nu_{1}^{N}\right)} .
$$

Then, we use $(210)$ to derive an expression for $\left(1-\tilde{u}^{N}\right) \omega_{31}^{N}-\tilde{u}^{N}$ :

$$
\left(1-\tilde{u}^{N}\right) \omega_{31}^{N}-\tilde{u}^{N}=-\frac{\left(s^{N}+\tilde{m}^{N}+r^{\star}-\nu_{1}^{N}\right)+\left(1-\tilde{u}^{N}\right) \tilde{m}^{N} P_{L^{N}} A^{N} \frac{\bar{\lambda}}{v_{F F}^{N}}}{\left(s^{N}+\tilde{m}^{N}+r^{\star}-\nu_{1}^{N}\right)} .
$$

Inserting (211) into eq. (209) gives us the slope of the stable path $X X^{N}$ in the $\left(u^{N}, L^{N}\right)$-space:

$$
\left.\frac{\hat{L}^{N}(t)}{\hat{u}^{N}(t)}\right|_{X X^{N}}=-\frac{s^{N}}{\tilde{m}^{N}} \frac{\left(s^{N}+\tilde{m}^{N}+r^{\star}-\nu_{1}^{N}\right)}{\left(s^{N}+\tilde{m}^{N}+r^{\star}-\nu_{1}^{N}\right)+\left(1-\tilde{u}^{N}\right) \tilde{m}^{N} P_{L^{N}} A^{N} \frac{\bar{\lambda}}{v_{F F}^{N}}}<0 .
$$

Since $v_{F F}^{N}<0$ and $P_{L^{N}}<0$, the stable branch $X X^{N}$ is downward-sloping in the $\left(u^{N}, L^{N}\right)$-space.

We now demonstrate that the slope of the stable branch $(212)$ in the $\left(u^{N}, L^{N}\right)$-space is larger (i.e., less negative) than the slope of the $D S N$-schedule described by eq. (206):

$$
\begin{aligned}
& 0>-\frac{s^{N}}{\tilde{m}^{N}} \frac{\left(s^{N}+\tilde{m}^{N}+r^{\star}-\nu_{1}^{N}\right)}{\left(s^{N}+\tilde{m}^{N}+r^{\star}-\nu_{1}^{N}\right)+\left(1-\tilde{u}^{N}\right) \tilde{m}^{N} P_{L^{N}} A^{N} \frac{\bar{\lambda}}{v_{F F}^{N}}}>-\left[\alpha_{V} \tilde{u}^{N}+\sigma_{L} \tilde{\chi}^{N}\right] \frac{1}{\alpha_{V}}\left(\frac{s^{N}+\tilde{m}^{N}}{\tilde{m}^{N}}\right), \\
& \left(s^{N}+\tilde{m}^{N}+r^{\star}-\nu_{1}^{N}\right) \alpha_{V} \tilde{u}^{N}<\left[\alpha_{V} \tilde{u}^{N}+\sigma_{L} \tilde{\chi}^{N}\right]\left[\left(s^{N}+\tilde{m}^{N}+r^{\star}-\nu_{1}^{N}\right)+\left(1-\tilde{u}^{N}\right) \tilde{m}^{N} P_{L^{N}} A^{N} \frac{\bar{\lambda}}{v_{F F}^{N}}\right] \\
& 0<\sigma_{L} \chi^{N}\left(s^{N}+\tilde{m}^{N}+r^{\star}-\nu_{1}^{N}\right)+\left[\alpha_{V} \tilde{u}^{N}+\sigma_{L} \tilde{\chi}^{N}\right]\left(1-\tilde{u}^{N}\right) \tilde{m}^{N} P_{L^{N}} A^{N} \frac{\bar{\lambda}}{v_{F F}^{N}} .
\end{aligned}
$$

Since the term on the RHS of inequality is unambiguously positive, the stable branch which corresponds to the $X X^{N}$-schedule is flatter than the $D S N$-schedule, as can be seen in Figure 7(b).

The adjustment of labor and unemployment rate in the non traded sector is depicted in Figure 2(b). Following an increase in productivity of tradables relative to non tradables, the decision of search-schedule shifts to the left as a result of the positive wealth effect (captured by a decline in $\bar{\lambda}$ ); at the same time, the vacancy creation-schedule which is upward-sloping also shifts to the left (see eq. (207)) as a result of the rise in $A^{N}$ which encourages firms to post more job vacancies. More 
specifically, a rise in $A^{N}$ has an ambiguous effect on $P A^{N}$. Assuming $\sigma_{C}=\phi=1, A^{N}$ has no impact whilst the positive wealth effect stimulates consumption in non tradables and thus appreciates the relative price of non tradables which increases the surplus from an additional job. Consequently, $\theta^{N}$ increases which raises the probability of finding a job and thus lowers $u^{N}$ in the long-run. The unemployment rate declines significantly on impact and overshoots its new steady-state level. Along the stable path, $u^{N}$ increases while employment declines. Intuitively, as $L^{N}$ falls along $X X^{N}$, the relative price appreciates which induces non traded firms to post more job vacancies. The rise in the labor market tightness $\theta^{N}$ leads agents to search for a job and thus increases the number of job seekers. The decline in employment $L^{N}$ triggered by the positive wealth effect and the rise in the number of job seekers $U^{N}$ produces an increase in $u^{N}$ along the stable path.

\section{H Steady-State and Short-Run Effects of Higher Relative Productivity}

In this section, we first solve the steady-state and derive the long-term changes following a rise in the productivity differential between tradables and non tradables, $\hat{a}^{T}-\hat{a}^{N}$. Steady-state values are denoted with a tilde while the rate of change relative to initial steady-state is denoted by a hat. Then, we analyze the dynamic adjustment toward the long-run equilibrium following higher productivity in tradables relative to non tradables. ${ }^{60}$

\section{H.1 Steady-State}

We now describe the steady-state of the economy consisting of six equations which can be solved for sectoral employment and labor market tightness, i.e., $\tilde{L}^{j}=L^{j}\left(A^{T}, A^{N}\right)$ and $\tilde{\theta}^{j}=L^{j}\left(A^{T}, A^{N}\right)$ with $j=T, N$, the stock of foreign assets, $\tilde{B}=B\left(A^{T}, A^{N}\right)$, and the shadow value of wealth, $\bar{\lambda}$.

First, setting $\dot{\theta}^{j}=0$ into eq. (114), we obtain the vacancy creation equation (which holds for the traded sector and non traded sector):

$$
\frac{\kappa^{j}}{f^{j}\left(\tilde{\theta}^{j}\right)}=\frac{\left(1-\alpha_{W}^{j}\right)}{s^{j}+r^{\star}} \tilde{\Psi}^{j}, \quad \tilde{\Psi}^{j} \equiv\left(\Xi^{j}+r^{\star} x^{j}\right)-\tilde{W}_{R}^{j}, \quad j=T, N,
$$

where $\Xi^{N}=P(.) A^{N}$ with $P($.$) given by eq. (108). The LHS term of eq. (214) represents the$ expected marginal cost of recruiting in sector $j=T, N$. The RHS term represents the marginal benefit of an additional worker which is equal to the share, received by the firm, of the rent created by the encounter between a vacancy and a job-seeking worker. A rise in labor productivity raises the surplus from hiring $\tilde{\Psi}^{j}$; as a result, firms post more job vacancies which increases the labor market tightness $\tilde{\theta}^{j}$.

Second, setting $\dot{\xi}^{j}=0$ into eq. (84) and using the fact that $\tilde{W}^{j}-\tilde{W}_{R}^{j}=\alpha_{W} \tilde{\Psi}^{j}$ leads to $\tilde{\xi}^{j}=\frac{\alpha_{W} \tilde{\Psi}^{j}}{s^{j}+r^{\star}}$. Rewriting the latter equation by inserting the vacancy creation equation (214) for sector $j$ to eliminate $\tilde{\Psi}^{j}$ gives the expected value of finding a job, i.e., $\tilde{m}^{j} \tilde{\xi}^{j}=\frac{\alpha_{W}}{1-\alpha_{W}} \kappa^{j} \tilde{\theta}^{j}$. Plugging this equation into (14b) leads to the equality between the utility loss from participating the labor market in sector $j$ and the marginal benefit from search, i.e., $\frac{\zeta^{j}\left(\tilde{F}^{j}\right)^{\frac{1}{\sigma_{L}}}}{\lambda}=\frac{\alpha_{W}}{1-\alpha_{W}} \kappa^{j} \tilde{\theta}^{j}+R^{j}$. Setting $\dot{L}^{j}=0$ into eq. (12) to eliminate $\tilde{U}^{j}$ so that $\tilde{F}^{j}=\left(\frac{s^{j}+\tilde{m}^{j}}{\tilde{m}^{j}}\right) \tilde{L}^{j}$, the decision of search equation reads as (which holds for the traded sector and non traded sector):

$$
\tilde{L}^{j}=\frac{\tilde{m}^{j}}{\tilde{m}^{j}+s^{j}}\left[\frac{\bar{\lambda}}{\zeta^{j}}\left(\frac{\alpha_{W}^{j}}{1-\alpha_{W}^{j}} \kappa^{j} \tilde{\theta}^{j}+R^{j}\right)\right]^{\sigma_{L}^{j}}, \quad j=T, N,
$$

where $\left(\frac{\alpha_{W}^{j}}{1-\alpha_{W}^{j}} \kappa^{j} \tilde{\theta}^{j}+R^{j}\right)$ corresponds to the reservation wage, $\tilde{W}_{R}^{j}$, reflecting the marginal benefit from search. According to (215), higher labor market tightness increases labor $\tilde{L}^{j}$ by raising the job-finding rate for the worker and thus the employment rate $\frac{\tilde{m}^{j}}{\tilde{m}^{j}+s^{j}}$. Moreover, for given $\bar{\lambda}$, the rise in the reservation wage $\frac{\alpha_{W}^{j}}{1-\alpha_{W}^{j}} \kappa^{j} \tilde{\theta}^{j}+R^{j}$ induces agents to supply more labor.

Third, setting $\dot{B}=0$ into eq. (25), we obtain the market clearing condition for the traded good:

$$
r^{\star} \tilde{B}+A^{T} \tilde{L}^{T}-\tilde{C}^{T}-\kappa^{T} \tilde{U}^{T} \tilde{\theta}^{T}-\kappa^{N} \tilde{U}^{N} \tilde{\theta}^{N}=0,
$$

\footnotetext{
${ }^{60}$ While we calibrate the model to data by considering government spending, we set $G^{j}=0$ to derive analytical results in order avoid unnecessary complications.
} 
where $\tilde{C}^{T}=C^{T}\left(\tilde{L}^{N}, \bar{\lambda}, A^{N}\right)$.

The system comprising eqs. (214)-(216) can be solved for the steady-state sectoral labor market tightness and employment, and traded bonds. All these variables can be expressed in terms of the labor productivity index $A^{j}$ and the marginal utility of wealth, i.e., $\tilde{\theta}=\theta\left(A^{T}\right), \tilde{L}^{T}=L^{T}\left(\bar{\lambda}, A^{T}\right)$, $\tilde{\theta}^{N}=\theta^{N}\left(\bar{\lambda}, A^{N}\right), \tilde{L}^{N}=L^{N}\left(\bar{\lambda}, A^{N}\right)$, and $\tilde{B}=B\left(\bar{\lambda}, A^{T}, A^{N}\right)$. Inserting first $\tilde{B}=B\left(\bar{\lambda}, A^{T}, A^{N}\right)$, and $\tilde{L}^{j}=L^{j}\left(\bar{\lambda}, A^{N}\right)$, the intertemporal solvency condition (149) can be solved for the equilibrium value of the marginal utility of wealth:

$$
\bar{\lambda}=\lambda\left(A^{T}, A^{N}\right) .
$$

Setting first $\dot{L}^{j}=0$ into (12), inserting $\tilde{L}^{j}=L^{j}\left(\bar{\lambda}, A^{j}\right)$, one can solve for $U^{j}$; then the relationship $V^{j}=\theta^{j} U^{j}$ can be solved for the steady-state job vacancy in sector $j$. Using the fact that $\tilde{C}^{T}=$ $C^{T}\left(\tilde{L}^{N}, \bar{\lambda}, A^{N}\right)$, inserting $L^{N}\left(\bar{\lambda}, A^{N}\right)$ and using the fact that $Y^{T}=A^{T} L^{T}$ with $\tilde{L}^{T}=L^{T}\left(\bar{\lambda}, A^{T}\right)$, allows us to solve for ratio $v_{N X}=\frac{Y^{T}-C^{T}}{Y^{T}}$ :

$$
v_{N X}=v_{N X}\left(A^{T}, A^{N}\right),
$$

where we have eliminated $\bar{\lambda}$ by using (217).

\section{H.2 Steady-State Effects of Productivity Shocks}

Eliminating $\tilde{U}^{T}$ from eq. (167d) by using (167b), i.e., $\tilde{U}^{T}=\frac{s^{T} \tilde{L}^{T}}{\tilde{m}^{T}}$, eliminating $\tilde{U}^{N}$ from eq. (167e) by using (167c), i.e., $\tilde{U}^{N}=\frac{s^{N} \tilde{L}^{N}}{\tilde{m}^{N}}$, and inserting the short-run static solution for the relative price of non tradables given by (108), inserting the short-run static solution for consumption in tradables given by (110) into the market clearing condition for traded goods (167i), the steady-state can be reduced to a system which comprises six equations:

$$
\begin{gathered}
\tilde{L}^{T}=\frac{\tilde{m}^{T}}{\tilde{m}^{T}+s^{T}}\left[\frac{\bar{\lambda}}{\zeta^{T}}\left(\frac{\alpha_{W}^{T}}{1-\alpha_{W}^{T}} \kappa^{T} \tilde{\theta}^{T}+R^{T}\right)\right]^{\sigma_{L}^{T}}, \\
\frac{\kappa^{T}}{f^{T}\left(\tilde{\theta}^{T}\right)}=\frac{\left(1-\alpha_{W}^{T}\right)}{\left(s^{T}+r^{\star}\right)}\left[\left(A^{T}+r^{\star} x^{T}\right)-\left(\frac{\alpha_{W}^{T}}{1-\alpha_{W}^{T}} \kappa^{T} \tilde{\theta}^{T}+R^{T}\right)\right], \\
\tilde{L}^{N}=\frac{\tilde{m}^{N}}{\tilde{m}^{N}+s^{N}}\left[\frac{\bar{\lambda}}{\zeta^{N}}\left(\frac{\alpha_{W}^{N}}{1-\alpha_{W}^{N}} \kappa^{N} \tilde{\theta}^{N}+R^{N}\right)\right]^{\sigma_{L}^{N}}, \\
\frac{\kappa^{N}\left(\tilde{\theta}^{N}\right)}{\left(1-\alpha_{W}^{N}\right)}\left(\left[\left(P\left(\tilde{L}^{N}, \bar{\lambda}, A^{N}\right) A^{N}+r^{\star} x^{N}\right)\right]-\left(\frac{\alpha_{W}^{N}}{1-\alpha_{W}^{N}} \kappa^{N} \tilde{\theta}^{N}+R^{N}\right)\right\}, \\
r^{\star} \tilde{B}+A^{T} \tilde{L}^{T}-C^{T}\left(\tilde{L}^{N}, \bar{\lambda}, A^{N}\right)-\kappa^{T} \frac{s^{T} \tilde{L}^{T}}{\tilde{f}^{T}}-\kappa^{N} \frac{s^{N} \tilde{L}^{N}}{\tilde{f}^{N},}
\end{gathered}
$$

and the intertemporal solvency condition

$$
\tilde{B}-B_{0}=\Phi^{T}\left(\tilde{L}^{T}-L_{0}^{T}\right)+\Phi^{N}\left(\tilde{L}^{N}-L_{0}^{N}\right),
$$

where we abstract from government spending on tradables and non tradables, $\Phi^{T}=-\frac{\left(A^{T}+\kappa^{T} \tilde{\theta}^{T}\right)}{\left(s^{T}+\tilde{m}^{T}+r^{\star}\right)}<$ 0 and $\Phi^{N} \equiv \frac{\Lambda^{N}}{\nu_{1}^{N}-r^{\star}}<0$ (see (150)); to get (219e), we use the fact that $\tilde{U}^{j}=\frac{s^{j} \tilde{L}^{j}}{\tilde{m}^{j}}$ and $f^{j}=m^{j} / \theta^{j}$. Note that the market clearing condition for non tradables (167h) can be solved for the relative price of non tradables. To avoid unnecessary complications, we set $G^{N}=0$ so that eq. (167h) reduces to $Y^{N}=C^{N}$. The solution for the relative price of non tradables is $P=P\left(L^{N}, \bar{\lambda}, A^{N}\right)$. Totally differentiating the market clearing condition for non tradables, we get:

$$
\hat{p}=\frac{-\hat{a}^{N}-\hat{l}^{N}-\sigma_{C} \hat{\bar{\lambda}}}{\left[\left(1-\alpha_{C}\right) \phi+\alpha_{C} \sigma_{C}\right]}
$$

Inserting (220) into the short-run static solution for consumption in tradables (106), we get:

$$
\hat{C}^{T}=-\frac{\left[\sigma_{C} \hat{\bar{\lambda}}+\alpha_{C}\left(\phi-\sigma_{C}\right)\left(\hat{a}^{N}+\hat{l}^{N}\right)\right]}{\left[\left(1-\alpha_{C}\right) \phi+\alpha_{C} \sigma_{C}\right]} .
$$

As will become clear later, it is convenient to first solve the steady-state without the intertemporal solvency condition (219f), i.e., to solve the system comprising (219a)-(219e), which allows us to 
express the steady-state values in terms of the stock of traded bonds, the marginal utility of wealth and labor productivity indices $A^{j}$ (with $j=T, N$ ). Totally differentiating the system of equations (219a)-(219e), using both (220) and (221), yields in matrix form:

$$
\begin{aligned}
& \left(\begin{array}{ccccc}
1 & -\left[\alpha_{V}^{T} \tilde{u}^{T}+\sigma_{L}^{T} \tilde{\chi}^{T}\right] & 0 & 0 & 0 \\
0 & {\left[\left(1-\alpha_{V}^{T}\right) \tilde{\Psi}^{T}+\tilde{\chi}^{T} W_{R}^{T}\right]} & 0 & 0 & 0 \\
0 & 0 & 1 & -\left[\alpha_{V}^{N} \tilde{u}^{N}+\sigma_{L}^{N} \tilde{\chi}^{N}\right] & 0 \\
0 & 0 & \tilde{P} A^{N} & a_{44} & 0 \\
a_{51} & -\omega_{V}^{T}\left(1-\alpha_{V}^{T}\right) & a_{53} & -\omega_{V}^{N}\left(1-\alpha_{V}^{N}\right)
\end{array}\right)\left(\begin{array}{c}
\hat{\tilde{L}}^{T} \\
\hat{\tilde{\theta}}^{T} \\
\hat{\tilde{L}}^{N} \\
\hat{\tilde{\theta}}^{N} \\
\mathrm{~d} \tilde{B} / \tilde{Y}
\end{array}\right) \\
& =\left(\begin{array}{c}
\sigma_{L}^{T} \hat{\bar{\lambda}} \\
A^{T} \hat{a}^{T} \\
\sigma_{L}^{N} \overline{\bar{\lambda}} \\
-\left(1-\omega_{N}\right) \hat{a}^{T}-\frac{\left(1-\alpha_{C}\right) \omega_{C} \alpha_{C}\left(\phi-\sigma_{C}\right)}{\left[\left(1-\alpha_{C}\right) \phi+\alpha_{C} \sigma_{C}\right]} \hat{a}^{N}-\frac{\left(1-\alpha_{C}\right) \omega_{C} \sigma_{C} \phi}{\left[\left(1-\alpha_{C}\right) \phi+\alpha_{C} \sigma_{C}\right]} \hat{\bar{\lambda}}
\end{array}\right),
\end{aligned}
$$

where we used the fact that $\frac{C^{T}}{Y}=\frac{C^{T}}{P_{C} C} \frac{P_{C} C}{Y}=\left(1-\alpha_{C}\right) \omega_{C}$, and $\frac{Y^{T}}{Y}=\left(1-\omega_{N}\right)$, we set $\omega_{V}^{j}=\frac{\kappa V}{Y}$; the terms $a_{44}, a_{51}, a_{53}$ are given by:

$$
\begin{aligned}
& a_{44}=\left[\left(1-\alpha_{V}^{N}\right) \tilde{\Psi}^{N}+\tilde{\chi}^{N} \tilde{W}_{R}^{N}\right]\left[\left(1-\alpha_{C}\right) \phi+\alpha_{C} \sigma_{C}\right], \\
& a_{51}=\left[\left(1-\omega_{N}\right)-\omega_{V}^{T}\right] \\
& a_{53}=\left\{\frac{\left(1-\alpha_{C}\right) \omega_{C} \alpha_{C}\left(\phi-\sigma_{C}\right)}{\left[\left(1-\alpha_{C}\right) \phi+\alpha_{C} \sigma_{C}\right]}-\omega_{V}^{N}\right\} .
\end{aligned}
$$

System (219a)-(219e) can be solved for steady-state employment and labor market tightness in the traded and non traded sectors, and the stock of foreign assets as follows:

$$
\begin{aligned}
\tilde{L}^{T} & =L^{T}\left(\bar{\lambda}, A^{T}\right), \\
\tilde{\theta}^{T} & =\theta^{T}\left(A^{T}\right), \\
\tilde{L}^{N} & =L^{N}\left(\bar{\lambda}, A^{N}\right), \\
\tilde{\theta}^{N} & =\theta^{N}\left(\bar{\lambda}, A^{N}\right), \\
\tilde{B} & =B\left(\bar{\lambda}, A^{T}, A^{N}\right),
\end{aligned}
$$


where partial derivatives are given by

$$
\begin{aligned}
& \frac{\hat{\tilde{\theta}}^{T}}{\hat{a}^{T}}=\frac{A^{T}}{\left[\left(1-\alpha_{V}^{T}\right) \tilde{\Psi}^{T}+\tilde{\chi}^{T} W_{R}^{T}\right]}>0, \\
& \frac{\hat{\tilde{L}}^{T}}{\hat{\bar{\lambda}}}=\sigma_{L}^{T}>0 \\
& \frac{\hat{\tilde{L}}^{T}}{\hat{a}^{T}}=\frac{\left[\alpha_{V}^{T} \tilde{u}^{T}+\sigma_{L}^{T} \tilde{\chi}^{T}\right] A^{T}}{\left[\left(1-\alpha_{V}^{T}\right) \tilde{\Psi}^{T}+\tilde{\chi}^{T} W_{R}^{T}\right]}>0 \\
& \frac{\hat{\tilde{\theta}}^{N}}{\hat{\bar{\lambda}}}=-\frac{\tilde{P} A^{N}\left(\sigma_{L}^{N}+\sigma_{C}\right)}{\left[\left(1-\alpha_{V}^{N}\right) \tilde{\Psi}^{N}+\tilde{\chi}^{N} W_{R}^{N}\right]\left[\left(1-\alpha_{C}\right) \phi+\alpha_{C} \sigma_{C}\right]+\tilde{P} A^{N}\left[\alpha_{V}^{N} \tilde{u}^{N}+\sigma_{L}^{N} \tilde{\chi}^{N}\right]}<0 \\
& \frac{\hat{\tilde{\theta}}^{N}}{\hat{a}^{N}}=\frac{\tilde{P} A^{N}\left\{\left[\left(1-\alpha_{C}\right) \phi+\alpha_{C} \sigma_{C}\right]-1\right\}}{\left[\left(1-\alpha_{V}^{N}\right) \tilde{\Psi}^{N}+\tilde{\chi}^{N} W_{R}^{N}\right]\left[\left(1-\alpha_{C}\right) \phi+\alpha_{C} \sigma_{C}\right]+\tilde{P} A^{N}\left[\alpha_{V}^{N} \tilde{u}^{N}+\sigma_{L}^{N} \tilde{\chi}^{N}\right]}>0, \\
& \frac{\hat{\tilde{L}}^{N}}{\hat{\bar{\lambda}}}=\frac{\sigma_{L}^{N}\left[\left(1-\alpha_{V}^{N}\right) \tilde{\Psi}^{N}+\tilde{\chi}^{N} W_{R}^{N}\right]\left[\left(1-\alpha_{C}\right) \phi+\alpha_{C} \sigma_{C}\right]-\sigma_{C} \tilde{P} A^{N}\left[\alpha_{V}^{N} \tilde{u}^{N}+\sigma_{L}^{N} \tilde{\chi}^{N}\right]}{\left[\left(1-\alpha_{V}^{N}\right) \tilde{\Psi}^{N}+\tilde{\chi}^{N} W_{R}^{N}\right]\left[\left(1-\alpha_{C}\right) \phi+\alpha_{C} \sigma_{C}\right]+\tilde{P} A^{N}\left[\alpha_{V}^{N} \tilde{u}^{N}+\sigma_{L}^{N} \tilde{\chi}^{N}\right]} \\
& \frac{\hat{\tilde{L}}^{N}}{\hat{a}^{N}}=\frac{\tilde{P} A^{N}\left\{\left[\left(1-\alpha_{C}\right) \phi+\alpha_{C} \sigma_{C}\right]-1\right\}\left[\alpha_{V}^{N} \tilde{u}^{N}+\sigma_{L}^{N} \tilde{\chi}^{N}\right]}{\left[\left(1-\alpha_{V}^{N}\right) \tilde{\Psi}^{N}+\tilde{\chi}^{N} W_{R}^{N}\right]\left[\left(1-\alpha_{C}\right) \phi+\alpha_{C} \sigma_{C}\right]+\tilde{P} A^{N}\left[\alpha_{V}^{N} \tilde{u}^{N}+\sigma_{L}^{N} \tilde{\chi}^{N}\right]}>0, \\
& \frac{\mathrm{d} \tilde{B} / \tilde{Y}}{\hat{a}^{T}}=-\left\{\left(1-\omega_{N}\right)+\frac{\left\{\left[\left(1-\omega_{N}\right)-\omega_{V}^{T}\right]\left[\alpha_{V}^{T} \tilde{u}^{T}+\sigma_{L}^{T} \tilde{\chi}^{T}\right]-\omega_{V}^{T}\left(1-\alpha_{V}^{T}\right)\right\} A^{T}}{\left[\left(1-\alpha_{V}^{T}\right) \tilde{\Psi}^{T}+\tilde{\chi}^{T} W_{R}^{T}\right]}\right\}<0, \\
& \frac{\mathrm{d} \tilde{B} / \tilde{Y}}{\hat{a}^{N}}=-\left\{\frac{\tilde{P} A^{N}\left\{\left[\left(1-\alpha_{C}\right) \phi+\alpha_{C} \sigma_{C}\right]-1\right\}\left[\alpha_{V}^{N} \tilde{u}^{N}+\sigma_{L}^{N} \tilde{\chi}^{N}\right]\left[\frac{\left(1-\alpha_{C}\right) \omega_{C} \alpha_{C}\left(\phi-\sigma_{C}\right)}{\left(1-\alpha_{C}\right) \phi+\alpha_{C} \sigma_{C}}-\omega_{V}^{N}\right]}{\left[\left(1-\alpha_{V}^{N}\right) \tilde{\Psi}^{N}+\tilde{\chi}^{N} W_{R}^{N}\right]\left[\left(1-\alpha_{C}\right) \phi+\alpha_{C} \sigma_{C}\right]+\tilde{P} A^{N}\left[\alpha_{V}^{N} \tilde{u}^{N}+\sigma_{L}^{N} \tilde{\chi}^{N}\right]}\right. \\
& \left.+\frac{\left(1-\alpha_{C}\right) \omega_{C} \alpha_{C}\left(\phi-\sigma_{C}\right)}{\left[\left(1-\alpha_{C}\right) \phi+\alpha_{C} \sigma_{C}\right]}\right\}<0, \\
& \frac{\mathrm{d} \tilde{B} / \tilde{Y}}{\hat{\bar{\lambda}}}=-\left\{\left[\left(1-\omega_{N}\right)-\omega_{V}^{T}\right] \sigma_{L}^{T}+\frac{\left(1-\alpha_{C}\right) \omega_{C} \sigma_{C} \phi}{\left[\left(1-\alpha_{C}\right) \phi+\alpha_{C} \sigma_{C}\right]}\right. \\
& +\frac{\sigma_{L}^{N}\left[\frac{\left(1-\alpha_{C}\right) \omega_{C} \alpha_{C}\left(\phi-\sigma_{C}\right)}{\left(1-\alpha_{C}\right) \phi+\alpha_{C} \sigma_{C}}-\omega_{V}^{N}\right]\left[\left(1-\alpha_{V}^{N}\right) \tilde{\Psi}^{N}+\tilde{\chi}^{N} W_{R}^{N}\right]\left[\left(1-\alpha_{C}\right) \phi+\alpha_{C} \sigma_{C}\right]}{\left[\left(1-\alpha_{V}^{N}\right) \tilde{\Psi}^{N}+\tilde{\chi}^{N} W_{R}^{N}\right]\left[\left(1-\alpha_{C}\right) \phi+\alpha_{C} \sigma_{C}\right]+\tilde{P} A^{N}\left[\alpha_{V}^{N} \tilde{u}^{N}+\sigma_{L}^{N} \tilde{\chi}^{N}\right]} \\
& \left.-\frac{\tilde{P} A^{N} \sigma_{C}\left[\alpha_{V}^{N} \tilde{u}^{N}+\sigma_{L}^{N} \tilde{\chi}^{N}\right]\left[\frac{\left(1-\alpha_{C}\right) \omega_{C} \alpha_{C}\left(\phi-\sigma_{C}\right)}{\left(1-\alpha_{C}\right) \phi+\alpha_{C} \sigma_{C}}-\omega_{V}^{N}\right]}{\left[\left(1-\alpha_{V}^{N}\right) \tilde{\Psi}^{N}+\tilde{\chi}^{N} W_{R}^{N}\right]\left[\left(1-\alpha_{C}\right) \phi+\alpha_{C} \sigma_{C}\right]+\tilde{P} A^{N}\left[\alpha_{V}^{N} \tilde{u}^{N}+\sigma_{L}^{N} \tilde{\chi}^{N}\right]}\right\} \lessgtr 0 .(22
\end{aligned}
$$

\section{H.3 The Dynamic Adjustment}

The tilde is suppressed below for the purposes of clarity. We now explore effects of higher productivity in tradables relative to non tradables by focusing on the labor market. Figure 8(a) depicts the labor market equilibrium in the traded sector which can be summarized by two schedules: ${ }^{61}$

$$
\begin{gathered}
L^{T}=\frac{m^{T}}{m^{T}+s^{T}}\left(\bar{\lambda} W_{R}^{T}\right)^{\sigma_{L}^{T}}, \\
\frac{\kappa^{T}}{f^{T}}=\frac{\left(1-\alpha_{W}^{T}\right)\left[\left(A^{T}+r^{\star} x^{T}\right)-W_{R}^{T}\right]}{s^{T}+r^{\star}},
\end{gathered}
$$

where $W_{R}^{T} \equiv\left(\frac{\alpha_{W}^{T}}{1-\alpha_{W}^{T}} \kappa^{T} \theta^{T}+R^{T}\right)$ is the reservation wage in the traded sector. The first equation (226a) represents the decision of search schedule in the traded sector (henceforth $D S T$ ) which

${ }^{61}$ Totally differentiating the $D S T$ - and $V C T$-schedule yields:

$$
\hat{l}^{T}=\sigma_{L}^{T} \hat{\bar{\lambda}}+\left[\alpha_{V}^{T} u^{T}+\sigma_{L}^{T} \chi^{T}\right] \hat{\theta}^{T}, \quad \hat{\theta}^{T}=\frac{A^{T}}{\left[\left(1-\alpha_{V}^{T}\right) \tilde{\Psi}^{T}+\tilde{\chi}^{T} W_{R}^{T}\right]} \hat{a}^{T} .
$$

The slope of the $D S T$-schedule in the $\left(\theta^{T}, L^{T}\right)$-space is given by $\left[\alpha_{V}^{T} u^{T}+\sigma_{L}^{T} \chi^{T}\right]>0$. 
is upward-sloping in the $\left(\theta^{T}, L^{T}\right)$-space. The reason is that a rise in the labor market tightness raises the probability of finding a job and thus increases employment $L^{T}$ by reducing the number of job seekers. Moreover, because we consider an endogenous labor force participation decision, the consecutive increase in the reservation wage induces agents to supply more labor. The second equation (226b) represents the vacancy creation schedule (henceforth $V C T$ ) which is a vertical line in the $\left(\theta^{T}, L\right)$-space. Note that Figure 8(a) depicts the logarithm form of the system (226).

By raising the surplus from hiring, a rise in labor productivity in the traded sector $A^{T}$ shifts to the right the $V C T$-schedule from $V C T_{0}$ to $V C T_{1}$. Because traded firms post more job vacancies, the labor market tightness $\theta_{1}^{T}$ exceeds its initial level $\theta_{0}^{T}$. Note that $\theta^{T}$ jumps immediately to its new higher steady-state level while traded employment builds up over time along the isocline $\dot{\theta}^{T}=0$ until the economy reaches the new steady-state. While increased labor market tightness raises traded employment by pushing up the reservation wage and reducing unemployment, the positive wealth effect moderates the expansionary effect on labor supply. Graphically, the fall in $\bar{\lambda}$ shifts to the right the $D S T$-schedule. The new steady state is $E_{1}^{T}$.

Since we are interested in the movement of sectoral wages, it is useful to explore the long-run adjustment in the traded wage following a rise in labor productivity $A^{T}$. The labor market in the traded sector can alternatively be summarized graphically in the $\left(\theta^{T}, W^{T}\right)$-space as shown in Figure 9 (a). Using the fact $\left(1-\alpha_{W}^{T}\right) \Psi^{T}=A^{T}-W^{T}$, the $V C T$-schedule is downward sloping and convex toward the origin, reflecting diminishing returns in vacancy creation. The slope of the $V C T$-schedule in the $\left(\theta^{T}, W^{T}\right)$-space is:

$$
\left.\frac{\mathrm{d} W^{T}}{\mathrm{~d} \theta^{T}}\right|^{V C T}=-\frac{\left(s^{T}+r^{\star}\right) \kappa^{T}\left(1-\alpha_{V}^{T}\right)}{f^{T} \theta^{T}}=-\frac{\left(1-\alpha_{W}^{T}\right) \Psi^{T}\left(1-\alpha_{V}^{T}\right)}{\theta^{T}}<0 .
$$

The wage setting-schedule (WST henceforth) is upward sloping (see eq. (22)). Using the fact that $\left(F^{T}\right)^{1 / \sigma_{L}^{T}} / \bar{\lambda}=W_{R}^{T}$, the $W S T$-schedule is $W^{T}=\alpha_{W}^{T}\left(A^{T}+r^{\star} x^{T}\right)+\left(1-\alpha_{W}^{T}\right) W_{R}^{T}$ with a slope in the $\left(\theta^{T}, W^{T}\right)$-space given by:

$$
\left.\frac{\mathrm{d} W^{T}}{\mathrm{~d} \theta^{T}}\right|^{W S T}=\frac{\left(1-\alpha_{W}^{T}\right) \chi^{T} W_{R}^{T}}{\theta^{T}}=\alpha_{W}^{T} \kappa^{T}>0 .
$$

A rise in $A^{T}$ shifts to the right the $V C T$-schedule by stimulating labor demand which exerts an upward pressure on the the traded wage. Because workers get a fraction $\alpha_{W}^{T}$ of the increased surplus, the productivity shock shifts to the left the WST-schedule. ${ }^{62}$ Hence, the new steady-state at $F_{1}^{T}$ is associated with a higher traded wage. The higher the worker bargaining power, the larger the shift of the WST curve and thereby the more $W^{T}$ increases. To see it formally, totally differentiating the Nash bargaining traded wage and eliminating $\theta^{T}$ by using the vacancy creation schedule (i.e., eq. (226b)) yields the deviation in percentage of the traded wage from its initial steady state: ${ }^{63}$

$$
\hat{w}^{T}=\Omega^{T} \hat{a}^{T}>0, \quad \Omega^{T}=\frac{\alpha_{W}^{T}\left[\left(1-\alpha_{V}^{T}\right)\left(s^{T}+r^{\star}\right)+m^{T}\right]}{\left[\left(1-\alpha_{V}^{T}\right)\left(s^{T}+r^{\star}\right)+\alpha_{W}^{T} m^{T}\right]} \frac{A^{T}}{W^{T}},
$$

where $\Omega^{T}>0$ represents the sensitivity of the traded wage to a change in the labor productivity index $A^{T}$.

We now turn to the non traded labor market equilibrium depicted in Figure 8(b) which is summarized by two schedules:

$$
\begin{gathered}
L^{N}=\frac{m^{N}}{m^{N}+s^{N}}\left(\bar{\lambda} W_{R}^{N}\right)^{\sigma_{L}^{N}} \\
\frac{\kappa^{N}}{f^{N}}=\frac{\left(1-\alpha_{W}^{N}\right)\left[\left(P\left(L^{N}, \bar{\lambda}, A^{N}\right) A^{N}+r^{\star} x^{N}\right)-W_{R}^{N}\right]}{s^{N}+r^{\star}},
\end{gathered}
$$

where we have inserted the short-run static solution for the relative price of non tradables (108) and $W_{R}^{N} \equiv\left(\frac{\alpha_{W}}{1-\alpha_{W}} \kappa^{N} \theta^{N}+R^{N}\right)$ is the reservation wage in the non traded sector. While eq. (230a) represents the decision of search schedule (henceforth $D S N$ ) which is upward-sloping in the $\left(\theta^{N}, L^{N}\right)$ space, eq. (230b) corresponds to the vacancy creation schedule in the non traded sector (henceforth $V C N)$. Note that whether we consider the traded or the non traded sector, the same logic applies to explain the positive relationship between the employment and the labor market tightness along the $D S j$-schedule (with $j=T, N$ ).

\footnotetext{
${ }^{62}$ Note that the shift in the $V C T$-schedule dominates the shift in the $W S T$-schedule because workers and firms have to share the surplus, i.e., $0<\alpha_{W}^{T}<1$.

${ }^{63}$ To get (229), we used the fact that $\chi^{T} W_{R}^{T}=m^{T} \frac{\alpha_{W}^{T} \Psi^{T}}{s^{T}+r^{\star}}$.
} 


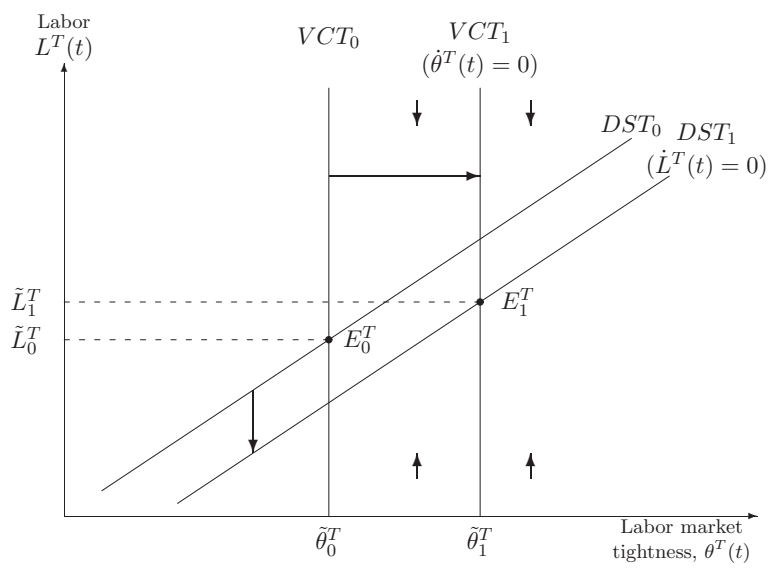

(a) $\left(\theta^{T}, L^{T}\right)$-space

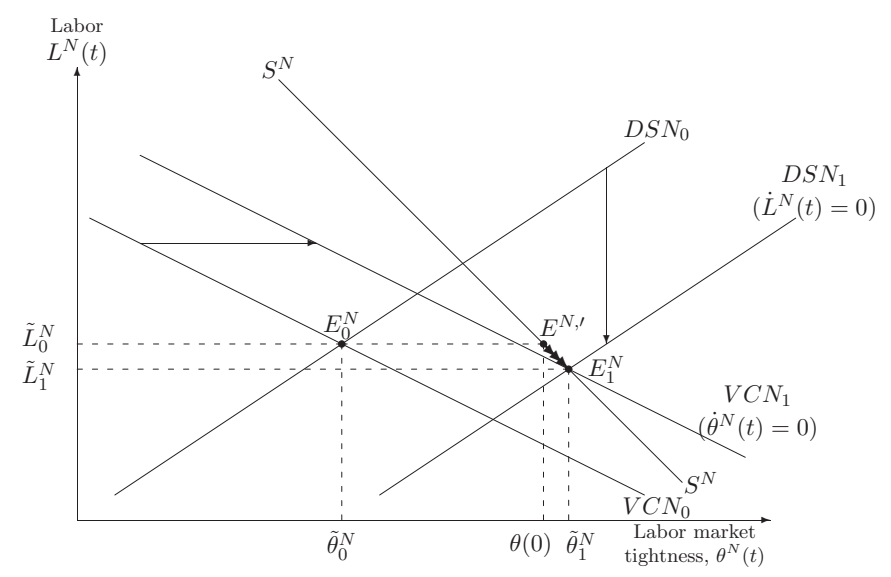

(b) $\left(\theta^{N}, L^{N}\right)$-space

Figure 8: Effects of a Productivity Differential and the Stable Adjustment 


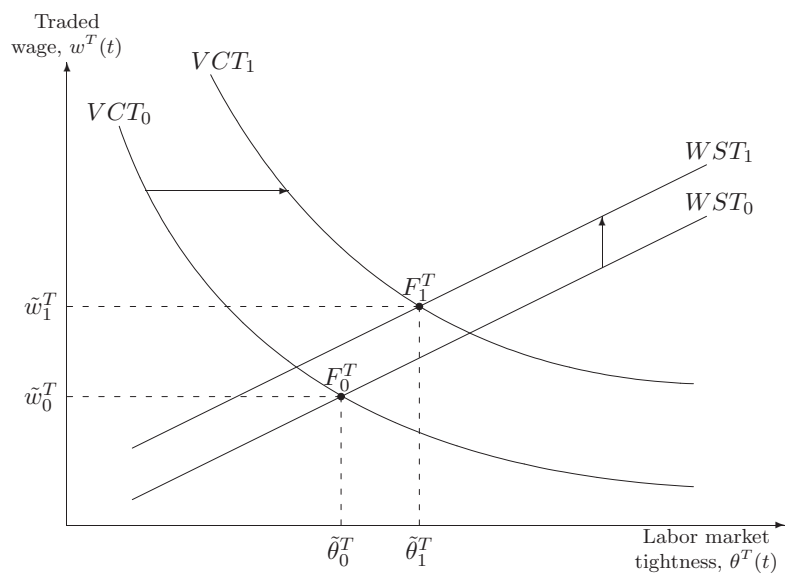

(a) $\left(\theta^{T}, W^{T}\right)$-space

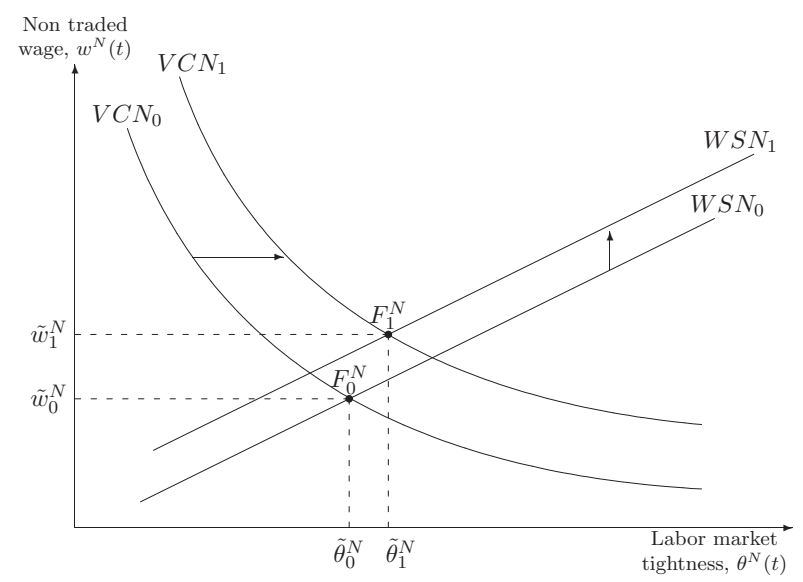

(b) $\left(\theta^{N}, W^{N}\right)$-space

Figure 9: Long-Run Sectoral Wage Effects of a Productivity Differential 
Totally differentiating eq. (230a) gives the slope of the $D S N$-schedule:

$$
\hat{l}^{N}=\sigma_{L}^{N} \hat{\bar{\lambda}}+\left[\alpha_{V}^{N} u^{N}+\sigma_{L}^{N} \chi^{N}\right] \hat{\theta}^{N}
$$

The slope of the $D S N$-schedule in the $\left(\theta^{N}, L^{N}\right)$-space is given by $\left[\alpha_{V}^{N} u^{N}+\sigma_{L}^{N} \chi^{N}\right]>0$. Totally differentiating (230b) gives the slope of the $V C N$-schedule:

$$
\begin{gathered}
\hat{\theta}^{N}\left[\left(1-\alpha_{V}^{N}\right) \tilde{\Psi}^{N}+\tilde{\chi}^{N} W_{R}^{N}\right]\left[\left(1-\alpha_{C}\right) \phi+\alpha_{C} \sigma_{C}\right] \\
=-P A^{N}\left\{\hat{l}^{N}+\sigma_{C} \hat{\bar{\lambda}}+\left\{1-\left[\left(1-\alpha_{C}\right) \phi+\alpha_{C} \sigma_{C}\right]\right\} \hat{a}^{N}\right\} .
\end{gathered}
$$

The slope of the $V C N$-schedule is negative and given by:

$$
\left.\frac{\hat{L}^{N}}{\hat{\theta}^{N}}\right|^{V C N}=-\frac{P A^{N}}{\left[\left(1-\alpha_{V}^{N}\right) \tilde{\Psi}^{N}+\tilde{\chi}^{N} W_{R}^{N}\right]\left[\left(1-\alpha_{C}\right) \phi+\alpha_{C} \sigma_{C}\right]}<0 .
$$

As depicted in Figure 8(b), the $V C N$-schedule is downward-sloping in the $\left(\theta^{N}, L^{N}\right)$-space. The reason is as follows. Because an increase in non traded labor raises output of this sector, the relative price of non tradables must depreciate for the market clearing condition (24) to hold. The fall in $P$ drives down the surplus from hiring an additional worker in the non traded sector which results in a decline in labor market tightness $\theta^{N}$ as firms post less job vacancies.

Imposing $\sigma_{C}=1$, a rise in $A^{N}$ raises the surplus from hiring if and only if the elasticity of substitution $\phi$ between traded and non traded goods is larger than one. The reason is that only in this case, the share of non tradables in total expenditure rises which results in an expansionary effect on labor demand in the non traded sector. In Figure $8(\mathrm{~b})$, we assume that $\sigma_{C}=\phi=1$, so that the productivity shock does not impinge on the vacancy creation decision because the share of non tradables remains unchanged. Yet, by producing a positive wealth effect, higher labor productivity of non tradables shifts the $V C N$-schedule to the right by inducing agents to consume more which in turn raises $P$ and thereby the surplus from hiring. The fall of the shadow value of wealth also shifts the $D S N$-schedule to the right as agents are induced to supply less labor. While $\theta^{N}$ is unambiguously higher at the new steady-state $E_{1}^{N}$, the positive wealth effect exerts two conflicting effects on $L^{N}$. In Figure 8(b), non traded employment falls in line with our numerical results. ${ }^{64}$

We now explore the long-run adjustment in the non traded wage which is depicted in Figure 9(b). As for the traded sector, the $W S N$-schedule is upward sloping while the $V C N$-schedule is downward sloping. Formally, using the fact $\left(1-\alpha_{W}^{N}\right) \Psi^{N}=P A^{N}+r^{\star} x^{N}-W^{N}$, the wage setting and vacancy creation decisions are described by the following equalities:

$$
\begin{gathered}
W^{N}=\alpha_{W}^{N}\left(P A^{N}+r^{\star} x^{N}\right)+\left(1-\alpha_{W}^{N}\right) W_{R}^{N}, \\
W^{N}=\left(P A^{N}+r^{\star} x^{N}\right)-\frac{\kappa^{N}\left(s^{N}+r^{\star}\right)}{f^{N}} .
\end{gathered}
$$

Before analyzing in more details the effects of a productivity shock on the non traded wage, it is convenient to determine analytically the long-run response of $W^{N}$. Totally differentiating the wage setting decision in the non traded sector allows us to solve for the change in the labor market tightness $\hat{\theta}^{N}=\frac{P A^{N}\left(\hat{p}+\hat{a}^{N}\right)}{\left[\left(1-\alpha_{V}^{N}\right) \Psi^{N}+\chi^{N} W_{R}^{N}\right]}$. Totally differentiating the Nash bargaining non traded wage and plugging $\hat{\theta}^{N}$, yields the deviation in percentage of the non traded wage from its initial steady state:

$$
\hat{w}^{N}=\Omega^{N}\left(\hat{p}+\hat{a}^{N}\right), \quad \Omega^{N}=\frac{\alpha_{W}^{N}\left[\left(1-\alpha_{V}^{N}\right)\left(s^{N}+r^{\star}\right)+m^{N}\right]}{\left[\left(1-\alpha_{V}^{N}\right)\left(s^{N}+r^{\star}\right)+\alpha_{W}^{N} m^{N}\right]} \frac{P A^{N}}{W^{N}} .
$$

According to (232), the combined effects of higher labor productivity $A^{N}$ and the appreciation of the relative price of non tradables pushes up the non traded wage in the long-run. Inserting the long-run change in the equilibrium value of the relative price of non tradables, i.e., $\hat{p}=\frac{(1+\Theta)\left(\hat{a}^{T}-\hat{a}^{N}\right)}{(\phi+\Theta)}-\frac{\mathrm{d} v_{N X}}{(\phi+\Theta)}$ (see eq. (31)), and using the fact that $\chi^{N} W_{R}^{N}=m^{N} \frac{\alpha_{W}^{N} \Psi^{N}}{s^{N}+r^{\star}}$ allows us to rewrite (232) as follows:

$$
\hat{w}^{N}=\frac{\Omega^{N}}{\left(\phi+\Theta^{N}\right)}\left[\hat{a}^{T}\left(1+\Theta^{T}\right)+\hat{a}^{N}(\phi-1)-\mathrm{d} v_{N X}\right] .
$$

Imposing the elasticity of substitution $\phi$ to be equal to one, labor productivity in the non traded sector does no longer impinge on $W^{N}$. In this case, the change in the non traded wage is only driven by $\hat{a}^{T}>0$ which appreciates the relative price of non traded goods and thereby stimulates

\footnotetext{
${ }^{64}$ In all scenarios, we numerically find that $L^{N}$ declines.
} 
labor demand in that sector. Further assuming that labor market parameters are similar across sectors so that $\Theta^{j} \simeq \Theta$ and $\Omega^{j} \simeq \Omega$ (with $j=T, N$ ), we find that the non traded wage is equal to $\Omega\left[\hat{a}^{T}-\frac{\mathrm{d} v_{N X}}{(1+\Theta)}\right]$. By producing a long-run improvement in the trade balance $N X$ and thereby stimulating the demand for tradables, a productivity shock exerts a negative impact on the relative wage $W^{N} / W^{T}$. As depicted in Figure 9(b), due to the labor accumulation effect, a productivity shock biased toward the traded sector induces smaller shifts in the $V C N$ - and the $W S N$-schedule. Note that, as for the traded labor market, the shift in the $V C N$-schedule dominates the shift in the $W S N$-schedule because the worker bargaining power $\alpha_{W}^{N}$ is smaller than one.

\section{Solving Graphically for the Steady-State: Graphical Ap- paratus}

The steady-state can be described by considering alternatively the goods market or the labor market. Due to the lack of empirical estimates at a sectoral level, and to avoid unnecessary complications, we impose $\alpha_{V}^{j}=\alpha_{V}, \alpha_{W}^{j}=\alpha_{W}$ from now on.

\section{I.1 The Goods Market: Graphical Apparatus}

To build intuition about steady-state changes, we investigate graphically the long-run effects of a rise in $A^{T} / A^{N}$. To do so, it is convenient to rewrite the steady-state (219) as follows:

$$
\begin{aligned}
& \frac{C^{T}}{C^{N}}=\frac{\varphi}{1-\varphi} \tilde{P}^{\phi} \\
& \frac{L^{T}}{L^{N}}=\frac{m^{T}}{m^{N}} \frac{\left(s^{N}+m^{N}\right)}{\left(s^{T}+m^{T}\right)} \frac{\left[\bar{\lambda} W_{R}^{T} / \zeta^{T}\right]^{\sigma_{L}^{T}}}{\left[\bar{\lambda} W_{R}^{N} / \zeta^{N}\right]^{\sigma_{L}^{N}}}, \\
& \frac{\kappa^{T}}{f^{T}\left(\theta^{T}\right)}=\frac{\left(1-\alpha_{W}\right) \Psi^{T}}{\left(s^{T}+r^{\star}\right)}, \\
& \frac{\kappa^{N}}{f^{N}\left(\theta^{N}\right)}=\frac{\left(1-\alpha_{W}\right) \Psi^{N}}{\left(s^{N}+r^{\star}\right)}, \\
& \frac{Y^{T}\left(1+v_{B}-v_{V}^{T}-v_{V}^{N}\right)}{Y^{N}}=\frac{C^{T}}{C^{N}} .
\end{aligned}
$$

We denote by $v_{B} \equiv \frac{r^{\star} B}{Y^{T}}$ the ratio of interest receipts to traded output, by $v_{V}^{j} \equiv \frac{\kappa^{j} V^{j}}{Y^{T}}$ the share of hiring cost in sector $j=T, N$ in traded output. Remembering that $Y^{T}=A^{T} L^{T}$ and $Y^{N}=A^{N} L^{N}$, the system (234) can be solved for $C^{T} / C^{N}, L^{T} / L^{N}, \theta^{T}, \theta^{N}$, and $P$, as functions of $A^{T}, A^{N},\left(1+v_{B}-v_{V}^{T}-v_{V}^{N}\right)$. Inserting these functions into $Y^{N}=C^{N}$ (see eq. (167h)), and $B-B_{0}=\Phi^{T}\left(L^{T}-L_{0}^{T}\right)+\Phi^{N}\left(L^{N}-L_{0}^{N}\right)$ (see eq. (167j)), the system can be solved for $B$ and $\bar{\lambda}$ as functions of $A^{T}$ and $A^{N}$. Hence, when solving the system (234), we assume that the stock of foreign bonds and the marginal utility of wealth are exogenous which allows us to separate intratemporal reallocation effects triggered by the change in the share of tradables from the dynamic (or intertemporal) effects stemming from the accelerated hiring process that increases the demand for tradables in the long-run.

When focusing on the goods market, the equilibrium can be characterized by two schedules in the $\left(y^{T}-y^{N}, p\right)$-space where we denote the logarithm in lower case. The steady state is summarized graphically in Figure 10(b).

Denoting by $v_{N X} \equiv N X / Y^{T}$ the ratio of net exports to traded output, with $v_{N X} \equiv-\left(v_{B}-v_{V}^{T}-v_{V}^{N}\right)$, and inserting (234a) into the market clearing condition (234e) leads to

$$
\frac{Y^{T}}{Y^{N}}=\frac{\varphi}{1-\varphi} \frac{1}{\left(1-v_{N X}\right)} P^{\phi} .
$$

Eq. (235) corresponds to eq. (26) in the text. Totally differentiating (235) and denoting the percentage deviation from its initial steady-state by a hat yields the goods market equilibriumschedule (GME henceforth):

$$
\left.\left(\hat{y}^{T}-\hat{y}^{N}\right)\right|^{G M E}=\phi \hat{p}-d \ln \left(1-v_{N X}\right) .
$$

According to (236), the GME-schedule is upward-sloping in the $\left(y^{T}-y^{N}, p\right)$-space with a slope equal to $1 / \phi$. Following a rise in traded output relative to non traded output, the relative price of non tradables must appreciate to clear the goods market, and all the more so as the elasticity of 


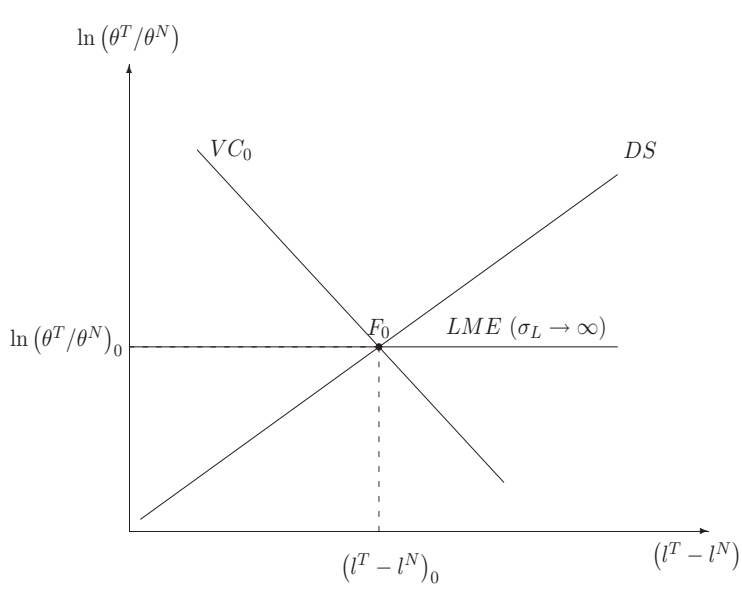

(a) $\left(l^{T}-l^{N}, \ln \left(\theta^{T} / \theta^{N}\right)\right)$-space

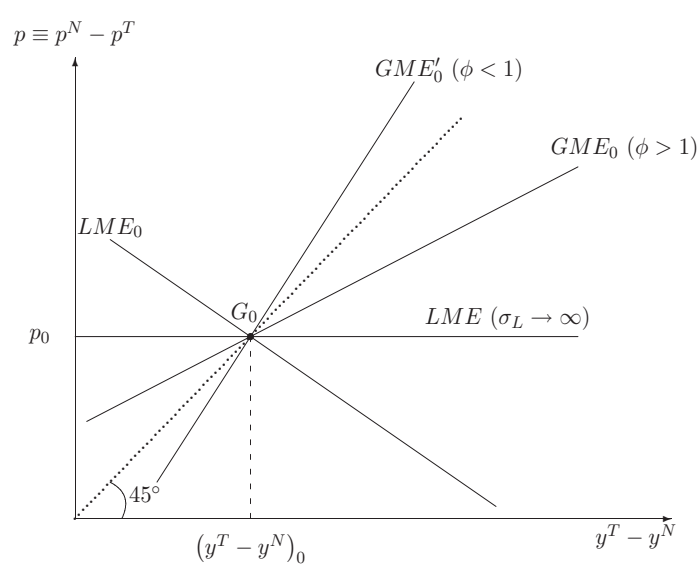

(b) $\left(y^{T}-y^{N}, p\right)$-space

Figure 10: Steady-State

substitution $\phi$ is smaller. The $45^{\circ}$ dotted line allows us to consider two cases. When $\phi>1(\phi<1)$, the $G M E$-schedule is flatter (steeper) than the $45^{\circ}$ dotted line.

We now characterize the labor market equilibrium. Totally differentiating (214) gives the deviation in percentage of the sectoral labor market tightness from its initial steady-state, i.e., $\hat{\theta}^{j}=\frac{\Xi^{j}}{\left[\left(1-\alpha_{V}^{j}\right) \Psi^{j}+\chi^{j} W_{R}^{j}\right]} \hat{\Xi}^{j}$. Totally differentiating (215) gives the deviation in percentage of sectoral labor from its initial steady-state, i.e., $\hat{l}^{j}=\left[\alpha_{V}^{j} u^{j}+\sigma_{L} \chi^{j}\right] \hat{\theta}^{j}$. Substituting the former into the latter, differentiating the production function $Y^{j}=A^{j} L^{j}$ to eliminate $\hat{l}^{j}$, and using the fact that $\chi^{j} W_{R}^{j}=\frac{\alpha_{W}^{j} \Psi^{j}}{s^{j}+r^{\star}}$ at the steady-state, one obtains the labor market equilibrium (LME henceforth) schedule:

$$
\left.\left(\hat{y}^{T}-\hat{y}^{N}\right)\right|^{L M E}=-\Theta^{N} \hat{p}+\left(1+\Theta^{T}\right) \hat{a}^{T}-\left(1+\Theta^{N}\right) \hat{a}^{N},
$$

where we set

$$
\Theta^{j} \equiv \frac{\Xi^{j}\left(s^{j}+r^{\star}\right)\left[\alpha_{V} u^{j}+\sigma_{L} \chi^{j}\right]}{\Psi^{j}\left[\left(1-\alpha_{V}\right)\left(s^{j}+r^{\star}\right)+\alpha_{W}^{j} m^{j}\right]},
$$

in order to write formal solutions in a compact form. As depicted in Figure 10(b), the $L M E$-schedule is downward-sloping in the $\left(y^{T}-y^{N}, p\right)$-space with a slope equal to $-1 / \Theta^{N}$ (see eq. (237)). An appreciation in the relative price of non tradables raises the surplus from hiring which induces non traded firms to post more job vacancies. By raising the expected value of a job, the consecutive rise in the labor market tightness induces agents to increase the search intensity for a job in the non traded sector but less so as the elasticity of labor supply $\sigma_{L}$ is lower. More precisely, lower values of $\sigma_{L}$ indicate that workers experience a larger switching cost from one sector to another; in this configuration, the term $\Theta^{j}$ is smaller so that the $L M E$-schedule is steeper. Conversely, when we let $\sigma_{L}$ tend toward infinity, the case of perfect mobility of labor across sectors is obtained; in this configuration, the $L M E$-schedule becomes a horizontal line.

\section{I.2 The Labor Market: Graphical Apparatus}

When focusing on the labor market, the model can be summarized graphically by two schedules in the $\left(l^{T}-l^{N}, \ln \left(\frac{\theta^{T}}{\theta^{N}}\right)\right)$-space, as shown in Figure 10(a).

As will be useful later, we first solve for the relative price of non tradables by using the goods market clearing condition (235). Using production functions, i.e., $Y^{j}=A^{j} L^{j}$, solving (235) for the relative price yields:

$$
P=\left[\left(\frac{1-\varphi}{1-\varphi}\right)\left(1-v_{N X}\right)\left(\frac{A^{T}}{A^{N}}\right)\left(\frac{L^{T}}{L^{N}}\right)\right]^{\frac{1}{\phi}} .
$$

Applying the implicit function theorem, we have:

$$
P=P\left[\left(\frac{L^{T}}{L^{N}}\right),\left(1-v_{N X}\right),\left(\frac{A^{T}}{A^{N}}\right)\right],
$$

where

$$
\hat{p}=\frac{1}{\phi}\left[d \ln \left(\frac{L^{T}}{L^{N}}\right)+d \ln \left(\frac{A^{T}}{A^{N}}\right)+d \ln \left(1-v_{N X}\right)\right] .
$$




\section{I.2.1 The Decision of Search Schedule in the $\left(l^{T}-l^{N}, \ln \left(\frac{\theta^{T}}{\theta^{N}}\right)\right)$-space}

Imposing $\sigma_{L}^{j}=\sigma_{L}$ into (234b), which implies that the marginal utility of wealth does not impinge relative labor supply, the decision of search equation reduces to:

$$
\frac{L^{T}}{L^{N}}=\frac{m^{T}}{m^{N}} \frac{m^{N}+s^{N}}{m^{T}+s^{T}}\left(\frac{W_{R}^{T}}{W_{R}^{N}} \frac{\zeta^{N}}{\zeta^{T}}\right)^{\sigma_{L}},
$$

where $W_{R}^{j} \equiv \frac{\alpha_{W}^{j}}{1-\alpha_{W}^{j}} \kappa^{j} \tilde{\theta}^{j}+R^{j}$ is the reservation wage. Eq. (242) corresponds to eq. (28) in the text. Taking logarithm and differentiating eq. (239) yields:

$$
\hat{l}^{T}-\hat{l}^{N}=\left[\alpha_{V} u^{T}+\sigma_{L} \chi^{T}\right] \hat{\theta}^{T}-\left[\alpha_{V} u^{N}+\sigma_{L} \chi^{N}\right] \hat{\theta}^{N},
$$

where we used the fact that $d \ln \left(\frac{m^{j}}{m^{j}+s^{j}}\right)=\alpha_{V} u^{j} \hat{\theta}^{j}$ and $\hat{w}_{R}^{j}=\chi^{j} \hat{\theta}^{j}$ with $\chi^{j}=\frac{\frac{\alpha_{W}}{1-\alpha_{W}} \kappa^{j} \theta^{j}}{W_{R}^{j}}$. Assuming that the labor markets display initially similar features across sectors, i.e., $u^{j} \simeq u, \chi^{j} \simeq \chi$, eq. (243) reduces to:

$$
\left.\left(\hat{\theta}^{T}-\hat{\theta}^{N}\right)\right|^{D S}=\frac{1}{\left[\alpha_{V} u+\sigma_{L \chi}\right]}\left(\hat{l}^{T}-\hat{l}^{N}\right) .
$$

Inspection of (244) reveals that the $D S$-schedule:

- is upward-sloping in the $\left(l^{T}-l^{N}, \ln \left(\frac{\theta^{T}}{\theta^{N}}\right)\right)$-space;

- is steeper as the workers are more reluctant to shift hours worked across sectors (i.e., the elasticity of labor supply $\sigma_{L}$ is smaller), the unemployment benefit scheme is more generous or the worker bargaining power $\alpha_{W}$ is lower (because higher unemployment benefits $R$ or a lower worker bargaining power both reduce the share of the surplus associated with a labor contract in the marginal benefit of search $\chi$ ).

\section{I.2.2 The Vacancy-Creation Schedule in the $\left(l^{T}-l^{N}, \ln \left(\frac{\theta^{T}}{\theta^{N}}\right)\right)$-space}

Dividing (234c) by (234d) and using (98) leads to the vacancy creation equation:

$$
\frac{\kappa^{T}}{\kappa^{N}} \frac{\left(s^{T}+r^{\star}\right)}{\left(s^{N}+r^{\star}\right)} \frac{X^{N}}{X^{T}}\left(\frac{\theta^{T}}{\theta^{N}}\right)^{1-\alpha_{V}}=\frac{\Xi^{T}+r^{\star} x^{T}-W_{R}^{T}}{\Xi^{N}+r^{\star} x^{N}-W_{R}^{N}},
$$

where $\frac{\Xi^{T}+r^{\star} x^{T}-W_{R}^{T}}{\Xi^{N}+r^{\star} x^{N}-W_{R}^{N}}=\frac{\Psi^{T}}{\Psi^{N}}$. Eq. (245) corresponds to eq. (27) in the text. Totally differentiating (245) by sing the fact that the change in overall surplus $\Psi^{j}$ in percentage is given by

$$
\hat{\Psi}^{j}=\frac{\Xi^{j} \hat{\Xi}^{j}-\chi^{j} W_{R}^{j} \hat{\theta}^{j}}{\Psi^{j}}
$$

yields:

$$
\left.\left(\hat{\theta}^{T}-\hat{\theta}^{N}\right)\right|^{V C}=\frac{\Xi^{T} \hat{a}^{T}}{\left[\left(1-\alpha_{V}\right) \tilde{\Psi}^{T}+\chi^{T} W_{R}^{T}\right]}-\frac{\Xi^{N}\left(\hat{p}+\hat{a}^{N}\right)}{\left[\left(1-\alpha_{V}\right) \tilde{\Psi}^{N}+\chi^{N} W_{R}^{N}\right]} .
$$

Eliminating the relative price by using (241), collecting terms, assuming that initially $\Xi^{j} \simeq \Xi$, $\Psi^{j} \simeq \Psi, W_{R}^{j} \simeq W_{R}, \chi^{j} \simeq \chi$, eq. (247) can be rewritten as follows:

$$
\begin{aligned}
\left.\left(\hat{\theta}^{T}-\hat{\theta}^{N}\right)\right|^{V C} & =-\frac{\Xi}{\phi\left[\left(1-\alpha_{V}\right) \Psi+\chi W_{R}\right]}\left(\hat{l}^{T}-\hat{l}^{N}\right) \\
& +\frac{\Xi\left[(\phi-1)\left(\hat{a}^{T}-\hat{a}^{N}\right)-d \ln \left(1-v_{N X}\right)\right]}{\phi\left[\left(1-\alpha_{V}\right) \Psi+\chi W_{R}\right]} .
\end{aligned}
$$

Inspection of (248) reveals that the $V C$-schedule:

- is downward-sloping in the $\left(l^{T}-l^{N}, \ln \left(\frac{\theta^{T}}{\theta^{N}}\right)\right)$-space with a slope equal to $-\frac{\Xi}{\phi\left[\left(1-\alpha_{V}\right) \Psi+\chi W_{R}\right]}$;

- is steeper as the elasticity of substitution between traded and non traded goods $\phi$ is smaller or the worker bargaining power is lower (because it reduces $\chi W_{R}$ );

- shifts to the right following higher productivity of tradables relative to non tradables (i.e., $\left.\left(\hat{a}^{T}-\hat{a}^{N}\right)>0\right)$ as long as $\phi>1$ or when the country experiences a higher steady-state trade balance surplus, i.e., if $-d \ln \left(1-v_{N X}\right) \simeq d v_{N X}>0$; 


\section{J Long-Run Relative Price and Relative Wage Effects of Higher Relative Productivity of Tradables}

This section analyzes analytically the consequences on the relative wage and the relative price of an increase in relative sectoral productivity $A^{T} / A^{N}$. It compares the steady-state of the model before and after the productivity shock biased towards the traded sector. To shed some light on the transmission mechanism, we analytically break down the relative wage and relative price effects in two components: a labor market frictions effect and a labor accumulation effect. yields

Equating demand for tradables in terms of non tradables given by eq. (236) and supply (237)

$$
\begin{aligned}
\left(\hat{y}^{T}-\hat{y}^{N}\right) & =\phi \hat{p}-d \ln \left(1-v_{N X}\right), \\
& =-\Theta^{N} \hat{p}+\left(1+\Theta^{T}\right) \hat{a}^{T}-\left(1+\Theta^{N}\right) \hat{a}^{N} .
\end{aligned}
$$

Collecting terms leads to the deviation in percentage of the relative price from its initial steady-state:

$$
\hat{p}=\frac{\left(1+\Theta^{T}\right) \hat{a}^{T}-\left(1+\Theta^{N}\right) \hat{a}^{N}}{\left(\phi+\Theta^{N}\right)}+\frac{\mathrm{d} \ln \left(1-v_{N X}\right)}{\left(\phi+\Theta^{N}\right)} .
$$

Eq. (249) corresponds to eq. (29) in the text. It is worthwhile noticing that $\hat{p}$ given by eq. (249) is determined by the system which comprises the goods market equilibrium (235), the decision of search equation (242), and the vacancy creation equation (245). This implies that $P=P\left(A^{T}, A^{N}, v_{N X}\right)$. Invoking the intertemporal solvency condition (149) allows us to solve for $v_{N X}=v_{N X}\left(A^{T}, A^{N}\right)$.

To determine the long-run adjustment in the relative wage, $\Omega \equiv W^{N} / W^{T}$, we first derive the deviation in percentage of the sectoral wage. To do so, we totally differentiate the vacancy creation equation for sector $j$ given by eq. (214):

$$
\hat{\theta}^{j}=\frac{\Xi^{j}}{\left[\left(1-\alpha_{V}\right) \Psi^{j}+\chi^{j} W_{R}^{j}\right]} \hat{\Xi}^{j} .
$$

We repeat the Nash bargaining wage given by eq. (22) for convenience by imposing $\alpha_{W}^{j}=\alpha_{W}$ :

$$
W^{j}=\alpha_{W}\left(\Xi^{j}+r^{\star} x^{j}\right)+\left(1-\alpha_{W}\right) W_{R}^{j} .
$$

Totally differentiating (251) and plugging the change in the labor market tightness leads to:

$$
\begin{aligned}
\hat{w}^{j} & =\frac{\alpha_{W} \Xi^{j}}{W^{j}} \hat{\Xi}^{j}+\frac{\left(1-\alpha_{W}\right) \chi^{j} W_{R}^{j}}{W^{j}} \hat{\theta}^{j}, \\
& =\frac{\Xi^{j}}{W^{j}} \frac{\left[\alpha_{W}\left(1-\alpha_{V}\right) \Psi^{j}+\chi^{j} W_{R}^{j}\right]}{\left[\left(1-\alpha_{V}\right) \Psi^{j}+\chi^{j} W_{R}^{j}\right]} .
\end{aligned}
$$

Using the fact that at the steady-state, we have $\chi^{j} W_{R}^{j}=m^{j} \xi^{j}=\frac{m^{j} \alpha_{W} \Psi^{j}}{s^{j}+r^{\star}}$, eq. (252) can be rewritten as follows:

$$
\begin{aligned}
\hat{w}^{j} & =\frac{\Xi^{j}}{W^{j}} \frac{\left[\alpha_{W}\left(1-\alpha_{V}\right) \Psi^{j}+\frac{m^{j} \alpha_{W} \Psi^{j}}{s^{j}+r^{\star}}\right]}{\left[\left(1-\alpha_{V}\right) \Psi^{j}+\frac{m^{j} \alpha_{W} \Psi^{j}}{s^{j}+r^{\star}}\right]}, \\
& =\frac{\Xi^{j}}{W^{j}} \frac{\alpha_{W}\left[\left(1-\alpha_{V}\right)\left(s^{j}+r^{\star}\right)+m^{j}\right]}{\left[\left(1-\alpha_{V}\right)\left(s^{j}+r^{\star}\right)+\alpha_{W} m^{j}\right]} \hat{\Xi}^{j} .
\end{aligned}
$$

Eq. (253) corresponds to eq. (32) in the text. In order to write formal solutions in a compact form, we set:

$$
\Omega^{j} \equiv \frac{\Xi^{j}}{W^{j}} \frac{\alpha_{W}\left[\left(1-\alpha_{V}\right)\left(s^{j}+r^{\star}\right)+m^{j}\right]}{\left[\left(1-\alpha_{V}\right)\left(s^{j}+r^{\star}\right)+\alpha_{W} m^{j}\right]} .
$$

Using the fact that $\hat{\Xi}^{N}=\hat{p}+\hat{a}^{N}$ and $\hat{\Xi}^{T}=\hat{a}^{T}$, subtracting $\hat{w}^{T}$ from $\hat{w}^{N}$ by combining (253) and (254) and inserting (249) leads to the deviation in percentage of the relative wage:

$$
\begin{aligned}
\hat{\omega} & =\hat{w}^{N}-\hat{w}^{T}, \\
& =\Omega^{N}\left(\hat{p}+\hat{a}^{N}\right)-\Omega^{T} \hat{a}^{T}, \\
& =\left\{\Omega^{N}\left[\frac{\left(1+\Theta^{T}\right) \hat{a}^{T}+(\phi-1) \hat{a}^{N}}{\left(\phi+\Theta^{N}\right)}\right]-\Omega^{T} \hat{a}^{T}\right\}-\Omega^{N} \frac{\mathrm{d} v_{N X}}{\phi+\Theta^{N}} .
\end{aligned}
$$

Eq. (255) corresponds to eq. (33) in the text. 


\section{K Analyzing Graphically the Long-Run Effects of Techno- logical Change Biased toward the Traded Sector}

This section analyzes graphically the consequences on the relative wage and the relative price of an increase in relative sectoral productivity $A^{T} / A^{N}$, by breaking down the relative wage and relative price effects in a labor market frictions effect and a labor accumulation effect.

\section{K.1 Effects of Higher Productivity in Tradables Relative to Non Trad- ables}

In order to facilitate the discussion, we assume that $\Theta^{j} \simeq \Theta$. Under this assumption, eq. (249) reduces to:

$$
\hat{p}=\frac{(1+\Theta)\left(\hat{a}^{T}-\hat{a}^{N}\right)}{(\phi+\Theta)}+\frac{\mathrm{d} \ln \left(1-v_{N X}\right)}{(\phi+\Theta)},
$$

where $\mathrm{d} \ln \left(1-v_{N X}\right) \simeq-d v_{N X}$ by using a first-order Taylor approximation.

Eq. (256) breaks down the relative price response into two components: a labor market frictions effect and a labor accumulation effect. The first term on the RHS of eq. (256) corresponds to the labor market frictions effect. When we let $\sigma_{L}$ tend toward infinity, we have $\lim _{\sigma_{L} \rightarrow \infty} \frac{(1+\Theta)}{(\phi+\Theta)}=1$; in this configuration, a productivity differential between tradables and non tradables by $1 \%$ appreciates the relative price by $1 \%$ as well, in line with the prediction of the standard BS model. Graphically, as shown in Figure 11(a), the $L M E$-schedule is a horizontal line because the allocation of the labor force across sectors is perfectly elastic to the ratio of sectoral reservation wages. A productivity shock biased toward the traded sector shifts higher the $L M E$-schedule which results in a relative price appreciation, from $p_{0}$ to $p_{B S}$, i.e., by the same amount as the productivity differential. The $L M E$-schedule intercepts the $45^{\circ}$ line at point $B S^{\prime}$.

As long as $\sigma_{L}<\infty$, workers experience a mobility cost when moving from one sector to another; hence, the term $\Theta$ takes finite values while graphically, the $L M E$-schedule is downward sloping in the $\left(y^{T}-y^{N}, p\right)$-space. Graphically, higher productivity in tradables relative to non tradables shifts to the right the $L M E$-schedule from $L M E_{0}$ to $L M E_{1}$ : this shift corresponds to the labor market frictions effect. If $\phi>1$, the $G M E$-schedule is flatter than the $45^{\circ}$ line so that the intersection is at $G^{\prime}$; since $p^{\prime}<p_{B S}$, the relative price appreciates by less than the productivity differential between tradables and non tradables, in line with our empirical findings. Conversely, if $\phi<1$, the relative price must appreciate more than proportionately (i.e., by more than $1 \%$ ) following higher productivity of tradables relative to non tradables (by 1 percentage point). In this configuration, the $G M E$-schedule is steeper that the $45^{\circ}$ line so that the $L M E_{1}$-schedule intercepts the $G M E$-schedule at a point which lies to the north west of $B S^{\prime}$. Hence, through the labor market frictions channel, a productivity differential between tradables and non tradables by $1 \%$ appreciates the relative price of non tradables by less (more) than $1 \%$ if traded and non traded goods are substitutes (complements).

The second term on the RHS of eq. (256) reveals that a productivity differential between tradables and non tradables also impinges on the relative price of non tradables by affecting net exports and hiring expenditure expressed as a share of traded output, as summarized by $d v_{N X}$. The combined effect of the improvement in the trade balance and permanently increased hiring expenditure has an expansionary effect on the demand for tradables which drives down the relative price of non tradables, as captured by $d v_{N X}>0$. In terms of Figure 11(a), the labor accumulation channel shifts the $G M E$-schedule to the right, regardless of the value of the elasticity of substitution between traded and non traded goods. It is worthwhile noticing that a change in $v_{N X}$ no longer impinges on the relative price $p$ and thus the labor accumulation channel vanishes when we let $\sigma_{L}$ tend toward infinity, i.e., if agents are not subject to switching costs from one sector to another. Formally, we have $\lim _{\sigma_{L} \rightarrow \infty} \frac{1}{\phi+\Theta}=0$. In this case, the $G M E_{1}$-schedule intercepts the $L M E_{1}$ schedule at $B S_{1}$. Unlike, when $\sigma_{L}<\infty$, the intercept is at $G_{1}$ if $\phi>1$.

We turn to the relative response. To facilitate the discussion, we assume that $\Theta^{j} \simeq \Theta$ and $\Omega^{j} \simeq \Omega$ so that eq. (255) reduces to:

$$
\hat{\omega}=-\Omega\left[\frac{(\phi-1)}{\phi+\Theta}\left(\hat{a}^{T}-\hat{a}^{N}\right)+\frac{\mathrm{d} v_{N X}}{\phi+\Theta}\right] .
$$

Through the labor market frictions channel, captured by the first term in brackets in the RHS of eq. (257), higher productivity growth in tradables relative to non tradables lowers the relative wage $\omega$ only if $\phi>1$. In terms of Figure 11(b), technological change biased toward the traded sector shifts to the right the $V C$-schedule from $V C_{0}$ to $V C^{\prime}$. Unlike, with an elasticity $\phi$ smaller than one, the $V C$-schedule would shift to the left because the share of non tradables rises which has an expansionary effect on recruitment in the non traded sector.

As captured by the second term on the RHS of eq. (257), a productivity differential between tradables and non tradables also impinges on the relative wage through a labor accumulation chan- 


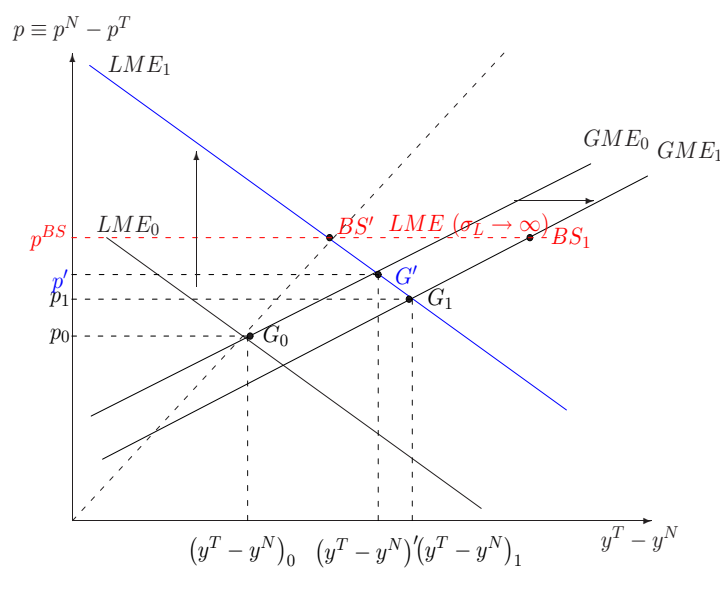

(a) $\left(y^{T}-y^{N}, p\right)$-space

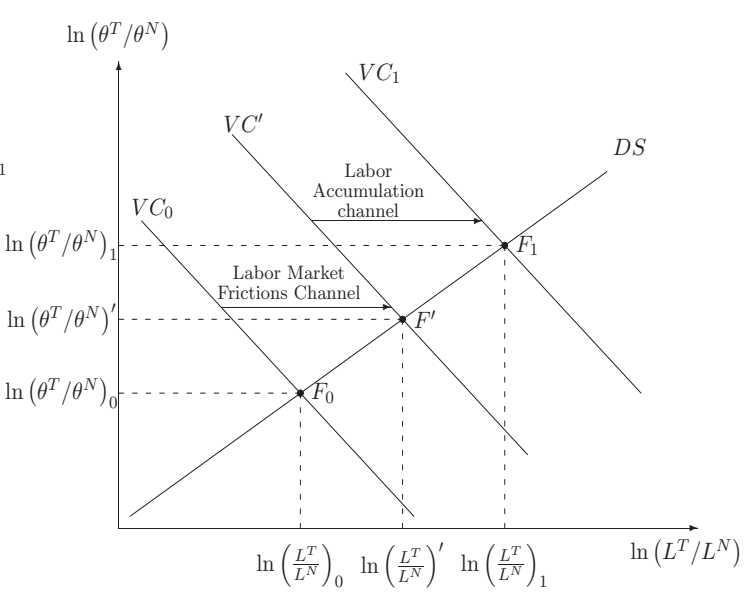

(b) $\left(l^{T}-l^{N}, \ln \left(\theta^{T} / \theta^{N}\right)\right)$-space

Figure 11: Long-Run Relative Price and Relative Wage Effects of Technological Change Biased toward the Traded Sector

nel. Graphically, as depicted in Figure 11(b), higher productivity in tradables relative to non tradables shifts further to the right the $V C$-schedule from $V C^{\prime}$ to $V C_{1}$. Hence, while $\omega$ unambiguously declines if the elasticity of substitution is larger than one, when $\phi<1$, the relative wage response to a productivity differential is ambiguous. In the latter case, a productivity differential between tradables and non tradables drives down $\omega$ through the labor accumulation channel while it increases the relative wage through the labor market frictions channel.

\section{K.2 Implications of Labor Market Institutions}

In this subsection, we analyze graphically the implications of labor markets institutions for the relative wage response to technological change biased toward the traded sector. In our framework, the strictness of legal protection against dismissals is captured by a firing tax denoted by $x^{j}$ paid to the State by the representative firm in the sector which reduces employment. The generosity of the unemployment benefit scheme is captured by the level of $R^{j}$; unemployment benefits are assumed to be a fixed proportion $\varrho$ of the wage rate $W^{j}$, i.e., $R^{j}=\varrho W^{j}$. Additionally, a higher worker bargaining power measured empirically by the bargaining coverage is captured by the parameter $\alpha_{W}$. Because the transmission mechanism varies according the type of labor market institution, we differentiate between the firing cost on the one hand, the generosity of the unemployment benefit scheme and the worker bargaining power on the other.

The implications of a higher firing tax is depicted in Figure 12(a) where we assume an elasticity between traded and non traded goods in consumption $\phi$ larger than one. In this configuration, as mentioned previously, technological change biased toward the traded sector shifts to the right the $V C$-schedule. As highlighted in Figure 12(a), higher productivity in tradables relative to non tradables shifts further to the right the $V C$-schedule from $V C^{\prime}$ to $V C^{\prime \prime}$, thus resulting in a larger increase in $\theta^{T} / \theta^{N}$ because hiring in the non traded sector which decumulates employment is limited by the firing tax. Consequently, the relative wage $\omega$ declines more, in line with our empirical findings, through a stronger labor market frictions effect. However, a higher firing tax also moderates the decline in the relative wage since net exports increase less. Intuitively, as recruiting expenditure are curbed by the firing tax, the productivity differential leads to a smaller current account deficit, thus moderating the necessary trade balance improvement.

In contrast to a firing tax, raising the unemployment benefit replacement rate or the worker bargaining power leads to a larger long-run rise in net exports and thus amplifies the decline in the relative wage through the labor accumulation channel. The implication of a higher replacement rate $\varrho$ or a larger worker bargaining power $\alpha_{W}$ is depicted in Figure 12(b) where we consider an elasticity of substitution $\phi$ larger than one. Figure 12(b) shows that technological change biased toward the traded sector shifts further to the right the $V C$-schedule from $V C_{1}$ to $V C_{2}$ in countries where the replacement rate $\varrho$ is higher or the worker bargaining power $\alpha_{W}$ larger. As mentioned above, the larger increase in net exports amplifies the expansionary effect on hiring in the traded sector which pushes up further the ratio of labor market tightness $\theta^{T} / \theta^{N}$. Hence, the relative wage of non tradables falls more through a stronger labor accumulation effect. Raising $\varrho$ or $\alpha_{W}$ also modifies the labor market frictions channel by increasing the mobility of labor across sectors. ${ }^{65}$

\footnotetext{
${ }^{65}$ In countries with a higher worker bargaining power $\alpha_{W}$, firms are willing to recruit more (because it
} 


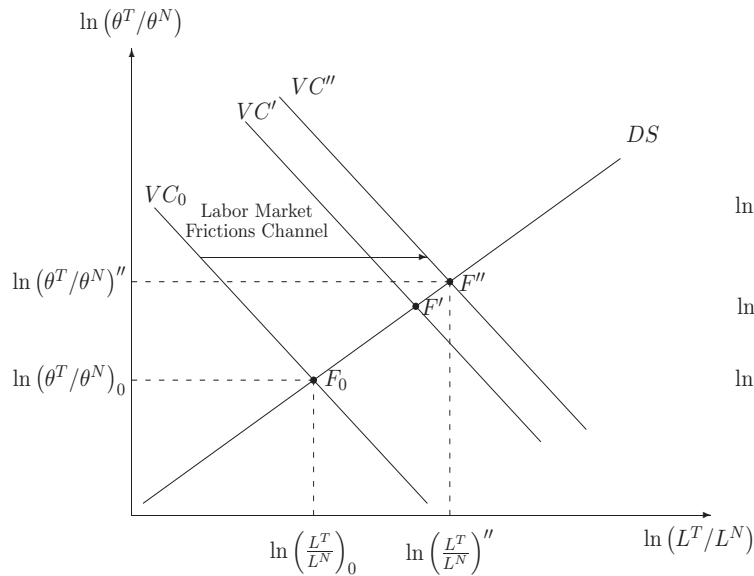

(a) Consequences of a higher firing tax

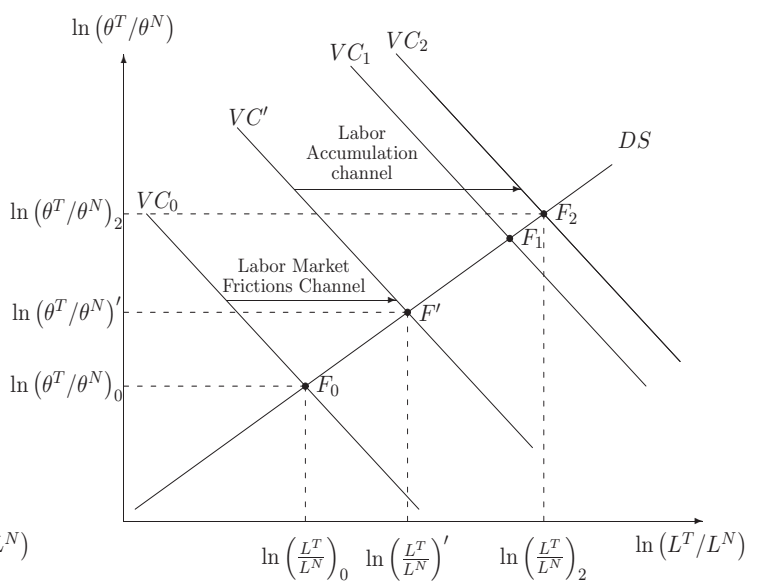

(b) Consequences of a higher replacement rate or worker bargaining power

Figure 12: Implications for the Relative Wage Response of Labor Market Regulation in the $\left(l^{T}-l^{N}, \ln \left(\theta^{T} / \theta^{N}\right)\right)$-space

Because we find numerically that raising $\varrho$ or $\alpha_{W}$ merely modifies the relative wage response to a productivity differential between tradables and non tradables through the labor market frictions channel, we restrict our attention to the labor accumulation channel in Figure 11(b).

\section{Effects of Higher Relative Productivity of Tradables on Unemployment Rate Differential}

In this section, we investigate the effects of higher productivity in tradables relative to non tradables on the unemployment rate of tradables relative to non tradables. To alleviate the notation, we drop the superscript $\tilde{x}$ to denote steady-state values since we focus on steady-state changes.

To write analytical expression in a compact form, it is useful to set:

$$
\Sigma^{j}=\frac{\Xi^{j}}{\left(1-\alpha_{V}\right) \Psi^{j}+\chi^{j} W_{R}^{j}} .
$$

which implies (see eq (172) for the traded sector and eq. (180) for the non traded sector):

$$
\hat{\theta}^{j}=\Sigma^{j} \hat{\Xi}^{j} \text {. }
$$

Differentiating the definition of the steady-state level for the sectoral unemployment rate described by:

$$
u^{j}=\frac{s^{j}}{s^{j}+m^{j}\left(\theta^{j}\right)},
$$

one obtains the standard negative relationship between $u^{j}$ and the labor market tightness in sector $j$ :

$$
\hat{u}^{j}=-\alpha_{V} \frac{m^{j}}{s^{j}+m^{j}} \hat{\theta}^{j} .
$$

Using the fact that $\hat{\Xi}^{T}=\hat{a}^{T}$ and $\hat{\Xi}^{N}=\hat{p}+\hat{a}^{N}$, subtracting $\hat{u}^{N}$ from $\hat{u}^{T}$ by using (259) and (261), one obtains:

$$
\begin{aligned}
\hat{u}^{T}-\hat{u}^{N} & =-\alpha_{V}\left[\frac{m^{T}}{s^{T}+m^{T}} \Sigma^{T} \hat{a}^{T}-\frac{m^{N}}{s^{N}+m^{N}} \Sigma^{N}\left(\hat{p}+\hat{a}^{N}\right)\right], \\
& =-\alpha_{V}\left\{\left[\frac{m^{T}}{s^{T}+m^{T}} \Sigma^{T}-\frac{m^{N}}{s^{N}+m^{N}} \Sigma^{N}\left(\frac{1+\Theta^{T}}{\phi+\Theta^{N}}\right)\right] \hat{a}^{T}-\frac{m^{N}}{s^{N}+m^{N}} \Sigma^{N}\left(\frac{\phi-1}{\phi+\Theta^{N}}\right) \hat{a}^{N}\right\} \\
& +\alpha_{V} \frac{m^{N}}{s^{N}+m^{N}} \Sigma^{N} \frac{\mathrm{d} \ln \left(1-v_{N X}\right)}{\left(\phi+\Theta^{N}\right)},
\end{aligned}
$$

is relatively less costly due to a higher probability to fill a job vacancy) while workers are less reluctant to move from one sector to another (since they receive a larger share $\chi$ of the surplus associated with a labor contract in the marginal benefit of search). In economies with a more generous unemployment benefit scheme, while workers are more reluctant to move from one sector to another (because $\chi$ falls), the vacancy creation is more elastic to technological change. Since the latter effect predominates, the labor mobility rises. 
where we have inserted the decomposition of the steady-state change of the relative price of non tradables given by eq. (249) to determine the percentage change in the labor market tightness in the non traded sector:

$$
\begin{aligned}
\hat{\theta}^{N} & =\Sigma^{N}\left(\hat{p}+\hat{a}^{N}\right), \\
& =\Sigma^{N}\left(\frac{1+\Theta^{T}}{\phi+\Theta^{N}}\right) \hat{a}^{T}+\Sigma^{N}\left[1-\frac{1+\Theta^{N}}{\phi+\Theta^{N}}\right] \hat{a}^{N}+\Sigma^{N} \frac{\mathrm{d} \ln \left(1-v_{N X}\right)}{\left(\phi+\Theta^{N}\right)}, \\
& =\Sigma^{N}\left(\frac{1+\Theta^{T}}{\phi+\Theta^{N}}\right) \hat{a}^{T}+\Sigma^{N}\left(\frac{\phi-1}{\phi+\Theta^{N}}\right) \hat{a}^{N}+\Sigma^{N} \frac{\mathrm{d} \ln \left(1-v_{N X}\right)}{\left(\phi+\Theta^{N}\right)} .
\end{aligned}
$$

Using the fact that at the steady-state, $\frac{m^{j}}{s^{j}+m^{j}}=\left(1-u^{j}\right)$, eq. (262) can be rewritten as follows:

$$
\begin{aligned}
\hat{u}^{T}-\hat{u}^{N} & =-\alpha_{V}\left\{\left[\left(1-u^{T}\right) \Sigma^{T}-\left(1-u^{N}\right) \Sigma^{N}\left(\frac{1+\Theta^{T}}{\phi+\Theta^{N}}\right)\right] \hat{a}^{T}-\left(1-u^{N}\right) \Sigma^{N}\left(\frac{\phi-1}{\phi+\Theta^{N}}\right) \hat{a}^{N}\right\} \\
& +\alpha_{V}\left(1-u^{N}\right) \Sigma^{N} \frac{\mathrm{d} \ln \left(1-v_{N X}\right)}{\left(\phi+\Theta^{N}\right)} .
\end{aligned}
$$

To facilitate the discussion of the effect of a productivity differential on the unemployment rate in the traded relative to the non traded sector, we assume that at the initial steady-state, we have $\Theta^{j} \simeq \Theta, u^{j} \simeq u, \Sigma^{j} \simeq \Sigma$, and we multiply both sides of eq. (264) by $u$ in order to express the unemployment differential in percentage point so that eq. (264) reduces to:

$$
d u^{T}-d u^{N}=-\alpha_{V} u(1-u) \Sigma\left[\left(\frac{\phi-1}{\phi+\Theta}\right)\left(\hat{a}^{T}-\hat{a}^{N}\right)-\frac{\mathrm{d} \ln \left(1-v_{N X}\right)}{(\phi+\Theta)}\right] .
$$

Eq. (265) corresponds to equation (37) in the main text. Eq. (265) breaks down the response of the unemployment differential to a productivity differential into two components: a labor market frictions effect and a labor accumulation effect. The first term on the RHS of (265) corresponds to the labor market frictions effect. Through this channel, higher productivity gains in tradables relative to non tradables lower or increase the unemployment rate in the traded sector relative to the non traded sector depending on whether the elasticity of substitution between tradables and non tradables $\phi$ is smaller or higher than one. If $\phi<1$, as our evidence suggest, a productivity differential between tradables and non tradables appreciates the relative price of non tradables more than proportionately. Because the share of non tradables increases, non traded firms recruit more which result in a larger decline in $u^{N}$ relative to $u^{T}$. The second term on the RHS corresponds to the labor accumulation effect. Through this channel, the long-run increase in net exports raises the demand for tradables and thus encourages firms to recruit more. When $\phi<1$, the labor market frictions effect and the labor accumulation effect have conflicting effects on the unemployment differential between tradables and non tradables. If the labor accumulation effect predominates, a productivity differential lowers the unemployment rate in the traded sector by a larger amount than that in the non traded sector. When $\phi>1$, higher productivity in tradables relative to non tradables unambiguously drives down the unemployment differential between tradables and non tradables.

\section{The Role of Endogenous Sectoral Labor Force Participa- tion Decision}

In this section, we look at a special case of the model for which the sectoral labor force is inelastic, i.e., $\sigma_{L}=0$ (reflecting the situation of labor immobility across sectors), in order to highlight the role of an endogenous sectoral labor force participation decision in driving the long-run effects of a productivity differential between tradables and non tradables. Then, we analyze the implications of $\sigma_{L} \rightarrow \infty$ (reflecting the situation of perfect mobility of labor across sectors).

\section{M.1 Equilibrium Dynamics when $\sigma_{L}=0$}

To begin with, we determine the dynamic system. Denoting by $W_{R}^{j}$ the reservation wage in sector $j$, the first-order conditions for the traded and the non traded sector described by eqs. (83b)-(83c) respectively, implies that $F^{j} \equiv L^{j}+U^{j}=\left(\bar{\lambda} W_{R}^{j} / \zeta^{j}\right)^{\sigma_{L}}$ with $W_{R}^{j} \equiv R^{j}+m^{j}\left(\theta^{j}\right) \xi^{j}$. Using the fact that $U^{j}=\left(\bar{\lambda} W_{R}^{j} / \zeta^{j}\right)^{\sigma_{L}}-L^{j}$, the dynamic equation for employment (12) can be rewritten as follows:

$$
\dot{L}^{j}=m^{j}\left(\theta^{j}\right)\left(\bar{\lambda} W_{R}^{j} / \zeta^{j}\right)^{\sigma_{L}}-\left[s^{j}+m^{j}\left(\theta^{j}\right)\right] L^{j} .
$$


Assuming that labor force is fixed, i.e., setting $\sigma_{L}=0$, then the equation above reads as:

$$
\dot{L}^{j}=m^{j}\left(\theta^{j}\right)-\left[s^{j}+m^{j}\left(\theta^{j}\right)\right] L^{j} .
$$

Imposing $\alpha_{W}^{j}=\alpha_{W}$ and using the fact that $m^{j}\left(\theta^{j}\right) \xi^{j}=\frac{\alpha_{W}}{1-\alpha_{W}} \kappa^{j} \theta^{j}$ together with $-\frac{v_{F}^{j}}{\lambda}=W_{R}^{j}$ and $W_{R}^{j} \equiv R^{j}+m^{j}\left(\theta^{j}\right) \xi^{j}$, the Nash bargaining wage can be rewritten as follows:

$$
\begin{aligned}
W^{j} & =\alpha_{W}\left(\Xi^{j}+r^{\star} x^{j}\right)-\left(1-\alpha_{W}\right) \frac{v_{F}^{j}}{\bar{\lambda}}, \\
& =\alpha_{W}\left(\Xi^{j}+r^{\star} x^{j}+\kappa^{j} \theta^{j}\right)+\left(1-\alpha_{W}\right) R^{j} .
\end{aligned}
$$

We now determine the dynamic equation for the labor market tightness. Plugging (267) into (114) yields:

$$
\begin{aligned}
\dot{\theta}^{j}(t) & =\frac{\theta^{j}(t)}{\left(1-\alpha_{V}^{j}\right)}\left\{\left(s^{j}+r^{\star}\right)-\frac{f^{j}\left(\theta^{j}(t)\right)}{\kappa^{j}}\left[\left(\Xi^{j}+r^{\star} x^{j}\right)-W^{j}\right]\right\}, \\
& =\frac{\theta^{j}(t)}{\left(1-\alpha_{V}^{j}\right)}\left\{\left(s^{j}+r^{\star}\right)-\frac{f^{j}\left(\theta^{j}(t)\right)\left(1-\alpha_{W}\right)}{\kappa^{j}} \Psi^{j}\right\},
\end{aligned}
$$

where the overall surplus from an additional job $\Psi^{j}$ is:

$$
\Psi^{j} \equiv \Xi^{j}+r^{\star} x^{j}-\frac{\alpha_{W}}{1-\alpha_{W}} \kappa^{j} \theta^{j}-R^{j}
$$

with $\Xi^{T}=A^{T}$ and $\Xi^{N}=P A^{N}$.

\section{Traded Sector}

Linearizing the accumulation equation for labor (266) and the dynamic equation for labor market tightness (268) in the traded sector, we get in matrix form:

$$
\left(\dot{L}^{T}, \dot{\theta}^{T}\right)^{T}=J^{T}\left(L^{T}(t)-\tilde{L}^{T}, \theta^{T}(t)-\tilde{\theta}^{T}\right)^{T}
$$

where $J^{T}$ is given by

$$
J^{T} \equiv\left(\begin{array}{cc}
-\left(s^{T}+\tilde{m}^{T}\right) & \left(\tilde{m}^{T}\right)^{\prime}\left(1-\tilde{L}^{T}\right) \\
0 & {\left[\left(s^{T}+r^{\star}\right)+\tilde{m}^{T} \frac{\alpha_{W}}{1-\alpha_{V}}\right]}
\end{array}\right),
$$

with $\tilde{m}^{T}=m^{T}(\tilde{\theta})$.

The trace denoted by $\operatorname{Tr}$ of the linearized $2 \times 2$ matrix (270) is given by:

$$
\operatorname{Tr} J^{T}=r^{\star}+\frac{\tilde{m}^{T}}{1-\alpha_{V}}\left[\alpha_{W}-\left(1-\alpha_{V}\right)\right] .
$$

The determinant denoted by Det of the linearized $2 \times 2$ matrix (118) is unambiguously negative:

$$
\operatorname{Det} J^{T}=-\left(s^{T}+\tilde{m}^{T}\right)\left[\left(s^{T}+r^{\star}\right)+\frac{\alpha_{W}}{1-\alpha_{V}} \tilde{m}^{T}\right]<0 .
$$

From now on, for clarity purpose, we impose the Hosios condition in order to avoid unnecessary complications:

$$
\alpha_{W}=\left(1-\alpha_{V}\right) .
$$

Denoting by $\nu^{T}$ the eigenvalue, the characteristic equation for the matrix $J(271)$ of the linearized system writes as follows:

$$
\left(\nu_{i}^{T}\right)^{2}-r^{\star} \nu_{i}^{T}+\operatorname{Det} J^{T}=0 .
$$

The characteristic roots obtained from the characteristic polynomial of degree two can be written as follows:

$$
\begin{aligned}
\nu_{i}^{T} & \equiv \frac{1}{2}\left\{r^{\star} \pm \sqrt{\left(r^{\star}\right)^{2}-4 \operatorname{Det} J^{T}}\right\} \gtrless 0, \quad i=1,2 \\
& \equiv \frac{1}{2}\left\{r^{\star} \pm \sqrt{\left(r^{\star}\right)^{2}+4\left(s^{T}+\tilde{m}^{T}\right)^{2}+4 r^{\star}\left(s^{T}+\tilde{m}^{T}\right)}\right\} \\
& \equiv \frac{1}{2}\left\{r^{\star} \pm\left[r^{\star}+2\left(s^{T}+\tilde{m}^{T}\right)\right]\right\}
\end{aligned}
$$


where we used the fact that $\operatorname{Det} J^{T}=-\left(s^{T}+\tilde{m}^{T}\right)\left(s^{T}+r^{\star}+\tilde{m}^{T}\right)$.

We denote by $\nu_{1}^{T}<0$ and $\nu_{2}^{T}>0$ the stable and unstable eigenvalues respectively which satisfy:

$$
\nu_{1}^{T}=-\left(s^{T}+\tilde{m}^{T}\right)<0<r^{\star}<\nu_{2}^{T}=\left(s^{T}+r^{\star}+\tilde{m}^{T}\right) .
$$

\section{Non Traded Sector}

Linearizing the accumulation equation for non traded labor (266) by setting $j=N$ and the dynamic equation for labor market tightness (268) in the non traded sector by inserting first the solution for the relative price of non tradables (108), i.e., $P=P\left(L^{N}, \bar{\lambda}, A^{N}\right)$, we get in matrix form:

$$
\left(\dot{L}^{N}, \dot{\theta}^{N}\right)^{T}=J^{N}\left(L^{N}(t)-\tilde{L}^{N}, \theta^{N}(t)-\tilde{\theta}^{N}\right)^{T}
$$

where $J^{N}$ is given by

$$
J^{N} \equiv\left(\begin{array}{cc}
-\left(s^{N}+\tilde{m}^{N}\right) & \left(m^{N}\right)^{\prime}\left(1-\tilde{L}^{N}\right) \\
-\frac{1-\alpha_{W}}{1-\alpha_{V}} \frac{\tilde{m}^{N}}{\kappa^{N}} P_{L^{N}} A^{N} & {\left[\left(s^{N}+r^{\star}\right)+\tilde{m}^{N} \frac{\alpha_{W}}{1-\alpha_{V}}\right]}
\end{array}\right),
$$

with $P_{L^{N}}=\frac{\partial P}{\partial L^{N}}=\frac{A^{N}}{C_{P}^{N}}<0$.

The trace is:

$$
\operatorname{Tr} J^{N}=r^{\star}+\frac{\tilde{m}^{N}}{1-\alpha_{V}}\left[\alpha_{W}-\left(1-\alpha_{V}\right)\right] .
$$

The determinant denoted by Det of the linearized $2 \times 2$ matrix (279) is unambiguously negative:

$$
\operatorname{Det} J^{N}=-\left(s^{N}+\tilde{m}^{N}\right)\left[\left(s^{N}+r^{\star}\right)+\frac{\alpha_{W}}{1-\alpha_{V}} \tilde{m}^{N}\right]+\frac{1-\alpha_{W}}{1-\alpha_{V}} \frac{\tilde{m}^{N}}{\kappa^{N}} P_{L^{N}} A^{N}\left(m^{N}\right)^{\prime}\left(1-\tilde{L}^{N}\right)<0 .
$$

Assuming that the Hosios condition (274) holds, the determinant (281) can be rewritten as follows:

$$
\begin{aligned}
\operatorname{Det} J^{N} & =-\left(s^{N}+\tilde{m}^{N}\right)\left(s^{N}+r^{\star}\right)\left[\left(\frac{s^{N}+r^{\star} \tilde{m}^{N}}{s^{N}+r^{\star}}\right)-\frac{1-\alpha_{W}}{1-\alpha_{V}} \frac{\tilde{m}^{N}}{\kappa^{N}} \frac{P_{L^{N}} A^{N} m^{N, \prime}}{\left(s^{N}+r^{\star}\right)} \frac{\left(1-\tilde{L}^{N}\right)}{\left(s^{N}+\tilde{m}^{N}\right)}\right], \\
& =-\left(s^{N}+\tilde{m}^{N}\right)\left(s^{N}+r^{\star}\right)\left[\left(\frac{s^{N}+r^{\star} \tilde{m}^{N}}{s^{N}+r^{\star}}\right)-\tilde{P} A^{N} \frac{P_{L^{N}} L^{N}}{\tilde{P}} \frac{\alpha_{V} \tilde{u}^{N}}{\left(1-\alpha_{V}\right) \tilde{\Psi}^{N}}\right]<0, \quad(282)
\end{aligned}
$$

where we computed the following term:

$$
\begin{aligned}
& \frac{1-\alpha_{W}}{1-\alpha_{V}} \frac{\tilde{m}^{N}}{\kappa^{N}} \frac{P_{L^{N}} A^{N} m^{N, \prime}}{\left(s^{N}+r^{\star}\right)} \frac{\left(1-\tilde{L}^{N}\right)}{\left(s^{N}+\tilde{m}^{N}\right)} \\
= & \frac{\left(1-\alpha_{W}\right)}{\left(s^{N}+r^{\star}\right)} \frac{\tilde{m}^{N}}{\tilde{\theta}^{N} \kappa^{N}} \frac{m^{N,} \tilde{\theta}^{N}}{\tilde{m}^{N}} \frac{\tilde{m}^{N} \tilde{U}^{N}}{\left(1-\alpha_{V}\right)} \frac{P_{L^{N}} A^{N}}{\left(s^{N}+\tilde{m}^{N}\right)}, \\
= & \frac{\alpha_{V}}{\tilde{\Psi}^{N}} \frac{s^{N} \tilde{L}^{N}}{\left(1-\alpha_{V}\right)} \frac{P_{L^{N}} A^{N}}{\left(s^{N}+\tilde{m}^{N}\right)}, \\
= & \left(\frac{\alpha_{V}}{1-\alpha_{V}}\right) \frac{\tilde{u}^{N}}{\tilde{\Psi}^{N}} \frac{P_{L^{N}} L^{N}}{\tilde{P}} \tilde{P} A^{N} .
\end{aligned}
$$

To get (283), we used the fact that $\frac{\left(1-\alpha_{W}\right) \tilde{f}^{N}}{\kappa^{N}\left(s^{N}+r^{\star}\right)}=\frac{1}{\tilde{\Psi}^{N}}, 1-\tilde{L}^{N}=\tilde{U}^{N}, \tilde{m}^{N} \tilde{U}^{N}=s^{N} \tilde{L}^{N}$, and $\tilde{u}^{N}=\frac{s^{N}}{s^{N}+\tilde{m}^{N}}$.

We denote by $\nu_{1}^{N}<0$ and $\nu_{2}^{N}>0$ the stable and unstable eigenvalues respectively which satisfy:

$$
\nu_{1}^{N}<0<r^{\star}<\nu_{2}^{N} .
$$

\section{M.2 Formal Solutions for $L^{T}(t)$ and $\theta^{T}(t)$}

The stable paths for the labor market in the traded sector are given by :

$$
\begin{aligned}
L^{T}(t)-\tilde{L}^{T} & =D_{1}^{T} e^{\nu_{1}^{T} t}, \\
\theta^{T}(t)-\tilde{\theta}^{T} & =\omega_{21}^{T} D_{1}^{T} e^{\nu_{1}^{T} t},
\end{aligned}
$$

where $D_{1}^{T}=L_{0}^{T}-\tilde{L}^{T}$, and element $\omega_{21}^{T}$ of the eigenvector (associated with the stable eigenvalue $\nu_{1}^{T}$ ) is given by:

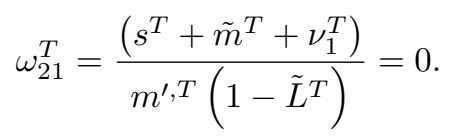

where we used the fact that $\nu_{1}^{T}=-\left(s^{T}+\tilde{m}^{T}\right)$ (see eq. (277)). From (285a), the dynamics for labor market tightness $\theta^{T}$ degenerate. 


\section{M.3 Formal Solutions for $L^{N}(t)$ and $\theta^{N}(t)$}

The stable paths for the labor market in the non traded sector are given by :

$$
\begin{aligned}
L^{N}(t)-\tilde{L}^{N} & =D_{1}^{N} e^{\nu_{1}^{N} t}, \\
\theta^{N}(t)-\tilde{\theta}^{N} & =\omega_{21}^{N} D_{1}^{N} e^{\nu_{1}^{N} t},
\end{aligned}
$$

where $D_{1}^{N}=L_{0}^{N}-\tilde{L}^{N}$, and element $\omega_{21}^{N}$ of the eigenvector (associated with the stable eigenvalue $\left.\nu_{1}^{N}\right)$ is given by:

$$
\begin{aligned}
\omega_{21}^{N} & =\frac{\left(s^{N}+\tilde{m}^{N}+\nu_{1}^{N}\right)}{m^{\prime, N}\left(1-\tilde{L}^{N}\right)}, \\
& =\frac{\frac{1-\alpha_{W}}{1-\alpha_{V}} \frac{\tilde{m}^{N}}{\kappa^{N}} P_{L^{N}} A^{N}}{\left(s^{N}+r^{\star}+\tilde{m}^{N}-\nu_{1}^{N}\right)}<0 .
\end{aligned}
$$

\section{M.4 Formal Solution for the Stock of Foreign Bonds $B(t)$}

Substituting first the short-run static solutions for consumption in tradables given by (110), and using the fact that $V^{j}=U^{j} \theta^{j}$, the accumulation equation for traded bonds (112) can be written as follows:

$$
\dot{B}(t)=r^{\star} B(t)+A^{T} L^{T}(t)-C^{T}\left(L^{N}(t), \bar{\lambda}, A^{N}\right)-\kappa^{T} \theta^{T}(t)\left(1-L^{T}(t)\right)-\kappa^{N} \theta^{N}(t)\left(1-L^{N}(t)\right),
$$

where we used the fact that $U^{j}=1-L^{j}$ when $\sigma_{L}=0$.

Linearizing (289) in the neighborhood of the steady-state and inserting stable solutions given by (285) and (287) yields:

$$
\dot{B}(t)=r^{\star}(B(t)-\tilde{B})+\Lambda^{T}\left(L^{T}(t)-\tilde{L}^{T}\right)+\Lambda^{N}\left(L^{N}(t)-\tilde{L}^{N}\right),
$$

where we set:

$$
\begin{aligned}
\Lambda^{T} & =A^{T}+\kappa^{T} \tilde{\theta}^{T}>0 \\
\Lambda^{N} & =-C_{L^{N}}^{T}-\kappa^{N} \tilde{U}^{N} \omega_{21}^{N}-\kappa^{N} \tilde{\theta}^{N} \omega_{31}^{N} \\
& =-C_{L^{N}}^{T}+\kappa^{N} \tilde{\theta}^{N}\left[1-\frac{\left(s^{N}+\tilde{m}^{N}+\nu_{1}^{N}\right)}{\alpha_{V} \tilde{m}^{N}}\right]>0,
\end{aligned}
$$

where we have inserted (144b) and used the fact that $\left(m^{N}\right)^{\prime} \theta^{N} / m^{N}=\alpha_{V}$ to get (291b); note that $C_{L^{N}}^{T} \simeq 0$ as long as $\phi \simeq \sigma_{C}$ in line with evidence for a typical OECD economy. The sign of (291b) follows from the fact that $\omega_{21}^{N}<0$ (see (288)).

Solving the differential equation (290) yields:

$$
B(t)=\tilde{B}+\left[\left(B_{0}-\tilde{B}\right)-\frac{\Lambda^{T} D_{1}^{T}}{\nu_{1}^{T}-r^{\star}}-\frac{\Lambda^{N} D_{1}^{N}}{\nu_{1}^{N}-r^{\star}}\right] e^{r^{\star} t}+\frac{\Lambda^{T} D_{1}^{T}}{\nu_{1}^{T}-r^{\star}} e^{\nu_{1}^{T} t}+\frac{\Lambda^{N} D_{1}^{N}}{\nu_{1}^{N}-r^{\star}} e^{\nu_{1}^{N} t} .
$$

Invoking the transversality condition for intertemporal solvency, and using the fact that $D_{1}^{T}=$ $L_{0}^{T}-\tilde{L}^{T}$ and $D_{1}^{N}=L_{0}^{N}-\tilde{L}^{N}$, we obtain the linearized version of the nation's intertemporal budget constraint:

$$
\tilde{B}-B_{0}=\Phi^{T}\left(\tilde{L}^{T}-L_{0}^{T}\right)+\Phi^{N}\left(\tilde{L}^{N}-L_{0}^{N}\right),
$$

where we set

$$
\Phi^{T} \equiv \frac{\Lambda^{T}}{\nu_{1}^{T}-r^{\star}}=-\frac{\left(A^{T}+\kappa^{T} \tilde{\theta}^{T}\right)}{\left(s^{T}+\tilde{m}^{T}+r^{\star}\right)}<0, \quad \Phi^{N} \equiv \frac{\Lambda^{N}}{\nu_{1}^{N}-r^{\star}}<0 .
$$

Equation (294) can be solved for the stock of foreign bonds:

$$
\tilde{B}=B\left(\tilde{L}^{T}, \tilde{L}^{N}\right), \quad B_{L^{T}}=\Phi^{T}<0, \quad B_{L^{N}}=\Phi^{N}<0 .
$$

For the national intertemporal solvency to hold, the terms in brackets of equation (292) must be zero so that the stable solution for net foreign assets finally reduces to:

$$
B(t)-\tilde{B}=\Phi^{T}\left(L^{T}(t)-\tilde{L}^{T}\right)+\Phi^{N}\left(L^{N}(t)-\tilde{L}^{N}\right) .
$$




\section{M.5 Solving Graphically for the Steady-State}

We investigate graphically the long-run effects of a rise in the the ratio of sectoral productivity. Assuming $\alpha_{W}^{j}=\alpha_{W}$ and setting $\sigma_{L}=0$, the steady-state (234) reduces to the following system which comprises five equations:

$$
\begin{gathered}
\frac{\tilde{C}^{T}}{\tilde{C^{N}}}=\frac{\varphi}{1-\varphi} \tilde{P}^{\phi}, \\
\frac{\tilde{L}^{T}}{\tilde{L}^{N}}=\frac{\tilde{m}^{T}}{\tilde{m}^{N}} \frac{\left(s^{N}+\tilde{m}^{N}\right)}{\left(s^{T}+\tilde{m}^{T}\right)} \frac{\zeta^{N}}{\zeta^{T}}, \\
\frac{\kappa^{T}}{f^{T}\left(\tilde{\theta}^{T}\right)}=\frac{\left(1-\alpha_{W}^{T}\right) \tilde{\Psi}^{T}}{\left(s^{T}+r^{\star}\right)}, \\
\frac{\kappa^{N}}{f^{N}\left(\tilde{\theta}^{N}\right)}=\frac{\left(1-\alpha_{W}^{N}\right) \tilde{\Psi}^{N}}{\left(s^{N}+r^{\star}\right)}, \\
\frac{\tilde{Y}^{T}\left(1-v_{N X}\right)}{\tilde{Y}^{N}}=\frac{\tilde{C}^{T}}{\tilde{C}^{N}},
\end{gathered}
$$

where $-v_{N X}=v_{B}-v_{V}^{T}-v_{V}^{N}$.

\section{Goods Market}

Because we restrict ourselves to the analysis of the long-run effects, the tilde is suppressed for the purposes of clarity. To characterize the steady-state, we focus on the goods market which can be summarized graphically by two schedules in the $\left(y^{T}-y^{N}, p\right)$-space, where we denote the logarithm of variables with lower-case letters. $(236)$ :

The goods market equilibrium $(G M E)$-schedule that we repeat for convenience is identical to

$$
\left.\left(\hat{y}^{T}-\hat{y}^{N}\right)\right|^{G M E}=\phi \hat{p}-d \ln \left(1-v_{N X}\right)
$$

The $G M E$-schedule is upward-sloping in the $\left(y^{T}-y^{N}, p\right)$-space and the slope of the $G M E$-schedule is equal to $1 / \phi$.

The labor market equilibrium $(L M E)$-schedule that we repeat for convenience is identical to $(244)$

$$
\hat{y}^{T}-\left.\hat{y}^{N}\right|^{L M E}=-\Theta^{N} \hat{p}+\left(1+\Theta^{T}\right) \hat{a}^{T}-\left(1+\Theta^{N}\right) \hat{a}^{N},
$$

except for the elasticity $\Theta^{j}$ of employment to the marginal revenue of labor which reduces to:

$$
\begin{aligned}
\Theta^{T} & \equiv \frac{A^{T} \alpha_{V}^{T} u^{T}}{\left[\left(1-\alpha_{V}\right) \Psi^{T}+\tilde{\chi}^{T} W_{R}^{T}\right]}>0, \\
\Theta^{N} & \equiv \frac{P A^{N} \alpha_{V}^{N} u^{N}}{\left[\left(1-\alpha_{V}\right) \Psi^{N}+\chi^{N} W_{R}^{N}\right]}>0 .
\end{aligned}
$$

The $L M E$-schedule is downward-sloping in the $\left(y^{T}-y^{N}, p\right)$-space and the slope of the $L M E$-schedule is equal to $-\frac{1}{\Theta^{N}}$. When $\sigma_{L}=0, \Theta^{j}$ is smaller so that the $L M E$-schedule is steeper.

\section{Labor Market}

Imposing $\sigma_{L}=0$ into eq. (234b), the decision of search $(D S)$-schedule reduces to:

$$
\frac{L^{T}}{L^{N}}=\frac{m^{T}}{m^{N}} \frac{m^{N}+s^{N}}{m^{T}+s^{T}} \frac{\zeta^{N}}{\zeta^{T}} .
$$

Taking logarithm and differentiating eq. (301) yields:

$$
\hat{l}^{T}-\hat{l}^{N}=\alpha_{V} u^{T} \hat{\theta}^{T}-\alpha_{V} u^{N} \hat{\theta}^{N} .
$$

Assuming that the labor markets display similar features across sectors, i.e., $u^{j} \simeq u$, eq. reduces to:

$$
\left.\left(\hat{\theta}^{T}-\hat{\theta}^{N}\right)\right|_{\sigma_{L}=0} ^{D S}=\frac{1}{\alpha_{V} u}\left(\hat{l}^{T}-\hat{l}^{N}\right) .
$$

The $D S$-schedule is upward-sloping in the $\left(l^{T}-l^{N}, \ln \left(\frac{\theta^{T}}{\theta^{N}}\right)\right)$-space. Comparing (303) with (244), it is straightforward to show that the $D S$-schedule becomes steeper when $\sigma_{L}=0$. The $V C$-schedule is downward-sloping and identical to (248). 


\section{M.6 Effects of Higher Relative Productivity of Tradables when $\sigma_{L}=0$}

Equating demand for tradables in terms of non tradables given by eq. (298) and supply (299) yields the deviation in percentage of the relative price from its initial steady-state (249). When assuming $\Theta^{j, \prime} \simeq \Theta^{\prime}$, eq. (249) reduces to:

$$
\hat{p}=\frac{\left(1+\Theta^{\prime}\right)\left(\hat{a}^{T}-\hat{a}^{N}\right)}{\left(\phi+\Theta^{\prime}\right)}+\frac{\mathrm{d} \ln \left(1-v_{N X}\right)}{\left(\phi+\Theta^{\prime}\right)},
$$

where

$$
\Theta^{\prime} \equiv \frac{\Xi \alpha_{V} u}{\left[\left(1-\alpha_{V}\right) \Psi+\tilde{\chi} W_{R}\right]}<\Theta \equiv \frac{\Xi\left[\alpha_{V} u+\sigma_{L} \chi\right]}{\left[\left(1-\alpha_{V}\right) \Psi+\tilde{\chi} W_{R}\right]},
$$

with $\Theta$ given by (238). Assuming $\sigma_{L}=0$ lowers the elasticity $\Theta$ of sectoral employment w.r.t. marginal revenue of labor. Intuitively, increased productivity induce firms to post more job vacancies which raises the labor market tightness and thus the probability of finding a job. When $\sigma_{L}>0$, higher $\theta^{j}$ increases $L^{j}$ through two channels: i) by triggering an outflow from unemployment, and ii) by inducing agents to increase the search intensity for a job. Because the latter effect vanishes if $\sigma_{L}=0$, employment becomes less responsive to productivity gains, as captured by a lower $\Theta$, i.e., $\Theta^{\prime}<\Theta$ (see inequality (305)). Since $\Theta^{\prime}<\Theta$, comparing eq. (304) with eq. (31) shows that when setting $\sigma_{L}=0$, the labor market frictions effect captured by the first term on the RHS of eq. (304) is moderated or amplified depending on whether $\phi$ is larger or smaller than one. In the former case, traded output increases less so that the relative price of non tradables must appreciate by a smaller amount to clear the goods market. If $\phi<1$, a productivity differential between tradables and non tradables raises the share of non tradables and thus has an expansionary effect on labor demand in the non traded sector. When $\sigma_{L}=0$, as detailed below, firms must increase wages by a larger amount. To compensate for the higher unit labor cost, non traded firms set higher prices so that $p$ increases more. Irrespective of whether $\phi$ is larger or smaller than one, a productivity differential between tradables and non tradables exerts a larger negative impact on $p$ when $\sigma_{L}=0$ through the labor accumulation effect. The reason is that following higher net exports, because the reallocation of labor across sectors is absent, traded output increases less which in turn triggers a greater excess of demand for tradables, thus leading to a larger depreciation in the relative price of non tradables (i.e., a larger decline in $p$ ).

Equating labor supply (303) with labor demand (248) while assuming $\Theta^{j} \simeq \Theta$ and $\Omega^{j} \simeq \Omega$ leads to the deviation in percentage of the relative wage from its initial steady-state:

$$
\hat{\omega}=-\frac{\Omega}{\phi+\Theta^{\prime}}\left[(\phi-1)\left(\hat{a}^{T}-\hat{a}^{N}\right)+\mathrm{d} v_{N X}\right] .
$$

Eq. (306) shows that assuming a fixed labor force by setting $\sigma_{L}=0$ amplifies both the labor market frictions effect (captured by the first term on the RHS of eq. (306)) and the labor market accumulation effect (captured by the second term on the RHS of eq. (306)). Intuitively, higher productivity shifts the $V C$-schedule along a steeper $D S$-schedule, thus resulting in larger changes in the ratio $\theta^{T} / \theta^{N}$ and in the relative wage $\omega$. As discussed in section 5.2, across all scenarios, even if the labor market frictions effect raises the relative wage (when setting $\phi<1$ ), the labor market accumulation effect predominates. Setting $\sigma_{L}=0$ amplifies the negative impact of the labor accumulation effect on the relative wage by such an amount that the model cannot account quantitatively for the size of decline in the relative wage (i.e., tends to overstate the decline in $\omega$ ) found in the data.

\section{M.7 Effects of Higher Relative Productivity of Tradables when $\sigma_{L} \rightarrow \infty$}

In this subsection, we investigate the relative price and relative wage effects of higher productivity of tradables relative to non tradables when we let $\sigma_{L}$ tend toward infinity. In this configuration, the case of perfect mobility of labor emerges.

As mentioned in section I, the steady-state can be characterized graphically by considering alternatively the goods market or the labor market. When we let $\sigma_{L}$ tend toward infinity, eq. (238) implies that $\Theta$, which captures the elasticity of sectoral employment w.r.t. the marginal revenue of labor, tends toward infinity. Inspection of (236) and (237) indicates that when $\sigma_{L} \rightarrow \infty$, the slope of the $G M E$-schedule (equal to $1 / \phi$ ) is unaffected while the $L M E$-schedule (whose slope is equal to $1 / \Theta^{N}$ ) becomes a horizontal line. Applying l'Hôpital's rule, eq. (249) reduces to:

$$
\begin{aligned}
\lim _{\sigma_{L} \rightarrow \infty} \hat{p} & =\frac{1+\Theta^{T}}{1+\Theta^{N}} \hat{a}^{T}-\hat{a}^{N} \\
& =\frac{\Xi^{T} \chi^{T}\left[\left(1-\alpha_{V}^{N}\right) \Psi^{N}+\chi^{N} W_{R}^{N}\right]}{\Xi^{N} \chi^{N}\left[\left(1-\alpha_{V}^{T}\right) \Psi^{T}+\chi^{T} W_{R}^{T}\right]} \hat{a}^{T}-\hat{a}^{N} .
\end{aligned}
$$


According to our quantitative analysis, while labor market parameters are allowed to vary across sectors, the term in front of $\hat{a}^{T}$ is close to one for the baseline calibration. As a result, a 1 percentage point increase in the productivity differential between tradables and non tradables appreciates the relative price of non tradables by $1 \%$ approximately. Assuming that $\Theta^{j} \simeq \Theta$ and applying l'Hôpital's rule, the rate of change of the relative price described by eq. (31) reduces to:

$$
\lim _{\sigma_{L} \rightarrow \infty} \hat{p}=\hat{a}^{T}-\hat{a}^{N} .
$$

Consequently, a model with labor market frictions reaches the same conclusion as the standard neoclassical model with a competitive labor market as long as the elasticity of labor supply at the extensive margin tends toward infinity.

Inspection of (244) and (248) indicates that when $\sigma_{L} \rightarrow \infty$, the $D S$-schedule (whose slope is equal to $\frac{1}{\left[\alpha_{V} u+\sigma_{L} \chi\right]}$ ) becomes a horizontal line while the $V C$-schedule (whose slope is equal to $\left.-\frac{\Xi}{\phi\left[\left(1-\alpha_{V}\right) \Psi+\chi W_{R}\right]}\right)$ is unaffected. Applying l'Hôpital's rule, eq. (255) reduces to:

$$
\begin{aligned}
\lim _{\sigma_{L} \rightarrow \infty} \hat{\omega} & =\left[\Omega^{N} \frac{1+\Theta^{T}}{1+\Theta^{N}}-\Omega^{T}\right] \hat{a}^{T}, \\
& =\left\{\Omega^{N} \frac{\Xi^{T} \chi^{T}\left[\left(1-\alpha_{V}^{N}\right) \Psi^{N}+\chi^{N} W_{R}^{N}\right]}{\Xi^{N} \chi^{N}\left[\left(1-\alpha_{V}^{T}\right) \Psi^{T}+\chi^{T} W_{R}^{T}\right]}-\Omega^{T}\right\} \hat{a}^{T} .
\end{aligned}
$$

Assuming that $\Theta^{j} \simeq \Theta$ and applying l'Hôpital's rule, the rate of change of the relative wage described by eq. (34) reduces to:

$$
\lim _{\sigma_{L} \rightarrow \infty} \hat{\omega}=\left(\Omega^{N}-\Omega^{T}\right) \hat{a}^{T}
$$

where $\Omega^{j}$ captures the elasticity of the sectoral wage w.r.t the marginal revenue of labor; according to (310), the effect of higher productivity in tradables relative to non tradables on the relative wage is proportional to $\Omega^{N}-\Omega^{T}$. More precisely, when we let $\sigma_{L} \rightarrow \infty$, while the ratio of labor market tightness remains unaffected if $\Theta^{j} \simeq \Theta$, technological change biased toward the traded sector may influence the relative wage as long as the elasticity of sectoral wage w.r.t. the marginal revenue of labor $\Omega^{j}$ varies across sectors. For our benchmark parametrization, we have $\Omega^{j} \simeq \Omega$ so that the relative wage is (almost) unaffected by a productivity differential.

When we let search parameters vary across sectors and $\sigma_{L}$ tend toward infinity in eq. (264), we have:

$$
\lim _{\sigma_{L} \rightarrow \infty} \hat{\theta}^{N}=\Sigma^{N}\left(\lim _{\sigma_{L} \rightarrow \infty} \hat{p}+\hat{a}^{N}\right)=\Sigma^{N} \hat{a}^{T},
$$

where we inserted (308). Making use of (265), the unemployment rate differential reduces to:

$$
\lim _{\sigma_{L} \rightarrow \infty}\left(d u^{T}-d u^{N}\right)=-\alpha_{V}\left[u^{T}\left(1-u^{T}\right) \Sigma^{T}-u^{N}\left(1-u^{N}\right) \Sigma^{N}\right] \hat{a}^{T} .
$$

In conclusion, a model with labor market frictions reaches the same conclusions as the standard neoclassical model with a competitive labor market as long as the elasticity of labor supply at the extensive margin tends toward infinity.

\section{N Calibration Procedure}

In this section, we provide more details about the calibration to a representative OECD economy and to data from 18 OECD countries. Section A.2 and section A.3 present the source and construction of data.

\section{N.1 Initial Steady-State}

Assuming that the elasticity of labor supply at the extensive margin $\left(\sigma_{L}^{j}\right)$, the elasticity of vacancies in job matches $\left(\alpha_{V}^{j}\right)$, and the worker bargaining power $\left(\alpha_{W}^{j}\right)$ are symmetric across sectors, i.e., $\sigma_{L}^{j}=\sigma_{L}, \alpha_{V}^{j}=\alpha_{V}$ and $\alpha_{W}^{j}=\alpha_{W}$, and normalizing to 1 the parameters $\zeta^{T}$ and $A^{N}$ that correspond to the disutility from working and searching for a job in the traded sector and the productivity of labor in the non traded sector, respectively, the calibration reduces to 20 parameters: $r^{\star}, \beta, \sigma_{C}, \sigma_{L}$, $\phi, \varphi, \zeta^{N}, \omega_{G}\left(=\frac{G}{Y}\right) \omega_{G^{N}}\left(=\frac{P G^{N}}{G}\right), A^{T}, s^{T}, s^{N}, 1-\alpha_{V}, \alpha_{W}, \kappa^{T}, \kappa^{N}, X^{T}, X^{N}, x^{N}, \varrho$, and initial conditions $B_{0}, L_{0}^{T}, L_{0}^{N}$. 
Since we focus on the long-run equilibrium, the tilde is suppressed for the purposes of clarity. The steady-state of the open economy comprises 14 equations:

$$
\begin{aligned}
& C=\left(P_{C} \bar{\lambda}\right)^{-\sigma_{C}}, \\
& U^{T}=\frac{s^{T} L^{T}}{m^{T}}, \\
& U^{N}=\frac{s^{N} L^{N}}{m^{N}}, \\
& m^{T}=X^{T}\left(\theta^{T}\right)^{\alpha_{V}}, \\
& m^{N}=X^{N}\left(\theta^{N}\right)^{\alpha_{V}} \\
& L^{T}=\frac{m^{T}}{s^{T}+m^{T}}\left[\frac{\bar{\lambda} W_{R}^{T}}{\zeta^{T}}\right]^{\sigma_{L}}, \\
& L^{N}=\frac{m^{N}}{s^{N}+m^{N}}\left[\frac{\bar{\lambda} W_{R}^{N}}{\zeta^{N}}\right]^{\sigma_{L}}, \\
& \frac{\kappa^{T}}{f^{T}}=\frac{\left(1-\alpha_{W}\right) \Psi^{T}}{s^{T}+r^{\star}}, \quad \Psi^{T} \equiv A^{T}-W_{R}^{T}, \\
& \frac{\kappa^{N}}{f^{N}}=\frac{\left(1-\alpha_{W}\right) \Psi^{N}}{s^{N}+r^{\star}}, \quad \Psi^{N} \equiv P A^{N}+r^{\star} x^{N}-W_{R}^{N}, \\
& V^{T}=\theta^{T} U^{T}, \\
& V^{N}=\theta^{N} U^{N}, \\
& A^{N} L^{N}=C^{N}+G^{N}, \\
& r^{\star} B+A^{T} L^{T}=C^{T}+G^{T}+\kappa^{T} \theta^{T} U^{T}+\kappa^{N} \theta^{N} U^{N}, \\
& \text { and the intertemporal solvency condition } \\
& B-B_{0}=\Phi^{T}\left(L^{T}-L_{0}^{T}\right)+\Phi^{N}\left(L^{N}-L_{0}^{N}\right),
\end{aligned}
$$

where the system jointly determines $C, U^{T}, U^{N}, m^{T}, m^{N}, L^{T}, L^{N}, \theta^{T}, \theta^{N}, V^{T}, V^{N}, P, B, \bar{\lambda}$.

Some of the values of parameters can be taken directly from data, but others need to be endogenously calibrated to fit a set of an average OECD economy features. Among the 20 parameters, 6 parameters, i.e., $\kappa^{T}, \kappa^{N}, X^{T}, X^{N}, \zeta^{N}, \varphi$, together with initial conditions $\left(B_{0}, L_{0}^{T}, L_{0}^{N}\right)$ must be set in order to match key properties of a typical OECD economy. More precisely, the parameters $\kappa^{T}, \kappa^{N}, X^{T}, X^{N}, \zeta^{N}, \varphi$, together with the set of initial conditions are set to target $\theta^{T}, \theta^{N}, m^{T}$, $m^{N}, L^{N} / L, \alpha_{C}, v_{N X}$. Denoting by $v_{G^{N}}$ the ratio of government spending in non tradables, $G^{N}$, to the non traded output, $Y^{N}$, the steady-state can be reduced to the following seven equations:

$$
\begin{gathered}
\frac{\kappa^{T}}{f^{T}}=\frac{\left(1-\alpha_{W}\right) \Psi^{T}}{s^{T}+r^{\star}}, \\
\frac{\kappa^{N}}{f^{N}}=\frac{\left(1-\alpha_{W}\right) \Psi^{N}}{s^{N}+r^{\star}}, \\
m^{T}=X^{T}\left(\theta^{T}\right)^{\alpha_{V}}, \\
m^{N}=X^{N}\left(\theta^{N}\right)^{\alpha_{V}}, \\
\frac{A^{T} L^{T}\left(1-v_{N X}\right)}{A^{N} L^{N}\left(1-v_{G^{N}}\right)}=\frac{\varphi}{1-\varphi} P^{\phi}, \\
\frac{L^{T}}{L^{N}}=\frac{m^{T}}{m^{N}} \frac{m^{N}+s^{N}}{m^{T}+s^{T}}\left(\frac{W_{R}^{T}}{W_{R}^{N}} \zeta^{N}\right)^{\sigma_{L}}, \\
B-B_{0}=\Phi^{T}\left(L^{T}-L_{0}^{T}\right)+\Phi^{N}\left(L^{N}-L_{0}^{N}\right),
\end{gathered}
$$

which jointly determine $\theta^{T}, \theta^{N}, m^{T}, m^{N}, L^{T} / L^{N}, P, B$. The ratio $L^{T} / L^{N}$ implicitly determines $L^{N} / L$ :

$$
\frac{L^{N}}{L}=\frac{L^{N}}{L^{T}+L^{N}}=\frac{1}{\frac{L^{T}}{L^{N}}+1} .
$$

The relative price of non tradables $P$ implicitly determines the non tradable content of consumption expenditure:

$$
\alpha_{C}=\frac{(1-\varphi) P^{1-\phi}}{\varphi+(1-\varphi) P^{1-\phi}} .
$$

The net foreign asset position $B$ implicitly determines $v_{N X}=\frac{N X}{Y^{T}}$ with $N X=Y^{T}-C^{T}-G^{T}$ and $-v_{N X}=v_{B}-v_{V^{T}}-v_{V^{N}}$ with $v_{B} \equiv \frac{r^{\star} B}{Y^{T}}, v_{V^{T}}=\frac{\kappa^{T} V^{T}}{Y^{T}}$ and $v_{V^{N}}=\frac{\kappa^{N} V^{N}}{Y^{T}}$. To see it, multiply both 
sides of eq. (314g) by $\frac{r^{\star}}{Y^{T}}$ :

$$
v_{B}=v_{B_{0}}+r^{\star} \Phi^{T}\left(\frac{1}{A^{T}}-v_{L_{0}^{T}}\right)+r^{\star} \Phi^{N}\left(\frac{L^{N}}{A^{T} L^{T}}-v_{L_{0}^{N}}\right),
$$

where $v_{B_{0}} \equiv \frac{r^{\star} B_{0}}{Y^{T}}, v_{L_{0}^{T}} \equiv \frac{L_{0}^{T}}{Y^{T}}, v_{L_{0}^{N}} \equiv \frac{L_{0}^{N}}{Y^{T}}$. Since we have

$$
\begin{gathered}
v_{V^{T}}=\frac{\kappa^{T} \theta^{T} s^{T}}{A^{T} m^{T}}, \\
v_{V^{N}}=\frac{\kappa^{N} \theta^{N} s^{N}}{A^{T} m^{N}} \frac{L^{N}}{L^{T}},
\end{gathered}
$$

where we used the fact that $V^{j}=\theta^{j} U^{j}$ and $U^{j}=\frac{s^{j} L^{j}}{m^{j}}$ at the steady-state; according to (318) the ratios $v_{V^{T}}=\frac{\kappa^{T} V^{T}}{Y^{T}}$ and $v_{V^{N}}=\frac{\kappa^{N} V^{N}}{Y^{T}}$ are pinned down by $\theta^{T}, \theta^{N}, m^{T}, m^{N}, L^{N} / L^{T}$ which are endogenously determined by system (314). Eqs (317) and (318) determine the ratio of net exports to traded output (i.e., $v_{N X}$ ):

$$
v_{B}-v_{V^{T}}-v_{V^{N}} \equiv-v_{N X} .
$$

In order to finish the proof that system (314) can be solved for $\theta^{T}, \theta^{N}, m^{T}, m^{N}, L^{T} / L^{N}, P, B$, we have to determine analytical expressions of $W_{R}^{T}, W_{R}^{N}, \Psi^{T}, \Psi^{N}$. The reservation wage in sector $j$, $W_{R}^{j}$, is defined as the sum of the expected value of a job $m^{j} \xi^{j}=\frac{\alpha_{W}}{1-\alpha_{W}} \kappa^{j} \theta^{j}$ and the unemployment benefit $R^{j}=\varrho W^{j}$. The Nash bargaining wage in sector $j, W^{j}$, can be rewritten as follows:

$$
\begin{aligned}
W^{j} & =\alpha_{W}\left(\Xi^{j}+r^{\star} x^{j}\right)+\left(1-\alpha_{W}\right)\left(\frac{\alpha_{W}}{1-\alpha_{W}} \kappa^{j} \theta^{j}+\varrho W^{j}\right), \\
& =\frac{\alpha_{W}\left(\Xi^{j}+r^{\star} x^{j}+\kappa^{j} \theta^{j}\right)}{1-\left(1-\alpha_{W}\right) \varrho} .
\end{aligned}
$$

Plugging (320) into the definition of the reservation wage in sector $j$, we have:

$$
\begin{aligned}
W_{R}^{j} & =\frac{\alpha_{W}}{1-\alpha_{W}} \kappa^{j} \theta^{j}+\varrho W^{j}, \\
& =\frac{\alpha_{W}}{1-\alpha_{W}} \kappa^{j} \theta^{j}+\varrho \frac{\alpha_{W}\left(\Xi^{j}+r^{\star} x^{j}+\kappa^{j} \theta^{j}\right)}{1-\left(1-\alpha_{W}\right) \varrho} .
\end{aligned}
$$

Since $\Xi^{T}=A^{T}$ and $\Xi^{N}=P A^{N}$, the reservation wage in the traded sector, $W_{R}^{T}$, is a function of $\theta^{T}$, while the reservation wage in the non traded sector, $W_{R}^{N}$, is a function of $\theta^{N}$ and $P$. Since $\Psi^{j}=\Xi^{j}-W_{R}^{j}$, the overall surplus from an additional job in the traded sector, $\Psi^{T}$, is a function of $\theta^{T}$, while the overall surplus from an additional job in the non traded sector, $\Psi^{N}$, is a function of $\theta^{N}$ and $P$.

To begin with, labor market parameters of the traded sector, i.e., the matching efficiency $X^{T}$ and the recruiting cost $\kappa^{T}$, can be set to target the monthly job finding rate $m^{T}$ and the labor market tightness $\theta^{T}$. To show it more formally, we first compute the share of the overall surplus from an additional worker obtained by the firm, $\left(1-\alpha_{W}\right) \Psi^{T}$, which is equal to the excess of labor productivity over the Nash bargaining wage, $A^{T}-W^{T}$; inserting (320), one obtains:

$$
\begin{aligned}
\left(1-\alpha_{W}\right) \Psi^{T} & =A^{T}-\frac{\alpha_{W}\left(A^{T}+\kappa^{T} \theta^{T}\right)}{1-\left(1-\alpha_{W}\right) \varrho}, \\
& =\frac{\left(1-\alpha_{W}\right)(1-\varrho) A^{T}-\alpha_{W} \kappa^{T} \theta^{T}}{1-\left(1-\alpha_{W}\right) \varrho} .
\end{aligned}
$$

Plugging (322) into (314a) and using the fact that $f^{T}=\frac{m^{T}}{\theta^{T}}$ allows us to rewrite the vacancy-creation equation in the traded sector as follows:

$$
\frac{\kappa^{T} \theta^{T}}{m^{T}}\left(s^{T}+r^{\star}\right)=\frac{\left(1-\alpha_{W}\right)(1-\varrho) A^{T}-\alpha_{W} \kappa^{T} \theta^{T}}{1-\left(1-\alpha_{W}\right) \varrho} .
$$

Equations (314c) and (323) form a separate subsystem which jointly determine $\theta^{T}$ and $m^{T}$; parameters $\kappa^{T}$ and $X^{T}$ are set in order to target $\theta^{T}$ and $m^{T}$ shown in Table 6 . It is worthwhile mentioning that while theoretically $\kappa^{T}$ and $X^{T}$ jointly determine $\theta^{T}$ and $m^{T}$, we find numerically that $\theta^{T}$ is mostly affected by $\kappa^{T}$ while $m^{T}$ is mostly determined by $X^{T}$. 
The remaining equations (314b), (314d)-(314g) form a separate subsystem which jointly determine $m^{N}, \theta^{N}, P, L^{T} / L^{N}$, and $v_{N X}$ :

$$
\begin{gathered}
\frac{\kappa^{N} \theta^{N}}{m^{N}}\left(s^{N}+r^{\star}\right)=\frac{\left(1-\alpha_{W}\right)(1-\varrho)\left(P A^{N}+r^{\star} x^{N}\right)-\alpha_{W} \kappa^{N} \theta^{N}}{1-\left(1-\alpha_{W}\right) \varrho} \\
\frac{m^{N}=X^{N}\left(\theta^{N}\right)^{\alpha_{V}}}{A^{T} L^{T}\left(1-v_{N X}\right)}=\frac{\varphi}{1-\varphi} P^{\phi} \\
\frac{L^{T}}{L^{N}}=\frac{m^{T}}{m^{N}} \frac{m^{N}+s^{N}}{m^{T}+s^{T}}\left(\frac{W_{R}^{T}}{W_{R}^{N}} \zeta^{N}\right)^{\sigma_{L}} \\
v_{N X}=-\left(v_{B}-v_{V^{T}}-v_{V^{N}}\right)
\end{gathered}
$$

where $v_{B}, v_{V^{T}}, v_{V^{N}}$ are given by eqs. (317), (319), (320), respectively; to rewrite (314b) as (324a), we used the fact that $\left(1-\alpha_{W}\right) \Psi^{N}=\frac{\left(1-\alpha_{W}\right)(1-\varrho)\left(P A^{N}+r^{\star} x^{N}\right)-\alpha_{W} \kappa^{N} \theta^{N}}{1-\left(1-\alpha_{W}\right) \varrho}$. Remembering that $P$ determines $\alpha_{C}$ and $L T / L N$ determines $L N / L$, parameters $\kappa^{N}, X^{N}, \varphi, \zeta^{N}$ and initial conditions $\left(B_{0}, L_{0}^{T}, L_{0}^{N}\right)$ are set in order to target $\theta^{N}$ and $m^{N}$ (see columns 11 and 7 in Table 6 ), $\alpha_{C}$ and $L^{N} / L$ (see columns 2 and 1 in Table 5 ), $v_{N X} \simeq 0$ as we assume that at the initial steady-state, the balance of trade is nil. While theoretically the four parameters and initial conditions are endogenously determined to target $\theta^{N}, m^{N}, \alpha_{C}, L^{N} / L$ and $v_{X}$, we find numerically that $\theta^{N}$ is mostly affected by $\kappa^{N}, m^{T}$ by $X^{N}, \alpha_{C}$ by $\varphi, L^{N} / L$ by $\zeta^{N}$, and $v_{N X}$ by initial conditions.

\section{N.2 Calibration to a Representative OECD Economy}

In order to assess the ability of our model to account for the evidence, we proceed in two stages. Since we find analytically that a productivity differential between tradables and non tradables exerts two opposite effects on the relative wage if the elasticity of substitution in consumption between tradables and non tradables is smaller than one, we have to investigate whether the model can generate a decline in the relative wage that is similar to that in the data for the whole sample. To do so, we first calibrate our model to a representative OECD economy. The quantitative exploration of a productivity shock biased toward the traded sector allows us to investigate whether our model can produce:

- a fall in the relative wage regardless of the value of the elasticity of substitution which displays a large dispersion across countries;

- a larger decline in the relative wage in countries where labor markets are mode regulated.

This section provides more details about how we calibrate the model to match the key empirical properties of a representative OECD economy. Our reference period for the calibration of the non tradable share given in Table 5 is running from 1990 to 2007 while labor market parameters have been computed over various periods. Due to the availability of data, we were able to estimate sectoral unemployment rates for 10 European countries and 5 OECD economies as ILO does not provide series for sectoral employment and unemployment for France, the Netherlands, and Norway at a sectoral level. Regarding Korea, while ILO provides data necessary for the computation of sectoral unemployment rates, the OECD does not provide unemployment by duration for this country which prevents the computation of job finding and job destruction rates. Data for the labor markets are described in Table $6 .{ }^{66}$

We first describe the parameters that are taken directly from the data; we start with the preference parameters shown in panel A of Table 23:

- One period in the model is a month.

- The world interest rate, $r^{\star}$, equal to the subjective time discount rate, $\beta$, is set to $0.4 \%$.

- We assume that utility for consumption is logarithmic and thus set the intertemporal elasticity of substitution for consumption, $\sigma_{C}$, to 1 .

- We set the elasticity of substitution (in consumption) between traded and non traded goods to 1 in the baseline calibration. ${ }^{67}$

\footnotetext{
${ }^{66}$ For sectoral unemployment rates, and monthly job finding and job destruction rates, we take the EU-10 unweighed average due to data availability.

${ }^{67}$ Excluding estimates of $\phi$ for Italy which are negative (see Table 9), column 1 of Table 8 reports consistent estimates for the elasticity of substitution $\phi$ between traded and non traded goods which average to 0.9 . The advantage of setting $\phi$ to 1 in the baseline scenario is twofold. First, the share of non traded goods in consumption expenditure $\alpha_{C}$ coincides with the weight of the non traded good in the overall consumption bundle $1-\varphi$ if $\phi=1$. Second, setting $\phi=1$ implies that only the labor accumulation channel is (mostly) in effect as the labor market frictions channel almost totally vanish which allows us to highlight the intertemporal effect trigged by the hiring boom.
} 
- Next, we turn to the elasticity of labor supply at the extensive margin which is assumed to be symmetric across sectors. We choose $\sigma_{L}$ to be 0.6 in our baseline setting but conduct a sensitivity analysis with respect to this parameter. ${ }^{68}$

We pursue with the non-tradable content of consumption expenditure, employment, government spending displayed in panel B:

- The weight of consumption in non tradables $1-\varphi$ is set to 0.42 to target a non-tradable content in total consumption expenditure (i.e. $\alpha_{C}$ ) of $42 \%$, in line with the average of our estimates shown in the last line of Table 5.

- In order to target a non tradable content of labor of $66 \%$ which corresponds to the 18 OECD countries' unweighted average shown in the last line of Table 5, we set $\zeta^{N}$ to 0.18 (see eq. (11)) while $\zeta^{T}$ has been normalized to 1 .

- Government spending as a percentage of GDP is set to $20 \%$ and we set the non tradable content of government expenditure, i.e., $\omega_{G^{N}}=\frac{P G^{N}}{G}$, to $90 \% .{ }^{69}$

- We assume that traded firms are 28 percent more productive than non traded firms in line with our estimates; we thus normalize $A^{N}$ to 1 and set $A^{T}$ to 1.28 ;

We describe below the choice of parameters characterizing the labor markets of a typical OECD economy in panel C:

- In line with our estimates shown in the last line of Table 6 , we set the rates of separation in the traded (i.e., $s^{T}$ ) and the non traded (i.e., $s^{N}$ ) sector to $1.48 \%$ and $1.54 \%$ respectively. To capture the U.S. (EU-12) sectoral labor markets, we set $s^{T}$ and $s^{N}$ to $2.24 \%\left(s^{T}=1.18 \%\right)$ and $2.46 \%\left(s^{N}=1.25 \%\right)$, respectively.

- We set $1-\alpha_{V}$ to 0.6 in line with the estimates documented by Barnichon [2012] who reports an elasticity of the matching function with respect to unemployed workers of about 0.6.

- As it is common in the literature, we impose the Hosios [1990] condition, and set the worker bargaining power $\alpha_{W}$ to 0.6 in the baseline scenario.

- To target the labor market tightness for a representative OECD economy in the traded sector, $\theta^{T}=0.24$, and in the non traded sector, $\theta^{N}=0.34$, we set the recruiting cost to $\kappa^{T}=1.482$ and $\kappa^{N}=0.575$ in the traded and the non traded sector respectively. To target the sectoral labor market tightness for the US (EU-12), i.e., $\theta^{T}=0.43\left(\theta^{T}=0.21\right)$ and $\theta^{N}=0.65$ $\left(\theta^{N}=0.30\right)$, respectively, we choose $\kappa^{T}=1.333\left(\kappa^{T}=1.535\right)$ and $\kappa^{N}=0.476\left(\kappa^{N}=0.597\right)$.

- When calibrating to a representative OECD economy, we set the matching efficiency in the traded (non traded) sector $X^{T}\left(X^{N}\right)$ to $0.307(0.262)$ to target a monthly job finding rate $m^{T}\left(m^{N}\right)$ of $17.4 \%(17.0 \%)$. A job destruction rate in the traded (non traded) sector $s^{T}$ $\left(s^{N}\right)$ of $1.48 \%(1.54 \%)$ together with a monthly job finding rate of $17.4 \%(17.0 \%)$ leads to an unemployment rate $u^{T}\left(u^{N}\right)$ of $7.9 \%(8.3 \%)$ in the traded (non traded) sector. To target a monthly job finding rate $m^{T}$ for the US (EU-12) in the traded sector and in the non traded sector $m^{N}$ of $44.4 \%(12.4 \%)$ and $44.0 \%$ (12.2\%), respectively, in line with the data shown in Table 6, we set the matching efficiency parameters $X^{T}$ and $X^{N}$ to $0.620(0.231)$ and 0.521 (0.197), respectively. The job destruction rates $s^{T}$ and $s^{N}$ are set to $2.2 \%(1.2 \%)$ and $2.4 \%$ $(1.2 \%)$ which leads to an unemployment rate in the traded sector $u^{T}$ and in the non traded sector $u^{N}$ of $4.8 \%(8.7 \%)$ and $5.3 \%(9.3 \%)$, respectively.

Finally, we present the parameters that capture the labor market institutions shown in panel D:

- Since the advance notice and the severance payment are both expressed in monthly salary equivalents, we have $x^{j}=\tau W^{j}$ with $\tau \geq 0$. Values of $\tau$ are shown in the last column of Table 6. For the baseline calibration, we set the firing $\operatorname{tax} \tau$ to 4.2. When calibrating to the US (EU-12) economy, we set $\tau=0(\tau=4.3)$ in line with estimates shown in the last column of Table 6 . When conducting the sensitivity analysis, we set $\tau$ to 13 which corresponds to the highest value for the firing cost.

\footnotetext{
${ }^{68}$ Using data from the Panel Study of Income Dynamics, Fiorito and Zanella [2012] find that aggregate time-series results deliver an extensive margin elasticity in the range 0.8-1.4, which is substantially larger than the corresponding estimate (0.2-0.3) reported by Chetty, Friedman, Manoli, and Weber [2011]. Using Japanese data, Kuroda and Yamamoto [2008] report a Frisch elasticity on the extensive margin which falls in the range of 0.6 to 0.8 for both sexes. By calibrating a model with endogenous participation decision, Haefke and Reiter [2011] find labor supply elasticities for the baseline case of 0.4 and 0.65 for men and women, respectively.

${ }^{69}$ The market clearing condition for the traded good and the non traded good at the steady-state are $r^{\star} B+Y^{T}=C^{T}+G^{T}+\kappa^{T} V^{T}+\kappa^{N} V^{N}$ and $Y^{N}=C^{N}+G^{N}$, respectively.
} 
- Assuming that unemployment benefits are a fixed proportion of the wage rate, i.e., $R^{j}=\varrho W^{j}$, with $\varrho$ the replacement rate, we choose a value for $\varrho$ of $52.4 \%$, in line with our estimates shown in Table 6. When calibrating to the US (EU-12) economy, we set $\varrho=26.1 \%(\varrho=55.9 \%)$ in line with estimates shown in column 14 of Table 6 . When conducting the sensitivity analysis, we set $\varrho$ to $78.2 \%$ which corresponds to the highest value for the unemployment benefit replacement rate.

Finally, we choose values for $B_{0}, L_{0}^{T}, L_{0}^{N}$ for the ratio of net exports to traded output to be nil at the initial steady-state, i.e., $v_{N X} \simeq 0$.

\section{N.3 Calibration to Each OECD Economy}

In a second stage, we move a step further and compare the predicted values with estimates for each country and the whole sample as well. The initial steady-state of each OECD economy is described by the system (314) that comprises seven equations. To calibrate our model to each OECD economy in our sample, we use the same baseline calibration for each country, except for the elasticity of substitution $\phi$ between traded and non-traded goods, and labor market parameters which are allowed to vary across economies. More specifically, the elasticity of substitution $\phi$ between traded and non traded goods is set in accordance with its estimates shown in the first column of Table $8 .{ }^{70}$ The parameters which capture the degree of labor market regulation such as the firing cost $x$, and the replacement rate $\varrho$ are set to their values shown in the last two columns of Table 6 . The matching efficiency $X^{j}$ in sector $j$ is set to target the job finding rate $m^{j}$ summarized in columns 5 and 7 of Table 6 . The job destruction rate $s^{j}$ is set in accordance to its value reported in columns 6 and 8 of Table 6 . Ideally, the recruiting cost $\kappa^{j}$ would be set in order to target $\theta^{j}$; however, the series for job vacancies by economic activity are available for a maximum of seven years and for a limited number of countries. On the contrary, the OECD provides data for job openings (for the whole economy) over the period 1980-2007 allowing us to calculate the labor market tightness, i.e., $\theta=V / U$, for several countries that we target along with the ratio $\theta^{T} / \theta^{N}$ by choosing $\kappa^{T}$ and $\kappa^{N}$. Thus, when calibrating the model to each OECD economy, the costs per job vacancy $\kappa^{T}$ and $\kappa^{N}$ are chosen to target the aggregate labor market tightness $\theta$ shown in column 13 and the ratio of sectoral labor market tightness $\theta^{T} / \theta^{N}$ obtained by dividing column 10 by column 11 .

When data for sectoral labor market tightness are not available, we target the average value $\theta^{T} / \theta^{N}$ for EU-12 if the country is a member of the European Union, the average value for the US for English-speaking countries (excluding European economies), and average value for the OECD otherwise. When data for job openings are not available at an aggregate level, we first calibrate the model to EU-12 (US, OECD), in particular choosing $\kappa^{T}$ and $\kappa^{N}$ to target an aggregate labor market tightness $\theta$ of $0.12(0.59,0.18)$ and a ratio $\theta^{T} / \theta^{N}$ of $0.75(0.66,0.77)$; then, we set $\kappa^{T}$ and $\kappa^{N}$ chosen for EU-12 if the country is a member of the European Union, chosen for the US for Canada, and chosen for the OECD otherwise. Finally, because labor market parameters cannot be calculated at a sectoral level for France, the Netherlands and Norway, we assume that the job destruction rate $s$ and the matching efficiency $X$ are identical across sectors and are chosen in accordance with estimates shown in column 6 (or alternatively in column 8) of Table 6 for the former and to target $m^{j}$ shown in column 5 (or alternatively in column 7 ) of Table 6 for the latter.

\section{N.4 Correction of the bias to map theoretical results into elasticities estimated empirically}

In this section, we compute the bias originating from search frictions varying across sectors which must be accounted for in order to map theoretical results for relative price and relative responses to a productivity differential into elasticities estimated empirically.

The long-run change of the relative price (29) can be rewritten as follows:

$$
\begin{aligned}
\hat{p} & =\frac{\left(1+\Theta^{T}\right) \hat{a}^{T}-\left(1+\Theta^{N}\right) \hat{a}^{N}}{\left(\phi+\Theta^{N}\right)}+\frac{\mathrm{d} \ln \left(1-v_{N X}\right)}{\left(\phi+\Theta^{N}\right)}, \\
& =\left(\frac{1+\Theta^{T}}{\phi+\Theta^{N}}\right)\left\{\left(\hat{a}^{T}-\hat{a}^{N}\right)+\hat{a}^{N}\left[1-\left(\frac{1+\Theta^{N}}{1+\Theta^{T}}\right)\right]\right\}+\frac{\mathrm{d} \ln \left(1-v_{N X}\right)}{\left(\phi+\Theta^{N}\right)} .
\end{aligned}
$$

Because empirically we consider a productivity differential $\hat{a}^{T}-\hat{a}^{N}$, to make our estimates comparable with our numerical results, we have to adjust the long-run change in the relative price computed numerically with the following term:

$$
\text { bias } \hat{p}=\left(\frac{1+\Theta^{T}}{\phi+\Theta^{N}}\right)\left[1-\left(\frac{1+\Theta^{N}}{1+\Theta^{T}}\right)\right] \hat{a}^{N} .
$$

\footnotetext{
${ }^{70}$ We also choose the weight of consumption in non tradables $1-\varphi$ to target a non-tradable content in total consumption expenditure (i.e., $\alpha_{C}$ ) for each country in line with our estimates shown in column 2 of Table 5 .
} 


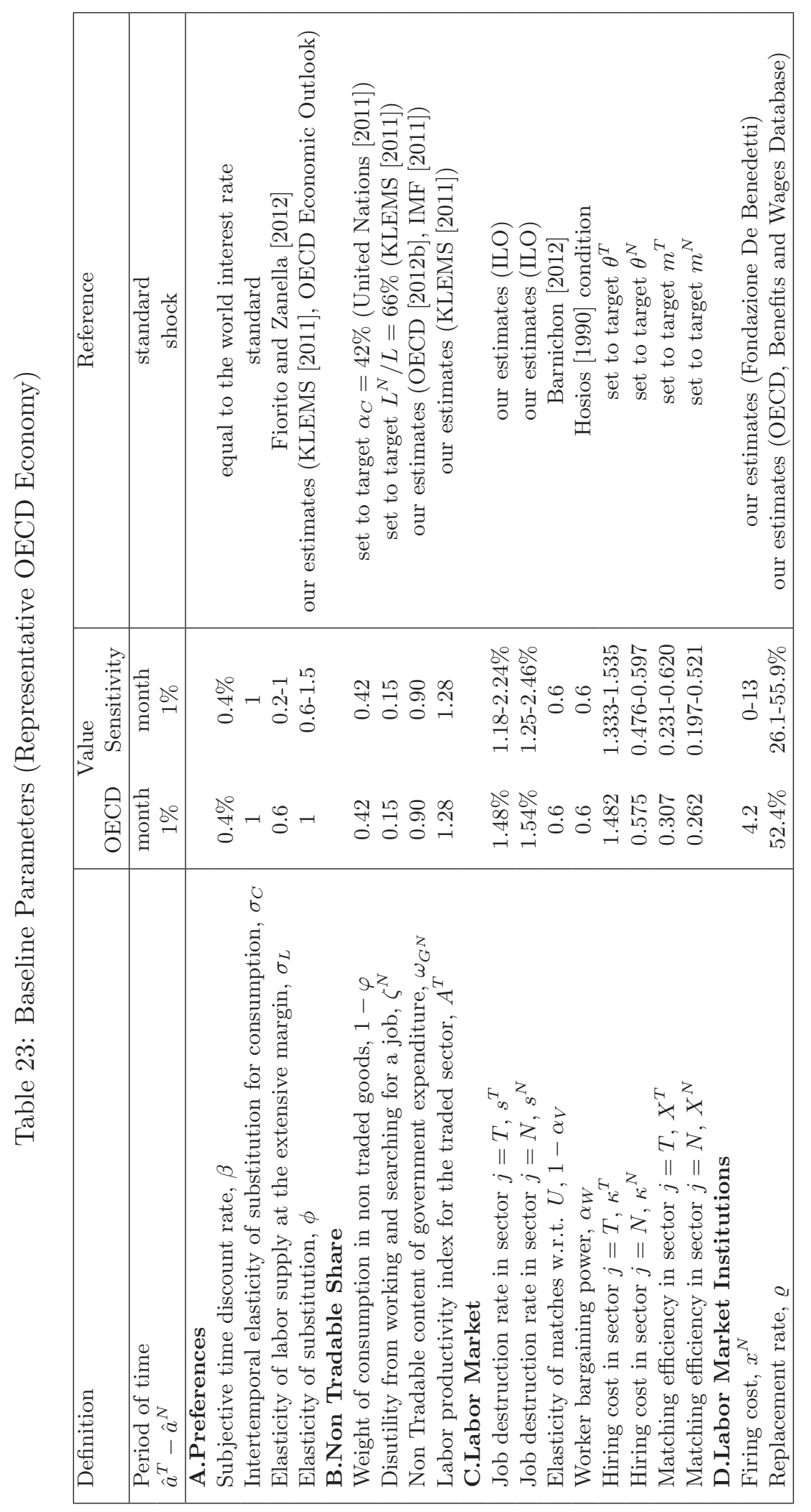


Subtracting (326) from (325) leads to:

$$
\begin{aligned}
\hat{p}^{\prime} & =\hat{p}-\text { bias } \hat{p} \\
& =\left(\frac{1+\Theta^{T}}{\phi+\Theta^{N}}\right)\left(\hat{a}^{T}-\hat{a}^{N}\right)+\frac{\mathrm{d} \ln \left(1-v_{N X}\right)}{\left(\phi+\Theta^{N}\right)},
\end{aligned}
$$

where we denote by $\hat{p}^{\prime}$ the value of $\hat{p}$ which has been adjusted with the bias originating from the presence of search frictions which vary across sectors and thus make the elasticity $\Theta^{j}$ of sectoral employment $L^{j}$ w.r.t. the marginal revenue of labor, $\Xi^{j}$, slightly different between sectors. Once the value of $\hat{p}$ has been adjusted with, we can map the deviation in percentage of the relative price of non tradables from its initial steady-state derived analytically into the elasticity of the relative price, $\gamma$, estimated empirically:

$$
\begin{aligned}
\gamma & =\frac{\hat{p}^{\prime}}{\hat{a}^{T}-\hat{a}^{N}}, \\
& =\left(\frac{1+\Theta^{T}}{\phi+\Theta^{N}}\right)+\frac{1}{\left(\phi+\Theta^{N}\right)} \frac{\mathrm{d} \ln \left(1-v_{N X}\right)}{\hat{a}^{T}-\hat{a}^{N}} .
\end{aligned}
$$

Eq. (329) corresponds to eq. (38a) in the main text. The first term on the RHS of eq. (329) corresponds to the effect of a productivity differential $\hat{a}^{T}-\hat{a}^{N}$ of $1 \%$ on the relative price keeping net exports fixed while the second term captures the impact of the long-run adjustment in net exports caused by rise in productivity of tradables relative to non tradables of $1 \%$.

The same logic applies to the relative wage. The long-run reaction of the relative wage described by $(167 \mathrm{j})$ can be rewritten as follows:

$$
\begin{aligned}
\hat{\omega}= & -\left\{\left[\Omega^{T}-\Omega^{N}\left(\frac{1+\Theta^{T}}{\phi+\Theta^{N}}\right)\right] \hat{a}^{T}-\left[\Omega^{N}-\Omega^{N}\left(\frac{1+\Theta^{N}}{\phi+\Theta^{N}}\right)\right] \hat{a}^{N}\right\}+\Omega^{N} \frac{\mathrm{d} \ln \left(1-v_{N X}\right)}{\phi+\Theta^{N}}, \\
= & -\left[\Omega^{T}-\Omega^{N}\left(\frac{1+\Theta^{T}}{\phi+\Theta^{N}}\right)\right]\left\{\left(\hat{a}^{T}-\hat{a}^{N}\right)+\left\{1-\frac{\left[\Omega^{N}-\Omega^{N}\left(\frac{1+\Theta^{N}}{\phi+\Theta^{N}}\right)\right]}{\left[\Omega^{T}-\Omega^{N}\left(\frac{1+\Theta^{T}}{\phi+\Theta^{N}}\right)\right]}\right\} \hat{a}^{N}\right\} \\
+ & \Omega^{N} \frac{\mathrm{d} \ln \left(1-v_{N X}\right)}{\phi+\Theta^{N}} .
\end{aligned}
$$

We have to adjust the long-run change in the relative wage computed numerically with the following term:

$$
\operatorname{bias} \hat{\omega}=-\left[\Omega^{T}-\Omega^{N}\left(\frac{1+\Theta^{T}}{\phi+\Theta^{N}}\right)\right]\left\{1-\frac{\left[\Omega^{N}-\Omega^{N}\left(\frac{1+\Theta^{N}}{\phi+\Theta^{N}}\right)\right]}{\left[\Omega^{T}-\Omega^{N}\left(\frac{1+\Theta^{T}}{\phi+\Theta^{N}}\right)\right]}\right\} \hat{a}^{N} .
$$

Subtracting (331) from (330) leads to:

$$
\begin{aligned}
\hat{\omega}^{\prime} & =\hat{\omega}-\operatorname{bias} \hat{\omega} \\
& =-\left[\Omega^{T}-\Omega^{N}\left(\frac{1+\Theta^{T}}{\phi+\Theta^{N}}\right)\right]\left(\hat{a}^{T}-\hat{a}^{N}\right)+\Omega^{N} \frac{\mathrm{d} \ln \left(1-v_{N X}\right)}{\phi+\Theta^{N}},
\end{aligned}
$$

where we denote by $\hat{\omega}^{\prime}$ the value of $\hat{\omega}$ which has been adjusted with the bias originating from the presence of search frictions which vary across sectors and thus make $\Theta^{j}$ along with $\Omega^{j}$ slightly different between sectors. Once the value of $\hat{\omega}$ has been adjusted with, we can map the deviation in percentage of the relative wage from its initial steady-state derived analytically into the elasticity of the relative wage, $\beta$, estimated empirically:

$$
\begin{aligned}
\beta & =\frac{\hat{\omega}^{\prime}}{\hat{a}^{T}-\hat{a}^{N}}, \\
& =-\left[\Omega^{T}-\Omega^{N}\left(\frac{1+\Theta^{T}}{\phi+\Theta^{N}}\right)\right]+\frac{\Omega^{N}}{\phi+\Theta^{N}} \frac{\mathrm{d} \ln \left(1-v_{N X}\right)}{\hat{a}^{T}-\hat{a}^{N}} .
\end{aligned}
$$

Eq. (334) corresponds to eq. (38b) in the main text. The first term on the RHS of eq. (334) corresponds to the effect of a productivity differential $\hat{a}^{T}-\hat{a}^{N}$ of $1 \%$ on the relative wage keeping net exports fixed while the second term captures the impact of the long-run adjustment in net exports caused by rise in productivity of tradables relative to non tradables of $1 \%$. It is worthwhile mentioning that the rise in net exports exerts a negative impact on both $\hat{p}^{\prime}$ and $\hat{\omega}^{\prime}$ and thus the term $\frac{\mathrm{d} \ln \left(1-v_{N X}\right)}{\hat{a}^{T}-\hat{a}^{N}}$ which shows up in eqs. (329) and (334) is negative.

Table 24 gives a sense of the correction term in columns 3 and 6 and compares $\hat{\omega}$ with $\hat{\omega}^{\prime}$, and $\hat{p}$ with $\hat{p}^{\prime}$. 
Table 24: Comparison of Computed Numerically Responses Before and After Bias Correction

\begin{tabular}{l|ccc|ccc}
\hline Country & \multicolumn{3}{|c|}{ Relative wage response } & \multicolumn{3}{|c}{ Relative price response } \\
\hline & $(1)$ & $(2)$ & $(3)$ & $(4)$ & $(5)$ & $(6)$ \\
& $\hat{\omega}$ & $\hat{\omega}^{\prime}$ & bias $\hat{\omega}$ & $\hat{p}$ & $\hat{p}^{\prime}$ & bias $\hat{p}$ \\
\hline AUS & 0.179 & 0.172 & 0.007 & 1.179 & 1.166 & 0.013 \\
AUT & -0.337 & -0.318 & -0.019 & 0.691 & 0.684 & 0.007 \\
BEL & -0.294 & -0.281 & -0.013 & 0.724 & 0.715 & 0.009 \\
CAN & 0.009 & 0.015 & -0.006 & 1.017 & 1.011 & 0.006 \\
DEU & -0.423 & -0.420 & -0.003 & 0.572 & 0.562 & 0.010 \\
DNK & -0.527 & -0.515 & -0.012 & 0.473 & 0.468 & 0.005 \\
ESP & -0.286 & -0.261 & -0.025 & 0.760 & 0.750 & 0.010 \\
FIN & -0.384 & -0.355 & -0.029 & 0.628 & 0.638 & -0.010 \\
FRA & -0.355 & -0.346 & -0.009 & 0.650 & 0.645 & 0.005 \\
GBR & -0.049 & -0.050 & 0.001 & 0.956 & 0.944 & 0.012 \\
IRL & -0.171 & -0.148 & -0.023 & 0.831 & 0.844 & -0.013 \\
ITA & -0.272 & -0.266 & -0.006 & 0.729 & 0.729 & 0.000 \\
JPN & -0.152 & -0.145 & -0.007 & 0.860 & 0.853 & 0.007 \\
KOR & -0.685 & -0.640 & -0.045 & 0.379 & 0.373 & 0.006 \\
NLD & -0.286 & -0.280 & -0.006 & 0.711 & 0.706 & 0.005 \\
NOR & -0.292 & -0.286 & -0.006 & 0.705 & 0.703 & 0.002 \\
SWE & 0.134 & 0.144 & -0.010 & 1.161 & 1.152 & 0.009 \\
USA & -0.037 & -0.035 & -0.002 & 0.972 & 0.974 & -0.002 \\
EU-12 & -0.160 & -0.149 & -0.011 & 0.855 & 0.849 & 0.006 \\
Whole sample & -0.229 & -0.218 & -0.011 & 0.783 & 0.778 & 0.005 \\
\hline
\end{tabular}

Notes: $\hat{p}$ and $\hat{\omega}$ correspond to deviations in percentage of the relative price and the relative wage from their initial steady-state which are computed numerically following a productivity differential of $1 \%$; we denote by $\hat{p}^{\prime}$ and $\hat{\omega}^{\prime}$ the steady-state changes in the relative price and relative wage computed numerically once their values have been adjusted with the bias originating from the presence of search frictions which vary across sectors. Columns 3 and 6 show that magnitude of bias for the relative wage and the relative price which must be subtracted from $\hat{p}$ and $\hat{\omega}$ in order to make elasticities computed numerically directly comparable with $\beta$ and $\gamma$ which are estimated empirically. 
The numerical computation of the unemployment rate differential is subject to the same bias the relative price and the relative wage. The long-run reaction of the unemployment differential between tradables and non tradables described by (264) can be rewritten as follows:

$$
\begin{aligned}
d u^{T}-d u^{N} & =-\alpha_{V}\left\{\left[u^{T}\left(1-u^{T}\right) \Sigma^{T}-u^{N}\left(1-u^{N}\right) \Sigma^{N}\left(\frac{1+\Theta^{T}}{\phi+\Theta^{N}}\right)\right] \hat{a}^{T}-u^{N}\left(1-u^{N}\right) \Sigma^{N}\left(\frac{\phi-1}{\phi+\Theta^{N}}\right) \hat{a}^{N}\right\} \\
& +\alpha_{V} u^{N}\left(1-u^{N}\right) \Sigma^{N} \frac{\mathrm{d} \ln \left(1-v_{N X}\right)}{\left(\phi+\Theta^{N}\right)} \\
& =-\alpha_{V} \Delta^{T}\left\{\hat{a}^{T}-\hat{a}^{N}+\hat{a}^{N}\left[1-\frac{u^{N}\left(1-u^{N}\right) \Sigma^{N}}{\Delta^{T}}\left(\frac{\phi-1}{\phi+\Theta^{N}}\right)\right]\right\} \\
& +\alpha_{V} u^{N}\left(1-u^{N}\right) \Sigma^{N} \frac{\mathrm{d} \ln \left(1-v_{N X}\right)}{\left(\phi+\Theta^{N}\right)},
\end{aligned}
$$

where we set

$$
\Delta^{T}=\left[u^{T}\left(1-u^{T}\right) \Sigma^{T}-u^{N}\left(1-u^{N}\right) \Sigma^{N}\left(\frac{1+\Theta^{T}}{\phi+\Theta^{N}}\right)\right] .
$$

We have to adjust the long-run change in the relative wage computed numerically with the following term:

$$
\operatorname{bias}\left(d u^{T}-d u^{N}\right)=-\alpha_{V} \Delta^{T} \hat{a}^{N}\left[1-\frac{u^{N}\left(1-u^{N}\right) \Sigma^{N}}{\Delta^{T}}\left(\frac{\phi-1}{\phi+\Theta^{N}}\right)\right] .
$$

Subtracting (337) from (335) leads to:

$$
\begin{aligned}
\left(d u^{T}-d u^{N}\right)^{\prime} & =\left(d u^{T}-d u^{N}\right)-\operatorname{bias}\left(d u^{T}-d u^{N}\right) \\
& =-\alpha_{V} \Delta^{T}\left(\hat{a}^{T}-\hat{a}^{N}\right)+\alpha_{V} u^{N}\left(1-u^{N}\right) \Sigma^{N} \frac{\mathrm{d} \ln \left(1-v_{N X}\right)}{\left(\phi+\Theta^{N}\right)}
\end{aligned}
$$

where we denote by $\left(d u^{T}-d u^{N}\right)^{\prime}$ the value of $d u^{T}-d u^{N}$ which has been adjusted with the bias originating from the presence of search frictions which vary across sectors and thus make $\Theta^{j}$ along with $\Sigma^{j}$ slightly different between sectors. Once the value of $d u^{T}-d u^{N}$ has been adjusted with, we can map the unemployment rate differential derived analytically into its response, $\sigma$, estimated empirically:

$$
\begin{aligned}
\sigma & =\frac{\left(d u^{T}-d u^{N}\right)^{\prime}}{\hat{a}^{T}-\hat{a}^{N}} \\
& =-\alpha_{V} \Delta^{T}+\alpha_{V} u^{N}\left(1-u^{N}\right) \frac{\Sigma^{N}}{\phi+\Theta^{N}} \frac{\mathrm{d} \ln \left(1-v_{N X}\right)}{\hat{a}^{T}-\hat{a}^{N}}
\end{aligned}
$$

Eq. (340) corresponds to eq. (39) in the main text. Eq. (340) is used to compute numerically the response of the unemployment rate differential to higher relative productivity of tradables by $1 \%$, as reported in column 8 of Table 8 . Column 9 of Table 8 shows results when we let $\sigma_{L}$ tend toward infinity. When we abstract from labor mobility costs, the unemployment rate differential reduces to eq. (312). In this case, changes in $u^{T}$ relative to $u^{N}$ are only driven by differences in search frictions between sectors.

\section{References}

Bai, Jushan, and Serena Ng (2002) Determining the Number of Factors in Approximate Factor Models. Econometrica, 70(1), pp. 191-221.

Breitung Jörg (2000) The Local Power of Some Unit Root Tests for Panel Data, in B. Baltagi (ed.), Advances in Econometrics, vol. 15: Nonstationary Panels, Panel Cointegration, and Dynamic Panels, Amsterdam: JAI Press, 161-178.

Cashin, Paul and John C. McDermott (2003) Intertemporal Substitution and Terms-of-Trade Shocks. Review of International Economics, vol. 11(4), 604-618.

Chang, Yoosoon (2002) Nonlinear IV Unit Root Tests in Panels with Cross-Sectional Dependency. Journal of Econometrics, 110, pp. 261-292.

Choi In (2001) Unit Root Tests for Panel Data. Journal of International Money and Finance, 20, pp. 249-272.

Cordoba (de), Gonzalo Fernandez and Timothy J. Kehoe (2000) Capital Flows and Real Exchange Rate Fluctuations Following Spain's Entry into the European Community. Journal of International Economics, 51(1), 49-78. 
Elsby, Michael W. L., Bart Hobijn and Aysegül Sahin (2013) Unemployment Dynamics in the OECD. The Review of Economics and Statistics, vol. 95(2), pp. 530-548.

Hadri, Kaddour (2000) Testing for Unit Roots in Heterogeneous Panel Data. Econometrics Journal, 3, pp. 148-161.

Haefke, Christian and Michael Reiter (2011) What Do Participation Fluctuations Tell Us About Labor Supply Elasticities? IZA Discussion Paper, No. 6039.

Hosios, Arthur J. (1990) On the Efficiency of Matching and Related Models of Search and Unemployment. The Review of Economic Studies, 57(2), pp. 279-98.

Im, Kyung So, Hashem M. Pesaran and Yongcheol Shin (2003) Testing for Unit Roots in Heterogeneous Panels. Journal of Econometrics, 115, pp. 53-74.

Kuroda, Sachiko and Isamu Yamamoto (2008) Estimating Frisch Labor Supply Elasticity in Japan. Journal of the Japanese and International Economies, 22(4), pp. 566-585.

Levin Andrew, Chien-Fu Lin and Chia-Shang James Chu (2002) Unit Root Test in Panel Data: Asymptotic and Finite Sample Properties. Journal of Econometrics, 108, pp. 1-24.

Maddala, Gangadharrao S. and Shaowen Wu (1999) A Comparative Study of Unit Root Tests with Panel Data and a New Test. Oxford Bulletin of Economics and Statistics, 61, pp. 631-652.

Mark, Nelson C. and Donggyu Sul (2003) Vector Estimation by Panel DOLS and Long-run Money Demand. Oxford Bulletin of Economics and Statistics, 65(5), pp. 655-680.

Mendoza, Enrique, G. (1995) The Terms of Trade, Real Exchange Rate and Economic Fluctuations. International Economic Review, 36, pp. 101-137.

Morshed, Mahbub A. K. M., and Stephen J. Turnovsky (2004) Sectoral Adjustment Costs and Real Exchange Rate Dynamics in a Two-sector Dependent Economy. Journal of International Economics, 63, pp. 147-177.

Nickell, Stephen, Luca Nunziata and Wolfgang Ochel (2005) Unemployment in the OECD since the 1960s: What do we Know? Economic Journal, 115, pp. 1-27.

Ostry, Jonathan, and Carmen M. Reinhart (1992) Private Saving and Terms of Trade Shocks: Evidence from Developing Countries, IMF Staff Papers 39(3), pp. 495-517.

Pedroni, Peter (1999) Critical Values for Cointegration Tests in Heterogeneous Panels with Multiple Regressors. Oxford Bulletin of Economics and Statistics, 61, pp. 653-670.

Pedroni, Peter (2004) Panel Cointegration: Asymptotic and Finite Sample Properties of Pooled Time Series Tests with an Application to the PPP Hypothesis. Econometric Theory, 20, pp. 597-625.

Pesaran, Hashem M. (2007) A Simple Panel Unit Root Test In The Presence Of Cross Section Dependence. Journal of Applied Econometrics, 22(2), pp. 265-312.

Pesaran, Hashem M. and Ron P. Smith (1995) Estimating Long-run Relationships from Dynamic Heterogeneous Panels. Journal of Econometrics, 68, pp. 79-113.

Pesaran, Hashem M., Yongcheol Shin and Ron P. Smith (1999) Pooled Mean Group Estimation of Dynamic Heterogeneous Panels. Journal of the American Statistical Association, 94, pp. 621634 .

Shimer, Robert (2005) The Cyclical Behavior of Equilibrium Unemployment and Vacancies. American Economic Review 95(1), pp. 25-49.

Stockman Alan C. and Linda L. Tesar (1995) Tastes and Technology in a Two-Country Model of the Business Cycle: Explaining International Comovements. American Economic Review 85(1), pp. 168-185. 